\title{
Resúmenes de los Trabajos Libres del 76 Congreso de las Américas de Neumología y Cirugía de Tórax (Puebla, Puebla, 2017)*
}

\section{Identificación de proteína EGFR (receptor del factor de crecimiento epidérmico) en muestras de lavado broncoalveolar de pacientes con diagnóstico de cáncer pulmonar}

\section{Baltazar PA, Mercado CG, Cicero $S R J$, Villagómez OG}

Hospital General Naval de Alta Especialidad, SEMAR; UNAM; Hospital General de México

Introducción: El cáncer de pulmón es la causa más común de muerte por cáncer en la población mundial. Afecta predominantemente a hombres mayores de 65 años con historia de tabaquismo. El cáncer de pulmón se clasifica en dos variedades histológicas: cáncer pulmonar de células

*La transcripción de los resúmenes es responsabilidad de los autores y de acuerdo con las indicaciones y numeración otorgada por el Comité Científico de la Sociedad Mexicana de Neumología y Cirugía de Tórax.

La extensión de los resúmenes es de 340 palabras; por lo tanto, aquéllos que están excedidos sólo en línea aparecen completos, en la versión impresa sólo hasta las 340 palabras. pequeñas y cáncer pulmonar de células no pequeñas (CPCNP). El pronóstico en los pacientes depende del estadío clínico al momento del diagnóstico. El tratamiento farmacológico dirigido a moléculas específicas ha mostrado resultados benéficos. Un ejemplo, son los inhibidores del factor de crecimiento epidérmico (EGFR) como Erlotinib y Gefitinib, aprobados como terapia de primera línea en pacientes con CPCNP y mutación en receptores de receptores de tirosin-kinasa. Objetivos: Cuantificar la expresión de proteína EGFR en muestras de lavado broncoalveolar (LBA) en sujetos con cáncer pulmonar y sujetos sin cáncer pulmonar. Material y métodos: Se realizó un estudio exploratorio y se incluyeron sujetos con diagnóstico histopatológico de cáncer pulmonar y controles. Se realizó fibrobroncoscopia para obtener una muestra de LBA. Éstas fueron procesadas por ELISA sándwich para identificar la cantidad de proteína EGFR en LBA en ambos grupos. Para el análisis estadístico se uso estadística descriptiva, prueba de Ji cuadrada y comparación de medianas por U de Mann-Whitney. Resultados: En este estudio se incluyeron 28 sujetos, la media de edad para el grupo de casos fue de 59.7 (DE: 7.38) y para el de controles de 58.6 (DE: 10.39). Del total, 12 fueron sujetos con cáncer de pulmón y 16 controles. La media de EGFR en los sujetos con cáncer fue de 1381.89 (DE: 980.13) y para los controles de 216.94 (DE: 165.45), con un valor de $\mathrm{p}=0.004$ y un tamaño del efecto por comparación de medias según d de Cohen de 0.63. Conclusión: La expresión de proteína EGFR en muestras de LBA, se encuentra sobreexpresada en sujetos con cáncer pulmonar comparado con controles sin cáncer.

\section{Efectos de la privación aguda de sueño después de una guardia en el grado}

de atención, memoria y velocidad de reacción en médicos residentes

Saucedo DDI, Ramírez MJF, Ramírez $R A$, Valdez LHG, Guzmán DNE

IMSS

Introducción: El sueño es una actividad fisiológica fundamental, en éste se lleva a cabo la consolidación de la memoria de corto a largo plazo y facilita la capacidad de aprendizaje. La privación de sueño ocasiona alteraciones en dichas funciones por lo que es de interés evaluar sus efectos en los médicos residentes, ya que puede verse afectado su desempeño. Objetivos: Evaluar los efectos de la privación aguda de sueño después de una guardia en el grado de atención, memoria y velocidad de reacción en residentes de la UMAE 34. Material y métodos: Estudio observacional, analítico, longitudinal y prospectivo. Se incluyeron los residentes de todas las especialidades de la UMAE 34, a los cuales se les aplicaron pruebas de atención, memoria y de velocidad de reacción en dos ocasiones, la primera ocasión después de dos días de descanso y la segunda en el día posterior de una guardia. Todos realizaron: cuestionario de horas de sueño, escala de sueño de Epworth, prueba de conexión mediante trazado, span de dígitos, test de memoria auditiva y visual de Wechsler y prueba de tiempo de reacción. Los resultados se analizaron utilizando el paquete estadístico SPSS v22. Resultados: Se evaluaron 59 individuos, mediana de edad de 29 años, siendo 46 (78\%) hombres y $13(22 \%)$ mujeres. Según la distribución por especialidad correspondió: angiología 9 (15.3\%), cardiología 21 (35.6\%), cardiología pediátrica $4(6.8 \%)$, cirugía cardiotorácica 9 (15.3\%), neumología 13 (22\%) y neumología pediátrica $3(5.1 \%)$. 
Cuarenta y siete $(79.7 \%)$ presentaron somnolencia posguardia siendo de predominio moderada en 29/47 (61.7\%). La mediana de horas de sueño previa a la guardia fue de 6 horas. En todas la evaluaciones existió deterioro posterior a la guardia con una $\mathrm{p}<$ 0.001. Conclusión: La privación aguda de sueño después de una guardia en médicos residentes afecta de manera negativa en el grado de velocidad de reacción, memoria y atención, que podría repercutir en el rendimiento académico y laboral.

\section{Microbiología de la infección pleural mediante el cultivo en medio de transporte para hemocultivo} Marín CBA, Vega SÁE, Martínez OJA,
Báez SAR

INER Ismael Cosío Villegas

Introducción: La microbiología del derrame pleural paraneumónico o en su defecto propiamente dicho de la infección pleural en México es poco conocida, esto debido a la mala calidad en la manipulación de las muestras así como su retardo en la entrega oportuna al laboratorio de destino, entre otras cosas. El contar con medios de transporte en el cual el factor tiempo no se vea involucrado puede ayudarnos a caracterizar las etiologías infecciosas de los derrames pleurales infecciosos en nuestro país. Objetivos: Comparar la frecuencia de aislamientos positivos de líquido pleural inoculado en medio para hemocultivo vs. el cultivo estándar en pacientes con derrame pleural infeccioso. Material y métodos: Se recolectaron pacientes del $1^{\circ}$ de enero al 31 de julio de 2016 con el diagnóstico de derrame pleural infeccioso. Se les realizó toracocentesis diagnóstica, se tomaron 30 $\mathrm{mL}$ de líquido pleural más de lo habitual para fines de este estudio. Se inoculó 10 $\mathrm{mL}$ de líquido en medio para hemocultivo de microorganismos piógenos, $10 \mathrm{~mL}$ en medio para hemocultivo de micobacterias y $10 \mathrm{~mL}$ en medio estándar (estéril). Se registraron datos demográficos, clínico e imagenológicos así como su evolución desde su padecimiento actual hasta su egreso hospitalario. Los resultados se compararon entre aquéllos en los que se identificó agente microbiológico en líquido pleural y los que no. Resultados: Se incluyeron 29 pacientes de los cuales, el aislamiento en medio para hemocultivo de microorganismos piógenos, micobacterias y medio estándar fue 41, 37 y 31\%, respectivamente $(\mathrm{p}<0.05)$. En la suma de ambos métodos se obtuvo el $48.3 \%$ de aislamiento. Conclusión: El transporte de líquido pleural infeccioso en medio para hemocultivo de microorganismos piógenos y micobacterias es comparable, e incluso mejor que el medio estándar en la detección de patógenos bacterianos en el espacio pleural.

Una mascarilla personalizada para suministrar presión positiva en pacientes con trastornos respiratorios del dormir y enfermedad neuromuscular

Ramírez MVR, Carrillo AJL, Urrusti AJL, Buzali WL

INER Ismael Cosío Villegas; Universidad Iberoamericana

Introducción: El tratamiento de los trastornos respiratorios del dormir (TRD) en presencia de enfermedad neuromuscular (ENM) es un dispositivo de presión positiva durante el sueño, pero su efectividad se puede ver afectada por la fuga del flujo aérea en el circuito, cuya causa más común es la mala adherencia de la mascarilla sobre la piel del paciente. Objetivos: Objetivo general: describir el proceso para desarrollar una mascarilla personalizada para suministrar presión positiva en pacientes con TRD y ENM. Secundarios: describir el apego, fuga y efectos adversos usando una mascarilla personalizada. Material y métodos: Estudio observacional y descriptivo. Con el objetivo de estandarizar el proceso para desarrollar la mascarilla inicialmente se realizaron pruebas en sujetos sanos, una vez desarrollado el proceso se incluyeron 10 pacientes con TRD y ENM con indicación de tratamiento con un dispositivo de presión positiva por primera vez. Una vez fabricada la mascarilla todos los pacientes recibieron una prueba de 1 semana, los parámetros utilizados fueron los indicados por el médico tratante. Resultados: Se realizaron distintas pruebas en sujetos voluntarios sin TRD. Se fabricó una mascarilla personalizada con base en lo aprendido durante la elaboración de las mascarillas anteriores bajo el siguiente procedimiento: réplicas faciales, escaneado 3D de la réplica facial, procesamiento de la imagen $3 \mathrm{D}$, diseño de la mascarilla, impresión de la mascarilla, ensamble del arnés, válvula en mascarilla y sello antifugas, pruebas de la mascarilla, resultados de la prueba. Durante el período de prueba de una semana, las mascarillas no causaron irritación alguna a los pacientes. Conclusión: Este proyecto demuestra la factibilidad de fabricar mascarillas personalizadas para administrar presión positiva en las vías aéreas de pacientes con TRD y ENM, con comodidad y desempeño aceptables. Su continuación podría mejorar significativamente la técnica, sin embargo, se requerirá del estudio económico correspondiente.

Consumo de oxígeno en caminata de 6 minutos comparado con el obtenido en prueba de ejercicio cardiopulmonar a la altura de la Ciudad de México

Reyes EA, Jiménez COG, Arroyo $H L J$, Cid JS, Pérez PR, Gochicoa RL, Torre $B L$

INER Ismael Cosío Villegas

Introducción: En México existe una gran diversidad geográfica con respecto a la altitud. La exposición a la altura impacta el rendimiento en el ejercicio; el $\mathrm{VO}_{2} \mathrm{Max}$ disminuye en aproximadamente $1 \%$ por cada $100 \mathrm{~m}$ por arriba de los 1,500 $\mathrm{m}$ sobre el nivel del mar. En México debido a la altura, las pruebas de ejercicio cardiopulmonar representan un reto físico mayor para el 
individuo a evaluar. Objetivos: Comparar el consumo de oxígeno obtenido durante la prueba de caminata de 6 minutos a la altura de la Ciudad de México vs. prueba de ejercicio cardiopulmonar. Material y métodos: Se realizó caminata de 6 minutos con analizador de gases portátil y prueba incremental de ejercicio cardiopulmonar en cicloergómetro. Se realizó correlación mediante la $r$ de Pearson para observar la diferencia entre $\mathrm{VO}_{2}$ Pico en PC6M y VO Máx en PECP. Resultados: Se reclutaron 76 sujetos de noviembre de 2015 a abril de 2016. Se realizó caminata de 6 minutos con equipo de analizador de gases Oxycon Mobile By Jaeger. La distancia recorrida (m) 634.84 \pm 58.20, $\mathrm{VO}_{2}$ Pico (mL/min) 1455.72 $\pm 428, \mathrm{VO}_{2} \mathrm{Pico} / \mathrm{kg} 20.39 \pm .58, \mathrm{VCO}_{2}(\mathrm{~mL} /$ min) $1366.92 \pm 437.06$, frecuencia cardíaca máxima $137.43 \pm 18$, pulso de oxígeno $\left(\mathrm{O}_{2} /\right.$ HR mL) 10.59. A 29 sujetos se les realizó prueba de ejercicio cardiopulmonar en cicloergómetro con protocolo incremental. Trabajo realizado (watts) $145.90 \pm 30.23$, ventilación minuto $(\mathrm{L} / \mathrm{min}) 88.10 \pm 21.68$, VO Máx (mL/min) 2052.31 $\pm 536.05, \mathrm{VO}_{2} /$ $\mathrm{kg}(\mathrm{mL} / \mathrm{min} / \mathrm{kg}) 29.81 \pm 5.49, \mathrm{VCO}_{2}(\mathrm{~mL} /$ min) $2077.16 \pm 571.3$, FC máxima 172.72 \pm 17.46 , pulso de oxígeno $12.25 \pm 3.27$. Se realizó un análisis de correlación de Pearson entre el $\mathrm{VO}_{2}$ obtenido en caminata de 6 minutos y el $\mathrm{VO}_{2}$ Máx en PECP ( $r=0.890)$. Conclusión: El consumo de oxígeno medido con analizador de gases portátil durante caminata 6 minutos tiene una correlación lineal fuerte $(\mathrm{r}=0.89, \mathrm{p}<$ 0.001 ) con $\mathrm{VO}_{2}$ Máx obtenido en prueba de ejercicio cardiopulmonar a una altitud de 2,240 msnm.

\section{Reporte de caso: Trauma torácico contuso, tórax inestable y fijación de fracturas costales con clavos de Kirschner}

\section{González QA, Flores SLO, Wong GM, Pérez RE, Muñoz MGE}

Hospital Universitario «Dr. José E. González», UANL

Introducción: El tórax inestable representa el $10 \%$ del trauma contuso torácico, causa una importante morbimortalidad asociada a IRA y hemorragia. Múltiples estudios a corto y largo plazo sugieren la estabilización de los segmentos inestables. El uso de PEEP aumentó la sobrevivencia, pero requiere un tiempo prolongado en UCI, con mortalidad de hasta $36 \%$ en algunas series. La reparación quirúrgica temprana disminuye la morbimortalidad (38-78\%) y la estancia en UCI. Presentación del caso: Masculino 49a, inicia $1 \mathrm{~h}$ previa sufriendo atropello por vehículo automotor en vía de alta velocidad, es traído a urgencias por paramédicos, llegando hemodinámicamente estable, en 9 pts ECG, combativo, taquicárdico, taquipneico, $\mathrm{SpO}_{2} 80 \%$ AA, hemitórax izquierdo hipoventilado, mate, con crepitación y dolor a la palpación, múltiples abrasiones y escoriaciones en ambos hemitórax, resto sin alteraciones, se coloca sonda de toracostomía obteniendo aire a presión y $300 \mathrm{~cm}^{3}$ de sangre, FAST y TAC de cráneo normales, se realiza IOT por insuficiencia respiratoria y deterioro neurológico, se le realiza una TAC tórax e ingresa a la UCI; parámetros ventilatorios mínimos, BH sin alteraciones, bioquímica sin alteraciones, segundo día de internamiento se redujo y fijó el 4, 5, 6, 7 arcos con clavo de Kirschner intramedular, se remodeló y fijó el octavo espacio intercostal con alambre, se colocó sonda de toracostomía Argyl 28 Fr, se da de alta de la UCI al cuarto día de internamiento. Conclusión: As de Moya et al. demostraron mayor beneficio en fijación quirúrgica en la reducción del dolor. Tanaka et al. y Granetzny et al. reportaron de manera independiente reducción en la estancia en UCI y días de internamiento en fijación de fracturas tempranamente. En este paciente no fue posible utilizar materiales de titanio por cuestión económica, se decide por clavos de Kirschner con excelentes resultados. Aporte a la práctica clínica diaria: Disminución de estancia en UCI en la fijación temprana en tórax intable con materiales de bajo costo.

Tumores de mediastino: Experiencia de dos años en el servicio de Neumología de Centro Médico Nacional de Occidente

\section{González C, Hernández GD}

Centro Médico Nacional de Occidente

Introducción: El mediastino es un sitio frecuente de presentación de tumoraciones. En nuestro país es una entidad poco descrita en la bibliografía y lo descrito discrepa ampliamente de la literatura internacional. Objetivos: Describir los principales diagnósticos histopatológicos y características clínicas de los tumores de mediastino en nuestro servicio. Material y métodos: La selección de pacientes se realizó de manera retrospectiva por medio de los censos del Servicio de Neumología y las boletas de biopsia del Servicio de Anatomía Patológica. Resultados: En el estudio retrospectivo de dos años existió un total de 1,243 ingresos, 65 casos de tumores de mediastino representan el $5.2 \%$ de todos los ingresos al servicio. El principal sitio de afectación anatómico fue el mediastino anterior con un $47.5 \%$, seguido de medio $44.5 \%$ y posterior $8 \%$. El principal diagnóstico histopatológico independiente de la localización fue el carcinoma pulmonar (38.46\%), seguido de tumores linfoides (21.54\%), tumores germinales $(9.23 \%)$, un $4.62 \%$ de los casos quedaron sin diagnóstico. En el mediastino anterior el principal diagnóstico fueron los tumores de origen linfoides con el $38 \%$, en el medio el carcinoma pulmonar con el $65 \%$ y en el posterior el schwanoma $60 \%$. El principal método diagnóstico fue la biopsia a cielo abierto $(38.46 \%)$, la punción fue el segundo lugar (21.54\%) y la broncoscopia el tercero (18.46\%). La asociación de derrame pleural fue observada en el $30.77 \%$ de los casos y de síndrome de vena cava superior en el 20\%. Conclusión: Este estudio da pie a futuros estudios prospectivos. Los hallazgos discrepan de la literatura internacional, pero concuerdan con la poca información previamente documentada en México. Ante la presencia de un tumor mediastinal se debe considerar la biopsia a cielo abierto para su diagnóstico, en el mediastino medio la broncoscopia mostró buen rendimiento. $\mathrm{La}$ asociación de derrame pleural y síndrome de vena cava superior sincrónicamente se relacionó mayormente al carcinoma pulmonar.

Uso de omalizumab como tratamiento en el síndrome 


\section{de sobreposición asma-EPOC}

\section{Herrera JC, Arellano El, Jaramillo E, Espinosa $A$}

Hospital Universitario de Puebla; IMSS La Margarita Puebla; Benemérita Universidad Autónoma del Estado de Puebla

Introducción: La enfermedad pulmonar obstructiva crónica (EPOC) y el asma son enfermedades pulmonares comunes de vía aérea. Existen pacientes con síndrome de sobreposición asma/EPOC (SSAE) que han sido pocos estudiados, que comparten características etiológicas y funcionales de ambas enfermedades las cuales han ido en incremento en los últimos años por sus exacerbaciones severas. La necesidad de un tratamiento eficaz y seguro es necesario en esta población. Omalizumab es una terapia efectiva ya descrita en los pacientes con enfermedad asmática severa por su seguridad y eficacia que ha permitido mejoría sintomática. Existen pocos estudios disponibles en población con SSAE. Objetivos: Se describen a continuación nuestra experiencia en estudio retrospectivo el uso de omalizumab (terapia anti-IgE) como tratamiento en 5 pacientes con síndrome de sobreposición asma/EPOC (SSAE) sin mejoría. Material y métodos: Se describe nuestra experiencia en estudio retrospectivo el uso de omalizumab (terapia anti-IgE) como tratamiento en 5 pacientes con síndrome de sobreposición asma/EPOC (SSAE) sin respuesta a tratamiento en la clínica tras 52 semanas de tratamiento. Utilizamos diferentes definiciones descritas en la literatura de SSAE que compartían ambas enfermedades. Se administró omalizumab y se registraron parámetros clínicos, funcionales y sintomáticos por escalas ACT. Resultados: Tras la administración de omalizumab por 1 año, los pacientes presentaron mejoría de los síntomas, disminución de exacerbaciones y hospitalización. Se reportó mejoría de los síntomas (tos y disnea), mejoría del $\mathrm{FEV}_{1}$ en un $20 \%$ y de ACT (Asthma Control Test) de 10 a 20 puntos. Conclusión: Nuestro estudio muestra mejoría en los pacientes con el uso de omalizumab en pacientes con SSAE.
Estos hallazgos demuestran estadística de vida real y sugieren de manera contundente la seguridad y eficacia de omalizumab. Éste es el primer estudio mexicano donde se da tratamiento a pacientes con SSAE que no mejoran con terapia estándar descrita por guías internacionales.

\section{Uso exitoso de omalizumab como tratamiento en paciente con rinosinusitis crónica, poliposis nasal y asma severa}

Herrera GJC, Arellano MEI, Jaramillo $A E$, Espinosa $A A$

Hospital Universitario de Puebla; IMSS La Margarita Puebla; Benemérita Universidad Autónoma del Estado de Puebla

Introducción: La rinosinusitis crónica, poliposis nasal y asma es un complejo de enfermedades que suponen un riesgo vital en los pacientes que la presentan, por el aumento del número de exacerbaciones que presentan y asistencia a urgencias ya que ven comprometida su calidad de vida por la cantidad de tratamiento prolongados con esteroides sistémicos y número de intervenciones quirúrgicas de repetición. Presentación del caso: Se presenta el caso de paciente de 37 años de edad con diagnóstico de rinosinusitis crónica/poliposis nasal y asma grave con antecedente de polipectomía en 5 ocasiones, pruebas cutáneas negativas, eosinofilia e IgE de $85 \mathrm{UI} / \mathrm{mL}$, quien presentaba 10 exacerbaciones al año con uso de esteroides sistémicos y múltiples tratamientos y ausencia laboral. Se inició omalizumab a dosis de 1 ampolleta SC cada mes por 6 meses. Tras la administración de omalizumab por 24 semanas presentó mejoría de los síntomas, disminución de exacerbaciones al año y asistencia a urgencias, mejoría del $\mathrm{FEV}_{1}$ en un $10 \%$ y de ACT (Asthma Control Test) de 7 a 20 puntos. No ha requerido nuevas intervenciones quirúrgicas, disminución de esteroide nasal y sistémico. Conclusión: Este caso representa de manera puntual y exitosa el uso de omalizumab en pacientes con rinosinusitis crónica, poliposis nasal y asma severa mejorando parámetros clínicos y de control de enfermedad mejorando su calidad de vida. Estos hallazgos demuestran estadística de vida real y sugieren de manera contundente la seguridad y eficacia de omalizumab con dicha tríada. Aporte a la práctica clínica diaria: Los pacientes con rinosinusitis crónica, poliposis nasal y asma severa presentan exacerbaciones frecuentes que impiden que trabajen, usan de manera crónica esteroides sistémicos y nasales, el uso de omalizumab en pacientes con dicha tríada permite que se incorporen a sus trabajos. El medicamento ya ha demostrado buena tolerancia y buena seguridad. Omalizumab debe ser una alternativa segura de tratamiento.

\section{Uso de rivaroxaban como tratamiento en hipertensión pulmonar asociada a tromboembolia crónica}

\section{Herrera GJC, Ceron EN, Arellano $M E I$, Jaramillo $A E$, Espinosa $A A$}

Hospital Universitario de Puebla; IMSS La Margarita Puebla; Benemérita Universidad Autónoma del Estado de Puebla

Introducción: La hipertensión pulmonar asociada a tromboembolismo crónico (HPTEC) es una de las enfermedades emergentes actuales de elevada morbimortalidad. Es actualmente una de las causas más frecuentes de hipertensión pulmonar severa y está clasificada en el grupo cuatro de la OMS. La fisiopatogenia es realmente multifactorial, hasta el momento se trata de episodios recurrentes de trombosis y remodelado vascular con obstrucción parcial o total crónica de las arterias pulmonares. La anticoagulación es la terapia médica primaria para este subgrupo de pacientes que está soportado por el gran beneficio del tratamiento al no permitir más eventos trombóticos que conlleven a un desenlace a corto plazo a los pacientes. Objetivos: Rivaroxaban es un novedoso anticoagulante oral inhibidor del factor $\mathrm{Xa}$ que actualmente es una alternativa segura y eficaz a los tradicionales anticoagulantes como la heparina y warfarina para la prevención de enfermedades tromboembó- 
licas. Rivaroxaban tiene hasta el momento muchas ventajas como su administración oral una vez al día, rápido inicio de acción, no necesita monitorización de la coagulación y tiene bajo riesgo de interacción con otros fármacos o restricciones dietéticas. Material y métodos: Se presentan 5 casos de pacientes con presencia de hipertensión pulmonar asociada a tromboembolismo crónico HPTEC, tras el diagnóstico iniciaron tratamiento con rivaroxaban a dosis de 20 mg al día. La etiología de la HPTEC fue: 3 casos secundarios a tratamiento ortopédico, 1 caso secundario a síndrome de apnea del sueño y 2 casos secundarios a cirugía abdominal. Resultados: Se usó rivaroxaban $20 \mathrm{mg}$ V.O. cada $24 \mathrm{~h}$ en conjunto con su tratamiento habitual. Cien por ciento de los pacientes no presentaron evidencia de sangrado. Ningún paciente presentó sangrado mayor o mínimo. Conclusión: Rivaroxaban es un medicamento seguro y eficaz en los pacientes con hipertensión pulmonar asociada a tromboembolia crónica.

\section{Manejo racional del empiema en niños: cirugía toracoscópica vs. drenaje pleural temprano videoasistido \pm fibrinolítico. Reporte preliminar}

Sancho R, Arredondo VJG, Diliz NHS, Cuevas SFJ, Solorio RL

Instituto Nacional de Pediatría; Pediatría Integral y Terapia Respiratoria

Introducción: Las complicaciones pleuropulmonares de las neumonías en niños conllevan la necesidad de variados procedimientos conservadores o quirúrgicos con hospitalización prolongada. Proponemos una técnica para el tratamiento de los empiemas basado en las principales recomendaciones de una revisión de la literatura: Drenaje pleural temprano videoasistido \pm fibrinolítico (DPTVA \pm FIB). Objetivos: Analizar las variables estadísticas de pronóstico y eficacia entre las dos modalidades terapéuticas: VATS vs. DPTVA \pm FIB. Material y métodos: Estudio descriptivo, retrospectivo y comparativo entre dos grupos de pacientes, grupo I: VATS 20092010 y grupo II DPTVA \pm FIB 2014-2016 evaluados por el mismo equipo quirúrgico. Resultados: 10 pacientes del grupo I: 4 de VATS como primera línea de tratamiento y 6 VATS como segunda línea, en el grupo II: 8 con DPTVA \pm FIB, encontrándose: tiempo quirúrgico grupo I de $2 \mathrm{~h}$ y para el grupo II de $40 \mathrm{~min}$; el $50 \%$ del grupo I $>$ de 3 semanas con síntomas, en el VATS de segunda línea recibieron 20 días (rango 7-40) de manejo con sonda pleural y antibióticos en todos los casos, 2 pacientes de este subgrupo requirieron de lobectomía y necrosectomía, respectivamente; del subgrupo de VATS de primera línea sólo uno requirió toracotomía con decorticación; la estancia de las sondas pleurales fue de 13 días (rango 3-40) para el grupo I con VATS. En el grupo II de DPTVA \pm FIB sólo un paciente requirió de una segunda intervención, la estancia de la sonda pleural para este grupo II fue de 7 días (rango 4-9). Conclusión: La cirugía VATS como primera línea de tratamiento tiene resultados similares al DPTVA \pm FIB en cuanto a pronóstico e índice de fallas; sin embargo, DPTVA \pm FIB muestra disminución de la estancia intrahospitalaria y de drenaje pleural. El DPTVA \pm FIB es un procedimiento reproducible con menor tiempo quirúrgico, baja morbilidad y nula mortalidad.

\section{Carcinoma epidermoide queratinizante traqueal: Reporte de caso clínico}

\section{Flores SMR, Rivera RJ}

IMSS
Introducción: Los tumores primarios de
tráquea son infrecuentes pero un interesante
grupo de neoplasia en su mayoría malignas;
por sus implicaciones funcionales que ponen
en riesgo la vida del paciente, requieren un
manejo adecuado y oportuno para lograr
los mejores resultados. Su tratamiento es
principalmente quirúrgico, ameritando
manejo interdisciplinario. Presentación
del caso: Hombre de 47 años, originario
y residente de Mérida, carpintero últimos
20 años, con índice tabáquico de 22 hasta
la actualidad, sin ningún otro antecedente

relevante, ingresa con cuadro de 6 meses de evolución caracterizado por tos de difícil expectoración, disnea progresiva hasta MMRC 3 y estridor laríngeo de predominio espiratorio, se realiza broncoscopia encontrando tumoración traqueal a $3 \mathrm{~cm}$ de la carina principal, pediculada con oclusión de la luz traqueal en un $90 \%$. Se realiza biopsia concluyéndose histopatológicamente: carcinoma epidermoide queratinizante. Se realizaron estudios de extensión en busca de metástasis sin evidencia de las mismas, decidiendo la realización de resección de dicha tumoración y traqueoplastía con adecuada evolución postquirúrgica, actualmente bajo radioterapia a 4 meses de la misma. Conclusión: Aproximadamente ocurren 2 a 3 nuevos casos por millón de habitantes por año. El carcinoma adenoidequístico y el epidermoide constituyen tres cuartas partes de los tumores primarios traqueales. El pico de incidencia del epidermoide es entre los 50 y 60 años, género masculino, donde el antecedente de tabaquismo es preponderante. Puede ser exofítico circunscrito o diseminado en la tráquea, hasta el $40 \%$ son irresecables por invasión a mediastino. Aporte a la práctica clínica diaria: Siendo los tumores de tráquea en su mayoría de origen órganos adyacentes a la tráquea, es de interés presentar un tumor primario de tráquea por su baja incidencia, la dificultad que implica su tratamiento y el pronóstico que tienen. En este caso se presenta uno de los dos tumores primarios más frecuentes: el carcinoma epidermoide.

\section{Hallazgos tomográficos frecuentes en pacientes con adenocarcinoma pulmonar EGFR positivos en México}

\section{Sánchez RCP, Bastidas MJE, Alatorre AJA, Pensado PL}

INER Ismael Cosío Villegas

Introducción: El cáncer de pulmón sigue siendo la principal causa de muerte por cáncer a nivel mundial. La identificación de mutaciones en el receptor del factor de crecimiento epidérmico (EGFR) ha permitido caracterizar a los pacientes 
orientando las decisiones sobre la terapia dirigida. Características como el tipo histológico del adenocarcinoma, sexo femenino, antecedente de no fumador se han relacionado con la presencia de mutaciones EGFR. Objetivos: Describir los hallazgos tomográficos más frecuentes de pacientes con adenocarcinoma pulmonar EFGR positivos en el INER. Material y métodos: Estudio descriptivo retrospectivo. Se trabajó el expediente clínico y radiológico de pacientes con adenocarcinoma de pulmón atendidos en el INER durante el año 2015. El análisis se realizó en términos de frecuencias absolutas y relativas así como medidas de tendencia central y dispersión para las variables cuantitativas. Resultados: Se identificaron 62 pacientes. La media de edad fue de 61 años. Se observaron mutaciones del exón 19 y 21 en 38.7 y $25.8 \%$, respectivamente. En 30 pacientes se halló registro del patrón histológico: $40 \%$ correspondían al subtipo acinar, lepídico y sólido en $20 \%$ cada uno. Los patrones radiológicos más frecuentes en pulmón fueron el reporte de masa tumoral en 23 pacientes (37.1\%) y consolidación en 17 pacientes (27.4\%); la pleura se reportó en 25 casos como normal (40.3\%). Conclusión: Promover la posible utilización de las características tomográficas en pacientes con adenocarcinoma de pulmón para predecir la identificación temprana de pacientes susceptibles de beneficiarse de tratamiento con inhibidores de tirocinkinasa previo a la obtención de resultados de medicina molecular.

\section{Estudio directo de mutación EGFR como técnica fiable, sencilla y rápida para caracterizar pacientes con adenocarcinoma pulmonar}

\section{Sánchez RCP, Bastidas MJE, Luna RC}

INER Ismael Cosío Villegas

Introducción: El estudio mutacional del receptor del factor de crecimiento epidérmico (EGFR) permite caracterizar pacientes con adenocarcinoma pulmonar.
A continuación presentamos 3 casos de análisis de mutación EGFR con técnica directa. Objetivos: Identificación rápida de mutación EGFR para disminuir tiempos en la toma de decisiones para el tratamiento de pacientes con adenocarcinoma pulmonar. Material y métodos: Técnica directa. Se parte del extendido citológico directo del material de biopsia. Se confirma la presencia de células tumorales y se genera una impronta sobre papel filtro para hidratarla con agua tritiada. Se coloca en cartucho de análisis mediante el sistema Idylla. Presentación de los casos: 1. Femenino de 56 años que refiere 9 meses tos, disnea y dolor pleurítico. TAC: masa en lóbulo superior izquierdo, adenopatías 4L. SPECT/CT: metástasis óseas. EBUS: positivo. Inmunohistoquímica: adenocarcinoma pulmonar. Rebiopsia con análisis con técnica directa obteniendo concordancia para EGFR mutado. 2. Masculino de 39 años que refiere 24 meses con tos, disnea y pérdida ponderal. TAC: masa apical derecha. Resultado histopatológico: Adenocarcinoma pulmonar. Gammagrama óseo: enfermedad multimetastásica. Fallece por neumonía asociada a los cuidados de la salud en espera de resultado de perfil mutacional. Post mortem revela EGFR no mutado. 3. Femenino de 60 años que refiere 14 meses con tos y disnea. Resultado histopatológico: Adenocarcinoma pulmonar ECIIIA patrón acinar EGFR negativo en 2014. Se ofrece lobectomía y resección ganglionar. PEC-CT de seguimiento positivo en estación 4L, recibiendo adyuvancia con QT a base de paclitaxel carboplatino. En agosto 2016 con progresión de la enfermedad, EBUS positivo con EGFR mutado concordante en ambas técnicas. Conclusión: Esta búsqueda permite el reporte de mutaciones en 2-3 horas acortando los tiempos para la toma de decisiones. El costo adicional es compensado por la rapidez diagnóstica, permitiendo ahorro en cuanto a días de hospitalización, estudios adicionales y angustia del paciente permitiendo un tratamiento temprano mejorando el pronóstico.

\section{Técnica de elongación esofágica para esofagoplastía temprana}

\section{en recién nacidos de alto riesgo con atresia de esófago tipo long gap} Sancho HR, Solorio RL, Iribe GY,
Ham AKO, Cuevas SFJ

Instituto Nacional de Pediatría; Hospital

Materno Perinatal Mónica Pretelini Sáenz

Introducción: La atresia de esófago con puente amplio (long gap) se emplea como sinónimo de atresia tipo I, pero para efectos operativos son todas aquéllas que independientemente de su tipo imposibilitan la anastomosis primaria, el crecimiento esofágico puede ser estimulado por fuerzas de tracción aplicado a los cabos atrésicos, no existe en la literatura nacional alguna experiencia de la eficacia con esta técnica de elongación esofágica externa como opción de anastomosis temprana en el período neonatal. Presentación de los casos: Caso 1. Pretérmino con trisomía 21, atresia esofágica tipo I con puente amplio de $4.5 \mathrm{~cm}$, por imposibilidad de anastomosis se realiza elongación esofágica externa de los cabos hasta conseguir a los 4 días de tracción condiciones para realizar a los 33 días de vida esofagoplastía con anastomosis sin tensión. Caso 2. Pretérmino con síndrome de Down, atresia esofágica tipo I con long gap de 6 cuerpos vertebrales, se realiza a los 2 días duodenoplastía de Kimura con gastrostomía por atresia duodenal y cierre de PCA a los 18 días, a los 25 días se practica procedimiento de Foker, con elongaciones por 7 días se concilia la anastomosis primaria a los 37 días de vida con evolución satisfactoria. Caso 3. Neonato de término, atresia esofágica con puente amplio de 5 $\mathrm{cm}$, cierre de PCA, elongación esofágica externa por 5 días y anastomosis primaria a los 27 días, estenosis esofágica residual que revierte con dilataciones neumáticas Conclusión: La técnica de elongación esofágica permitió en nuestros pacientes alcanzar longitudes suficientes en 4 y 7 días para concebir la esofagoplastía temprana en las atresias de esófago tipo long gap; esta técnica puede representar una opción para esta conducta de esofagoplastía por etapas en los recién nacidos de alto riesgo. Aporte a la práctica clínica diaria: La técnica de elongación esofágica es una opción eficaz 
para la esofagoplastía temprana en las atresias esofágicas tipo long gap.

\section{Escala de predicción clínica para el diagnóstico de tos ferina en pacientes menores de 1 año}

Camacho ME, Ortega ASE, Rodríguez de Ita J, Chávez CKL, Santos GJ, Góngora CJJ

Tecnológico de Monterrey

Introducción: La tos ferina afecta predominantemente a la población menor de 1 año, y se encuentra entre las primeras 10 causas de muerte infantil. Representa un reto diagnóstico por su heterogeneidad clínica entre lactantes y pacientes con estado vacunal incierto. Objetivos: Desarrollar una guía de predicción clínica para identificar los lactantes menores con enfermedad por Bordetella pertussis. Material y métodos: Estudio retrospectivo a 5 años, observacional y analítico de pacientes de 0 a 12 meses de edad que consultan por Síndrome coqueluchoide. Se analizaron las variables que muestran una asociación alta con los casos confirmados de tos ferina. Resultados: Se evaluaron 251 expedientes de donde se obtuvo una muestra de 157 pacientes (109 casos confirmados de infección por Bordetella pertussis por PCR o cultivo y 96 casos controles con prueba negativa). Se eligieron 6 variables estudiadas con Odds ratio de $>1.2$ y se les asignó un punto a las que reportaron un valor entre 1.2 y 1.99 , dos puntos entre 2 y 2.99 y 3 puntos entre 3 y 3.99. Con un score final de 12 puntos se estableció que los pacientes con un puntaje de 7 o más poseen un alto riesgo de presentar tos ferina, con una sensibilidad de $87 \%$, especificidad de $40 \%$, un valor predictivo positivo de $77 \%$ y un valor predictivo negativo de $57 \%$. Conclusión: Este score establece el diagnóstico tos ferina en la primera consulta, requiere sólo un estudio accesible y comparado con el tiempo que demora el resultado de un cultivo o PCR, brinda una herramienta objetiva para un diagnóstico y tratamiento oportunos.

\section{Utilidad de la biopsia pulmonar transtorácica con}

\section{aguja de Trucut y de Chiba guiada por TAC, para el diagnóstico de tumoración pulmonar periférica}

\section{Gutiérrez CE, Rodríguez CC, Cancino MME, Aguilar ZCA, Gutiérrez de La Cruz $P$, Romero $C Y$}

IMSS; Universidad Autónoma de Nayarit

Introducción: El tumor pulmonar ocupa un lugar importante en el campo de la neumología y representa un reto para el diagnóstico y tratamiento. Cuando se localiza en la periferia, la biopsia guiada por TAC es el método de elección. Objetivos: Comparar la utilidad de la BPTT con la aguja de Trucut y de Chiba en pacientes con tumoración pulmonar periférica. Material y métodos: Estudio descriptivo, transversal y comparativo. Realizado en un Hospital de Segundo Nivel de Atención, se incluyeron 49 pacientes mayores de 18 años, con lesión(es) pulmonar periférica y datos clínicos sospechosos de malignidad. Mediante guía tomográfica y posición decúbito, se realizó biopsia con aguja de Chiba, seguida con Trucut. Se excluyeron 2 por no completar los estudios. Las muestras se analizaron por 2 patólogos distintos. Resultados: De los 47 pacientes estudiados, 34 fueron del género masculino y 13 del femenino, con rango de edad de 42 a 86 y media de 68.9 años. Con la técnica de BAAF (aguja de Chiba) se diagnosticaron 45 de los 47 pacientes, 41 malignos y 4 benignos, en 2 se reportaron falsos negativos que finalmente fueron positivos a malignidad. Con la técnica de Trucut se diagnosticaron 38 casos malignos, 9 negativos a malignidad, 6 de ellos fueron de origen benignos y 3 fueron falsos negativos. Sensibilidad para BAAF 0.95 y para Trucut 0.89 , especificidad y valor predictivo positivo de 1 (100\%), respectivamente. Valor predictivo negativo 0.66 para BAAF y 0.44 para Trucut. Falsos positivos 0 y falsos negativos 0.04 y 0.11 , respectivamente. Prevalencia de 0.91 en ambas técnicas y certeza diagnóstica 0.95 (95\%) para BAAF, y 0.89 (89\%) para Trucut. Conclusión: La BPTT con aguja de Chiba fue discretamente superior que Trucut. La combinación puede incrementar la certeza diagnóstica en lesión pulmonar periférica, con mínimas complicaciones y bajos costos.
Variante anatómica de arteria de Adamkiewicz: cuando no angioembolizar durante el tratamiento de una hemoptisis masiva, reporte de caso

\section{González TJ, Pacheco PMF, Flores SLO, Saldivar MDE, Muñoz MGE, Wong JM}

Hospital Universitario «Dr. José Eleuterio González», UANL

Introducción: La hemoptisis masiva puede ser una patología mortal en hasta el $80 \%$ de los casos, relacionada mayormente con asfixia. El 33\% de los pacientes suele abordarse de manera endovascular con arteriografía y embolización selectiva de la arteria bronquial, el control eficaz se logra en cerca del $81 \%$ de los casos, con una baja tasa de recurrencia. Sin embargo, la literatura reporta complicaciones relacionadas a este procedimiento, como las secuelas neurológicas, debidas al compromiso de la arteria de Adamkiewicz. Presentación del caso: Masculino de 42 años de edad con episodios de hemoptisis no masiva desde los 12 años, en intervalos de 2-3 años, asociadas a infecciones de vías respiratorias, ingresado a urgencias posterior a cuadro masivo de hemoptisis. Durante su exploración, como datos relevantes, campo pulmonar derecho con estertores. CT de tórax evidencia bronquiectasias pulmonares y múltiples cavernas en totalidad de pulmón derecho. Broncoscopia con coágulos sanguíneos y sangre fresca en bronquio principal, así como en bronquio de lóbulos medio e inferior; sin embargo, no se detecta sangrado franco. Resto de pruebas negativas. Angiografía identifica arteria de AdamKiewicz, proveniente de arteria bronquial inferior derecha, imposibilitando manejo endovascular por riesgo de daño espinal. Se decide abordaje por toracotomía posterolateral, identificándose afectación pulmonar total, por lo que se realiza neumonectomía derecha; siendo la evolución clínica posoperatoria adecuada. Conclusión: A pesar de las conductas propuestas en el manejo convencional de la hemoptisis, se sugiere el análisis detallado 
de las estructuras vasculares involucradas, ya que la falta de identificación de variantes anatómicas coexistentes podría conllevar a complicaciones. Aporte a la práctica clínica diaria: Ante hallazgos inhabituales en las exploraciones diagnósticas es siempre interesante el poder plantear la necesidad de un cambio en la actitud terapéutica como en este caso, donde se identifican estos hallazgos y se evitan complicaciones asociadas al manejo habitual.

\section{Hipertensión pulmonar tromboembólica crónica. Experiencia en el Hospital General de México: reporte de 20 casos}

\section{Gómez LSA, Cueto RG, Barragán $P G$, Heredia AAL, Cicero SR}

Hospital General de México

Introducción: Hipertensión pulmonar (HP) es la presencia de una presión arterial pulmonar media (PAPm) en reposo de 25 mmHg durante el cateterismo cardíaco derecho en reposo. La HP del grupo IV corresponde a hipertensión pulmonar tromboembólica crónica (HPTEC), patología con incidencia de aproximadamente $3 \%$. El tratamiento de elección es endarterectomía pulmonar (EP); sin embargo, aquéllos pacientes no candidatos a EP y/o, aquéllos con HP residual, reciben tratamiento médico con drogas específicas. Objetivos: Presentar el protocolo de estudio y la experiencia de 20 pacientes con HPTEC tratados con drogas específicas en el Servicio de Neumología del Hospital General de México. Material y métodos: Estudio retrospectivo realizado de enero de 2012 a diciembre de 2016. Se presentan 20 pacientes con diagnóstico de HPTEC. Las variables de interés fueron género, edad, índice de masa corporal y antecedente de enfermedad tromboembólica venosa (ETV). A todos los pacientes se les practicó estudios de laboratorio básicos, además de angioTC y gammagrama perfusorio pulmonar. Todos fueron sometidos a cateterismo cardíaco derecho. Resultados: Predominio del género femenino (12/8). Edad media de 47 años (DE 12.8). No- venta por ciento de los pacientes tuvieron antecedente de ETV. La clase funcional predominante fue II y III. La PAPm fue de $49.8 \mathrm{mmHg}$ (DE 14.6), las resistencias vasculares pulmonares fueron de 9.15 unidades Wood (DS 5.4), e índice cardíaco de $2.8 \mathrm{~L} /$ $\mathrm{min} / \mathrm{m}^{2}$ (DE 0.6). Conclusión: La edad de aparición en nuestro grupo es menor que en series mundiales de HPTEC. El antecedente trombofílico fue documentado el $30 \%$. Todos los pacientes tienen tratamiento con anticoagulantes orales, $70 \%$ cumarínicos y 30\% anticoagulantes orales específicos. Todos son tratados con drogas específicas del tipo inhibidores de fosfodiesterasa $5 \mathrm{y}$, la mitad de éstos, en combinación con antagonistas de receptores de endotelina tipo bosentán o macitentán. La sobrevida durante los 48 meses de seguimiento fue del $90 \%$.

\section{Hipertensión arterial pulmonar. Evaluación clínica, hemodinámica y tratamiento. Experiencia en el Hospital General de México}

\section{Cueto RG, Gómez LSA, Cicero SR, Barragán $P G$}

Hospital General de México

Introducción: Hipertensión arterial pulmonar (HAP) se refiere al grupo 1 de la clasificación de hipertensión pulmonar (HP) con incidencia y prevalencia estimadas de 2.4-7.6 casos/millón/año y 15-26 casos/ millón, respectivamente. Objetivos: Dar a conocer las características de los pacientes con HAP en el Servicio de Neumología del Hospital General de México. Material y métodos: Estudio observacional, descriptivo. Se realizó diagnóstico de HAP por cateterismo cardíaco derecho. Analizamos características demográficas, clínicas, hemodinámicas y terapéuticas. Resultados: Se incluyeron 84 pacientes. Ochenta y dos por ciento (69) mujeres y $18 \%$ (15) hombres. Edad media 39.9 años (DE \pm 19.1$)$. Índice de masa corporal $25.2 \mathrm{~kg} / \mathrm{m}^{2}$ ( $\mathrm{DE} \pm 5.33$ ). Correspondieron a subgrupos de HAP: $48 \%$ asociada a cardiopatías congénitas, $32 \%$ idiopática y $20 \%$ relacionada a enfer- medades del tejido conectivo. En la caminata de 6 minutos recorrieron en promedio 371 metros ( $\mathrm{DE} \pm 142$ ). La clase funcional predominante fue II. En el ecocardiograma se reportó media de la presión sistólica de la arteria pulmonar de $81.3 \mathrm{mmHg}$ (DE \pm 19.9) y disfunción del ventrículo derecho en $34.4 \%$ de los pacientes. La capacidad vital forzada se encontró por debajo (media $66 \%$, $\mathrm{DE} \pm 19)$ del valor predicho. Están en tratamiento con drogas específicas: bosentán 48 pacientes, sildenafil 16 y terapia combinada 20. Conclusión: Los resultados mostraron similitudes con lo reportado en la literatura, siendo el sexo predominante mujeres. Sin embargo, a diferencia de la bibliografía que establece la HAP idiopática como el subgrupo más frecuente, en nuestros pacientes fue la HAP asociada a cardiopatías congénitas. También, el diagnóstico se hizo a edad más temprana. Mediante la información obtenida este trabajo podrá ser la base para futuros estudios de mayor rigurosidad metodológica que establezcan en nuestra población las relaciones entre las variables y el pronóstico en estos pacientes.

\section{Mortalidad y lesión renal aguda en una cohorte de pacientes con neumonía grave por influenza a H1N1}

\section{León RMI, Hernández ZRJ, Reyes TG, Casas AG}

INER Ismael Cosío Villegas

Introducción: En el año 2009 aparece una nueva cepa pandémica de influenza A (H1N1) en México. La pandemia fue responsable de miles de hospitalizaciones, admisiones a terapia intensiva y muertes en el mundo. Entre los pacientes se reportó una incidencia de 53\% de lesión renal aguda (LRA); lo que incrementó la morbilidad y mortalidad en un 20-25\%. Objetivos: Analizar factores de riesgo asociados al desarrollo de LRA en pacientes críticamente enfermos con diagnóstico de neumonía grave por influenza A H1N1 y describir sí el balance acumulado de líquidos influyó en la mortalidad y desarrollo de LRA. Material y métodos: Retrospectivo, observacional. Criterios de inclusión: diagnóstico 
comprobado de neumonía por influenza A H1N1 por análisis de PCR en tiempo real, edad $>18$, tasa de filtrado glomerular estimada al ingreso $>60 \mathrm{~mL} / \mathrm{min} / 1.73 \mathrm{~m}^{2} \mathrm{SC}$, sin antecedente de enfermedad renal crónica, $\mathrm{PaO}_{2} / \mathrm{FiO}_{2}<200 \mathrm{mmHg}$ al ingreso. Resultados: Incluimos 60 pacientes, $65 \%$ hombres, promedio de edad 47.5, con diversas comorbilidades. El 71.6\% desarrolló LRA, AKIN-1 = 18\%, AKIN-2 = 24.6\% y AKIN-3 $=27.9 \%$, presentaron lo siguiente: fiebre 48 horas previas al ingreso: $95.3 \%$, $\mathrm{p}=0.048$, OR 6.30, IC (1.03-38.48). Defunción: $39.5 \%, \mathrm{p}=0.037$, OR 4.9, IC (0.99-24.2). Uso de vancomicina: $79.1 \%$, $\mathrm{p}=0.001$, OR 6.9, IC (2.2-3.85). Nivel de PEEP > 10: 83.3, $\mathrm{p}=0.031$, OR 5 (1.0922.82). Mortalidad mayor en el grupo de individuos más añosos, con puntuaciones más elevadas en las escalas PORT, APACHE II y SOFA. $\mathrm{PaO}_{2}$ al ingreso más bajos. El balance acumulado de líquidos tuvo un promedio de 10.65 litros en los primeros 7 días. Este balance fue mayor en el grupo con LRA 13,262 mL (9586-155596) vs. $8044 \mathrm{~mL}(5268-12910) \mathrm{p}=0.010$ al día 7 de hospitalización, siendo esta diferencia significativa desde el día 3. Conclusión: Un balance acumulado de líquidos mayor en pacientes con neumonía grave por influenza puede favorecer el desarrollo de LRA. Escalas pronósticas APACHE II, SOFA y PORT son predictoras de mortalidad en este grupo de pacientes.

\section{Hipertensión arterial pulmonar. Caracterización clínica, funcional pulmonar y ecocardiográfica en un Hospital de 3er. nivel del Sureste de México (RESURHAP)}

\section{Cortés A, Manjarrez MDA, Vega SÁE, Che MJL}

Hospital Regional de Alta Especialidad de la Península de Yucatán

Introducción: La hipertensión arterial pulmonar es una enfermedad progresiva que impacta la sobrevida. Actualmente se clasifica en 5 grupos (Consenso Niza
2013). La frecuencia y pronóstico de cada grupo varía geográficamente. En México, los datos más importantes derivan del análisis de la población circunscrita en el centro del país; sin embargo, los datos no necesariamente aplican a otras regiones. Objetivos: Caracterizar a los pacientes con HAP registrados en un Hospital del Sureste de México. Material y métodos: Estudio observacional, retrospectivo que incluye la totalidad de expedientes de casos con HAP diagnosticados de forma consecutiva en un período de cuatro años. Se generaron 2 grupos centrales de estudio: 1) HAP grupo 1 y 2) HAP No grupo 1 (grupo 3, 4 y 5). Se excluyeron los casos con HAP grupo 2. De cada expediente se extrajeron datos clínicos, séricos, función pulmonar y mediciones ecocardiográficas. Se analizó la población de forma global y contrastando los grupos para identificar características distintivas. Resultados: Se incluyeron los expedientes de 50 casos. La mediana de edad fue de 47 años (IIC 31-67). Sesenta y ocho por ciento fueron del sexo femenino. Los pacientes de HAP Grupo I fueron diferentes en IMC (23.8 kg/ $\mathrm{m}^{2}$ vs. $\left.35.4 \mathrm{~kg} / \mathrm{m}^{2}\right), \mathrm{PaCO}_{2}$ (34.8 mmHg vs. $44.8 \mathrm{mmHg}), \mathrm{HCO}_{3}$ (21.8 mmol/L vs. 27.2 $\mathrm{mmol} / \mathrm{L})$ y exceso de base $(-1.6 \mathrm{mmol} / \mathrm{L} v s$. $4.1 \mathrm{mmol} / \mathrm{L})$. Asimismo, contrastaron en PsAP (74 mmHg vs. $48 \mathrm{mmHg}$ ), TAPSE (18 vs. 21), diámetro de AD (37 mm vs. 26 $\mathrm{mm})$. No se observaron diferencias en clase funcional, BNP sérico y función pulmonar incluyendo C6M. Conclusión: En el Sureste de México, la mediana de edad en la que se realiza el diagnóstico de pacientes con HAP fue de 47 años. Más aún, los casos con HAP predominan en el Grupo 1 y se caracterizan por ser mujeres jóvenes con PsAP basal de $74 \mathrm{mmHg}$ y datos gasométricos de hiperventilación crónica.

\section{Evaluación de la} integridad de la membrana alveolocapilar en pacientes adultos con diagnóstico de asma asociado a diabetes mellitus tipo 2

Vargas DC, García TR, Becerra RT, Pellerin FK, Hernández PJE, Naranjo
MA, Cruz BI, Almeda VP, García SJR, Olivares Cl, Chávez AJ, Bobadilla LK, López SE, Miguel RJL, Aguilar SC, Sierra VMP

INER Ismael Cosío Villegas; Instituto Nacional de Ciencias Médicas y Nutrición «Salvador Zubirán»; Instituto Politécnico Nacional, Escuela Superior de Medicina

Introducción: El asma y la obesidad son enfermedades muy prevalentes y la incidencia de DM2 está incrementando rápidamente. Hay asociación entre asma, obesidad y DM2. El asma aumenta la resistencia a la insulina 1.5 veces en obesos comparados con no obesos. La vía inflamatoria es la responsable. La obesidad incrementa la reactividad y remodelación de las vías aéreas, además, tiene impacto negativo en la función pulmonar. La DM2 provoca un incremento en estado inflamatorio y estrés oxidativo promoviendo complicaciones micro y macrovasculares (incluye capilares alveolares). Además de disminución en la FVC y en la DLCO. Los daños pulmonares ocasionados por la asociación asma-diabetes no han sido dilucidados. Objetivos: Evaluar la integridad de la membrana alveolocapilar (MA-V) mediante DLCO y proteína CC-16 en: obesidad, asma+obesidad, obesidad+DM2 y asma+obesidad+DM2. Material y métodos: Medimos la función respiratoria y la proteína CC-16 sérica. Análisis estadístico multivariado. Criterios de inclusión: Hombres/mujeres entre 30 y 55 años, no fumadores. Grupos: (ob) IMC 24-34.9 kg/m²; (asma+ob): IMC > 24 y asma moderada a grave persistente (según GINA 2013), (ob+DM2): IMC 24-34.9 kg/ $\mathrm{m}^{2}$ y DM2 y (asma+ob+DM2): IMC > 24 + asma moderada a grave persistente y DM2. Criterios de exclusión: Daño renal, complicaciones macrovasculares, infección respiratoria seis semanas previas. Resultados: La función pulmonar está disminuida en el grupo asma+ob y en el grupo asma+ob+dm. El índice RV/TLC (atrapamiento aéreo) es significativamente mayor en estos grupos. No hubo diferencia significativa pero los grupos: asm+ob y asm+ob+DM2 tienen menor concentración de proteína cc16 sérica $(\mathrm{p}=0.312)$. Discusión: El grupo asma+ob+DM2 muestra mayor reactividad bronquial provocado 
por un proceso inflamatorio agravado por las tres enfermedades. Estudios clínicos han mostrado disminución de la CC16 en asma probablemente causado por un daño de las células Club. Conclusión: La MA-V tiene mayor daño en asma+ob+DM2. Limitación: la muestra es insuficiente para obtener resultados concluyentes.

\section{Tumor de Askin en paciente adulto. Reporte de caso clínico y revisión de la literatura}

García HS, Enríquez DLL, Pacheco PMF, Wong JM, Muñoz MG, Pérez RE

Hospital Universitario
«Dr. José Eleuterio González».
Universidad Autónoma de Nuevo León

Introducción: Los tumores de Askin son parte de los sarcomas de Ewing. Es más común en niños y adultos jóvenes, representa el $10-15 \%$ de todos los tumores óseos primarios, seguido del osteosarcoma. El dolor locorregional es el síntoma más común de presentación en pacientes con sarcoma de Ewing. Se debe pensar en su diagnóstico al encontrar lesiones sugestivas en la radiografía simple, tomografía computada o resonancia magnética. Presentación del caso: Masculino de 40 años de edad que acude al Servicio de Cirugía General del Hospital Universitario «Dr. José Eleuterio González», con evolución clínica de 3 años, presentando un inicio insidioso, caracterizado por dolor mal localizado en cara anterior de tórax, a lo cual se agrega de manera tardía disnea e incremento en la intensidad del dolor; así como aumento importante de volumen de manera progresiva en región esternal durante los tres meses previos a su valoración en nuestro servicio. Se realizan estudios de imagen en donde se demuestra tumoración que infiltra esternón, por lo que se procede a resección quirúrgica del mismo así como reconstrucción de esternón. El reporte histopatológico con diagnóstico de tumor de Askin, grado histológico alto, márgenes libres y sin invasión angiolinfática. Conclusión: Los tumores de Askin son entidades poco frecuentes y aún más en pacientes adultos, la mayoría de ellos se presentan en niños y jóvenes; por lo que consideramos relevante el reporte de nuestro caso, ya que la edad de presentación es inusual y aporta datos clínicos importantes a considerar así como información sobre su manejo y pronóstico. Aporte a la práctica clínica diaria: El reportar el caso clínico de un paciente con tumor de Askin en región toracopulmonar dado su baja incidencia y su presentación extraordinaria en el adulto nos brinda la oportunidad de identificar, diagnosticar y manejar a pacientes con esta patología desde estadíos clínicos más tempranos brindando mayor beneficio al paciente.

\section{Proceso de atención para personas con tuberculosis y VIH en México}

\section{Dávila LGY, García AMA, Castellanos JM}

Programa Nacional de Tuberculosis

Introducción: La tuberculosis (TB) asociada al VIH en México ha oscilado entre el 5 y $6 \%$ en los últimos tres años. Desde hace una década en el país, el Programa Nacional de Tuberculosis ha fortalecido los lazos de vinculación con el Programa Nacional de VIH con el fin de ofrecer estrategias de atención integrada. Objetivos: Mostrar los avances en la vinculación y coordinación de la atención de las personas con tuberculosis y VIH. Material y métodos: Descripción y contexto: La coordinación entre ambos programas ha generado un proceso de comunicación e intercambio de información gradual con el fin de ofrecer atención integrada. Impacto: En el año 2012 inició la medición del indicador nacional de detección de VIH en casos nuevos con TB, la última medición fue de $83.9 \%$ y correspondió al segundo trimestre del 2016. La concordancia de casos con TB y VIH en las plataformas de información de ambos programas se ha visto fortalecida y cada trimestre existe un proceso de revisión manual para asegurar el registro de las personas afectadas. Por otro lado, la ministración de isoniazida como tratamiento para TB latente en personas con VIH tiene alcances del $30 \%$ en el país. La proporción de personas con la comorbi- lidad que alcanzaron éxito de tratamiento de TB fue de hasta del 65\%, desafortunadamente, los porcentajes de abandono y defunciones fueron elevados (10.6 y $22.2 \%$, respectivamente) en la cohorte 2015 . Conclusión: La coordinación favorece la atención integrada de los casos con TB y $\mathrm{VIH}$, desde la detección, tratamiento de ambas enfermedades y la curación de la TB. Aún hace falta fortalecer estrategias orientadas a la ministración de isoniazida para tratamiento de la TB latente. Sin embargo, existen procesos de planeación, organización, dirección y control conjunto e indicadores de resultado como la detección de VIH que han mejorado.

\section{Efectos de la cirugía bariátrica sobre la función pulmonar}

Rosas MA, Carrión RAL, Foulkespieck $S$

Anáhuac

Introducción: Dentro de las patologías respiratorias más asociadas a la obesidad están aquéllas con patrones obstructivos como el síndrome de apnea obstructiva del sueño o patologías asociadas a hiperreactividad bronquial. En este artículo se expondrán los resultados obtenidos en cuanto a la mejora de la función pulmonar tras realizarse la cirugía bariátrica en un grupo de pacientes de un hospital privado de la ciudad de Querétaro. Objetivos: Determinar la relación que tiene la cirugía bariátrica en la función pulmonar de pacientes obesos que acudieron al Servicio de Neumología de un hospital privado del estado de Querétaro, de enero 2015 a julio 2016. Material y métodos: 10 pacientes que fueron sometidos a cirugía bariátrica y de los cuales se tenía registrada una espirometría previa y posterior a la cirugía, quienes aceptaron participar en el protocolo. Resultados: El $100 \%$ de los pacientes tuvo un cambio positivo sobre FVC. El paciente que más pérdida de peso tuvo $(66.3 \mathrm{~kg})$ tuvo una mejora del FVC de .23. Por otro lado, el paciente que tuvo mayor cambio en FVC (3.28-4.33) únicamente perdió $38 \mathrm{~kg}$. El $100 \%$ de los pacientes tuvo una mejora en 
$\mathrm{FEV}_{1}$. El cambio más importante se observó en un paciente que antes de la cirugía tenía un $\mathrm{FEV}_{1}$ de 3 y posterior a la cirugía de 4.28, el cual tuvo una pérdida de peso de $33 \mathrm{~kg}$. El paciente que menos cambio tuvo sobre el $\mathrm{FEV}_{1}$, únicamente perdió 16 kg. Conclusión: El impacto que tiene la cirugía bariátrica sobre la calidad de vida de los pacientes es sumamente significativo. Todos los pacientes sometidos a la cirugía tuvieron cambios significativos sobre su peso, IMC y sobre su función pulmonar.

\section{Diabetes y tuberculosis en México, estrategia nacional de atención}

\section{Dávila LY, García AMA, Castellanos JM}

Programa Nacional de Tuberculosis

Introducción: La diabetes (DM) en México representa un problema de salud pública, la prevalencia registrada en la Encuesta Nacional de Salud y Nutrición 2012 fue de $9.25 \%$ en población general. Con relación a tuberculosis todas las formas (TB), las tasas de incidencia de los últimos 5 años se han mantenido estables. El registro en 2015 fue de 17 casos por 100 mil habitantes y la asociación TB y DM fue de $23.3 \%$. Objetivos: Mostrar los avances del fortalecimiento del proceso de atención de personas con tuberculosis y diabetes. Material y métodos: Descripción y contexto: existe evidencia relacionada con la carga de la enfermedad de TB atribuible a DM, la cual se ha reportado de hasta $10 \%$. Además, el riesgo de presentar TB en personas con DM es tres veces mayor comparada con personas sin DM. Debido a esta relación estadística y causal, en México se ha trabajado en impulsar procesos de vinculación, coordinación e integración, según lo establece el Institute for Healthcare Improvement y la propuesta de Triple Meta. Impacto: Los programas de atención de TB y DM a nivel nacional y local han fortalecido lazos de comunicación que se han visto reflejados en el proceso de atención. El porcentaje de detección de DM en personas con TB mayores de 20 años en 2015 fue de $90.6 \%$. Con relación a la cohorte 2015 de casos TB con DM, la curación alcanzó el $80.3 \%$ y el éxito de tratamiento el $89.0 \%$. Finalmente, se ha avanzado en la normatividad nacional para contar con documentos que desde ambos programas cuenten con información homogénea en relación con el tratamiento de los casos. Conclusión: Los procesos de atención de personas con la comorbilidad TB y DM han mejorado a partir del fortalecimiento de los procesos de vinculación y coordinación entre ambos programas de atención en todos los niveles.

\section{Relación del índice neutrófilo/ linfocito con el índice de gravedad neumónico en casos con neumonía adquirida en la comunidad}

\section{Che MJL, Cortés TA, Bañuelos FP}

Hospital Regional de Alta Especialidad de la Península de Yucatán; IMSS

Introducción: El índice neutrófilo-linfocito (INL) se ha propuesto como marcador pronóstico en diversas circunstancias clínicas, incluyendo neumonía adquirida en la comunidad. Los datos disponibles enfatizan que valores altos del INL se relacionan con la gravedad del proceso neumónico evaluado mediante la escala CURB-65, bacteriemia y curso clínico desfavorable. Derivado de nuestro conocimiento existen pocos estudios que exploren la asociación entre INL y el índice de gravedad de neumonía. Objetivos: Conocer la relación entre la gravedad de la neumonía por PSI y la puntuación obtenida del índice neutrófilo/linfocito. Material y métodos: Estudio observacional, retrospectivo basado en los expedientes de pacientes adultos con diagnóstico clínico-radiológico de NAC atendidos de manera consecutiva en el área de Urgencias de un hospital de $2^{\circ}$ nivel. Para fines del estudio, se generaron 3 grupos (PSI I-II, PSI III, PSI IV-V). Se registró el valor del INL con base en la citometría hemática de ingreso y se comparó entre los diferentes grupos. Finalmente se exploró la probabilidad de predicción del INL sobre el PSI. Resultados: Se incluyeron 116 ex- pedientes. El 54\% fueron hombres; entre las comorbilidades más comunes: $47 \%$ tenían enfermedad respiratoria crónica, $36 \%$ DM2 y 36\% hipertensión arterial sistémica. De manera interesante, $30 \%$ de los casos obtuvieron un PSI I y fueron hospitalizados. La mediana global del INL fue 6 (IIC 3.6-10.4). No obstante, el valor mostró un incremento lineal acorde con la gravedad de cada grupo, 5 (IIC 3-8), 6.1 (IIC 3.6-12) y 7.5 (IIC 4.5-12.1), respectivamente. Mediante un análisis de regresión logística, usando como variable dependiente cada grupo de PSI, se identificó que existe una probabilidad del 13\% de incrementar la gravedad del PSI por cada unidad que aumente el INL (OR: 1.13; IC 95\%: 1.02-1.25, $\mathrm{p}=0.017)$. Conclusión: En el presente estudio el valor del INL mostró un incremento gradual asociado con la gravedad del proceso neumónico medido con PSI.

\section{Comparación de dos escalas de riesgo de síndrome de apnea obstructiva del sueño en pacientes evaluados con monitor tipo III}

Che MJL, Sánchez CJF

Hospital Regional de Alta Especialidad de la Península de Yucatán; IMSS

Introducción: El síndrome de apnea obstructiva del sueño (SAOS) tiene una prevalencia de 2-4\%. El diagnóstico puede ser realizado con monitores tipo III cuando la probabilidad preprueba es alta. Existen varias escalas de predicción de riesgo validadas para SAOS, entre ellos el SACS (Sleep Apnea Clinical Score por sus siglas en inglés) y recientemente, NOSAS (Neck circumference, Obesity, Snoring, Age, Sex, por sus siglas en inglés). Se desconoce si NOSAS tiene similar sensibilidad y especificidad en la predicción de SAOS en un grupo de pacientes del sureste mexicano. Objetivos: Comparar la sensibilidad y especificidad de SACS y NOSAS en pacientes con diagnóstico de SAOS y el grado de correlación entre ellas. Material y 
métodos: Estudio observacional, longitudinal de pacientes adultos con diagnóstico de SAOS por poligrafía respiratoria. Para fines del estudio, se registraron los valores de IAH (índice de apnea-hipopnea), SACS y NOSAS obteniéndose sensibilidad, especificidad, valor predictivo positivo y negativo. Se construyó una curva ROC y calculó $r^{2}$ de Pearson. Resultados: Se analizó un total de 372 pacientes con sospecha de SAHOS, 200 varones y 172 mujeres. El $77 \%$ eran de la península de Yucatán. El 83\% (312 pacientes) tuvieron un índice de apnea/hipopnea (IAH) $>15$. El $87 \%$ de los casos tuvo NOSAS $>8$ puntos y el $84.4 \%$ un SACS > 43 puntos. La sensibilidad, especificidad, VPP y VPN para SAOS con IAH > 15 puntos con SACS fue: $87,31,87$ y $31 \%$, respectivamente y con NOSAS: 90.7, 32.2, 88 y 40\%, respectivamente. El área bajo la curva de SACS y NOSAS fue de $0.66(0.60-0.73)$ y 0.68 (0.61-0.76), respectivamente. La correlación entre SACS y NOSAS fue moderada $(r=0.63$; $\mathrm{p}<0.001$ ) y baja entre IAH y SACS e IAH y NOSAS. Conclusión: NOSAS y SACS tienen un grado de acuerdo moderado y rendimiento diagnóstico similar en una muestra de sujetos del sureste mexicano con SAOS moderado-grave.

\section{Ultrasonido pulmonar como herramienta diagnóstica en la consulta neumológica}

\section{Marín CBA, Guadarrama PC}

INER Ismael Cosío Villegas

Introducción: El ultrasonido pulmonar (UP) permite obtener información en tiempo real de la patología pleuropulmonar y diafragmática. Presentación de los casos: 1) Masculino 58 años, antecedentes de IAM, reemplazo valvular cardíaco y anticoagulación. Enviado por tos con hemoptoicos, ortopnea y disnea. Radiografía de tórax (RxT): opacidades nodulares bilaterales difusas. UP patrón B en todos los campos pulmonares. Se solicita TAC ante la sospecha de hemorragia alveolar y envío a Cardiología para manejo de falla cardíaca. 2) Masculino de 33 años, antecedente de neumotórax espontáneo secundario en tres ocasiones, último hace 3 meses, recibió manejo con sonda endopleural más pleurodesis. RxT vidrio despulido generalizado derecho y borramiento del ángulo costofrénico. UP engrosamiento pleural generalizado e inmovilidad diafragmática derecha. Se envía a cirugía de tórax para valorar decorticación y rehabilitación pulmonar. 3) Femenino de 78 años, antecedente de cáncer cervicouterino, enviada por derrame pleural izquierdo, RxT: patrón nodular hemitórax derecho y radiopacidad homogénea del 90\% izquierda. UP múltiples nódulos en pleura parietal y diafragmática izquierda, se marca sitio seguro de punción y se envía a Urgencias para toracentesis diagnóstica y biopsia pleural cerrada. 4) Masculino de 57 años, enviado por tos crónica. RxT con derrame pleural bilateral más radiopacidad homogénea en cisura medial del pulmón derecho. UP: derrame pleural bilateral, más hiperecogenicidad en cisura medial derecha, se descarta síndrome del lóbulo medio e ingresa para estudio de probable tumoración pulmonar. Conclusión: El UP es una herramienta accesible y fácil de utilizar por los neumólogos en el consultorio que permite la toma de decisiones más oportunas y objetivas, así como abordajes diagnósticos más precisos y seguros. Aporte a la práctica clínica diaria: UP es una herramienta para el neumólogo en consultorio.

\section{Programa de cirugía de tórax ambulatoria en un centro institucional de México. Experiencia de 2 años}

\section{Menjivar ROM, Martínez AM, Téllez BJL, Loyola GU, Díaz MJL}

Centro Médico ISSEMYM Toluca

Introducción: La cirugía ambulatoria se define como los procedimientos quirúrgicos, terapéuticos o diagnósticos que se realizan con anestesia general, regional o local, con o sin sedación, y que requieren cuidados posoperatorios de corta duración. La primera indicación publicada de cirugía mayor ambulatoria aplicada a cirugía torácica fue la mediastinoscopia como método de estadificación del carcinoma broncogénico $\mathrm{y}$, en la actualidad, es la que con mayor frecuencia se utiliza. Sin embargo, la cirugía torácica ambulatoria ha sido hasta hace pocos años prácticamente inexistente en nuestro país. Objetivos: Presentar la experiencia obtenida en la realización de cirugía torácica ambulatoria, donde se demuestre la factibilidad para la realización de forma segura de procedimientos torácicos con carácter ambulatorio. Material y métodos: Reporte de un estudio transversal descriptivo. Durante el período 2015-2016 se realizaron 35 procedimientos ambulatorios, incluyendo biopsia pulmonar, biopsia pleural, mediastinoscopia y simpatectomía. Fueron captados por consulta externa y enviados a valoración preoperatoria, se ingresaron directamente para la realización de procedimiento quirúrgico, se mantuvieron en vigilancia en unidad de recuperación, previo a su alta. Resultados: Los pacientes presentaban un rango de edad de 25-65 años, con una edad media de 45 años. Veinte mujeres y 15 hombres. La duración media de los procedimientos fue de 40 minutos (rango de 20-60 minutos). Treinta y cuatro casos fueron egresados de manera ambulatoria, una paciente presentó en radiografía de tórax de control datos de derrame pleural por lo que se decidió permanencia en hospitalización y fue egresada al día siguiente. Trece pacientes refirieron náusea y dificultad respiratoria secundario a dolor en período posquirúrgico inmediato que remitió con tratamiento médico previo a su egreso. Conclusión: La cirugía ambulatoria es aplicable para los procedimientos descritos de forma segura, el programa de cirugía de tórax ambulatorio es aplicable para cualquier centro hospitalario que cuente con el personal capacitado.

\section{Comparación de la respuesta $\mathrm{FEV}_{1}$ en micronebulizador tipo jet con boquilla vs. micronebulizador de activación inspiratoria Aeroeclipse $^{\circledR}$}

Huertero VI, Toral FSC, García TR, Olmos ZJR, Reyes PA, Castañón 


\section{RRP, Mendoza RVM}

INER-EFT-TR

Introducción: Las metas en el tratamiento del asma incluyen reducir las visitas al Servicio de Urgencias y lograr un buen control a largo plazo con la reducción de síntomas. Los medicamentos inhalados son los preferidos para el tratamiento debido a su actividad directa sobre la vía aérea. Los nuevos dispositivos para administrar aerosoles deben promover el mejor aprovechamiento del medicamento y ser cada vez más sencillos en su uso, es necesario demostrar que mantienen ventajas sobre las técnicas comunes. Objetivos: Comparar el parámetro $\mathrm{FEV}_{1}$ en espirometría posbroncodilatador en tres grupos de pacientes usando el dispositivo Aeroeclipse ${ }^{\circledR}$ con boquilla (grupo I, $\mathrm{n}=12$ ), dispositivo jet con boquilla (grupo II, $\mathrm{n}=14$ ) y dispositivo jet con mascarilla (grupo III, $\mathrm{n}=13$ ). Material y métodos: Estudio descriptivo, observacional, prospectivo y longitudinal. Maniobra espirométrica estandarizada (ATS/ERS). Se instruyó al paciente en el uso del equipo de micronebulización. Registro de datos espirométricos basales y postratamiento $\mathrm{FEV}_{1}$, FVC, $\mathrm{FEV}_{1} / \mathrm{FVC}$, PEF, FEF 25-75\%, talla, peso, IMC, frecuencia cardíaca, frecuencia respiratoria y $\mathrm{SpO}_{2}$. Análisis estadístico con SPSS19 para Windows, prueba ANDEVA, $t$ de Student y Tukey para análisis paramétrico. Valor de p significativa menor o igual 0.005. Resultados: Mejoría considerable con Aeroeclipse ${ }^{\circledR}$ para diferencia de $\mathrm{FEV}_{1}$ en $\mathrm{mL}$ pre- y postratamiento comparada con grupos II y III pero sin significancia estadística. El uso de boquilla es superior para Aeroeclipse ${ }^{\circledR}(410 \mathrm{~mL})$ de $\mathrm{FEV}_{1}$, para jet con boquilla $340 \mathrm{~mL}$ y jet con mascarilla $270 \mathrm{~mL}$, para los tres sistemas después de administrar $5 \mathrm{mg}$ de salbutamol. Se requiere ampliar la muestra de estudio a pesar de observar mejoría clínica. Conclusión: El éxito del tratamiento para crisis asmática depende entre otros factores, de la correcta aplicación y operación de los dispositivos para administración de medicamentos inhalados. Usar dispositivos que demuestren mayor eficacia es vital para mejorar la respuesta a tratamiento.
Eficacia del micronebulizador tipo jet con boquilla vs. mascarilla facial en depósito pulmonar con salbutamol por el cambio en el FEV ${ }_{1}$ y FVC prepos- broncodilatador en pacientes con crisis asmática

Sánchez GS, Toral FSC, Reyes PA, García TR, Nava AJF, Castañón RRP, Mendoza RVM

INER-EFT-TR

Introducción: El asma bronquial es un padecimiento inflamatorio caracterizado por la limitación al flujo aéreo y la causa más común, tanto de ingreso a urgencias respiratorias como de hospitalización hasta en el 30\% de los casos. El objetivo es revertir la obstrucción al flujo aéreo y la hipoxemia de la forma más rápida y eficaz posible. El uso de salbutamol vía inhalada es el fármaco de primera elección para este tratamiento. Objetivos: Comparar la eficacia del uso de nebulizador tipo jet con boquilla $v s$. mascarilla simple comparando el cambio mediante maniobra espirométrica estandarizada (ATS) de $\mathrm{FEV}_{1}$ y FVC pre- y posbroncodilatador. Material y métodos: Estudio clínico, prospectivo, observacional, comparativo. En un total de 20 pacientes con crisis asmática en dos grupos (grupo I Mascarilla y grupo II Boquilla) divididos al azar. Se ministró un ciclo de tres dosis de $5 \mathrm{mg}$ de salbutamol cada 20 minutos, se instruyó al paciente para maniobra espirométrica y en el uso del kit de inhalación. Monitoreo constante de $\mathrm{SatO}_{2}$, frecuencia cardíaca y frecuencia respiratoria. Evaluación de la calidad espirométrica y diagnóstico por el médico neumólogo. Análisis estadístico SPSS 18.0 Windows con prueba t de Student para muestras independientes. Resultados: Para FEV 1 mejora la media posbroncodilatador en el grupo II respecto a la del grupo I $(0.38 \%)$. Para FVC hay una diferencia de mejora de $6.23 \%$ posbroncodilatador en grupo II respecto a grupo I. Frecuencia cardíaca sin cambios. Conclusión: El uso de boquilla para dispositivo jet muestra una ligera mejora en los valores de $\mathrm{FEV}_{1}$ y FVC a la espirometría posbroncodilatador. Es necesario aumentar el tamaño de la muestra para significancia estadística. Se deben evaluar las ventajas clínicas en el uso de este dispositivo.

\section{Pericardioscopia con abordaje subxifoideo como herramienta diagnóstico de derrame pericárdico. Reporte de caso}

\section{Menjivar ROM, Martínez AM, Loyola GU, Díaz MJL}

\section{Centro Médico ISSEMYM}

Introducción: El pericardio puede afectarse virtualmente por cualquier tipo de enfermedad. Algunas de estas condiciones exigen terapias específicas y, consecuentemente, un diagnóstico etiológico preciso es de gran importancia. La investigación clínica y los métodos actuales de evaluación por imagen vienen haciendo del diagnóstico de derrame pericárdico y taponamiento cardíaco una práctica rutinaria. La biopsia pericárdica tiene un papel importante en la evaluación de derrames pericárdicos de origen indeterminado. Presentación del caso: Masculino de 45 años de edad, enfermedad renal crónica de 15 años de evolución tratamiento sustitutivo con hemodiálisis, carcinoma pulmonar de células pequeñas diagnosticado 1 año. Historia de disnea, acompañado de dolor abdominal localizado en epigastrio, tipo pulsátil, intensidad $7 / 10$, intermitente, ruidos cardíacos aumentados en frecuencia, disminuidos en intensidad, tensión arterial de 90/50 mmHg. Ecocardiograma con líquido pericárdico de 1,200 cc; $\mathrm{FEV}_{1}$ del 56\%. La pericardioscopia videoasistida se llevó a cabo y mostró invasión neoplásica macroscópica en la porción superior del pericardio. Se realizó retiro de drenaje pericárdico 4 días posteriores a evento quirúrgico, con adecuado control radiológico. El paciente egresó a su domicilio 5 días posterior a evento quirúrgico y continuó vigilancia de 
carcinoma pulmonar en centro oncológico estatal. Reporte de patología con cambios inflamatorios y tejido con cambios displásicos de alto grado en pericardio. Conclusión: El manejo videoasistido de la ventana pericárdica ofrece los beneficios de cirugía de mínima invasión como menor incidencia de complicación con herida quirúrgica, mejor resultado cosmético, reducción de dolor posoperatorio. Aporte a la práctica clínica diaria: La técnica ideal de biopsia operativa debe confirmar la etiología del derrame, así como ser terapéutica y mínimamente invasiva. La pericardioscopia videoasistida es un procedimiento seguro, permite la inspección completa de la superficie pericárdica, el involucro de cavidades cardíacas, arterias y venas centrales y la selección de la región de la biopsia, de esta forma aumentando la precisión diagnóstica.

\section{Resección de tumor de pared torácica con abordaje toracoscópico uniportal. Reporte de un caso}

Menjivar ROM, Martínez AM, Hernández-Arenas LÁ, Díaz MJL

Centro Médico ISSEMYM; Centro Médico ISSEMYM Toluca

Introducción: La cirugía videotoracoscópica o VATS (video-assisted thoracic surgery) consiste en intervenir sin necesidad de grandes incisiones y sin separar las costillas, eliminando dolor posoperatorio. El uso de un instrumental especialmente diseñado permite disecar y separar estructuras y realizar todos los pasos de la intervención a través de una o varias pequeñas incisiones de 1-2 cm de diámetro. Presentación del caso: Se presenta el caso de femenino de 74 años de edad, quien presentó un osteoma, con una historia de 2 años de evolución con tumoración de aproximadamente $5 \times$ $5 \mathrm{~cm}$ en línea axilar anterior de hemitórax izquierdo, niega dolor, cambios en sensibilidad y fuerza de miembro torácico, acude con facultativo quien posterior a valoración la refiere con Servicio de Tórax para continuar protocolo diagnóstico y terapéutico. Resuelto de manera quirúrgica por abordaje

toracoscópico uniportal. Conclusión: La cirugía toracoscópica uniportal es aplicable para los procedimientos descritos de forma segura, y su realización es aplicable para cualquier centro hospitalario que cuente con el personal capacitado. Aporte a la práctica clínica diaria: La protocolización adecuada, diagnóstico temprano y abordaje apropiado son la clave para el manejo toracoscópico uniportal, aprovechando los beneficios como menor incidencia de complicación con herida quirúrgica, mejor resultado cosmético, reducción de dolor posoperatorio, movilización y reinserción laboral precoz, mejor respuesta inmunológica a estrés quirúrgico, menor estancia hospitalaria y una ingesta oral precoz.

\section{Presión Plateau como predictor de mortalidad en pacientes con ventilación mecánica invasiva}

\section{Sánchez SFA, Toral FSC, García TR, Olmos ZJR, Reyes PA, R Castañón $R R P$, Mendoza RVM}

\section{INER-EFT-TR}

Introducción: El valor incrementado de la presión meseta o Plateau traduce un alza en la elastancia y disminución de la distensibilidad pulmonar. La estrategia de protección pulmonar con presión Plateau máxima de $30 \mathrm{cmH}_{2} \mathrm{O}$ se asocia a mejor supervivencia a 28 días y mayor tasa de destete para síndrome de Distress respiratorio agudo (SDRA) y algunos casos de neumonía. Objetivos: Evaluar si la presión Plateau es un indicador de mortalidad en pacientes con ventilación mecánica del INER ( $n=52$ ), en tres grupos (inicio, 24 y 48 h). Material y métodos: Estudio clínico, prospectivo, observacional, longitudinal. Se realizó registro de la base de datos desde el inicio de la ventilación hasta el destete comparando con modo ventilatorio, diagnóstico y otros parámetros mecánicos de la vía aérea. Se relacionaron los datos obtenidos con defunciones y sobrevivientes. Análisis estadístico por prueba de ANOVA. Resultados: Valores de presión Plateau de $31 \mathrm{cmH}_{2} \mathrm{O}$ y por arriba se asociaron a defunciones, obtenidas por el percentil 50. De la población total 25 pacientes fallecieron, asociando presiones entre 27 a $32 \mathrm{cmH}_{2} \mathrm{O}$. Los sobrevivientes se asocian a presiones por debajo de $25 \mathrm{cmH}_{2} \mathrm{O}$. Promedio de días en ventilación 11.3 para defunciones y 8.62 en sobrevivientes. Conclusión: Es necesario ampliar la muestra para obtener mayor significancia estadística. Los valores de presión Plateau de $25 \mathrm{cmH}_{2} \mathrm{O}$ y menores se asocian a sobrevida. Se requiere dar seguimiento a los pacientes con sobrevida en caso de defunciones posteriores al destete. El modo ventilatorio no parece tener significancia sobre la defunción o sobrevida, la estrategia protectora pulmonar es vital para tales efectos.

\section{Derivación \\ pleuroperitoneal como tratamiento definitivo para el derrame pleural recurrente}

Martínez AM, Menjivar ROM, Loyola
GU, Téllez BJL, Lara GVR, Escobedo
SE, Díaz MJL

Centro Médico ISSEMYM Toluca

Introducción: En los últimos años se ha popularizado el uso de esos catéteres para el control de los derrames pleurales malignos, incluso como alternativa a la pleurodesis química. Su colocación está especialmente indicada en pacientes con pulmón atrapado, o en aquéllos con corta expectativa de vida en los que ha fallado un intento previo de pleurodesis. Sus principales problemas radican en el costo del sistema, riesgo de infección, invasión neoplásica de la zona de inserción y pérdida crónica de proteínas por las evacuaciones repetidas del LP. Objetivos: En este trabajo se expone la derivación pleuroperitoneal mediante catéter unidireccional como método para el manejo del derrame pleural refractario en Centro Médico ISSEMYM Toluca de marzo del 2015 a febrero del 2017. Material y métodos: Se realizó un estudio transversal descriptivo con una muestra de pacientes que se sometieron a derivación pleuroperitoneal mediante el uso de catéter unidireccional de baja presión para el manejo de derrame pleural asociado a enfermedad renal 
en etapa terminal en manejo con diálisis peritoneal como tratamiento sustitutivo, en pacientes con enfermedad renal crónica en fase terminal en el Centro Médico ISSEMYM Toluca, en quienes el manejo médico y la toracocentesis evacuadora habían fracasado. Resultados: Se realizó el procedimiento a 12 pacientes desde marzo del 2015 a febrero del 2017. Disminuyendo la estancia hospitalaria (11 días en promedio) en un 60-80\% las complicaciones del tratamiento y aumentando la satisfacción del paciente. Se incluyeron pacientes del Centro Médico ISSEMYM Toluca, tratados entre marzo de 2015 y febrero de 2017. Conclusión: El manejo del derrame pleural recidivante en pacientes con enfermedad renal crónica en diálisis peritoneal en el Centro Médico ISSEMYM Toluca, ha resultado efectivo, disminuyendo la estancia hospitalaria y las complicaciones relacionadas con la persistencia del derrame.

\section{HLA-DRB1*04 en pacientes con y sin afección intersticial en artritis reumatoide}

\author{
Mobayed F, Rojas SJ, Buendía- \\ Roldán I, Falfán VR, Mejía ÁM, \\ Rodríguez HP, Ambrocio E \\ INER Ismael Cosío Villegas; \\ «Manuel Gea González»
}

Introducción: La artritis reumatoide es la enfermedad articular más frecuente en México, cerca del $50 \%$ tienen manifestaciones extra-articulares, de las más comunes las pulmonares son de interés por su gravedad y peor pronóstico. Entre los factores de riesgo para presentar daño intersticial están los factores genéticos como alteraciones en el HLA clase II, principalmente HLADRB1*04. Por lo que el presente estudio pretendió identificar si existen diferencias en la frecuencia de HLA-DRB1*04 entre los subgrupos de pacientes con AR. Objetivos: Identificar factores de riesgo y presencia de alelos HLA-DRB1*04 en pacientes con involucro pulmonar asociado a AR. Material y métodos: Se realizó un estudio prospectivo con muestra a con-

veniencia consecutiva en pacientes con AR con y sin afección intersticial en el Hospital General Gea González e INER durante el período de enero a diciembre de 2015, se obtuvo muestra sanguínea para determinar la presencia de HLA-DRB1*04 y se les realizó una evaluación clínica detallada, imagen tomográfica y pruebas de función respiratoria para determinar la presencia o ausencia de afección pulmonar. Resultados: Se incluyeron 113 pacientes con AR: 51 con afección intersticial y 62 sin afección intersticial. La frecuencia de HLA-DRB1*04 fue de $43 \%$ en el grupo con compromiso pulmonar vs. $58 \%$ en el grupo sin afección, $\mathrm{p}=0.13, \mathrm{RM}$ de 0.54 (IC95\% 0.24-1.23). Las variables que se encontraron asociadas a enfermedad intersticial y AR son: género masculino RM 8.14 (IC95\% 2.07-46.3) p < 0.0005, tabaquismo RM 4 (IC95\% 1.45-11.7) p < 0.004 y edad RM 1.04 (IC95\% 1.01-1.08) $\mathrm{p}=0.002$. Conclusión: En este estudio la frecuencia de HLA-DRB1*04 no mostró diferencias entre grupos, sin embargo, una limitante es el número de pacientes incluidos ya que no es posible determinar los subgrupos de HLA-DRB1*04; aunque se logró determinar que la afección intersticial en AR se asocia con características clínicas determinadas.

\section{Una nariz artificial disminuye la presión de salida en un dispositivo de presión positiva continua}

\section{Díaz SGA, Carrillo AJL, Baños FMR, Domínguez GHD, Anaya S, Torres FMG}

INER Ismael Cosío Villegas

Introducción: Los dispositivos de presión positiva continua generalmente se utilizan con humidificación para disminuir efectos adversos y su uso añade costo. En la práctica clínica no es infrecuente que utilicen narices artificiales como alternativa temporal. Éstas agregan resistencia y su efecto sobre la presión de salida es desconocido. Objetivos: Conocer los efectos de la nariz artificial (humidificación pasiva) sobre la presión de salida en un dispositivo CPAP. Material y métodos: A un dispositivo de presión positiva continua (REMstar Philips Respironics) previamente calibrado y sin error entre la presión programada y la presión de salida, se colocaron 7 narices artificiales de marcas diferentes y la presión de salida se midió, desde 4 hasta $20 \mathrm{cmH}_{2} \mathrm{O}$, con un manómetro manual después de 2 minutos de estabilizarse el flujo de aire; la fuga intencional se mantuvo constante en todo momento y la fuga no intencional fue de $0 \mathrm{~L} /$ min. Resultados: El acuerdo entre la presión programada y la presión medida después de colocar la nariz artificial fue variable: INTERSURGICAL coeficiente de correlación intraclase (CCI) 0.95, diferencia de medias (DM) $1.3 \pm 0.4 \mathrm{cmH}_{2} \mathrm{O}$; ALTECH CCI 0.95, DM $1.4 \pm 0.4 \mathrm{cmH}_{2} \mathrm{O}$; AIR CCI $0.98 \mathrm{DM} 0.8 \pm 0.005 \mathrm{cmH}_{2} \mathrm{O}$; DRAGER CCO 0.97, DM $1 \pm 0.3 \mathrm{cmH}_{2} \mathrm{O}$; HUMIDVENT 2S CCI 0.99, DM $0.5 \pm 0.2 \mathrm{cmH}_{2} \mathrm{O}$; HUMID-VENT FILTER PED CCI 0.87, DM $2.3 \pm 0.7 \mathrm{cmH}_{2} \mathrm{O}$; TWINSTAR DRAGER CCI 0.45, DM $5.5 \pm 2 \mathrm{cmH}_{2} \mathrm{O}$; además, se encontró una correlación directamente proporcional entre la presión programada y el delta de presión expresada en $\mathrm{cmH}_{2} \mathrm{O}$, pero inversamente proporcional cuando se expresa como \% de pérdida. Conclusión: La nariz artificial disminuye la presión de salida de un dispositivo de presión positiva continua en forma variable; los factores que afectan dicho cambio son la marca de la nariz y la presión programada.

\section{Función pulmonar en pacientes pediátricos con antecedente de quemadura de vía aérea}

\section{Rodríguez BEJ, del Razo RR,} Alemán ZJ

INER Ismael Cosío Villegas

Introducción: Las quemaduras son un problema de salud pública, en México se hospitalizan más de 10,000 pacientes quemados/año. Se han observado anormalidades en la función pulmonar de niños inmediatamente después de la quemadura y hasta 2.7 años posteriores en estudios previos se ha encontrado patología pulmonar residual como patrón mixto o 
patrón restrictivo, además de secuelas como aumento de la reactividad de la vía aérea persistente de 3 a 6 meses posterior a la inhalación. Objetivos: Se describió la función pulmonar de los pacientes con antecedente de quemadura de vía aérea, así como los hallazgos radiológicos. Material y métodos: Se realizó un estudio observacional, descriptivo, transversal, tomado de una cohorte de niños en seguimiento por la consulta externa del Hospital Materno Pediátrico de Xochimilco, Hospital Pediátrico de Tacubaya e Instituto Nacional de Rehabilitación. Resultados: Fueron 10 niños con quemaduras en cara y tórax, se realizó espirometría y radiografía de tórax. Presentaron alteraciones espirométricas el $50 \%$, patrón obstructivo (30\%), calificado por NIOSH. Las radiografías de tórax presentaron patrón reticular (20\%), vidrio deslustrado (10\%), sobre distensión pulmonar (10\%), reforzamiento hiliar bilateral $(10 \%)$ y sugestivo de bronquiectasias (10\%); el $50 \%$ de los pacientes con algún patrón radiográfico anormal presentaron también alteración espirométrica. Los síntomas persistentes predominantes fueron disnea (40\%) y sibilancias (20\%). Se encontró asociación entre patrones espirométricos y alteraciones radiográficas, como el patrón obstructivo valorado por EMPECE con patrón reticular $(\mathrm{p}=0.035)$, así como patrón sugerente de restricción por NIOSH con patrón en vidrio deslustrado $(\mathrm{p}=0.035)$. Conclusión: Los pacientes pediátricos con antecedente de quemadura pueden presentar alteraciones espirométricas hasta en un $50 \%$, más frecuente un patrón obstructivo leve, además de alteraciones radiográficas en un 50\%, como patrón reticular, aun en aquellos pacientes sin alteración espirométrica, ni sintomatología persistente. Existe una asociación entre patrón sugestivo de restricción por NIOSH y patrón radiológico en vidrio deslustrado. Aporte a la práctica clínica diaria: Se deberá dar seguimiento de pacientes con quemadura para detectar alteraciones en la función pulmonar, así como iniciar rutas de investigación para tratamiento óptimo.

\section{Programa de educación para el uso de medicamentos inhalados}

\section{a través de inhaladores de dosis medida e inhaladores de polvo seco en pacientes del INER}

\section{Díaz FJ, Toral FSC, Castañón RRP, Reyes PA, Mendoza RVM, García TRA, Palomar ME}

INER-EFT-TR

Introducción: Los medicamentos inhalados para tratar las enfermedades respiratorias son los ideales. La adecuada aplicación de medicamentos inhalados a través de IDM o IPS compromete el éxito del tratamiento. Cerca del $76 \%$ de los pacientes cometen errores que comprometen la eficacia del tratamiento. El personal de salud asociado debe brindar educación al paciente y orientación en el rubro, mediante el uso de estrategias específicas. Objetivos: Implementar un programa educativo demostrativo oral y con tríptico del adecuado uso de dispositivos IDM y/o IPS, evaluando el aprendizaje a corto plazo a través de hoja de cotejo en pacientes hospitalizados del INER. Material y métodos: Estudio clínico, observacional, descriptivo, prospectivo y longitudinal. Se evaluó el impacto en 60 pacientes en 3 grupos (obstructivos, intersticiales, tumor y cáncer) por un período de 3 meses, con prescripción de medicamento vía inhalada, antes y después de entrenarlos de manera verbal-demostrativa y con tríptico en el uso de los IDM e IPS. La evaluación fue con hoja de cotejo específica para cada dispositivo (Respimat, Evohaler, Evohaler con cámara, Modulite, Accuhaler, Aerolizer, Breezhaler, Ellipta, Genuair, Handihaler, Turbuhaler). Se cuantificó y registró periodicidad e incidencia de prescripción del dispositivo y diagnóstico. Estadística descriptiva con prueba t de Student a valor de p significativa ?0.05. Resultados: El grupo I presenta mejoría significativa para todos los dispositivos excepto Aerolizer. El grupo II significancia estadística en todos los casos exceptuando Accuhaler, Aerolizer y Modulite. En el grupo III únicamente se prescribieron inhaladores polvo seco y en ninguno de los casos hubo mejora significativa. Se establece una propuesta de programa educativo para pacientes agudos/crónicos dentro del Servicio de Terapia Respiratoria del INER. Conclusión: La enseñanza verbal-demostrativa y reforzar con tríptico del adecuado uso de IDM/IPS es de gran utilidad para el aprendizaje en los enfermos y puede impactar en el apego a tratamiento.

\section{Efecto del asma asociada a obesidad en la membrana alveolocapilar}

Sierra VMP, Vargas DC, García TR, Becerra RT, Pellerin FK, Hernández PJE, Naranjo MA, Cruz BI, Almeda VP, García SJR, Olivares Cl, Chávez AJ, Bobadilla LK, López SE, Miguel RJL, Aguilar SCA

INER Ismael Cosío Villegas; INCMNSZ; IPN, Escuela Superior de Medicina

Introducción: La obesidad y el asma son muy prevalentes y causan varias complicaciones. Hay aproximadamente 3 billones de obesos y más de 300 millones de asmáticos en el mundo. Los pacientes con ambas enfermedades tienen un mayor estado proinflamatorio y estrés oxidativo. Se desconoce si esta asociación produce daño epitelial pulmonar y su efecto sobre la función pulmonar. La proteína SCGB1A1, secretada por células Club, tiene efecto inmunosupresor e inmunomodulador; su disminución está asociada al daño de las células secretoras o del epitelio pulmonar. Objetivos: Evaluar el impacto de la asociación asma+obesidad en la integridad de la membrana alveolocapilar (MA-C) mediante la medición de SCGB1A1 sérica y DLCO. Material y métodos: Realizamos espirometría, DLCO y medición SCGB1A1. Análisis estadístico multivariado. Criterios de inclusión: Hombres/mujeres: 18 y 65 años, no fumadores. Grupos: (controles) sanos; (asma) asma leve a grave persistente (según GINA 2013), (asma+ob) asma leve a grave persistente y sobrepeso/ obesidad. Criterios de exclusión: Enfermedades crónico-degenerativas, infección respiratoria u hospitalización 6 semanas previas. Exposición a humos. Hipercolesterolemia, hipertriacilgliceridemia e hiperglucemia. Resultados: El grupo asma+ob $(\mathrm{n}=29)$ muestra niveles menores de CC16 sérica, aunque no estadísticamente sig- 
nificativo (0.079), también disminución más importante en: FVC (porcentaje del predicho) $(\mathrm{p}=0.0038), \mathrm{TLC}(\mathrm{p}=0.006) \mathrm{y}$ VA ( $\mathrm{p}=0.0036)$ e incremento de KCO no significativo. El grupo asma $(n=6)$ tiene $\mathrm{FEV}_{1}(\mathrm{p}=0.0038)$ y FEV25-75\% más disminuidos $(\mathrm{p}=0.0045)$. Conclusión: Discusión. En asma la SCGB1A1 sérica está disminuida; no hay estudios en obesidad. Según nuestros resultados la obesidad posiblemente cause disfunción de las células Club. Además, causa aumento del flujo sanguíneo intratorácico (más V/Q < 1) manifestándose con $\mathrm{KCO}$ elevado y VA disminuido, lo cual se confirma en nuestros resultados. Conclusión: La asociación asma+obesidad puede provocar daño epitelial debido a un estado proinflamatorio más grave. La medición de SCGB1A1 en expectoración dará más información sobre la integridad del epitelio respiratorio.

\section{Susceptibilidad genética a EPOC se modifica por} la contribución ancestral (amerindia-europea) en mestizos mexicanos

Pérez RG, Falfán-Valencia $R$, Ramírez-Venegas $A$, Sánchez-Romero C, Guzmán BN, Hernández-Zenteno $R$, Flores-Trujillo F, Velázquez-Montero A, Espinosa de los MC, Camarena OÁ

INER Ismael Cosío Villegas

Introducción: La variabilidad genética influye en la susceptibilidad y severidad a enfermedades complejas; en hispanos existe bajo riesgo de padecer EPOC en comparación a caucásicos (CEU) no hispanos. En México existen diferencias en el componente ancestral (amerindio/ europeo) que influencian el desarrollo de EPOC. Objetivos: Identificar marcadores genéticos asociados a EPOC en población con alto componente caucásico en comparación con población con alto componente amerindio. Material y métodos: Se incluyeron 299 pacientes con EPOC por tabaquismo y 531 fumadores sin EPOC (FS), mestizos mexicanos. Fue diseñado un microarreglo de polimorfismos de un solo nucleótido (SNPs) de los cuales: 1,285 se encuentran en genes candidatos y 251 fueron marcadores informativos de ancestría. El componente poblacional fue evaluado mediante análisis de componentes principales. La asociación se llevó a cabo con un modelo de regresión logística. El análisis de haplotipos se realizó mediante Haploview 4.2. Resultados: Se identificaron 118 individuos con alto componente caucásico ( $\geq 60 \%$ ), de los cuales, 51 son EPOC y 67 son FS. Setecientos doce individuos tuvieron alto componente amerindio ( $\geq 60 \%), 248$ EPOC y 464 FS. El análisis de SNPs en genes de interés, mostró 3 asociados $(\mathrm{p} \leq 0.01)$ a menor riesgo $(\mathrm{OR}<0.5)$ de padecer EPOC (rs2545771, rs4105144 y rs10426235) en los genes CYP2F1P, CYP2A6 y CYP2B6 en población con alto componente amerindio, sin embargo, existe riesgo incrementado $(\mathrm{p}=$ 0.007, OR = 2.47) cuando el componente ancestral es CEU en el haplotipo formado por los genes CHRNA5-CHRNA3. Conclusión: Existen diferencias en genes que codifican proteínas encargadas del metabolismo de la nicotina en población con alto componente amerindio que contribuyen a la baja prevalencia de la EPOC en México; sin embargo, en individuos con alto componente caucásico tienen mayor riesgo de padecer EPOC ya que existe un haplotipo que incluye genes que participan en el proceso de adicción a la nicotina.

\section{Capacidad inspiratoria en una población que reside a 2,240 metros sobre nivel del mar}

Cid JS, Thirion Rl, Pérez PR, Gochicoa LG, Torre-Bouscoulet L, León GP

INER Ismael Cosío Villegas; CMN 20 de Noviembre ISSSTE

Introducción: La capacidad inspiratoria (CI) permite identificar la presencia de hiperinflación dinámica y su disminución se asocia a disnea y mortalidad en enfermedades obstructivas. Desconocemos el comportamiento de la CI a lo largo de la vida en población de origen mexicano residente de alturas moderadas. Objetivos: Obtener valores de referencia de la capacidad inspiratoria mediante espirometría lenta en una población sana que reside a una altura moderada. Comparar los valores obtenidos con las diferentes ecuaciones que evalúan la CI. Material y métodos: Se incluyeron sujetos sanos de 9-81 años de edad, residentes en la zona metropolitana de la Ciudad de México a quienes se les realizó espirometría lenta de acuerdo con los estándares de ATS/ERS. Se realizaron modelos de regresión lineal y los resultados fueron comparados con los valores esperados por ecuaciones previamente publicadas. Resultados: Se estudiaron 441 sujetos (55.1\% mujeres), con una edad media de 32 años, (mínimo de 9 años y máximo de 81 años). La CI se asoció a género, edad, talla y peso. Se mostró un incremento acelerado de la CI de los 9 a los 20 años, y posteriormente una caída paulatina en ambos géneros. En términos generales la CI fue mayor en la población estudiada que en valores de referencia previas. Las ecuaciones realizadas en este estudio tienen un coeficiente de determinación de más del 40\%. Ecuaciones: Mujer: $-2.01+$ edad $(0.0423)+$ edad $2(-0.00055)+$ talla $(0.025)$. Hombre: $-4.43+$ edad $(0.039)+$ edad 2 $(-0.0004)+$ talla (0.044). Conclusión: La CI en nuestra población fue mayor que la reportada previamente para sujetos europeos y latinoamericanos a la misma talla, género y edad, comportamiento similar a la reportada para valores espirométricos. Por lo que no se recomienda utilizar ecuaciones recomendadas internacionalmente ya que no ajustan a nuestra población.

\section{Asociación del deterioro cognitivo, depresión y ansiedad en el adulto mayor con la calidad técnica de las pruebas de función respiratoria}

Cid JS, Guerrero ZS, León GP, Gochicoa RL, Fernández PR, Pérez $P R$, Torre-Bouscoulet L, Bautista BA, Salas El

INER Ismael Cosío Villegas; CMN 20 de Noviembre ISSSTE 
Introducción: Para realizar correctamente las pruebas de función respiratoria (PFR) se requiere de equipos que cumplan estándares y sean calibrados periódicamente, personal técnico con experiencia y del paciente que sea capaz de entender y cooperar con la maniobra. La presencia de deterioro cognitivo, ansiedad y depresión en adultos mayores dificultan las actividades dependientes del sujeto. Estudiar estos trastornos en población con enfermedades respiratorias ayudaría a predecir quiénes serán incapaces de realizar una adecuada prueba. Objetivos: Correlacionar la puntuación de los cuestionarios Mini Examen del Estado Mental (MMSE), la Escala de Depresión Geriátrica de Yesavage (GDSVE) y la Escala de Ansiedad y Depresión (HADS) con el grado de calidad técnica de la espirometría, pletismografía y DLCO en la población geriátrica que es atendida en el INER. Material y métodos: Se incluyeron pacientes mayores de 60 años referidos al INER para realizar alguna de las PFR: espirometría, pletismografía y DLCO evaluando su calidad técnica (guías ATS/ ERS). Se aplicaron cuestionarios sobre el estado cognitivo y emocional. Se evaluó la asociación con regresión logística. Resultados: Se estudiaron 309 pacientes, $37 \%$ hombres, con una mediana de edad: 70 años y de escolaridad: 6 años. La prevalencia fue: $32 \%$ para deterioro cognitivo, $57 \%$ y $45 \%$ para depresión (GDS-VE y HAD), $42 \%$ para ansiedad. La mala calidad técnica se presentó en el $37 \%$ de las espirometrías, $29 \%$ de las pletismografías y $9 \%$ en DLCO. Sin diferencias significativas en variables sociodemográficas. En espirometría, la ansiedad se asoció con un OR de 0.53 ( $\mathrm{p}<0.05)$. En pletismografía, el deterioro cognitivo y depresión tuvieron asociación (OR: 2.65 y 3.05), pero no estadísticamente significativa, y en DLCO ninguna puntuación del cuestionario fue asociada. Conclusión: El deterioro cognitivo, depresión y ansiedad no se asociaron con mala calidad técnica en las PFR. Ante personal técnico capacitado y entrenado estos trastornos no obstaculizan el abordaje funcional del paciente neumópata.

\section{Hipertensión pulmonar grupo 3. Experiencia y}

\section{manejo en el Hospital General de México}

\section{Cueto RG, Gómez LSA, Barragán PG, Cicero $S R$}

Hospital General de México

Introducción: Hipertensión pulmonar (HP) es la presión arterial pulmonar media (PAPm) igual o mayor a $25 \mathrm{mmHg}$ por cateterismo cardíaco derecho (CCD). Se clasifica en 5 grupos, siendo el tercero el que agrupa las patologías pulmonares que se acompañan de hipoxemia. La presencia de HP en las enfermedades respiratorias crónicas suele ser causa de muerte por insuficiencia cardíaca derecha, de ahí que se considere de mal pronóstico su presencia. Objetivos: Presentar la experiencia en el manejo de HP del grupo 3 en el Hospital General de México. Material y métodos: Estudio retrospectivo y descriptivo realizado en el período de enero 2012 a diciembre 2016. Se presentan 19 pacientes neumópatas crónicos a quienes se les realizó CCD. Se analizaron variables hemodinámicas como la PAPm, resistencias vasculares pulmonares (RVP), índice cardíaco (IC), presión de aurícula y presión de oclusión de la arteria pulmonar (POAP) en reposo. Todos los pacientes cuentan con exámenes de laboratorio básicos, perfil hormonal tiroideo y trombofílico, pruebas de funcionamiento respiratorio (PFR), ecocardiograma transtorácico y caminata de 6 minutos (PC6M). Resultados: La media de edad fue 53 años (DE 10.9). Las enfermedades más frecuentes fueron neumopatía intersticial no específica, fibrosis pulmonar idiopática y síndrome de apnea hipopnea obstructiva del sueño. La clase funcional predominante fue II/ III. La PAPm promedio fue $39.5 \mathrm{mmHg}$ (DE 12.2), RVP 5.3 Unidades Wood. El patrón espirométrico más frecuente fue restrictivo (CVF 47.2 DE 17.4) y en la C6M 261 m. Conclusión: La serie describe 19 pacientes con HP severa documentada por CCD en reposo que cursan con neumopatías crónicas habituales que reciben tratamiento crónico de base y oxígeno domiciliario. Servirá como punto de partida para conocer las características de neumópatas que se acompañan de HP y podrían ser candidatos a recibir tratamiento farmacológico con drogas específicas para mejorar sobrevida y calidad de vida.

\section{Antibioticoterapia en neumonía adquirida en la comunidad guiada con procalcitonina}

José Badillo AJl, Muñoz TJJ, Martínez FM, Garza VI, Díaz GVA

Hospital General Zacatecas y Universidad Autónoma de Zacatecas; UA. Medicina Humana; UA. Preparatoria 12

Introducción: La neumonía adquirida en la comunidad (NAC) es la infección respiratoria más potencialmente fatal. Procalcitonina (proCT) prohormona con características biológicas de «Hormoquina» secretada por varios tejidos, considerada un biomarcador para estimar probabilidad de infección bacteriana y su dinámica tiene implicaciones pronósticas. La iniciación y terminación de antibiótico-terapia guiada con proCT es un buen abordaje utilizado para un óptimo manejo de la NAC disminuyendo abuso de antimicrobianos para combatir emergencia de resistencia bacteriana a antibióticos. Objetivos: Evaluar dinámica de los niveles de proCT en pacientes con NAC para una adecuada duración de antibioticoterapia. Material y métodos: Se realizó estudio observacional, longitudinal, descriptivo y prospectivo en el Hospital General Zacatecas (HGZ), previo consentimiento informado por escrito incluyendo 40 pacientes con sospecha de NAC, cualquier clasificación CURB-65, se cuantificó proCT a su ingreso y a las 72 h, mediante ECLIA (Electro Chemi Luminescence Immunoassay) Elecsys BRAHMS PCTR. Se realizaron además protocolos diagnósticos para NAC. Excluyéndose pacientes con sospecha de influenza y enfermedades autoinflamatorias. Resultados: En 33 se diagnosticó NAC, 20 masculinos (60.6\%) 13 femeninos (39.4\%), edad promedio 61 años, mediana 2 puntos escala CURB-65, 7 casos (21.2\%) identificó germen causal sin predominancia alguna. En 10 pacientes (30.3\%) niveles de proCT se incrementaron reflejándose en promedio a 11 días de estancia hospita- 
laria y empeoramiento clínico; 5 (15.5\%) fallecieron. Los restantes 23 pacientes (69.6\%) presentaron niveles descendientes de proCT, cuyo valor promedio de ingreso $3.55 \mathrm{ng} / \mathrm{mL}$ disminuyó a $0.802 \mathrm{ng} / \mathrm{mL}$ a $72 \mathrm{~h}$ presentando mejoría clínica, estancia hospitalaria promedio 6 días, duración de antibioticoterapia 7-10 días. Conclusión: La observación de dinámica a la baja de valores de proCT permite inferir que podemos emplearla como biomarcador aunado a evolución clínica para disminuir días de estancia hospitalaria, acortar tratamiento antimicrobiano, menores costos de atención sin aumento en morbimortalidad por NAC.

\section{Prevalencia de eritrocitosis en pacientes adultos con apnea obstructiva del sueño en población mexicana}

\section{Colonia CJ, Romero LZ, Ochoa VMD, Gracia RAE, Mata MJA}

IMSS UMAE Hospital General «Dr. Gaudencio González Garza»; Hospital de Especialidades Antonio Fraga Mouret, CMN «La Raza»; Hospital de Infectología «Dr. Daniel Méndez Hernández» CMN «La Raza»

Introducción: El síndrome de apnea obstructiva de sueño (SAOS) es una enfermedad frecuente que afecta al $4-6 \%$ de los hombres, al 2-4\% de las mujeres. Predominantemente adultos y hombres. La eritrocitosis se define como el aumento significativo por encima de lo normal del número de eritrocitos, con un valor de HTC arriba de $47 \%$ en mujeres y $52 \%$ en hombres. Se ha encontrado asociación entre el grado de SAOS y el incremento del HTC, así como a disminución de este posterior al inicio del CPAP. Objetivos: Determinar la prevalencia de eritrocitosis en pacientes con síndrome de apnea obstructiva del sueño atendidos en el Hospital General «Dr. Gaudencio González Garza», CMN «La Raza» en el período comprendido entre 1 de abril al 1 de julio de 2016. Material y métodos: Se incluyeron pacientes con síndrome de apnea obstructiva de sueño que fueron diagnosticados en Clínica de Sueño del CMN «La Raza», se analizaron según el grado de SAOS y el grado de obesidad. La descripción general de los resultados se realizó mediante medidas de tendencia central y de dispersión. Resultados: De una muestra de 227 pacientes se encontró una prevalencia de eritrocitosis en pacientes con SAOS del $39.6 \%$ (IC 95\%, 0.33-0.46). Los hombres presentaron una mayor prevalencia de eritrocitosis. Los pacientes con SAOS grave presentaron una prevalencia del 29\% (IC 95\%, 0.23-0.35). Los pacientes con obesidad presentaron una prevalencia del $38.7 \%$ (IC 95\%, 0.32-0.45) y fue mayor en los pacientes con obesidad grado III. Se encontró una correlación fuerte con la presencia de eritrocitosis y los niveles de hemoglobina y eritrocitosis. Conclusión: La prevalencia de eritrocitosis en pacientes con síndrome de apnea obstructiva del sueño es mayor que la reportada previamente en la literatura. Siendo más prevalente en pacientes con diagnóstico de obesidad y en aquellos pacientes con SAOS grave.

\section{Efecto del CPAP sobre el riesgo cardiovascular en pacientes con apnea obstructiva del sueño y diabetes mellitus tipo 2}

\section{Canseco RAR, Toledo VMA, Fabian san MG, Anaya RS, Galicia PML, Torre-Bouscoulet L, Pérez PJR, Castorena MA}

INER Ismael Cosío Villegas

Introducción: La asociación entre apnea obstructiva del sueño y diabetes mellitus tipo 2 es conocida. Diferentes mecanismos de la apnea obstructiva del sueño se han visto involucrados en la generación de enfermedad cardiovascular, que sumados a los mecanismos de lesión presentes en la diabetes mellitus conducen a un incremento significativo de este riesgo. El efecto del CPAP sobre el riesgo cardiovascular permanece incierto. Objetivo: Evaluar el efecto del CPAP sobre el riesgo cardiovascular, medido por el algoritmo Framingham en una población con apnea obstructiva del sueño y diabetes mellitus tipo 2 , ajustada a un régimen de actividad física, nutrición y control médico óptimo. Material y méto- dos: Se incluyeron 45 pacientes del primer nivel de atención, de cualquier género, $>$ 20 años de edad, con antecedente de DM2, obesidad, sin comorbilidad cardíaca o pulmonar significativa y apnea obstructiva del sueño moderada a grave. Fueron aleatorizados a CPAP autoajustable vs. CPAP sham. Recibieron tratamiento médico óptimo y un régimen de actividad física y nutrición. Se hizo medición de colesterol total, colesterol-HDL y presión arterial sistólica de 24 horas, basal y 12 semanas después del uso de CPAP. Se realizó una comparación del riesgo cardiovascular antes y después del ensayo. Resultados: La mediana del riesgo cardiovascular basal en el grupo CPAP óptimo fue de $20.2 \%$ y postratamiento de $16.3 \%$ ( $p=0.00)$. En el grupo CPAP sham la mediana basal fue de $12.1 \%$ y postratamiento de $12.2 \%$ ( $\mathrm{p}=0.14)$. Conclusión: En pacientes con apnea obstructiva del sueño grave, diabetes mellitus 2 y obesidad con un tratamiento médico óptimo, actividad física y régimen nutrimental, el uso de CPAP disminuye el riesgo cardiovascular. La reducción estuvo ligada a la disminución de la tensión arterial sistólica y del colesterol total.

\section{Síndrome de Swyer- James-Mc Leod}

\section{Cásarez SIF, Alemán ZJE, Velázquez SJR, Alejandre GA}

INER Ismael Cosío Villegas

Introducción: El síndrome se caracteriza radiológicamente por un pulmón hiperclaro unilateral con vascularización disminuida y atrapamiento aéreo en espiración. Es infrecuente, suele ser un hallazgo radiológico incidental. La etiología es tras una bronquiolitis o neumonía vírica diagnosticada en la infancia. Anapatológicamente observa bronquitis y bronquiolitis. Puede ser asintomático o síntomas de disnea o tos. El tratamiento a las infecciones pulmonares y vacunación es lo indicado. Presentación del caso: Masculino de 7 años de edad, padres sanos. Gesta 1, nace vía cesárea, a las 39 semanas, Apgar 8/9, peso 3,250 g. Diagnóstico de neumonía adquirida en la comunidad a los 7 meses sin complicaciones. Posteriormente eventos de sibilancias 
en 7 ocasiones, cuenta con biopsia pulmonar, con diagnóstico de bronquiolitis alveolar crónica. Acude al INER debido a que desde los 5 años presenta disnea ocasional, tos y dificultad respiratoria. La radiografía de tórax posteroanterior con hiperclaridad en hemitórax derecho, con disminución de la vascularización. Tomografía de tórax: Pulmón derecho hiperclaro con patrón de mosaico, disminución en el calibre de la arteria pulmonar en la fase contrastada. Espirometría: Obstrucción grave con respuesta significativa al broncodilatador. Pletismografía: Hiperinsuflación con atrapamiento aéreo, DLCO: Disminución en la difusión moderada ajustada por altitud. Gamagrama VQ: Pulmón izquierdo con adecuada captación del radiotrazador. Pulmón derecho con severa disminución de la captación del radiotrazador de forma generalizada. Broncoscopia: Cambios inflamatorios, mucosa pálida en tercio distal de tráquea, árbol bronquial derecho con sólo dos segmentos, árbol bronquial izquierdo con variante anatómica língula con 3 segmentos. Se egresa con tratamiento a base de mometasona/formoterol $200 \mu \mathrm{g} / 5$ $\mu$ g. Conclusión: El síndrome se presenta de manera rara, ya que su presentación clínica es muy variable y puede ser un hallazgo radiológico en la mayoría de estos niños. Si no hay una enfermedad asociada, el pronóstico es excelente pudiendo disminuir los síntomas con el paso del tiempo.

\section{Enfermedad de Gorham-Stout. Reporte de un caso y revisión de la literatura}

\section{Aranda ROE, Hernández Fl,} González RJL Hospital Central Sur de Alta Especialidad
Pemex; INER Ismael Cosío Villegas

Introducción: La enfermedad de GorhamStout es una patología que cursa con proliferación vascular, angiomatosis y linfangiomatosis ósea que produce osteólisis progresiva, así pérdida de masa ósea. La afección torácica, pulmonar o pleural llevan a un compromiso de la función respiratoria que puede cursar con un desen- lace fatal. El involucro mandibular puede conllevar a presentar apnea obstructiva del sueño. La etiopatogenia es actualmente desconocida y ocurre esporádicamente. El 50\% de los pacientes refieren un traumatismo fútil antes del diagnóstico. Puede involucrar cualquier parte del esqueleto óseo. Gorham y Stout introdujeron el término de «osteólisis masiva» y reportaron 24 casos en 1955. El pronóstico es considerado benigno cuando sólo las extremidades o región pélvica se ven involucradas; sin embargo, cuando hay estructuras vitales afectadas el pronóstico suele ser fatal. Desde la descripción de la patología en 1838 por Jackson no se han documentado más de 200 casos en la literatura, siendo 50 de éstos en población pediátrica. El conocimiento de la enfermedad de Gorham-Stout es actualmente basado en reportes de casos esporádicos. Objetivos: Comunicar caso de enfermedad de Gorham-Stout y revisión de la literatura. Presentación del caso: Masculino de 13 años de edad con antecedente de nacimiento vía cesárea debido a ruptura prematura de membranas, aparentemente sin complicaciones. Adecuados hitos del desarrollo. Antecedente de ausencia congénita de arcos costales 5, 6 y 7 derechos, niega antecedentes de patología respiratoria. Alergia a cefalosporinas. Inició padecimiento posterior a traumatismo en región dorsolumbar durante actividad física. Tratamiento ambulatorio a base de AINES, sin mejoría posteriormente terapia física con mejoría parcial. Un año después reinicia dolor en misma zona, evolucionando tórpidamente con incremento de dolor, a la deambulación se añade al padecimiento tos de predominio nocturno, inicio insidioso, en accesos largos, sin expectoración, sin desencadenante aparente. Datos relevantes en exploración física: escoliosis torácica con desviación hacia la derecha amplexión y amplexación disminuidas, ruidos respiratorios disminuidos en región de hemitórax derecho. Dolor a la palpación en apófisis espinosas T4, T5, T6. Radiografía de tórax revela ausencia de arcos costales 5, 6 y 7 con dextroescoliosis dorsal. Se ingresa paciente para abordaje. Durante internamiento el paciente desarrolla datos de dificultad respiratoria, agregándose en la exploración física aumento del patrón respiratorio, matidez a la percusión y disminución de ruidos respiratorios con estertores crepitantes de predominio hacia región torácica derecha fiebre y desaturación. Clínicamente presenta un síndrome de derrame hacia región torácica derecha, el cual se confirma por estudio de imagen. Los estudios de laboratorio incluyeron inicialmente biometría hemática, electrolitos séricos. Es manejado con antibioticoterapia y toracocentésis con evolución hacia la mejoría. Durante el internamiento se observa progresión de lisis ósea en región escapular derecha y parrilla costal derecha, por lo cual se realiza abordaje para descartar las posibles causas de osteólisis. Al egreso de Terapia Intensiva es valorado por servicio de Ortopedia para manejo de escoliosis congénita, listesis T4-T5 y compresión de canal medular T6. Se maneja con alambrado sublaminar y colocación de barras de Luque de T2 a T10 y descompresión medular a nivel de T6. Resultados: Laboratoriales de ingreso: biometría hemática, electrolitos séricos, tiempos de coagulación y pruebas de funcionamiento hepático, donde sólo se observa elevación de leucocitos con predominio de neutrófilos los cuales fueron asociados al proceso infeccioso, el resto de laboratorios se encontraron dentro de rangos de normalidad. El estudio del líquido pleural demostró exudado con tinción de Gram negativo, baciloscopias y cultivos negativos. Por lo cual se integra diagnóstico de derrame paraneumónico típico. Resto de estudios por descartar otras causas de osteólisis secundaria: TSH: $1.071 \mathrm{mU} / \mathrm{L}$ (T3 y T4 no fueron realizadas). Glucosa 100 mg/dL. Subpoblaciones linfocitarias CD3: 472/69.2\% CD4: 84/12.3\% CD8:306/44.8\% relación C4/CD8:0.3 Complemento C3:118, C4:29 IgG:1620 IgM:125 IgE:93.9 Anticardiolipinas IgM 2.3 MPL u/mL IgG GPL u/mL 4.90. Anticuerpos antinucleares: mitocondria anti JO-1, anti-SCL-70, anti-DNAdc, anticel. HEP-2 positivo. Anticuerpos antinucleares DNA: ro. anti-la ant9 sm/rnp, anti-JO-1, anti SCL-70, anticentrómero negativo, paratohormona 10 pg/mL. Radiografía anteroposterior de tórax: ausencia de arcos costales 5, 6 y 7 y dextroescoliosis dorsal con listesis de t4-t5 y compresión del canal medular-tomografía dorsolumbar con reporte de hemivértebra derecha 4 , agenesia 
asociada 4, 5, 6 arcos costales ipsilateral. Reporte de patología cambios inflamatorios. Conclusión: La enfermedad de Gorham-Stout es una rara condición caracterizada por reabsorción ósea espontánea. En la mayoría de los casos ocurre en niños o adultos jóvenes sin causa genética clara. La patogénesis de esta entidad es poco comprendida, se le ha atribuido a causas como alteraciones en las células osteoclásticas (Gorham and Stout 1955), osteólisis secundaria a angiomatosis y osteclastos multinucleados con hiperactividad en la función de resorción. Basado en los hallazgos clínicos, patológicos y los cambios radiográficos se realiza el diagnóstico de osteólisis idiopática progresiva o enfermedad de Gorham-Stout, posterior a descartar otras patologías que ocasionan osteólisis secundaria. Aporte a la práctica clínica diaria: La enfermedad de Gorham-Stout es una patología esporádica; sin embargo, en la práctica clínica al enfrentarnos a un caso similiar debemos siempre hacer un abordaje completo y descartar todas las posibilidades diagnósticas para de este modo poder dirigir adecuadamente la terapéutica de cada paciente.

\section{Desempeño de los espirómetros y jeringas de calibración en el Instituto Nacional de Enfermedades Respiratorias}

\section{Hernández RFI, Gochicoa RL, Pérez $P R$, Torre-Bouscoulet $L$}

INER Ismael Cosío Villegas

Introducción: La Sociedad Americana de Tórax (ATS) ha propuesto un grupo de curvas estandarizadas para probar la precisión y exactitud de los equipos empleados para hacer espirometrías, este grupo de curvas simulan los patrones espirométricos habitualmente observados en la práctica clínica. Objetivo: Probar el desempeño de los espirómetros usados cotidianamente en un hospital de referencia de tercer nivel dedicado a las enfermedades respiratorias. Material y métodos: El estudio incluyó la evaluación de 19 equipos, 6 espiróme- tros ultrasónicos, 3 espirómetros de flujo dotados con una turbina, 6 equipos de neumotacógrafo y 4 equipos de medición de pico flujo. Cada uno de los equipos fue calibrado siguiendo el método tradicional con una jeringa electrónica de 3L (Jones) así como un pistón computarizado programado con las 24 curvas estandarizadas de la ATS. Resultados: Se evaluó un total de 19 espirómetros de 6 diferentes marcas de los cuales 6 fueron neumotacógrafos, 6 ultrasónicos, 3 turbinas y 4 de bolsillo (2 turbinas y 2 de presión de flujo). Los espirómetros de ultrasonido y el neumotacógrafo tienen un mejor rendimiento que los de turbina. Conclusión: Los sensores de neumotacógrafo y ultrasónico muestran un buen desempeño en sus mediciones. El sensor de presión de flujo (de bolsillo) muestra muy buenos resultados en las mediciones.

\section{Prevalencia de enfermedad pulmonar obstructiva crónica en pacientes con diagnóstico de $\mathrm{VIH}$ sin tratamiento antirretroviral previo}

Romero LZ, Rojas CFA, Ochoa VMD Hospital General CMN «La Raza»

Introducción: La EPOC es el problema respiratorio de mayor prevalencia e impacto socioeconómico en el mundo. Recién se ha propuesto una asociación entre la infección por VIH y el desarrollo de EPOC. Objetivos: Determinar la prevalencia de EPOC en pacientes con VIH referidos a nuestro Hospital. Material y métodos: Se incluyeron individuos con infección documentada por VIH sin importar el tiempo desde la adquisición de la misma, sin tratamiento antirretroviral previo, con sintomatología respiratoria crónica y que fueran capaces de realizar una espirometría de acuerdo con estándares de calidad de la ATS, siempre y cuando se hubiera descartado la presencia de infección respiratoria activa o datos clínicos sugerentes de proceso infeccioso en las últimas 4 semanas, sin tener antecedente de neumopatía crónica conocida. Se reali- zó espirometría pre- y posbroncodilatador, TC de alta resolución y determinación de carga viral y conteo de CD4. Se realizó un análisis descriptivo de las características sociodemográficas, síntomas respiratorios, hallazgos tomográficos y resultados espirométricos. Las variables cualitativas fueron expresadas mediante conteos y porcentajes, mientras que las variables numéricas fueron expresadas con mediana y rango intercuartilar. Se incluyó un total de 66 sujetos, 64 hombres y 2 mujeres. Resultados: Se encontró una prevalencia de obstrucción no reversible al flujo aéreo medida mediante espirometría compatible con diagnóstico de enfermedad pulmonar obstructiva crónica de $7.6 \%$. Al realizar un análisis por separado de los grupos con y sin obstrucción al flujo aéreo, se encontró que el grupo con obstrucción presentó un menor conteo de CD4 (27.3 vs. 225.9) y una mayor carga viral (165.000 vs. 57.722) en comparación con el grupo sin obstrucción. Conclusión: Los resultados sugieren que los individuos que muestran un menor conteo de CD4 y mayor carga viral tienden a presentar disminución de los valores espirométricos, independientemente de otras variables y factores exposicionales.

\section{Tumor miofibroblástico inflamatorio y tuberculosis pulmonar: reporte de caso y revisión de la literatura}

\section{Fragoso MM, Téllez NNA, Luna JJ, Rumbo UN}

INER Ismael Cosío Villegas

Introducción: El tumor miofibroblástico inflamatorio pulmonar (TMI), también denominado fibrohistiocitoma o granuloma de células plasmáticas, es una patología benigna poco frecuente en adultos $(0.7 \%$ de los tumores pulmonares). Las características radiológicas son inespecíficas y el diagnóstico es complicado debido a su variable composición celular. Objetivo: Describir la manifestación clínico-radiológica-patológica del TMI con tuberculosis pulmonar. Presentación del caso: Mujer 56 años sin enfermedades crónico-degenerativas. Inició hace 1 año con dolor torácico que cedía 
con AINES; pérdida de peso de $9 \mathrm{~kg}$ en 6 meses y tos crónica con disnea mMRC3. Exploración física sin alteraciones, IMC 17, $\mathrm{SatO}_{2} 88 \%$, gasometría con hipoxemia leve. Radiografía de tórax: se observan radiopacidades bilaterales en lóbulos superiores. Tomografía de tórax: imagen isodensa de $3 \times 4 \mathrm{~cm}$ de bordes irregulares en lóbulo superior derecho con diseminación linfangítica y nódulos con bordes mal definidos en lóbulos superiores. Laboratorio con anemia e hipoalbuminemia. Se realizó broncoscopia con reporte negativos para cultivo de bacterias y biopsias transbronquiales. Biopsia guiada por US: negativa. Se realizó toracoscopia con toma de biopsia de pleura y pulmón. Reporte histológico: Tumor miofibroblástico inflamatorio. A los 60 días se reportó crecimiento de Mycobacterium tuberculosis en biopsia pulmonar. Inició tratamiento con terapia de comprimido único. Conclusión: La etiopatogenia de este tumor es una incógnita. Por su capacidad para mimetizar el cáncer pulmonar, tanto en sus manifestaciones clínicas como radiológicas debe incluirse en el diagnóstico diferencial, especialmente cuando los estudios microbiológicos y de anatomía patológica resultan negativos. Se ha asociado a procesos infecciosos, sin embargo, la asociación con micobacterias es muy rara.

\section{Hemangioendotelioma epitelioide pulmonar}

\section{García TR, Ramírez HA, Barragán} CRA, Torres VRA

IMSS; ISSSTE; UMAE 189, IMSS

Introducción: El hemangioendotelioma epitelioide (HEE) es una enfermedad infrecuente, descrita en 1982 por Weiss y Enzinger. La presentación benigna de los tumores pulmonares es muy infrecuente. Martini et al. han reportado una incidencia menor al $1 \%$ entre los tumores pulmonares. Presentación del caso: Masculino de 71 años de edad, en protocolo preoperatorio para resección prostática transureteral, se detectó opacidad redondeada de bordes bien definidos en ápice pulmonar izquierdo. Antecedentes de tabaquismo intenso de una cajetilla al día durante 25 años. TAC de tórax en el cual se identifica tumoración redonda, de bordes bien definidos, sin broncograma aéreo, no calcificaciones intraparenquimatosas: en la fibrobroncoscopia con toma de biopsia arroja el probable diagnóstico de fibrosis y cepillado bronquial negativo a células malignas. Citología de aspiración por aguja fina guiada por TAC, altamente sugestiva de carcinoma epidermoide bien definido, en el control radiológico se observó crecimiento de la tumoración de $4 \mathrm{~mm}$ en un lapso de 3 meses. Se realiza tumorectomía: Diagnóstico histopatológico de hermantoma pulmonar a 3 años presenta recidiva, se realiza nuevamente tumorectomía reportándose en inmunohistoquímica hemangioendotelioma. Conclusión: En el presente caso tuvimos distractores como el reporte citológico de la punción transtorácica sugestivo de carcinoma epidermoide y por otro lado el discreto crecimiento observado del mismo, en un paciente con tabaquismo intenso, motivo que nos llevó a sospechar que se trataba efectivamente de una neoplasia maligna.

\section{Neumorraquis asociado a neumomediastino en pacientes asmáticos. Reporte de un caso}

\section{Hanssen CF, Cárdenas ESM, Domínguez RDU}

\section{IMSS}

Introducción: La neumatosis espinal es generalmente secundaria a traumatismos y procedimientos invasivos, aunque otra causa infreceunte es el asma. Cualquier patología que origine incremento del gradiente de presión alveolar transmural puede causar neumomediastino con posterior escape de aire a través del espacio paravertebral. Objetivos: Describir un caso de neumorraquis asociado a neumomediastino en presencia de una crisis asmática. Material y métodos: Reporte de caso de neumorraquis asociado a neumomediastino en masculino de 15 años con historia de asma que fue atendido en el HGZ Núm. 17 del IMSS en Monterrey, NL. Se utilizaron radiografías de tórax, tomografía de cráneo y tórax para evidenciar el neumomediastino y neumorraquis. Presentación del caso: Masculino de 15 años con antecedente de asma bronquial diagnosticado en su infancia. No fumador. Inicia su padecimiento mientras realizaba actividad física, presenta súbitamente tos no productiva, disnea y aumento de volumen en región anterior derecha de cuello y tórax superior por lo cual acudió al Servicio de Urgencias. La radiografía de tórax demostró enfisema subcutáneo e imagen sugerente de neumomediastino. Al realizar la TAC torácica se detectó aire en el canal raquídeo limitado al espacio epidural y neumomediastino anterior. Resultados: El paciente presentó buena evolución del cuadro respiratorio, neurológicamente asintomático. Valorado por Neurocirugía sin encontrar datos patológicos, no ameritó tratamiento quirúrgico. Fue dado de alta 4 días posterior a su ingreso. Conclusión: En el neumorraquis epidural la reabsorción ocurre de forma espontánea entre 1 y 3 semanas, con tratamiento conservador. Raramente produce dolor radicular y paraplejía, es infrecuente el tratamiento quirúrgico. En el neumorraquis subaracnoideo, el aire puede migrar al cráneo y provocar cefalea o síntomas focales, son menores las posibilidades de reabsorción espontánea y puede requerir cirugía. El diagnóstico se realiza mediante la TAC o la RMN. Aporte a la práctica clínica diaria: Conocer la presentación clínica y radiológica del neumorraquis asociado a neumomediastino ya que es una entidad rara en pacientes asmáticos.

\section{Reducción de la recurrencia de estenosis traqueal posoperatoria con el empleo de colágeno polivinilpirrolidona}

Berrios MJ, Iñiguez GMA, Ibarra JM, Carranza I, Marmolejo TME, Olmos $Z R$, Jasso VR

INER Ismael Cosío Villegas

Introducción: La resección y anastomosis traqueal es el estándar de tratamiento de la estenosis traqueal. La recurrencia en 
el Instituto Nacional de Enfermedades Respiratorias es de $21 \%$, principalmente resultado de la formación de fibrosis. La colágena polivinilpirrolidona reduce la formación de las fibras de colágena. Objetivos: Evaluar la utilidad del colágena polivinilpirrolidona adyuvante a la resección y anastomosis traqueal para reducir la recurrencia postquirúrgica. Material y métodos: Estudio observacional, prospectivo, longitudinal. Realizado en el Instituto Nacional de Enfermedades Respiratorias, Ciudad de México, en el período de 2014 al 2015. Se empleó un modelo de regresión logística para variables dependientes, p significativa con un valor $<0.05$. El análisis se realizó a través IBW SPSS versión 20.0. Se seleccionaron 2 grupos de forma prospectiva, en el grupo control se realizó la resección traqueal y la anastomosis terminoterminal, al grupo de casos se agregó la colocación de una esponja de colágena-polivinilpirrolidona $2.2 \mathrm{mg}$ (FIBROQUEL esponja, ASPIDPHARMA S.A. de C.V.). El seguimiento fue clínico con pruebas de función respiratorias y broncoscopia ante los síntomas de recurrencia de estenosis traqueal. Resultados: Se reclutaron 78 participantes, 39 del grupo de control y 39 del grupo de casos (fibroquel), la media de edad fue 35.5 años ( \pm 13.2 años), sexo masculino en el $70.5 \%$ (55/78), la reestenosis se presentó en el $11 \%$ (9/78), los grupos fueron comparables en relación con las variables predictoras de reestenosis. Encontramos que en el grupo que se empleó fibroquel la recurrencia fue de $2.6 \%$ (1/39), en el grupo de control $20.5 \%$ (8/39), con una OR 0.1 (IC 95\%: 0.01-0.8) $\mathrm{p}=0.013$. Conclusión: La administración de colágeno polivinilpirrolidona después de la anastomosis traqueal reduce la recurrencia de estenosis posoperatoria. Aporte a la práctica clínica diaria: Nuestros resultados soportan la recomendación del empleo de forma sistemática de colágena-polivinilpirrolidona en este grupo de pacientes. Se requiere la realización de un estudio prospectivo aleatorizados para confirmar nuestros resultados.

\section{Evaluación de la función tiroidea en hipertensión arterial pulmonar}

Gómez LSA, Cueto RG, Cicero SR

Hospital General de México

Introducción: Se ha descrito una mayor frecuencia de patología tiroidea (PT) en pacientes con hipertensión arterial pulmonar (HAP) que en población general, variando según series (25-49\%). Se desconocen los mecanismos asociados, algunos autores suponen que en ambas entidades subyace un mecanismo autoinmune. La Clínica de Hipertensión Pulmonar (HP) del Hospital General de México cuenta con un registro de 134 pacientes de los cuales, 84 pertenecen al grupo de HAP. Objetivos: Analizar la asociación de pacientes con HAP y PT (HAPcPT) vs. pacientes con HAP sin PT (HAPsPT), y describir las características clínicas, hemodinámicas y sobrevida. Material y métodos: Estudio observacional, descriptivo, comparativo. Se incluyeron 84 pacientes con diagnóstico de HAP por cateterismo cardíaco derecho de enero 2012 a diciembre 2016. A todos se les realizaron pruebas de función tiroidea (PFT), caminata de 6 minutos (C6M) y evaluación de clase funcional. El análisis estadístico utilizado fue la prueba de T pareada. Resultados: Se encontraron 23 pacientes (27\%) con HAPcPT, todos con hipotiroidismo (TSH $10.8 \mathrm{mlU} / \mathrm{L}$ ). Setenta y nueve por ciento fueron mujeres. Las variables hemodinámicas de pacientes con HAPcPT $v s$. HAPsPT, respectivamente, muestran que la presión media de la arteria pulmonar fue 58.8 vs. $50.4 \mathrm{mmHg}$, RVP 10.5 vs. $7.3 \mathrm{UW}, \mathrm{AD} 8.0$ vs. $6.8 \mathrm{mmHg}$, IC 3.7 vs. $4.2 \mathrm{~L} / \mathrm{min} / \mathrm{m}^{2}$; alcanzando significancia estadística las dos primeras ( $\mathrm{p}=0.03$ ambas). Los pacientes con HAPsPT tienen mejor CF y un mayor número de metros caminados (364 m). Durante el seguimiento falleció un paciente con HAPcPT y tres con HAPsPT. Conclusión: La prevalencia de PT en nuestros pacientes es similar a la descrita en la literatura, $100 \%$ de los pacientes corresponde a hipotiroidismo. Se encontró que pacientes con HAPsPT tienen mejor CF, así como hemodinamia pulmonar y oxigenación en sangre venosa mixta. Todos reciben inhibidores de fosfodiesterasa tipo sildenafil y algunos en combinación con bosentán o macitentan.

\section{Estudio de la duración real del cilindro tipo}

\section{E comparado con la corrección del factor de conversión y cuatro distintas fórmulas para el cálculo teórico}

Barrios MJM, Toral FSC, Nava

AJF, Rogelio García TR, Reyes PA, Castañón RRP, Mendoza RVM

INER-EFT-TR

Introducción: El oxígeno constituye el $50 \%$ peso de la corteza terrestre, densidad $1.429 \mathrm{~g} / \mathrm{L}$. Almacenado en cilindros de aluminio color gris con verde con $99.9 \%$ de pureza. Objetivos: Evaluar la fórmula para cálculo de duración de cilindros tipo E respecto a la duración real y la obtenida por diferentes fórmulas. Material y métodos: Conocer el tiempo de vaciamiento de los cilindros tipo E y los factores que lo modifican. La fórmula para la duración basada en capacidad y presión proporcionará el tiempo más preciso de vaciamiento comparando las fórmulas existentes. Estudio prospectivo, observacional, descriptivo. Grupos, 1: Cilindro tipo E (proveedor 1) presión a 2015 psi y 682 litros. 2: Cilindro tipo E (proveedor 2) presión a 2200 psi y 700 litros. Criterios de inclusión: Grupo 1: cilindro tipo E con regulador de presión a 2015 psi. Grupo 2 cilindro tipo E con regulador de presión a 2200 psi. Sellados en condiciones óptimas. Criterios de exclusión: No tener correcto sellado de la empresa. Datos analizados con SPSS 18.0 (Windows) se estimaron los estadísticos descriptivos, se calculó la desviación típica de las formulas. Resultados: La fórmula 1 y 5 (proveedor 1) son más precisas. Grupo 2, es más confiable la 2 (35 segundos a 6 minutos) mientras que la 3 más precisa (30-59 seg). Las 2 y 5 dieron el mismo resultado. La 4 fue la más alejada. La 6 no se recomienda su uso, las 4 y 7 no las recomendamos (constantes). Recomendamos incrementar muestra para aumentar potencia estadística. Conclusión: En México no existe consenso respecto al llenado de cilindros. El proveedor 1 maneja las características que marca la norma, el proveedor 2 maneja presiones diferentes (15 cilindros 
2000 PSI y 85 con 2200 PSI). Determinar el tiempo de vaciado real de los tanques tipo E permite mayor seguridad durante los traslados.

\section{Utilidad y seguridad de la biopsia pleural cerrada con aguja de Abrams guiada por ultrasonido torácico realizado por neumólogos}

\begin{abstract}
Valencia RJ, Aguirre PTJ, Rumbo UN, Castillo GP, Báez SRA, Peña MES
\end{abstract}

\section{INER}

Introducción: La biopsia pleural es esencial en el estudio del derrame pleural (DP). Se ha cuestionado el uso de la biopsia pleural cerrada (BPC) por su bajo rendimiento diagnóstico reportado en la literatura $48-56 \%$. El uso de ultrasonido (US) podría aumentar su rendimiento y disminuir las complicaciones. Objetivos: Comparar el rendimiento diagnóstico y las complicaciones de la BPC con aguja de Abrams a ciegas y asistida con US realizado por neumólogos. Material y métodos: Estudio descriptivo, comparativo y ambispectivo. Se incluyeron todos los pacientes con DP a los que se les haya realizado BPC a ciegas o con USG de 2014-2016. Todas se realizaron con aguja de Abrams con la técnica descrita en la literatura. Se consideró muestra adecuada cuando contiene tejido pleural. Se consideró suficiente para el diagnóstico cuando fue diagnóstico final benigno o cuando fue maligno y el tejido obtenido fue suficiente para realizar inmunohistoquímica. Se comparó el rendimiento diagnóstico y complicaciones con US y a ciegas. Resultados: Se incluyeron en total 63 pacientes, 32 a ciegas y 31 con US. En 3 pacientes con muestra inadecuada (sin pleura) todos con BPC a ciegas. En el grupo asistido con US, $87 \%$ tuvieron material suficiente para el diagnóstico y en el grupo a ciegas el $65 \%$. Del total de pacientes, $74 \%$ tuvieron diagnóstico de malignidad (adenocarcinoma pulmonar, mesotelioma, sarcoma sinovial). Únicamente 4 pacientes tuvieron complicaciones, de los cuales 3 fueron con BPC a ciegas (hemotórax, hidroneumotórax) y 1 con US (hematoma

subcutáneo). Conclusión: La BPC con aguja de Abrams, tanto a ciegas como con US tiene un alto rendimiento diagnóstico, mayor al reportado en la literatura. Al realizar la BPC asistida por US mejora el rendimiento diagnóstico y disminuye el número y gravedad de las complicaciones. Aporte a la práctica clínica diaria: Es momento de darle una nueva oportunidad a la BPC asistida por US realizado por neumólogos para el diagnóstico de patología pleural tanto benigna como maligna.

\section{Hipertensión pulmonar en pacientes con combinación fibrosis pulmonar/enfisema}

\section{Cueto RG, Gómez LSA, Cicero SR}

Hospital General de México

Introducción: La combinación fibrosis pulmonar/enfisema (CFPE) es una patología recién descrita, en la cual se sobreponen el patrón intersticial y disminución de la distensibilidad de la primera en contraparte con la sobredistensión de la segunda. El diagnóstico requiere cumplir criterios radiológicos y de pruebas funcionales, siendo la más afectada la DLCO. La complicación más común es hipertensión pulmonar, definida por presión arterial pulmonar media (PAPm) igual o mayor a $25 \mathrm{mmHg}$ por cateterismo cardíaco derecho (CCD). Objetivos: Presentar tres casos clínicos de CPFE en el Hospital General de México, así como tratamiento y seguimiento. Presentación de los casos: Caso 1. Femenino de 56 años con antecedente de tabaquismo. Se presenta con disnea de grandes esfuerzos y tos seca. A la exploración física con estertores en velcro difusos, edema de extremidades inferiores y acropaquias. TACAR de tórax con bullas subpleurales apicales y enfisema difuso. Pruebas de función respiratoria normales a excepción de DLCO en 39\%. PAPm por CCD de $52 \mathrm{mmHg}$. Caso 2. Masculino de 58 años de edad con tabaquismo intenso. Con disnea evolutiva a pequeños esfuerzos y tos seca. Con cianosis peribucal y acropaquias. Ruido respiratorio con estertores crepitantes bilaterales difusos. TACAR de tórax patrón en mosaico con zonas de enfisema y bullas apicales bilaterales, así como bronquiec- tasias difusas. DLCO 50\%. PAPm de 37 mmHg. Caso 3. Femenino de 64 años con tabaquismo involuntario intenso. Con disnea evolutiva y tos seca. Se presenta con cianosis peribucal. A la exploración con estertores en velcro difusos. TACAR de tórax con panalización en ambas bases. DLCO en 39\%. Conclusión: La CFPE es una patología en la que se sobreponen características de ambas enfermedades, siendo esencial la TACAR de tórax y DLCO para su diagnóstico. Estos pacientes se encuentran en seguimiento y tratados con oxígeno suplementario, broncodilatadores de larga acción y fisioterapia pulmonar.

\section{Perfil de variantes genéticas en IL4 e IL13 en combinación con factores ambientales condicionan al padecimiento de asma}

Falfán VR, Ambrocio-Ortiz E, GaliciaNegrete G, Escobar-Morales A, Pérez-Rubio G, Castillejos-López M, Chapela MR, Abarca-Rojano E, Hernández $A$

INER Ismael Cosío Villegas; Hospital Regional ISSSTE, León Guanajuato; Escuela Superior de Medicina, IPN

Introducción: El asma es una enfermedad crónica inflamatoria de las vías aéreas que afecta aproximadamente a 300 millones de personas. Hasta el momento se desconoce su etiología; sin embargo, se sabe que intervienen factores genéticos y ambientales. La presencia de variantes tipo SNP y CNV puede condicionar la respuesta inflamatoria de los individuos. Se han descrito la presencia de SNP y CNV en los genes IL4 e IL13. Sin embargo, no existen estudios que evalúen variantes genéticas y factores ambientales de exposición en la susceptibilidad a padecer asma. Objetivos: Describir la asociación entre los SNP y CNV en los genes IL4 e IL13 y la susceptibilidad de padecer asma. Material y métodos: Se evaluó en total 492 sujetos: 147 pacientes con asma (PA) y 345 sujetos sanos (no asmáticos, NA). Se genotipificaron 3 SNP, 2 en IL13 y 1 en IL4. Para el caso de las CNV se seleccionaron 2 variantes en IL4. Se usaron sondas comerciales TaqMan y qPCR para la discri- 
minación de genotipos. Las frecuencias de genotipos de casos y controles fueron comparadas usando Epi Info v. 7.2. Resultados: Se encontró asociación estadísticamente significativa entre el rs20541 (A; $\mathrm{p}=0.040$, $\mathrm{OR}=1.6), \operatorname{rs} 1800925(\mathrm{~T}, \mathrm{p}=0.047, \mathrm{OR}=$ 1.5) y rs2070874 (T, p = 0.046, OR = 1.65) y el antecedente de exposición a animales; con dermatitis (A del rs20541, $\mathrm{p}=0.0013$, OR 6.0), conjuntivitis (A, p < 0.001, OR 7.6, IC 2.1-28.4; T, p <0.001, OR 10.9) y exposición al humo de leña (A del rs20541, p < 0.001, OR 4.11; T del rs1800925, $\mathrm{p}<0.001$, OR 4.3). Conclusión: Existen alelos de riesgo en IL13 e IL4 que, en conjunto con factores de exposición ambiental, incrementan el riesgo al padecimiento del asma. Aporte a la práctica clínica diaria: La identificación de factores genéticos de riesgo en adición a aquéllos de exposición.

\section{Presencia de}

polimorfismos tipo SNP en genes HSPA1 se asocian con susceptibilidad genética de padecer EPOC secundaria a humo de leña y a la gravedad de la misma

Ortiz EA, Ramírez-Venegas $A$, Pérez-Rubio G, Ramírez-Díaz M, Aranda-Chávez A, Guzmán-Bouilloud NE, Amaya FR, Guevara R, Jaime-Capetillo ME, Sansores $R$, Abarca-Rojano E, Falfán-Valencia $R$

INER Ismael Cosío Villegas; Servicios de Salud de Oaxaca; Centro Respiratorio de México

Introducción: La enfermedad pulmonar obstructiva crónica (EPOC) es un padecimiento complejo, asociado a la presencia de partículas extrañas en los pulmones. Existe interacción entre factores ambientales e intrínsecos que influyen en la gravedad de la misma. El humo de leña es uno de los factores ambientales de riesgo asociados a padecer EPOC; sin embargo, es uno de los menos estudiados. Por otra parte, la participación del componente genético no ha sido del todo comprendida, por lo que resulta de gran importancia conocer y describir la presencia y la frecuencia de variantes tipo SNP en nuestra población. Objetivos: Describir la asociación entre polimorfismos en genes HSPA1, la susceptibilidad y gravedad de la EPOC secundaria a humo de leña. Material y métodos: Se incluyeron 442 sujetos expuestos al humo de leña: 244 que desarrollaron EPOC (EP-HL) y 198 sin EPOC, no fumadores (NFE). Se genotipificaron 7 variantes tipo SNP en los genes HSPA1A, HSPA1B y HSPA1L mediante qPCR. Las frecuencias genotípicas y alélicas se compararon con los software Epidat v. 4.1 y Epi info. Resultados: Mediante el análisis por modelo codominante, los SNP rs1043618 y rs17856061 se asociaron con un riesgo disminuido, mientras que el rs1008438 presenta riesgo aumentado. En el análisis por genotipos el rs1008438 muestra un genotipo asociado a riesgo (TT, $\mathrm{p}=0.017, \mathrm{OR}=1.96$ ) y otro a riesgo disminuido ( $\mathrm{GG}, \mathrm{p}=0.046$, $\mathrm{OR}=0.65$ ); mientras que en rs17856061 se encontró un genotipo asociado a riesgo disminuido (GG, $\mathrm{p}=0.003, \mathrm{OR}=0.276$ ). Al estratificar los casos por estadíos GOLD, se encontró el genotipo heterocigoto del rs1043618 (GC, $\mathrm{p}=0.047, \mathrm{OR}=2.59$ ) asociado a riesgo aumentado. Conclusión: Existen SNP en los genes HSPA1 que están asociados a la susceptibilidad genética de padecer EPOC secundaria al humo de leña y que además influyen en la gravedad de la enfermedad.

\section{Validación externa de las reglas de predicción clínica para mortalidad en pacientes hospitalizados con neumonía adquirida en la comunidad}

Castillo GP, Rumbo UN, Guadarrama PC, Gómez ZC, Escobar RA, Báez SR, Castañeda BA, Chávez MJ

INER Ismael Cosío Villegas; UNAM

Introducción: El desarrollo integral de una regla de predicción clínica incluye la demostración de su validación en una población diferente de la cual derivó dicha regla. Ni CURB-65, ni el índice de gravedad para neumonía (PSI) han sido validados en pacientes mexicanos. Objetivos: Identificar las variables asociadas a mortalidad hospitalaria en pacientes con neumonía adquirida en la comunidad (NAC) y evaluar el desempeño de las reglas de predicción clínica para mortalidad (PSI y CURB65). Material y métodos: Estudio de casos y controles. Casos pacientes con NAC que fallecieron durante la hospitalización, controles pacientes que egresaron vivos. Se midieron los índices PSI y CURB-65. La asociación de las diferentes variables independientes con la variable desenlace (muerte hospitalaria) se evaluó mediante regresión logística. Para evaluar la capacidad discriminatoria de los índices PSI y CURB-65, se graficó su respuesta de acuerdo con la variación del nivel de positividad respecto a la mortalidad y el área bajo la curva. Resultados: Estudiamos 317 casos, $87(27.4 \%)$ defunciones y $230(72.6 \%)$ controles. Los casos fueron mayores que los controles, 64 vs. 55 años. Variables asociadas a mortalidad: edad $>50$ años, OR 1.91 (1.12-3.28); enfermedad neurológica, OR2.13 (1.10-4.16); frecuencia cardíaca > 125, OR 2.39 (1.24-4.65); frecuencia respiratoria > 30, OR 2.86 (1.68-4.86); derrame pleural, OR 0.32 (0.12-0.84); desaturación, OR2.37 (1.3-4.3); leucocitos $>12,000$, OR 2.11 (1.3-3.5); hematocrito $<30 \%$, OR 2.6 (1.2-5.5); nitrógeno de la urea $>30 \mathrm{mg} / \mathrm{dL}$, OR 5 (2.9-8.7); índice PSI > 85 puntos, OR 6.5 (3.6-11.8) y CURB-65 > 2 puntos, OR 4.1 (2.4-7.1). La curva ROC para muerte y el puntaje PSI y CURB-65 tuvieron un área bajo la curva de 0.74 y 0.69 . La mortalidad para clases I y II de PSI y CURB-65 con menos de 2 puntos, fue de $11.6 \%$ y $25.3 \%$ respectivamente. Conclusión: El desempeño de PSI y CURB-65 fue aceptable, las variables asociadas a mortalidad están incluidas en estos índices. Aporte a la práctica clínica diaria: Estas reglas de predicción permiten identificar casos graves y no son útiles para casos con riesgo bajo de mortalidad ya que la subestiman.

\section{Síndrome de Swyer James en el adulto}

Lovera ZI, Mateos TH, Guzmán de $A E$, Rojas-Serrano J, Mejía AM

INER Ismael Cosío Villegas 
Presentación del caso: Femenino de 21 años de edad. Cuadros recurrentes de infección de vías respiratorias desde los seis meses de edad. Referida por tos crónica asociada a expectoración y disnea de grandes esfuerzos. En el examen físico se encontró: FR de 20 rpm, FC 99 lpm, TA 90/60 mmHg, $\mathrm{SO}_{2} 95 \%$ (aire ambiente), disminución del ruido respiratorio e hiperclaridad pulmonar en el hemitórax derecho. Los estudios de laboratorio demostraron anemia de $11.5 \mathrm{~g} / \mathrm{dL}$, niveles séricos de $\mathrm{IgG}$ elevados $(1,700 \mathrm{mg} / \mathrm{dL})$, el resto de las inmunoglobulinas fueron normales. La determinación de ANAs y Factor reumatoide fueron negativas. Las pruebas de función hepática y enzimas pancreáticas resultaron normales. Espirometría sugestiva de restricción pulmonar sin respuesta a prueba de broncodilatación. Pletismografía con aumento del volumen residual en forma significativa. La prueba de DLCO resultó con disminución leve. Recorrió 588 metros en la caminata de 6 minutos sin desaturación. La ecocardiografía resultó normal. Los estudios de imagen mostraron sobredistención, áreas de atenuación en mosaico y engrosamiento de la pared bronquiolar del lóbulo inferior derecho. Discusión: El síndrome de Swyer James es una bronquiolitis obliterante posinfecciosa, ocurre en niños antes de los 8 años de edad; sin embargo, suele describirse en adultos. Puede progresar a fibrosis bronquiolar disminuyendo significativamente la luz generando hiperinflación del parénquima pulmonar por atrapamiento aéreo y disminución de la perfusión sanguínea clásicamente en forma unilateral. En los estudios de imagen se observa: hiperlucencia pulmonar unilateral, puede haber bronquiectasias y áreas de menor atenuación. En las pruebas de mecánica pulmonar suele observarse hiperinflación pulmonar o grados de obstrucción variable. El objetivo del tratamiento es el control de los síntomas con fármacos broncodilatadores y la evaluación temprana de las exacerbaciones infecciosas.

Prevalencia de enfermedad pulmonar intersticial difusa diagnosticadas por biopsia pulmonar en el Servicio de Neumología del Hospital General «Dr. Gaudencio González Garza» del CMN «La Raza»

\section{Aleman MÁ, Basaldua ZPX Sánchez ÁTI}

\section{IMSS}

Introducción: Las enfermedades pulmonares intersticiales difusas (EPID) constituyen un grupo muy heterogéneo de afecciones con manifestaciones clínicas, radiológicas y funcionales comunes, en las cuales las principales alteraciones anatomopatológicas afectan a estructuras alvéolo intersticial. Se consideran patologías poco frecuentes; sin embargo, en la práctica clínica neumológica se ha reportado que pueden representar hasta un $15 \%$. Desconocemos la prevalencia real en nuestro medio y por esto se realizó el estudio. Objetivos: Determinar la prevalencia de enfermedad pulmonar intersticial difusa en pacientes en los que se realizó biopsia pulmonar en el Hospital General «Dr. Gaudencio González Garza» del CMN «La Raza». Material y métodos: Se realizó la revisión de todos los resultados histopatológicos de biopsia de pulmón a cielo abierto y se seleccionaron todos aquéllos que tuvieron como hallazgo patrón histopatológico compatible con enfermedad pulmonar intersticial difusa en un período comprendido de enero 2007 a septiembre 2016. Presentación del caso: Resultados: Encontramos 138 casos de EPID por biopsia de pulmón a cielo abierto. Predominó el tipo histológico de neumopatía intersticial usual (NIU) con una prevalencia del $50.4 \%$, la prevalencia de neumonitis por hipersensibilidad fue de $13.1 \%$ y la de neumonía intersticial no especificada fue de $12.4 \%$. Las prevalencias de neumonía intersticial aguda, neumonía organizada criptogenética, silicosis, neumonía descamativa, neumopatia intersticial linfoide, granulomatosis de Wegener, sarcoidosis y proteinosis alveolar fueron de 6.6, 5.1, 2.9, 2.9, 2.9, 2.2, 0.7 y $0.7 \%$, respectivamente. Variables como edad, género, comorbilidades y exposición requirieron análisis por subgrupos. Conclusión: Esta casuística es similar a la de otros estudios en la literatura internacional y representa un gran aporte para estimar la frecuencia de este grupo de enfermedades en un centro de referencia nacional como lo es la UMAE del CMN «La Raza», IMSS. Hasta donde tenemos conocimiento éste representa el primer estudio que estima la prevalencia de EPID en pacientes del IMSS.

\section{Fijación de arcos costales por mínima invasión}

\section{Martínez AM, Díaz MJL, Menjivar ROM, Lara GRV, Téllez BJL, Loyola GU}

Centro Médico ISSEMYM Toluca

Introducción: La fijación costal como tratamiento de las fracturas costales es un procedimiento que hoy se realiza comúnmente, mejorando así la mecánica ventilatoria, disminuyendo el dolor, acortando su estancia hospitalaria y reintegra al paciente a sus actividades normales en menor tiempo. Objetivos: Presentar una técnica innovadora, modificando la descrita para fijación de arcos costales mediante los resultados analizados. Material y métodos: Se realizó un estudio retrospectivo, descriptivo, de serie de casos incluyendo a pacientes posoperados de fijación de arcos costales por mínima invasión en el período de agosto 2015 a enero 2017 en el Centro Médico ISSEMYM. Treinta y cinco pacientes posoperados de fijación de arcos costales por mínima invasión en dicho período. Se analiza el abordaje y resultados en posoperatorio. Resultados: En 35 pacientes se realizó esta técnica por mínima invasión, se analizaron los tiempos quirúrgicos con un promedio de 1 hora, en todos los casos se realizó exploración toracoscópica, el promedio de costillas fijadas fue de 4 por paciente, no se reportaron complicaciones como seromas de herida quirúrgica o reoperación, la estancia hospitalaria promedio fue de 3 días, el tiempo para reintegración de actividades promedio fue de 2 semanas para realizar actividad laboral normal. Conclusión: La fijación de arcos costales por mínima invasión es una técnica útil, viable, reproducible, la cual logra reducir 
considerablemente la estancia hospitalaria así como la disminución de complicaciones posoperatorias y dolor crónico por la baja manipulación de tejidos blandos. Aporte a la práctica clínica diaria: La fijación de arcos costales por mínima invasión ha mostrado mejoría en dolor posoperatorio, ha demostrado reducir de manera considerable la estancia hospitalaria.

\section{Asociación del insomnio crónico y síndrome de apnea/hipopnea obstructiva del sueño en pacientes con uso de presión positiva continua de la vía aérea}

Millán RG, Guerrero ChA, Cortés $B M C$, Santana VÁD, Barrera MA, Jiménez CJL

UNAM; Hospital Español; Hospital General de México

Introducción: El síndrome de apnea/ hipopnea obstructiva del sueño (SAHOS) es parte de los diagnósticos a considerar en pacientes con insomnio. La asociación entre ambos ha sido motivo de estudio y se ha demostrado que el insomnio tiene una alta prevalencia en pacientes con diagnóstico de SAHOS. Objetivos: Estudiar el efecto del uso de la presión positiva continua de la vía aérea (CPAP) sobre los síntomas de insomnio, calidad de sueño, somnolencia diurna, depresión, ansiedad, calidad de vida y SAHOS. Material y métodos: Estudio comparativo, prospectivo y longitudinal realizado en la Clínica de Trastornos de Sueño, Facultad de Medicina, UNAM, en una muestra de 35 pacientes $(27 / 8, \mathrm{H} / \mathrm{M})$, con edad promedio de 48.5 ( \pm DE 9.5 años). El análisis estadístico se realizó mediante las pruebas de Wilcoxon y McNemar. La significancia se determinó con un valor de $\mathrm{p}<0.05$. Resultados: Después del uso de CPAP se identificó una disminución significativa en la Escala Atenas de Insomnio (p $<0.001$ ), Escala de Somnolencia Epworth ( $\mathrm{p}<0.001)$, Índice de Calidad de Sueño Pittsburgh $(\mathrm{p}<0.001)$ y en la Escala de Depresión Hamilton $(\mathrm{p}<0.001)$. En el cuestionario de calidad de vida Quebec hubo aumento en todas las subescalas ( $\mathrm{p}$ $<0.001$ ). Conclusión: Dentro del primer mes de tratamiento con CPAP, los pacientes con insomnio comórbido presentaron una disminución de los síntomas nocturnos y diurnos asociados al SAHOS; así como un incremento en la calidad de sueño y de vida. Aporte a la práctica clínica diaria: Contribuir al desarrollo del conocimiento en la asociación de pacientes con síndrome de apnea/hipoapnea del sueño e insomnio, pudiendo establecer relación con factores que puedan intervenir en la presentación del insomnio, tales como desórdenes psiquiátricos, índice de apnea/hipoapnea, obesidad e índice de masa corporal.

\section{Comparación de estrés percibido, bienestar psicológico y adherencia terapéutica entre hombres y mujeres con insuficiencia cardiorrespiratoria}

Torres MSC, Peláez HV, Robles UB, Figueroa HFA, Orea TA, González ID, Jiménez CA, Navarrete PAG, Verdeja VL, Pérez CGK, Sánchez SRN, Pérez CE

INER Ismael Cosío Villegas

Introducción: Los pacientes con insuficiencia cardiorrespiratoria (ICR) comúnmente presentan comorbilidades psicológicas como ansiedad y depresión. A este respecto, la literatura ha descrito diferencias entre hombres y mujeres, teniendo éstas resultados más desfavorables. Sin embargo, hay variables psicológicas que no han sido exploradas y también podrían presentar diferencias entre sexos. Objetivos: Comparar los niveles de estrés percibido, bienestar psicológico y adherencia terapéutica entre hombres y mujeres con ICR. Material y métodos: Participaron 32 pacientes con ICR, quienes completaron las escalas: a) estrés percibido, b) bienestar psicológico y c) Cuestionario Martín-Bayarre-Grau para adherencia terapéutica. Estos consisten en escalas tipo Likert que evalúan la frecuencia con que el paciente experimenta eventos estresantes o bienestar psicológico y en qué medida realizan conductas relacionadas con adherencia terapéutica, respectivamente. Las variables presentaron una distribución normal, por lo que se utilizó la prueba t de Student para determinar las diferencias entre grupos. Quince pacientes masculinos de $68.86 \pm 15.52$ años y 17 pacientes femeninos de $71.29 \pm 10.73$ años de edad, con ICR estable. Resultados: No existieron diferencias significativas en la edad de hombres (G1) y mujeres (G2). Se encontraron diferencias estadísticamente significativas en los puntajes de estrés percibido entre hombres y mujeres (XG1 $=20.60 \pm 4.96, \mathrm{XG} 2=25.29 \pm 5.74 ; \mathrm{t}(30)$ $=-2.45, \mathrm{p}<0.05)$. A pesar de que no se encontraron diferencias significativas en los puntajes de los demás inventarios, los hombres obtuvieron puntajes más altos de bienestar psicológico $(\mathrm{XG1}=53.92 \pm$ $6.09, \mathrm{XG} 2=52.05 \pm 8.96)$ y adherencia terapéutica $(\mathrm{XG} 1=37.76 \pm 6.90, \mathrm{XG} 2=$ $35.08 \pm 10.42$ ). Conclusión: Las mujeres de esta muestra perciben niveles más altos de estrés y bienestar psicológico más bajo, además reportan menor adherencia al tratamiento en comparación con los hombres. Aporte a la práctica clínica diaria: Se sugiere que la intervención especializada para las mujeres sea prioritaria, debido a que todos estos indicadores representan factores de riesgo de acuerdo a lo reportado en la literatura.

Efecto funcional del polimorfismo $-197 \mathrm{G}>\mathrm{A}$ en la producción de IL-17A en respuesta a la cepa hipervirulenta HN878 del linaje Beijing de $\mathrm{M}$. tuberculosis

Espinosa SR, Regino-Zamarripa NE,
Muñoz-Torrico M, Salazar-Lezama
MÁ, Márquez-García E, García-
Sancho C, Mendoza-Milla C, Cruz-
Lagunas A, Jiménez-Álvarez LA,
Ramírez-Martínez G, Zúniga J

INER Ismael Cosío Villegas

Introducción: La respuesta inmune mediada por citocinas Th1/Th2 es insufi- 
ciente para el control de la infección por $M$. tuberculosis (Mtb), particularmente contra cepas más virulentas del linaje W-Beijing. IL-17 es crucial para el control de $M t b$ promoviendo la formación de granulomas funcionales. Se sabe poco del efecto de polimorfismos del promotor de IL-17A en la producción de esta citocina en respuesta a Mtb. Objetivos: Evaluar el efecto funcional del polimorfismo rs2275913 en la producción de IL-17A en respuesta a antígenos de $M t b$. Material y métodos: Se incluyeron 30 pacientes mexicanos con tuberculosis activa (TBA) y 30 controles con tuberculosis latente (TBL) Quantiferón positivo. Se evaluó la distribución del polimorfismo rs2275913, localizado en la posición -197 del promotor de IL-17A, por PCR en tiempo real. Se estimularon in vitro células mononucleares $(\mathrm{CMN})$ con antígenos de las cepas H37Rv, HN878 WBeijing, CFP-10 y ESAT-6. Los niveles de IL-17, IFN- $\gamma$ e IL-4 se cuantificaron por Luminex. Las diferencias se evaluaron con t de Student y U de Mann-Withney y valores p menor 0.05 fueron significativos. Resultados: El polimorfismo-197G/A no se asoció con susceptibilidad a TBA; sin embargo, se observó un efecto funcional de este polimorfismo en la tasa de expresión de IL-17A. Las CMN de pacientes con TBA con genotipo A/G mostraron una mayor producción promedio de IL17A (185 pg/mL) en relación con las de pacientes con genotipo G/G (100 pg/mL, p $=0.008$ ). Esto no se observó en individuos con TBL y la producción de IL-17A no tuvo diferencias en presencia de otros antígenos. Los antígenos de H37Rv y HN878 estimularon mayor producción de IFN- $\gamma$ en CMN de pacientes con TBA (p menor 0.05). Conclusión: La presencia del alelo A en la posición -197 del promotor de IL-17A condiciona mayor producción de esta citocina en respuesta a los antígenos de la cepa hipervirulenta HN878 del linaje W-Beijing de $M t b$. Aporte a la práctica clínica diaria: Predicción de reactivación de TBL.

Tuberculosis diseminada: Afección pleural, cerebral y peritoneal en un paciente

\section{pediátrico reporte a propósito de un caso}

Domínguez EMG, Ayala PCG, Morett OE, Gil VM, Zamarripa MKS, Paz GFJ, Zavaleta $A R$

HRAEB

Introducción: Existe cerca de un millón de casos por año de niños con tuberculosis (TB). La afección diseminada (miliar) ocurre en aproximadamente 0.1-3.5\%. Objetivos: Reporte caso inusual. Presentación del caso: masculino de 14 años; antecedentes consumo de lácteos no pasteurizados, inmunizaciones completas, abuela finada por tuberculosis pulmonar. Dos meses con distensión abdominal, saciedad temprana, pérdida de $7 \mathrm{~kg}$, fiebre, evento convulsivo tónico-clónico generalizado y derrame pleural bilateral. Con linfopenia; anticuerpos anti-CMV y HIV negativos; radiografía de tórax derrame pleural bilateral; PCR para Mycobacterium tuberculosis, cultivo y $\mathrm{KOH}$ negativo, baciloscopias jugo gástrico negativas, PPD $0.0 \mathrm{~mm}$, adenosin deaminasa normal. TAC cerebral encefalitis y zona isquémica región occipital izquierda; TAC abdomen engrosamiento peritoneal en pared anterior, infiltra cavidad pélvica; EEG con disfunción focal fronto-temporal izquierda. Aspirado de médula ósea, punción lumbar, broncoscopia con lavado bronquial, toma de biopsia de epiplón por ultrasonido, mielocultivo, PCR para Mycobacterium y tinción ZN negativa. Derrame pleural bilateral recurrente. Se realiza LAPE diagnóstica; reporta engrosamiento de epiplón; pieza con lesiones granulares de 3-4 mm diseminadas en peritoneo visceral, con necrosis caseosa, detección de Mycobacterium tuberculosis por GeneXpert, se inicia tratamiento antifímico fase intensiva y esteroide sistémico. Resultados: Tuberculosis diseminada. Conclusión: El conocimiento de la evolución natural se requiere para conocer la variabilidad y la susceptibilidad para los diferentes espectros de manifestaciones clínicas; La TB diseminada se presenta en menores de 3 años. Los hallazgos clínicos y radiológicos son los menos frecuentes presentados, la vasculitis e infartos cerebrales en este paciente se asocian a menos del $10 \%$ de todos los casos de TB en SNC, así como la presentación abdominal en su forma «seca». La importancia del diagnóstico es crucial para el tratamiento, la naturaleza no específica de los síntomas complica el diagnóstico. Aporte a la práctica clínica diaria: Considerar presentación inusual de tuberculosis diseminada.

\section{Broncoscopia pediátrica. Experiencia de 20 años en un hospital de tercer nivel}

\section{Ramírez FJL, López JEJ, Furuya $M M E Y$, Vargas $B M H$}

IMSS

Introducción: La broncoscopia es la herramienta intervencionista diagnóstico-terapéutica más utilizada en la práctica neumológica, su utilidad ha sido demostrada. Permite explorar las vías aéreas, obtener muestras biológicas y aplicar medidas terapéuticas. Objetivos: Evaluar la experiencia en broncoscopia realizadas en la Unidad de Endoscopia Respiratoria (UER) de la UMAE Hospital de Pediatría CMN Siglo XXI, durante 20 años. Material y métodos: Estudio observacional, retrolectivo y descriptivo de las broncoscopias realizadas de enero de 1995 a diciembre de 2014. Se analizó sexo, edad, lugar de realización, tipo de broncoscopia, indicación, diagnósticos endoscópicos y comorbilidades, maniobras diagnóstico-terapéuticas, complicaciones y utilidad. Se utilizaron frecuencias y porcentajes, se analizaron grupos con prueba de Kruskall-Wallis con corrección de Bonferroni y asociación entre dos variables dicotómicas con $\chi^{2}$. Resultados: Se analizaron 4,261 broncoscopias (98\% flexibles, $1 \%$ mixtas y $1 \%$ rígidas), $57 \%$ hombres, mediana de edad de 7 meses (60\% < 1 años). El $54 \%$ se realizó en la unidad de endoscopia y $42 \%$ en Unidades de Terapia Intensiva. Las principales indicaciones fueron atelectasia (22\%), anormalidades radiológicas persistentes (20\%), extubación fallida (15\%), supuración pulmonar $(15 \%)$ y estridor $(9.8 \%)$, 
entre otros. Se encontró un promedio de dos o más hallazgos por procedimiento, predominando los datos de inflamación, malacias y estenosis. Se realizaron maniobras diagnósticas $74 \%$ y terapéuticas $24 \%$, con un $27 \%$ de complicaciones ( $0.4 \%$ graves) predominando en pacientes con comorbilidades y menores de 2 años. Conclusión: La broncoscopia rígida y/o flexible mostró ser una herramienta útil y segura incluyendo al paciente prematuro y/o en estado crítico. Debe existir una indicación precisa, personal de salud experimentado e instrumental adecuado. Las complicaciones son leves y transitorias en la mayoría de los casos y más frecuentes en la broncoscopia rígida y en menores de 2 años. Aporte a la práctica clínica diaria: La broncoscopia rígida y/o flexible mostró ser una herramienta útil y segura.

\section{Comparación de la nebulización con mascarilla facial y boquilla utilizando dispositivo generador de aerosol tipo Mesh con cámara reservorio en pacientes con crisis asmática}

\section{Hernández CMA, Toral FSC, Reyes PA, García TR, Nava AJF, Mendoza RVM, Castañón RRP}

\section{INER-EFT-TR}

Introducción: Existen diferentes medios para administrar medicamentos inhalados como aerosol, nebulización, vaporización, evaporación, atomización, inhaladores de dosis medida presurizados, polvo seco. Objetivos: Comparar eficacia de nebulización con dispositivo tipo MESH con boquilla vs. mascarilla facial en pacientes asmáticos en urgencias del INER. Material y métodos: Estudio clínico, prospectivo, aleatorizado, transversal y observacional, 26 pacientes. Criterios de inclusión: 18 a 65 años, ambos géneros, en Urgencias con asma, indicado salbutamol nebulizado. Criterios de exclusión: Pediátricos, otros diagnósticos, sin espirometría basal, esteroide sistémico o algún otro fármaco inhalado, embarazadas, traqueotomía, alérgicos al salbutamol. Criterios de eliminación. Inestabilidad, esquema incompleto, más de 3 nebulizaciones, esteroide sistémico previo medición. Grupo I: Tipo MESH con boquilla. Grupo II. Tipo MESH con mascarilla. Espirometría basal con $\mathrm{FEV}_{1} / \mathrm{FVC}<70 \%$ o $<\mathrm{LIN}$, un

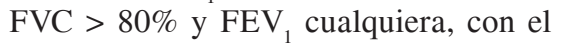
$\mathrm{FEV}_{1}<80 \%$, gravedad de la obstrucción según ATS. Análisis con SPSS 18.0 para Windows, se estimaron promedios y se compararon con $t$ de Student para muestras independientes. Resultados: 11 pacientes por grupo. En el grupo I, 4 (36\%) FEV < $70 \%$ (leve) y 7 (64\%) FEV $35-49 \%$ (grave). Aumento en saturación y frecuencia cardíaca posbroncodilatador. La media de la t de Student muestra: FEV 1.49 L y 2.33 L posbroncodilatador. FVC 2.24 L y 3.05 L posbroncodilatador. En el grupo II, 5 (45\%) FEV < 70\% (leve), 3 (27.5\%) $\mathrm{FEV}_{1}$ 60-69\% (moderada) y 3 (27.5\%) con $\mathrm{FEV}_{1}$ 35 a $49 \%$ (grave). Aumento fluctuante en saturación y frecuencia cardíaca. La media de la t de Student: FEV 1.85 L y $2.28 \mathrm{~L}$ posbroncodilatador, FVC 2.79 L y 3.18 L posbroncodilatador. Cambio estadísticamente significativo $(\mathrm{p}<0.0118)$ al comparar la media del porcentaje de la $\mathrm{FEV}_{1}$ y FVC de la boquilla contra la mascarilla. Conclusión: El micronebulizador tipo MESH demuestra ser más efectivo con promedio de reversibilidad mayor con boquilla (800 mL) comparando con mascarilla (400 $\mathrm{mL}$ ). Aporte a la práctica clínica diaria: La nebulización con dispositivo tipo Mesh es mejor con boquilla que con mascarilla ya que mejora $\mathrm{FEV}_{1}$ y FVC.

\section{Concordancia entre} el diagnóstico prequirúrgico y el anatomopatológico de las malformaciones congénitas pulmonares en un tercer nivel de atención López JZEJ, Ramírez JL, Rodríguez
VA, Furuya MMEY, Vargas BMH

IMSS
Introducción: Las malformaciones congénitas pulmonares (MCP), lesiones originadas durante el desarrollo pulmonar, pueden ser sintomáticas, asintomáticas o ser hallazgos de autopsia. En México, no hay estudios que evalúen la certeza del médico para realizar un diagnóstico prequirúrgico con base en la historia clínica, exploración física e imagen. Objetivos: Conocer la concordancia entre el diagnóstico prequirúrgico y el anatomopatológico de las MCP. Material y métodos: En la UMAE Hospital de Pediatría del CMN Siglo XXI se revisaron los expedientes y el informe de patología y citología de pacientes con diagnóstico de MCP de los últimos 10 años. Se analizó el tipo, edad al momento de la cirugía, localización de la lesión y diagnósticos prequirúrgico y anatomopatológico. Resultados: Se encontraron 39 estudios, 20 hombres (51.3\%); edad al diagnóstico 5 meses (de 1 día a 14 años); 4 pacientes con más de una malformación. Ochenta y siete por ciento unilobar predominando el LSD. Hubo sobreinfección bacteriana en $41 \%$. La malformación congénita de vía aérea (MCVA) fue la más frecuente $(79.5 \%)$ predominando el tipo $2(48.7 \%)$. Secuestro pulmonar (SP) se encontró en 6 niñas, con una mediana de edad de 15 días (mínimo 3 días, máximo 3 meses); 4 asociados con MCVA tipo 2 se sospechó y corroboró en 3 pacientes. Enfisema lobar congénito (ELC) se corroboró en 3 de 5 casos Los quistes broncogénicos (QB) se presentaron en 3 pacientes masculinos ( 2 de un mes de edad y uno de un año) en 2 se sospechó el diagnóstico previo a la cirugía. La Kappa y el IC 95\% para la correlación clínica prequirúrgica $v s$. el diagnóstico definitivo anatomopatológico fue de 0.72 (0.35-1.1) para ELC; de 0.64 (0.15-1.13) en QB; 0.43 (0.12-0.73) para MCVA y de 0.38 (-0.13-0.89) para SP. Conclusión: La MCVA tipo 2 fue la más frecuente; el LSD es el más afectado; la infección agregada alta. La concordancia clínica patológica fue mayor en ELC. Deberá analizarse si con las nuevas herramientas diagnósticas la concordancia se incrementa.

\section{Niveles circulantes elevados de MIR-150 se}




\section{asocian a desenlace fatal en pacientes con infección por influenza $\mathrm{A} / \mathrm{H} 1 \mathrm{~N} 1$}

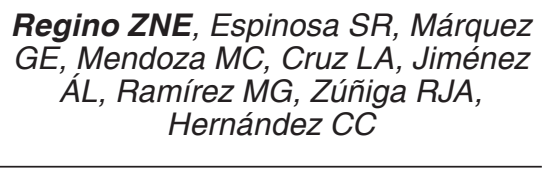

INER Ismael Cosío Villegas

Introducción: Además de otros factores de riesgo, una respuesta inflamatoria exacerbada y poco regulada contribuye con la patogénesis de neumonía grave por virus de influenza A/H1N1. Los microRNAs regulan inflamación y modelan la respuesta inmune innata contra los virus de influenza A. Sin embargo, su papel como biomarcadores de gravedad o mal pronóstico de la enfermedad no se conocen detalladamente. Objetivos: Evaluar niveles de microRNAs circulantes en pacientes con formas graves de neumonía. Material y métodos: Se incluyeron pacientes con neumonía grave por virus $\mathrm{A} / \mathrm{H} 1 \mathrm{~N} 1 \mathrm{de}$ la Unidad de Cuidados Intensivos (UCI) del INER: grupo 1: pacientes que sobrevivieron a la infección $(\mathrm{n}=9)$ y grupo 2 : pacientes con desenlace fatal $(n=17)$. Se obtuvieron muestras de sangre venosa periférica, una al ingreso de la UCI y al momento del desenlace, extubación o fallecimiento. Se aisló RNA total libre en suero por el método TRIZol, se sintetizó cDNA por RT-PCR y la expresión de miR-150 y miR-126 se cuantificó por PCR tiempo real. Las diferencias se analizaron con $\mathrm{U}$ de Mann-Whitney y valores $\mathrm{p}<0.05$ se consideraron significativos. Resultados: Se observaron diferencias significativas en edad, que fue mayor en pacientes con desenlace fatal en relación con sobrevivientes (51 años \pm 11 vs. 41 años $\pm 9, \mathrm{p}<$ $0.05)$ y género, con mayor mortalidad en varones $(\mathrm{p}<0.05)$. Se detectaron niveles significativamente más elevados de miR150 en ambos grupos de pacientes con A/H1N1 que fallecieron, en relación con pacientes que sobrevivieron $(\mathrm{p}=0.01)$. Se detectaron niveles bajos de expresión de miR-126 en ambas muestras en pacientes que fallecieron $(\mathrm{p}=0.04)$ y en los sobrevivientes se observó una baja expresión en la muestra inicial y una sobreexpresión en la

muestra final $(\mathrm{p}=0.04)$. Conclusión: Los pacientes con influenza grave por virus $\mathrm{A} / \mathrm{H} 1 \mathrm{~N} 1$ tienen niveles elevados de miR150 , incluso desde el momento en el cual ingresan a la UCI. Aporte a la práctica clínica diaria: miR-150 podría ser útil como biomarcador de desenlaces pobres.

\section{Enfisema lobar congénito una enfermedad poco frecuente en el adulto}

\section{Flores TF, Vega SÁE, Téllez NNA, Espinosa de los MC, Velazquez MA, Hernández ZRJ}

INER Ismael Cosío Villegas

Introducción: El enfisema lobar congénito (ELC) descrito por Nelson en 1932, es diagnóstico diferencial del pulmón hiperclaro, caracterizada por hiperinsuflación de los lóbulos pulmonares; su etiología no está descrita completamente. Pueden cursar con neumotórax recurrentes, con indicación de tratamiento quirúrgico. Objetivos: Presentar un caso raro de ELC en un adulto joven. Presentación del caso: Femenino de 30 años, inició desde la infancia con disnea y menor tolerancia al ejercicio intensificándose hace 3 años, cursó con 2 neumotórax derechos, manejados con sonda pleural. Acudió al INER para abordaje diagnóstico. A su ingreso refirió disnea mMRC3, sin otros datos, signos vitales normales, oximetría con $\mathrm{FiO}_{2} 21$ de $88 \%$. Clínicamente con síndrome de rarefacción pulmonar derecha. Resultados: Radiográficamente con hiperclaridad pulmonar derecha, con pulmón contralateral sin alteraciones. En las pruebas de función pulmonar CVF 1.76 1(50\%) y VEF1 1.41 (46\%). Pletismografía VR 219\%. Y difusión de CO 62\% (ajustado). Por imagen con enfisema panacinar del pulmón derecho, con gran desplazamiento hacia hemitórax contralateral, gammagrafía con exclusión funcional de pulmón derecho (ventilación $1.80 \%$, perfusión $0.84 \%$ ). Descartamos déficit de -1 antiripsina, ECOTT normal. Realizamos abordaje de pulmón hiperclaro, con afección del parénquima. Dando diagnóstico de síndrome de enfisema lobar congénito; actualmente en protocolo para neumonectomía derecha.
Conclusión: En adultos con hiperclaridad pulmonar unilateral, el abordaje diagnóstico es enfisema lobar congénito contra el síndrome de Swyer-James McLeod. No evidenciamos alteraciones cardíacas ni en vasos pulmonares; tomográficamente con enfisema unilateral sin bronquiolitis, y sin antecedentes de infecciones graves en la infancia, con disnea crónica, neumotórax derecho recurrente y exclusión pulmonar ipsilateral por gamagrafía pulmonar. Aporte a la práctica clínica diaria: $\mathrm{La}$ sospecha de ELC debe ser considerada en neonatos o niños que cursen hiperclaridad pulmonar con enfisema unipulmonar y/o neumotórax recurrente; extremadamente raro en adultos, como nuestra paciente, que con tratamiento quirúrgico mejoran sobrevida y calidad de vida.

\section{Afinidad de las NTPDAsas a nucleótidos extracelulares de adenosina en un modelo alérgico de cobayos}

Martínez ZJJ, Chávez J, Vargas BMH, Falfán-Valencia R, Ambrocio OE

UNAM; INER Ismael Cosío Villegas

Introducción: Las NTPDasas son enzimas encargadas de hidrolizar nucleótidos tridifosfatos extracelulares. Estas enzimas son importantes ya que regulan el tono vascular o muscular, inhiben la agregación plaquetaria o modulan el sistema inmunológico mediante la estimulación de receptores purinérgicos. Las NTPDasas se asocian a diversas patologías incluida el asma, aunque su participación no es clara. Objetivos: Investigar cómo se modifica la afinidad de las NTPDasas (NTPDasa1, NTPDasa3 y NPP1) y receptores (P2X1, P2X7, P2Y4, P2Y6) en un modelo animal sensibilizado a ovoalbúmina a nucleótidos de adenosina en leucocitos de cobayo y determinar en células mononucleares si hay una diferencia en la expresión genética que codifica NTPDasa y los receptores. Material y métodos: Se usaron leucocitos purificados de sangre periférica de cobayos machos sensibilizados y no sensibilizados $(\mathrm{n}=30)$. Se determinó mediante cinética enzimática a 
$2 \mathrm{~h}$ la actividad de las NTPDasas incubadas con diferentes concentraciones $(500,250 \mathrm{y}$ $125 \mu \mathrm{M}$ ) de nucleótidos de adenosina (ATP, ADP, AMP, adenosina) y timidina. En otro grupo de animales, se extrajo RNA total de células mononucleares para determinar la expresión de las NTPDasas y receptores mediante RT-PCR. Resultados: Se demostró que el proceso de sensibilización a OVA genera un incremento en la afinidad de las NTPDasas que hidrolizan tri o difosfatos extracelulares; sin embargo, no se vio incrementada la expresión de estas enzimas. Sólo el receptor P2X1 en sensibilizados se incrementó. Conclusión: Demostramos que la sensibilización a OVA aumentó la afinidad de las NTPDasas a nucleótidos de adenina tri o difosfato en este modelo animal, lo que supone un aumento en las concentraciones de ATP extracelular que se pudieran estar liberando. La respuesta del receptor P2X1 está aumentada como respuesta al aumento del ATP extracelular. Aporte a la práctica clínica diaria: Existen muchos tratamientos para el control de las crisis asmáticas, pero ninguna de ellas toma en cuenta a las NTPDasas como blanco terapéutico.

\section{Influencia de la diabetes sobre los niveles séricos de biomarcadores inmunológicos y su asociación con gravedad en pacientes con neumonía adquirida en la comunidad}

Báez SR, López EC, I Rumbo NU, Lascurain LR, Chávez GL, Escobar $R A$, Castillo GP, Gorocica RP

INER Ismael Cosío Villegas; UNAM

Introducción: En la diabetes hay defectos de la inmunidad y los sujetos con neumonía adquirida en la comunidad (NAC) y diabetes tienen mayor mortalidad comparada con los que no la tienen. Hay información escasa sobre las escalas de gravedad para neumonía asociada al estudio de biomarcadores en pacientes con diabetes. Objetivos: Comparar la concentración de biomarcadores inmunológicos y evaluar su asociación con los índices de gravedad en pacientes hospitalizados con NAC con y sin diabetes. Material y métodos: Estudio prospectivo transversal en pacientes hospitalizados con NAC con y sin diabetes. La gravedad de la neumonía se evaluó con las escalas PSI, CURB-65 y SMART-COP y se midieron los niveles séricos de citocinas proinflamatorias y reguladoras con el kit de Biorad sobre una plataforma Luminex. Se comparó la concentración sérica de las citocinas entre los pacientes diabéticos y no diabéticos y su correlación entre la puntuación de los índices de gravedad. Resultados: Se estudiaron 49 casos con NAC, 20 (40.82\%) con diabetes y 29 (59.18\%) sin diabetes. La concentración sérica de las citocinas y la puntuación de los índices de gravedad para NAC fue similar entre los casos de NAC con diabetes y sin diabetes. En el grupo de NAC con DM hubo correlación negativa entre el puntaje PSI y CURB-65 y los niveles séricos de TNFalfa, IL-2, IL-4, IL-8, IL10, IL-12, IL-15, FGF y VEGF. De igual manera hubo correlación negativa entre IL-4, IL-8, FGF, VEGF y albúmina y SMART-COP. Hubo correlación positiva entre el nivel sérico de glucosa e IL-12 y VEGF. En los pacientes con NAC sin diabetes hubo correlación negativa entre IP-10 y PSI, y entre TNF $\alpha$ y albúmina y SMART-COP. Conclusión: La diabetes preexistente no se correlaciona con la respuesta inmune inmediata; sin embargo, en los pacientes con diabetes se demostró una asociación potencial con la gravedad de la enfermedad.

\section{Secuestro pulmonar asociado a malformación congénita de la vía aérea pulmonar. Presentación de un caso clínico}

De León UZA, Sadowinski PS, Jamaica BLC, Penchyna GJ

Hospital Infantil de México Federico Gómez

Introducción: Las malformaciones congénitas de las vías aéreas inferiores son in- frecuentes. El uso del ultrasonido prenatal permite un abordaje precoz identificando la malformación en un $10 \%$ de los casos. El secuestro pulmonar es un segmento anormal de tejido broncopulmonar irrigado por una arteria anómala de origen sistémico. La malformación congénita de la vía aérea pulmonar es una alteración hamartomatosa del desarrollo pulmonar causada por el reemplazo de la pequeña vía respiratoria y el parénquima pulmonar por quistes. La asociación de ambas malformaciones es infrecuente. Presentación del caso: Femenino de 4 meses de edad. Se detecta lesión sugestiva de secuestro pulmonar a la semana 24 de edad gestacional, sometida a tratamiento quirúrgico intrauterino y en la semana 35 se reportó resolución del secuestro. En el Servicio de Neumología del Hospital Infantil de México Federico Gómez se realiza angiotomografía que muestra parénquima pulmonar heterogéneo por la presencia de una imagen de forma ovoidea, aspecto quístico. Vaso nutricio proveniente de la aorta segmento torácico a nivel de T11 que rodea la lesión y otro vaso proviene de las venas pulmonares izquierdas. Se realiza lobectomía y toracotomía posterolateral. Estudio histopatológico: Lóbulo inferior de pulmón izquierdo: secuestro pulmonar extralobar con malformación congénita de la vía aérea pulmonar tipo 2. Conclusión: La asociación de estas malformaciones se ha descrito en aproximadamente 40-60 casos. Los secuestros pulmonares representan un espectro de anomalías que se superponen con otras lesiones pulmonares, una de ellas es la MCVAP. Son consideradas lesiones híbridas, diagnosticadas únicamente por histopatología, por lo que se sugieren la existencia de un origen común para las MCVAP y los secuestros pulmonares. La sobrevida es favorable cuando son resecadas por cirugía. Aporte a la práctica clínica diaria: Con el diagnóstico de una de estas entidades se debe realizar estudios en busca de la otra incluida histopatología.

\section{Síndrome hepatopulmonar}

Velázquez GMV, Aguilar AA, Ruiz GHH, Hernández RR, Martínez BMC, Saucedo TJL, Sandoval RNN, Enrique Vargas BE, Irissont DJA, Oregón AAI

IMSS 
Introducción: El síndrome hepatopulmonar se caracteriza por hipoxemia debido a dilataciones intrapulmonares vasculares asociadas a disfunción hepática. El mecanismo exacto de las dilataciones es desconocido, la disminución del tono vascular se podría deber al desequilibrio entre agentes vasodilatadores y vasoconstrictores. Se caracteriza por: hipertensión portal con o sin cirrosis, hipoxemia y dilatación vascular intrapulmonar. Clínicamente presenta platipnea, ortodeoxia, acropaquias y cianosis. Objetivos: Presentar un caso de síndrome hepatopulmonar y revisión de la bibliografía. Presentación del caso: Masculino de 12 años, previamente sano, enviado por colestasis y hepatoesplenomegalia, ultrasonograma Doppler hepático con cirrosis. Durante su hospitalización con evidencia de acropaquias y desaturaciones valorado por cardiología con insuficiencia tricuspídea leve. A la exploración con cianosis central, sin dificultad respiratoria, campos pulmonares con rudeza y subcrepitantes bibasales. Satura en decúbito al aire ambiente $78 \%$, en bipedestación $68 \%$. Abdomen con telangiectasias, ascitis y hepatoesplenomegalia, extremidades con acropaquias. Gasometría con alcalosis respiratoria e hipoxemia. Tomografía de tórax con dilataciones vasculares bilaterales, ecocardiograma con contraste con evidencia de paso de microburbujas a cavidades izquierdas después del $8^{\circ}$ ciclo cardíaco. Cateterismo cardíaco sin evidencia de fístula arteriovenosa. Resultados: Como datos pivote en este paciente tiene hepatopatía, ortodeoxia, cianosis con acropaquias, con test de hiperoxia positivo por lo que se sospecha síndrome hepatopulmonar y ya que el estándar de oro es el ecocardiograma con contraste, se le realiza confirmando cortocircuito de derecha a izquierda. En la bibliografía se refiere una sensibilidad hasta $75 \%$ con especificidad de 93\%. Conclusión: El síndrome hepatopulmonar se presenta como complicación de dilataciones vasculares pulmonares que establecen cortocircuito de derecha a izquierda, el ecocardiograma con contraste es el estándar de oro, el tratamiento no farmacológico consiste en oxigenoterapia, el trasplante hepático es el único tratamiento efectivo con resolución de las dilataciones pulmonares a partir de los 3 meses postrasplante.

\section{Asociación de broncomalacia a síndrome de Ehlers-Danlos}

Silva CTM, del Razo RR, Aguirre PT

INER Ismael Cosío Villegas

Introducción: La broncomalacia es la colapsabilidad de la pared bronquial. Puede ser primaria debido a la debilidad congénita o malformación de los anillos cartilaginosos causando un colapso anterior contribuyendo a la intrusión posterior de la vía aérea; la secundaria es la forma más común y es causada por degeneración de los cartílagos, se asocia a lesiones torácicas como son anillos vasculares o tumores. Es más frecuente en prematuros pero también se puede encontrar asociada a síndromes como es el Ehlers-Danlos. Objetivos: Describir dos casos de broncomalacia en pacientes con Ehlers-Danlos. Material y métodos: Revisión de expedientes e imágenes broncoscópicas de dos pacientes con Ehlers-Danlos. Presentación de los casos. Femenino y masculino de 10 y 8 años de edad respectivamente, con exposición a biomasa. Diagnóstico de síndrome de Ehlers-Danlos a los 7 y 6 años, cursan con múltiples luxaciones en diferentes articulaciones, hospitalizaciones en varias ocasiones por crisis asmáticas. Se ingresan a nuestro instituto para estudio de asma de difícil control, durante su estancia se realizan pruebas de función pulmonar reportadas normales, espirometrías sin obstrucción sin respuesta a broncodilatador. Resultados: Se realiza broncoscopia reportándose en paciente femenino broncomalacia del bronquio principal izquierdo $(50 \%)$ y en el paciente masculino se reporta del bronquio del lóbulo inferior ipsilateral (70\%). Conclusión: Existe muy poca literatura en pacientes pediátricos y sus alteraciones a nivel respiratorio; se ha observado que estos pacientes suelen tener síntomas respiratorios recurrentes debido a alteraciones de tejido conectivo atribuidos de manera inadecuada a asma o concomitantes. $\mathrm{Al}$ abordar pacientes con Ehlers-Danlos y sibilancias persistentes, encontramos que existen otras etiologías causantes como disfunción de cuerdas vo- cales, compresión de vía aérea secundaria a alteraciones vasculares y broncomalacia como en nuestros pacientes, aunque la asociación es inferior al 5\%. Aporte a la práctica clínica diaria: Es importante realizar broncoscopia a los pacientes con síndrome de Ehlers-Danlos y sibilancias persistentes o asma de difícil control para descartar anomalías estructurales o dinámicas.

\section{Comparación de la calidad de vida relacionada con la salud entre pacientes con insuficiencia cardiorrespiratoria y diferentes niveles de disnea}

Torres MSC, Orea TA, Pelaez HV, Figueroa HFA, Robles UB, Pérez CE, González ID, Navarrete PAG, Verdeja VL, Jiménez CAG, Sánchez SRN, Pérez CGK

INER Ismael Cosío Villegas

Introducción: La disnea es un síntoma común entre pacientes con insuficiencia cardiorrespiratoria (ICR). Su presencia se asocia con menor calidad de vida. Sin embargo, no se conocen estudios que describan el impacto de la disnea en la calidad de vida según la severidad del síntoma al realizar actividad física de bajo impacto. Objetivos: Comparar los puntajes del Cuestionario SF-12 y sus subescalas entre pacientes con diferentes niveles de disnea durante la prueba de caminata de 6 minutos (PC6M) de acuerdo con la Escala Borg para disnea. Material y métodos: Participaron 22 pacientes con ICR quienes completaron el Cuestionario de Salud SF-12 y la PC6M. El SF-12 comprende 8 dimensiones: función física, función social, rol físico, rol emocional, salud mental, vitalidad, dolor corporal y salud general. Se utilizaron los resultados de la Escala Borg para dividir la muestra en: G1) quienes reportaron de 0 a 2 (nada a muy ligero), y G2) quienes reportaron de 3 a 5 (ligero a un poco pesado). Se utilizó U de Mann-Whitney para determinar las 
diferencias entre grupos. Resultados: 13 pacientes ambulatorios (50\% mujeres) de $71.07 \pm 10.92$ años reportaron disnea de 0 a 2, y 9 (54.5\% mujeres) de $68.27 \pm 15.95$ años, de 3 a 5 . No existieron diferencias estadísticamente significativas en la edad y sexo entre los grupos. Se encontraron diferencias en el puntaje total del SF-12 $(\mathrm{XG} 1=70.76 \pm 23.35, \mathrm{XG} 2=50.13 \pm 21.21$; $\mathrm{z}=-2.06, \mathrm{p}<0.05), \mathrm{y}$ en las subescalas función física $(X G 1=67.30 \pm 34.43, X G 2$ $=22.22 \pm 19.54$; $\mathrm{z}=-2.80, \mathrm{p}<0.01)$ y función social $(\mathrm{XG1}=82.69 \pm 27.73, \mathrm{XG} 2=$ $48.88 \pm 41.59 ; \mathrm{z}=-2.08, \mathrm{p}<0.05)$. Aunque no hubo diferencias significativas en las otras subescalas, el grupo con mayor nivel de disnea obtuvo puntajes más bajos, lo cual indica mayor deterioro. Conclusión: Los pacientes que perciben mayor nivel de disnea tienen menor calidad de vida asociada a la salud, lo cual impacta de manera significativa en su vida cotidiana. Aporte a la práctica clínica diaria: Se recomienda la implementación de un tratamiento interdisciplinario acorde a las necesidades de los pacientes.

\section{Comparación de la calidad de vida y la autoeficacia percibida entre cuidadores de pacientes con insuficiencia cardíaca y cuidadores de pacientes con insuficiencia cardiorrespiratoria}

Torres MSC, Pelaez HV, Figueroa HFA, Pérez CE, Robles UB, González $I D$, Verdeja VL, Jiménez CAG, Navarrete PAG, Pérez CGK, Orea TA, Sánchez SRN

INER Ismael Cosío Villegas

Introducción: Ser cuidador primario informal (CPI) de un paciente con insuficiencia cardíaca (IC) afecta negativamente la salud. Se cree que este deterioro depende principalmente de las características de los CPI, no tanto de las de los pacientes. Sin embargo, los pacientes con IC presentan comorbilidades como la enfermedad pulmonar obstructiva crónica, generando insuficiencia cardiorrespiratoria (ICR). No se conocen estudios que comparen las características de salud de los CPI de pacientes con IC y las de CPI de pacientes con ICR. Objetivos: Comparar la calidad de vida relacionada con la salud y la autoeficacia percibida entre CPI de pacientes con IC y CPI de pacientes con ICR. Material y métodos: Participaron 36 CPI de pacientes con IC (G1) oI CR (G2), quienes completaron el Cuestionario de Salud SF-12 y la Escala de Autoeficacia Percibida en Cuidadores Primarios Informales de Enfermos Crónicos. El primero comprende 8 dimensiones: función física, función social, rol físico, rol emocional, salud mental, vitalidad, dolor corporal, salud general. La escala clasifica la Autoeficacia como baja, moderada y alta. Se utilizó U de Mann-Whitney para determinar diferencias entre grupos. Presentación del caso: 18 CPI de $55.50 \pm 12.22$ años (77.8\% mujeres) cuidaban pacientes con IC controlada, y 18 CPI de $55.83 \pm 12.90$ años (77.8\% mujeres) cuidaban a pacientes con ICR controlada. Resultados: Se encontraron diferencias significativas en las dimensiones salud general $(\mathrm{XG1}=66.39 \pm$ 21.20, $\mathrm{XG} 2=50 \pm 27.11 ; \mathrm{U}=96, \mathrm{p}<0.05)$ y salud mental $(\mathrm{XG} 1=77.03 \pm 21.62, \mathrm{XG} 2$ $=64.81 \pm 16.41 ; \mathrm{U}=99, \mathrm{p}<0.05)$ del SF12 , y en la autoeficacia percibida $(\mathrm{XG1}=$ $100.44 \pm 8.64, \mathrm{XG} 2=80.39 \pm 28.32 ; \mathrm{U}=$ $85, \mathrm{p}<0.05)$. Para ambos inventarios un puntaje más bajo indica mayor deterioro. Conclusión: Los CPI de pacientes con ICR presentan una salud general y mental más deteriorada, y se perciben menos eficaces en comparación con los CPI de pacientes con IC. Aporte a la práctica clínica diaria: Se sugiere que la intervención para los CPI de pacientes con ICR sea prioritaria y les brinde habilidades de cuidado y de solución de problemas que incrementen su salud y autoeficacia.

\section{Cambios fisiológicos} pulmonares de la neumonectomía. Una complicación quirúrgica huérfana
Juárez LJE, Guerrero ZS

INER Ismael Cosío Villegas

Introducción: La neumonectomía se realiza desde finales del siglo XIX. Pocos reportes describen el estado funcional pulmonar a largo plazo en patologías benignas. Presentación del caso: Mujer de 42 años de edad con múltiples visitas a urgencias en los últimos 9 años por disnea y sibilancias, con antecedente de neumonectomía izquierda (1993) a sus 20 años de edad tras un accidente automovilístico; HAS en 1994; asma y trastorno depresivo en 2004; en 2008 hipertensión pulmonar (EcoTT), hipertensión gestacional y parto pretérmino por oligohidramnios. Desarrolló insuficiencia respiratoria postparto que requirió ventilación mecánica invasiva y apoyo vasopresor por cor pulmonale crónico agudizado. Se documentó traqueobroncomalacia con desplazamiento mediastinal izquierdo. Tratado como TEP sin evidencia en angiotomografía, con evolución hacia la mejoría. Egresó en condiciones estables. Actualmente con disnea mMRC3. La evolución funcional durante 7 años inicia en 2005 con obstrucción muy grave (CVF1.29L, 42\%p y VEF1 0.85 L, 32\%p) con caída anual 21 mL VEF1, $24 \mathrm{~mL}$ CVF y pérdida total VEF1 150 mL (-18\%) y 170 mL CVF (-13\%). Pletismografía 2005: CPT 60\%p y VR 71\%p. Gases arteriales hipoventilación crónica con compensación metabólica, equilibrio ácido-base. Resultados: El síndrome postneumonectomía es una complicación tardía tras el primer año, caracterizada por disnea, estridor inspiratorio e infecciones pulmonares recurrentes. Condiciona cambios fisiológicos cardiopulmonares: un hemidiafragma paralizado con pérdida de volúmenes espiratorios caracterizado por patrón obstructivo, principalmente tras neumonectomía derecha. Hiperinsuflación del pulmón residual, con mayor disminución de CPT que de VR. La disminución de la capacitancia vascular pulmonar aumenta el trabajo del VD deteriorando su función. Hasta un $40 \%$ de pacientes elevan PSAP de manera leve a moderada. La intervención farmacológica es deseable y puede iniciarse de manera temprana. Conclusión: El seguimiento regular con 
PFR y ecocardiografía podría disminuir la morbilidad de la adaptación cardiopulmonar tras la neumonectomía, permitiendo la detección oportuna de complicaciones.

\section{Timectomía por abordaje toracoscópico uniportal como tratamiento para miastenia gravis}

\section{Menjivar ROM, Díaz MJL, Martínez $A M$, Lara GVR, Romero DFN, Hernández-Arenas $L A$ \\ Centro Médico ISSEMYM; Centro Médico ISSEMYM Toluca}

Introducción: El timo ya no es solamente una estructura en el mediastino anterior con actividades dudosas para el cuerpo humano, ha resultado ser el único origen de elementos celulares que controlan la respuesta inmune dando protección en contra de patógenos que son amenaza mortal. Su función primaria es la siembra periférica de células T maduras, las cuales mantienen su población gracias a la autorreplicación. Objetivos: Presentar un video donde se demuestre la factibilidad del acceso toracoscópico uniportal para la realización de timectomía. Presentación del caso: Femenino de 35 años de edad, con antecedente crónico degenerativo de miastenia gravis de 7 años de evolución con tratamiento farmacológico. Antecedentes quirúrgicos negados. Alérgica a la penicilina, con historia de tratamiento médico de seis años de evolución. Se solicita tomografía de tórax contrastada en la cual se observa timo de dimensiones normales y aspecto nodular, por lo que se decide exploración quirúrgica mediante toracoscopia. Resultados: Con protocolo preoperatorio se realiza toracoscopia diagnóstica encontrando timo de aproximadamente $7 \times 6 \mathrm{~cm}$, de aspecto nodular. Se realiza timectomía presentando sangrado aproximado de $70 \mathrm{~cm}^{3}$, se explora hasta visualizar pleura contralateral y vena innominada. Se coloca sonda de pleurostomía tipo kardia spiral dirigido a lecho quirúrgico. Se afronta tejido celular subcutáneo con vycril 2-0, se afronta piel y se fija sonda endopleural. Conclusión: La protocolización adecuada, diagnóstico temprano y abordaje apropiado son la clave para el manejo toracoscópico uniportal, aprovechando los beneficios como menor incidencia de complicación con herida quirúrgica, mejor resultado cosmético, reduccion de dolor posoperatorio.

\section{Neumonía comunitaria} necrotizante y absceso pulmonar por Raoultella $s p$, en paciente diabético. Una etiología poco común e insospechada. Reporte de caso en México

\section{Toledo J, García HS, Alejo CJH, Lozada RP}

IMSS; Benemérita Universidad Autónoma de Puebla

Introducción: La neumonía comunitaria persiste dentro de las 10 causas de muerte en nuestro medio. Los diabéticos son más susceptibles a complicaciones debido a su inmunocompromiso. Raoultella $s p$ es un patógeno humano raro, existen menos de un centenar de casos de infección por esta bacteria reportados en la literatura, lo que lo hace un agente necesario de identificar. Objetivos: Describir caso clínico y revisión de la literatura. Presentación del caso: Mujer de 57 años, obesa, hipertensa y diabética descontrolada, sin inmunizaciones. 3 semanas con tos productiva, expectoración abundante, fétida y purulenta; fiebre oscilante, dolor pleurítico derecho y disnea progresiva. Ingreso con respuesta inflamatoria sistémica, pulsioximetría $82 \%$, vómica, condensación derecha, estado hiperosmolar, leucocitosis, BAAR negativo. Radiografía con consolidación multisegmentaria derecha y múltiples niveles hidroaéreos, datos de neumonía necrotizante y absceso pulmonar en la TACAR, cultivo de expectoración: Raoultella $s p$. Terapia empírica con levofloxacino y clindamicina, con base en resultados de cultivo y sensibilidad bacteriológica se completó terapia con quinolona por 14 días, con evolución clínica y radiológica satisfactoria. Caso clínico. Conclusión: Dentro de las complicaciones de la neumo- nía comunitaria encontramos a la necrosis del parénquima pulmonar y al absceso pulmonar, actualmente considerados como parte de un continuum secundario a la infección microbiana. El absceso pulmonar es causado frecuentemente por bacterias anaerobias. Klebsiella pneumoniae tiene mayor incidencia en pacientes inmunocomprometidos. El género Raoultella $s p$ es un bacilo gramnegativo aerobio de la familia entereobacteriacea, estrechamente relacionada con Klebsiella sp. Raoultella $s p$ ha adquirido importancia como agente emergente de diversas infecciones en el ser humano, en ocasiones suele ser drogorresistente; en las vías respiratorias se reporta muy poco en la literatura. Aporte a la práctica clínica diaria: El diagnóstico y tratamiento oportuno de las infecciones respiratorias por el género Raoultella $s p$ es de importancia médica por su potencial riesgo de complicaciones y drogorresistencia, sobre todo en población susceptible como los diabéticos.

\section{Ángulo de fase (biompedancia eléctrica por análisis vectorial) como predictor de estancia hospitalaria prolongada}

Hernández-Zenteno R, VerdejaVendrell L, González ID, Orea-Tejeda A, Velázquez-Montero A, NavarretePeñaloza AG, Sánchez-Santillán R, Jiménez-Cepeda A, Pérez-Cortés GK, Flores-Trujillo $F$

INER Ismael Cosío Villegas

Introducción: El ángulo de fase es indicador de integridad y funcionalidad de la membrana celular, así como de desnutrición y fragilidad, predictor de estancia hospitalaria prolongada en pacientes con sepsis, cáncer y cirrosis, resultados adversos después de la cirugía cardíaca y mortalidad en pacientes con insuficiencia cardíaca (IC). Sin embargo, en pacientes con IC y respiratoria (R) no se ha explorado el efecto del ángulo de fase sobre las estancias hospitalarias prolongadas. Objetivos: Determinar si el ángulo de fase es un factor de riesgo 
para estancia hospitalaria prolongada en pacientes con IC y R. Material y métodos: Estudio transversal en pacientes mayores de 18 años hospitalizados por diagnóstico confirmado de IC y R. Se definió estancia hospitalaria prolongada 7 días, mientras que el punto de corte para el ángulo de fase fue de 4.5. Se realizó una regresión logística para determinar el riesgo de estancia hospitalaria prolongada en relación a un ángulo de fase bajo. Resultados: Se incluyeron 43 sujetos con una edad de $54.02 \pm 21.76$ años, el $26.3 \%$ fueron hombres, los pacientes con estancia hospitalaria prolongada tuvieron mayor prevalencia de EPOC (52.6 vs. $10.2 \%, \mathrm{p}=0.005), \mathrm{IC}(42.1 \%$ vs. $10.5 \%, \mathrm{p}=0.027)$ y menor ángulo de fase $(4.63 \pm 1.38$ vs. $5.78 \pm 1.56 \%$, p $=0.022$ ) comparado con los pacientes con estancia hospitalaria corta. No se encontraron diferencias entre los grupos en agua corporal total, agua extracelular y otras comorbilidades como hipertensión arterial, diabetes mellitus, obesidad y nefropatía. Los sujetos con ángulo de fase < 4.5\&ordm; tuvieron 7 (OR: 7.65, CI $95 \%$; 1.37-42.71, p = 0.020) veces el riesgo de tener una estancia hospitalaria prolongada. Conclusión: Un ángulo de fase menor a 4.5 se asocia a mayor estancia hospitalaria prolongada en pacientes con IC y R. Aporte a la práctica clínica diaria: Método para identificar de forma rápida y simple a pacientes en riesgo de estancia hospitalaria prolongada.

\section{Circunferencia de cuello como predictor de hipertensión arterial}

\section{Jiménez-Cepeda A, González $I D$, Orea-Tejeda A, Pérez-Cortés $G$, Verdeja-Vendrell $L$, Navarrete- Peñaloza AG, Sánchez-Santillán $R$, Peláez-Hernández V, Robles-Uribe $B$, Figueroa-Herrera A, Torres-Montiel S}

INER Ismael Cosío Villegas

Introducción: La circunferencia de cuello (CC) es un método antropométrico simple, confiable, no invasivo y de bajo costo. Ha sido relacionado con obesidad y riesgo metabólico, ya que es depósito de grasa ectópica responsable de gran liberación de ácidos grasos libres sistémicos. Se ha encontrado una relación entre la CC y la hipertensión arterial (HTA). Sin embargo, se desconoce cuál es el incremento de la presión arterial (PA) por centímetro de incremento de la CC. Objetivos: Determinar cuánto incrementa la PA por aumento de la CC. Material y métodos: Estudio transversal. Se incluyeron sujetos mayores de 18 años aparentemente sanos. Sujetos con diabetes e HTA fueron excluidos. Se evaluó el peso, talla, índice de masa corporal, CC y PA. Resultados: Se reclutaron 54 sujetos de 49 \pm 13.3 años, $55.5 \%$ mujeres. Los hombres tuvieron mayor peso $(83.58 \pm 10.6 v s .74 .2$ $\pm 14.1 \mathrm{p}=0.01)$, estatura $(1.7 \pm 0.4 v s .1 .5$ $\pm 0.06, \mathrm{p}<0.001), \mathrm{CC}(40.7 \pm 2.2$ vs. 35.4 $\pm 2.3,<0.001)$, PA sistólica (PAS) (132 \pm 14.4 vs. $119.5 \pm 19.1, \mathrm{p}=0.011)$, PA diastólica (PAD) (80.1 \pm 7.9 vs. $72.2 \pm 11.6, \mathrm{p}$ $=0.006$ ) que las mujeres. De acuerdo con la regresión lineal se observó que por cada centímetro de CC incrementa $2.5 \mathrm{mmHg}$ la PAS, ( $\beta: 2.5$, CI 95\%, 1.2 a 3.7, p < 0.001) y 1.6 la PAD ( $\beta$ : $1.6,95 \%$ CI, 0.9 a 2.3 , p $<0.001$ ) ajustado por sexo. Además, por cada kilogramo de peso, la PAS incrementa $0.5 \mathrm{mmHg}(\beta: 0.5$, CI 95\%, 0.2 a $0.8, \mathrm{p}$ $=0.002)$ y $0.4 \mathrm{mmHg}$ la PAD $(\beta: 0.5, \mathrm{CI}$ 95\%, 0.2 a 0.8, p = 0.002). Conclusión: Por cada centímetro de CC incrementó $2.5 \mathrm{mmHg}$ la PAS y $1.6 \mathrm{mmHg}$ de PAD. Aporte a la práctica clínica diaria: $\mathrm{La}$ $\mathrm{CC}$ es un método simple y confiable se correlaciona con un incremento de la PA.

\section{Epidemiología y manejo del empiema torácico por absceso hepático}

\section{Reyna SF, García HS, Hernández GM, Sinsel AJ, Pérez RE, Muñoz MG, Wong JM}

Hospital Universitario «Dr. José Eleuterio González», Universidad Autónoma de Nuevo León

Introducción: El absceso hepático se clasifica en amebiano y piógeno. La causa más frecuente es amebiano según estudios realizados. El empiema es una complicación de neumonía pero puede surgir de una infec- ción a nivel hepático. Objetivos: Determinar la epidemiología y evaluar el manejo de empiema por absceso hepático en pacientes del norte de México. Material y métodos: Se realizó una revisión de esta casuística en el Hospital Universitario «Dr. José Eleuterio González» del 2011 a 2015 con diagnóstico de absceso y empiema. Resultados: Se presentan 24 pacientes, 6 masculinos y 14 femeninos, edad promedio de 33.9años, 10 (42\%) con diabetes mellitus y 2 con hipertensión arterial; tiempo de hospitalización de 20 días. El síntoma más común fue dolor abdominal en 18 (75\%) pacientes, fiebre y escalosfríos en 16 (67\%), disnea en 12(50\%), y la etiología amebiana con seroameba positiva en 4 (16\%). Cultivos positivos 5 Klebsiella p., 4 Estreptococcus, 3 E.coli y 2 E. faecalis. En estudios de imagen el tamaño promedio del absceso fue $4.4 \mathrm{~cm}$ con localización en lóbulo hepático derecho 18 (75\%). Se colocó sonda de toracostomía derecha en 24 pacientes y 4 bilaterales. Se egresaron 12 pacientes sin sonda y 10 con sonda. Se les colocó sonda de toracostomía para drenaje de empiema, se les realizó toracoscopia a 14 (58\%). Mortalidad de 8\%. Conclusión: La presentación de los casos fue tardía, la prevalencia de Klebsiella pneumonie con cuadros clínicos inespecíficos explica el retraso en el diagnóstico. Para el manejo del empiema se utiliza la sonda de toracostomía y toracoscopia demostrando ser útil en todas las fases de empiema. Reportamos una mortalidad más baja que la establecida. Aporte a la práctica clínica diaria: Es fundamental conocer la presentación de absceso hepático con la finalidad de diagnosticar de forma temprana y asi evitar complicaciones como el empiema, disminuyendo la morbimortalidad de nuestros pacientes.

\section{Composición corporal en pacientes con insuficiencia cardíaca y enfermedad pulmonar obstructiva crónica}

Navarrete-Peñaloza A, González

ID, Orea-Tejeda A, Verdeja-Vendrell

L, Jiménez-Cepeda A, Pérez-Cortés G, Sánchez-Santillán R, Peláez-

Hernández V, Robles-Uribe B, Figueroa-Herrera A, Torres-Montiel S

INER Ismael Cosío Villegas 
Introducción: Los pacientes con insuficiencia cardíaca (IC) y enfermedad pulmonar obstructiva crónica (EPOC) tienen desequilibrio en la función endotelial y el metabolismo, que favorece un estado procatabólico que se asocia con la progresión de la enfermedad. También alta prevalencia de caquexia caracterizada por disminución de masa muscular y tejido adiposo. La caquexia y el ángulo de fase se asocian a mal pronóstico en ambas poblaciones. Sin embargo, existe poca evidencia acerca de la composición corporal de los pacientes en los que coexiste IC y EPOC. Objetivos: Evaluar la composición corporal en pacientes con IC y EPOC vs. pacientes con EPOC. Material y métodos: Estudio transversal donde se incluyeron 77 sujetos mayores de 18 años de edad, con diagnóstico establecido de IC y/o EPOC. Los sujetos con asma fueron excluidos. La composición corporal se evaluó mediante el análisis vectorial de impedancia bioeléctrica (BIVA). La función endotelial fue evaluada mediante la fotopletismografía. Resultados: Se aleatorizaron 77 sujetos (edad media: $71.2 \pm$ 11.57 años) en $69.43 \%$ con EPOC y $30.57 \%$ IC y EPOC. Los sujetos con IC y EPOC tuvieron mayor prevalencia de DM (21.6 vs. 9.5, $\mathrm{p}=0.07$ ), hipertensión pulmonar (HAP, 29.7 vs. 9.5, $\mathrm{p}=0.005$ ), síndrome de apnea obstructiva del sueño (SAOS: $35.1 \mathrm{vs.}$ 10.7, $\mathrm{p}=0.001$ ) comparado con los sujetos que únicamente tuvieron EPOC. No hubo diferencia significativa en otras variables. Se encontró caquexia en $57.1 \%$, obesidad del $20.8 \%$ y con composición corporal normal del $22.1 \%$. Los pacientes con IC y EPOC tuvieron menor ángulo de fase (4.15 \pm 1.2 vs. $4.73 \pm 0.89, \mathrm{p}=0.05)$ y mayor disfunción endotelial $(0.361 \pm 0.086 v s$. $0.325 \pm 0.064, \mathrm{p}=0.035)$, menor cantidad de agua corporal total $(46 \pm 8.23$ vs. 51.06 $\pm 8.64, \mathrm{p}=0.019)$ y mayor extra celular (3.12 vs. 3.03, $\mathrm{p}=0.006$ ), comparado con los pacientes con EPOC. Conclusión: La composición corporal en pacientes IC y EPOC muestra un mayor deterioro, lo que favorece un peor pronóstico. Aporte a la práctica clínica diaria: Este estudio muestra las alteraciones en la composición que presentan los pacientes con IC y EPOC.

\section{La composición corporal como riesgo}

de hospitalizaciones prolongadas en pacientes con insuficiencia cardíaca y/o respiratoria

Leslie Verdeja-Vendrell L, González ID, Belmontes-Barraza JR, OreaTejeda A, Navarrete-Peñaloza AG, Jiménez-Cepeda A, Espinosa de los MC, Pérez-Cortés GK, Juárez-León E, Sánchez-Santillán $R$

INER Ismael Cosío Villegas

Introducción: El músculo esquelético pierde anualmente del $0.1-0.5 \%$ de su masa a partir de los 30 años, y es mayor a partir de los 65 años. La composición corporal se ha identificado como predictor de estancias hospitalarias prolongadas en diferentes poblaciones, la desnutrición prolonga, los días de hospitalización y ésta, a su vez, la morbimortalidad. Sin embargo, en los pacientes con insuficiencia cardíaca y respiratoria (IC y R) se desconoce el efecto de la composición corporal (CC) sobre hospitalizaciones prolongadas. Objetivos: Evaluar si existe asociación entre la composición corporal y estancia hospitalaria prolongada. Material y métodos: Estudio trasversal que incluyó pacientes mayores de 18 años hospitalizados por el diagnóstico confirmado de IC y/o (IR). La estancia hospitalaria prolongada se definió como mayor de 7 días. El análisis de la CC se realizó mediante impedancia eléctrica por análisis vectorial (BIVA) y se clasificó en composición normal, obesidad y caquexia. Se realizó una regresión logística para determinar el riesgo de hospitalización prolongada de acuerdo la CC. Resultados: El $71.7 \%$ de la población eran mujeres (edad, $54.6 \pm 21.18$ ), el $68.4 \%$ tuvo una estancia hospitalaria prolongada. Aquellos con estancia hospitalaria prolongada tuvieron mayor prevalencia de EPOC $(56.5 \%$ vs. $18.2 \%, \mathrm{p}=0.008)$, IC (45.8\% vs. $22.7 \%$, p $=0.100)$. El riego de tener estancia hospitalaria prolongada de acuerdo a la CC fue: obesidad (OR: 4.68, CI 95\%, 1.04-21.03, $\mathrm{p}=0.044)$ y caquexia (OR: 5.85, CI 95\%, 1.22-27.99, $\mathrm{p}=0.027$ ) comparado con los sujetos con composición corporal normal. Conclusión: La obesidad o caquexia incrementan el riesgo de hospitalizacio- nes prolongadas en pacientes con IC y/o respiratoria. Aporte a la práctica clínica diaria: La evaluación de la composición corporal es un método útil para identificar sujetos en riesgo de estancias hospitalarias prolongadas.

\section{Linfoma non Hodgkin primario de pulmón}

\section{Arriola NLM, Iñiguez GMA}

INER Ismael Cosío Villegas

Introducción: Los linfomas primarios de pulmón (LPP) son tumores confinados al pulmón, sin afección de ganglios mediastinales y sin evidencia de extensión extratorácica durante los tres meses posteriores al diagnóstico. Son considerados infrecuentes, constituyen el $0.3 \%$ de todos los tumores malignos de pulmón y el $0.5 \%$ de todos los linfomas. Sus manifestaciones clínicas consisten en síntomas respiratorios (tos y disnea), y generales (astenia, pérdida de peso, etc.), que suelen adjudicarse a otras enfermedades más frecuentes. Asimismo, las manifestaciones radiológicas y tomográficas pueden ser interpretadas como procesos infecciosos o tumorales. Debido a esto, se ha descrito un retraso de 5 meses a 8 años para llegar al diagnóstico. Objetivos: Reporte de caso de Linfoma non Hodgkin primario de pulmón. Material y métodos: Se realizó la revisión de estudios de gabinete (laboratorios, tomografias y gammagrafia V/Q) además del expediente clínico. Presentación del caso: Paciente de sexo masculino de 27 años de edad. Estudiante. Sin antecedentes familiares de importancia. Antecedentes personales no patológicos: Número de parejas sexuales 4 con orientación a la homosexualidad, uso de preservativo en todas. Antecedentes personales patológicos: Diagnóstico de VIH un año previo con tratamiento de truvada (tenofovir + emtricitabina), atazanavir y ritonavir. Sarcoma de Kaposi diagnosticado por biopsia cutánea 4 meses antes. Alérgico al ácido acetilsalicilico. Historia de la enfermedad: Paciente inicia su padecimiento 9 meses antes con tos productiva con expectoración purulenta, verdosa y hemoptoicos para 
lo que tomó tratamiento sintomático; sin embargo, en febrero inicia con fiebre de 39 ${ }^{\circ} \mathrm{C}$ de predominio vespertino y nocturno, por lo que acude a centro hospitalario en donde documentan neumonía necrotizante e inician tratamiento con quinolonas y betalactámicos por 1 mes. Paciente con mejoría leve, es dado de alta. Dos meses antes acude con neumólogo por persistir con síntomas quien le realizó broncoscopia, la cual no evidencia anomalías inicia tratamiento con tetraciclinas y es enviado al INER. Examen físico: Tensión arterial 110/70; frecuencia cardíaca 100 por minuto, frecuencia respiratoria 22 por minuto, temperatura $37^{\circ} \mathrm{C}$, pulso oximetría $94 \%$. De aspecto delgado, astenia y adinamia. Cuello: se palpan adenomegalias no dolorosas, móviles submandibulares. Tórax: disminución de murmullo vesicular en hemitórax izquierdo, ruidos cardíacos rítmicos, aumentados en frecuencia, no se distinguen soplos. Resto del examen físico dentro de la normalidad. Estudios de gabinete: Biometría hemática: glóbulos blancos 8,400 células $/ \mathrm{mm}^{3}$; hemoglobina $12.8 \mathrm{~g} / \mathrm{dL}$; hematocrito $39.9 \%$; plaquetas 214,000 células/ $/ \mathrm{mm}^{3}$; química sanguínea: glucosa $108 \mathrm{mg} / \mathrm{dL}$; creatinina 0.76 ; sodio $142 \mathrm{mEq} / \mathrm{mL}$; potasio $4.02 \mathrm{mEq} / \mathrm{mL}$; baciloscopia negativa. Cultivos de expectoración sin crecimiento de microorganismos patógenos. Inmunología: Determinación de CD4 180; carga viral indetectable. Broncoscopia: Infiltración tumoral endobronquial izquierda involucrando desde carina lobar con extensión a división inferior obstruyendo el $90 \%$ de luz y división superior de predominio en língula. Reporte de patología inflamación crónica severa inespecífica. Cultivo, bacilosocopia, genexpert negativos. El paciente es ingresado y se le coloca sonda endopleural izquierda obteniendo material purulento, es llevado a sala de operaciones con impresión clínica de empiema pleural izquierdo. Se realiza toracotomía posterolateral izquierda en donde se evidencian los siguientes hallazgos quirúrgicos: Material purulento escaso $500 \mathrm{~mL}$, atrapamiento pulmonar izquierdo, parénquima pulmonar friable sin poder encontrar un plano de disección, fístulas alveolopleurales múltiples. Por lo que se toman muestras de pulmón (biopsias) y se mandan a cultivo y a anatomía patológica realizando pleurostomía abierta. Diagnóstico histopatológico linfoma no Hodgkin de células B con inmunohistoquímica positiva para: CD20 +, CD45 +; y negativa para: CD 10, BCL2, BCL6. Evolución: Recibe tres ciclos de quimioterapia con R-EPOCH (rituximab, etoposido, prednisona, vinicristina, ciclofosfamida, doxorrubicina), además de su tratamiento retrovirual con atripla, trimetropim sulfametoxazol, itraconazol y ácido fólico. Se coloca válvula unidireccional por persistir con fístula alveolopleural, con buenos resultados por lo que se da alta para manejo ambulatorio. Gammagrafía pulmonar V/Q 6 meses postoperatoria evidencia pulmón izquierdo excluido funcionalmente con colección organizada residual a nivel basal posterior, pulmón derecho con perfusión adecuada e hipoventilación apical. Diez meses después la gammagrafía pulmonar V/Q evidencia buena perfusión en hemitórax izquierdo y derecho con seguimiento de 18 meses con buena evolución. Conclusión: El tratamiento del linfoma non Hodgkin primario de pulmón es realizado por quimioterapia. La cirugía está enfocada en el diagnóstico de la enfermedad y tratamiento de las complicaciones. Sin embargo, la detección temprana de la enfermedad es de buen pronóstico. Aporte a la práctica clínica diaria: Los linfomas no Hodgkin primario de pulmón son poco frecuentes, las manifestaciones clínicas y las imágenes son inespecíficas, por lo que el retraso diagnóstico es importante. Se estima que entre el momento de las primeras manifestaciones clínicas y la consulta médica pueden transcurrir entre 5 meses y 8 años, lo que cambia el pronóstico y la supervivencia. El linfoma ocurre en $3-10 \%$ de pacientes con SIDA y es la segunda neoplasia maligna más común en este grupo. Lo anteriormente expuesto nos hace pensar que ante una imagen tumoral pulmonar o proceso infeccioso tenemos que plantearnos en el diagnóstico diferencial la posibilidad de un linfoma pulmonar primario de alto grado de células B.

\section{Relación entre disfunción endotelial y composición corporal en pacientes con insuficiencia cardíaca y}

\section{enfermedad pulmonar obstructiva crónica}

Flores-Trujillo F, González ID, Jiménez-Cepeda A, HernándezZenteno R, Pérez-Cortés G, VerdejaVendrell $L$, Espinosa de los MC, Navarrete-Peñaloza AG, SánchezSantillán $R$, Orea-Tejeda $A$

INER Ismael Cosío Villegas

Introducción: La enfermedad pulmonar obstructiva crónica (EPOC) está asociada a un alto riesgo de mortalidad cardiovascular y disfunción endotelial (DE), conforme aumenta su GOLD, aumenta la DE y la prevalencia de caquexia, al igual que los pacientes con insuficiencia cardíaca (IC). Sin embargo, no se ha evaluado la relación entre la composición corporal (CC) y la DE en pacientes con IC y EPOC. Objetivos: Evaluar si existe relación entre la DE y el tipo de $\mathrm{CC}$ en los pacientes con IC y EPOC. Material y métodos: Estudio transversal, se incluyeron pacientes $>18$ años con diagnóstico de EPOC y/o insuficiencia cardíaca. Se clasificó la CC según el análisis vectorial de bioimpedancia eléctrica (BIVA) en normal, obesidad y caquexia. La DE se determinó mediante fotoplestimografía. Se consideró DE en aquéllos con un índice entre tiempo de amplitud máxima/tiempo total de la onda de pulso $($ TAM/TT) $>0.30$. Resultados: Se reclutaron 88 pacientes $(56.8 \%$ mujeres y $43.2 \%$ hombres) de $70.89 \pm 11.77$ años de edad. Las comorbilidades más frecuentes fueron EPOC $81.8 \%$; $45.2 \%$ por biomasa, $47.9 \%$ tabaquismo y el resto mixto; HTA $55.7 \%$, diabetes $18.2 \%$, SAOS $15.9 \%$ y TEP $13.6 \%$ Los síntomas más prevalentes que se observaron son disnea $55.7 \%$, intolerancia al decúbito $43.2 \%$, edema $36.4 \%$ y fatiga $65.9 \%$. Se encontraron con DE el $63.5 \%$ de los participantes. La prevalencia de DE fue mayor en los pacientes con obesidad (78.6\%) comparada con los de CC normal y caquexia $(78.3 \%$ y $52.1 \%$, respectivamente, $\mathrm{p}=0.044)$. El índice TAM/TT fue de $0.38 \pm 0.083$ en los participantes con obesidad, $0.34 \pm 0.052 \mathrm{de}$ CC normal y $0.32 \pm 0.064$ caquexia $(\mathrm{p}=0.029)$. Conclusión: Se observó mayor prevalencia de DE en los pacientes con obesidad, probablemente por el efecto que tienen las 
adipocinas sobre el endotelio y somete a alto riesgo en estos pacientes. Aporte a la práctica clínica diaria: La identificación de factores de riesgo cardiovascular puede tener grandes beneficios al paciente.

\section{Tratamiento de broncomalacia con colocación de stent bronquial en pediatría}

Cásarez SIF, del Razo RR, Iñiguez GMA, Santamaría AJ, Alejandre GA

INER Ismael Cosío Villegas

Introducción: Broncomalacia es la debilidad y tendencia al colapso de los bronquios, caracterizada por disnea, tos perruna, estridor o sibilancias; puede confundirse con asma y/o asociarse a cardiopatías, reflujo gastroesofágico. El tratamiento es control de los síntomas concomitantes o uso de CPAP. Los stent restauran la arquitectura endoluminal manteniéndola abierta, mejoran los síntomas y la función ventilatoria. Los stent de silicón tienen un éxito de $43 \%$, con una incidencia de migración del $35.7 \%$. Objetivos: Describir un caso de colocación de stent en paciente pediátrico con broncomalacia. Material y métodos: Revisión de expendiente e imágenes broncoscópicas. Presentación del caso: Masculino de 14 años, con diagnóstico de asma y rinitis alérgica desde los 8 años, exacerbaciones frecuentes a pesar de tratamiento adecuado, con reflujo gastroesofágico, obesidad. Historia de 2 meses con tos traqueal, seca, irritativa, predominio nocturno, sin modificación con actividades. Espirometría: Obstrucción leve sin respuesta a broncodilatador. Tomografía y radiografía de tórax normales. Broncoscopia: Broncomalacia de bronquio principal derecho $(70 \%)$. Se da dosis alta de esteroide inhalado, control de peso y rehabilitación pulmonar. Resultados: Tras 5 meses presenta aumento de la tos. Se coloca stent de silicón en bronquio principal derecho (tipo Dumon), sin complicaciones. Conclusión: El aplicar un stent no es la primera línea de tratamiento, se puede usar en niños enfermos en los que otros procedimientos quirúrgicos o endoscópicos han fallado o no están indicados. Si bien la colocación de stent bronquial en pediatría es poco realizada debido a cambios constantes del tamaño por la edad y la forma de la obstrucción, al momento nuestro paciente tiene adecuada tolerancia. Aporte a la práctica clínica diaria: Los stent son una alternativa en niños con broncomalacia para mejorar la sintomatología. Falta realizar estudios para determinar beneficios y posibles complicaciones a largo plazo.

\section{Asociación entre la distribución del líquido corporal y mortalidad en pacientes con insuficiencia cardíaca}

Velázquez-Montero A, NavarretePeñaloza AG, González ID, OreaTejeda A, Hernández-Zenteno R, Verdeja-Vendrell L, Jiménez-Cepeda A, Pérez-Cortés G, Sánchez-Santillán $R$, Espinosa de los MC

INER Ismael Cosío Villegas

Introducción: Los pacientes con insuficiencia cardíaca (IC) se caracterizan por retención de líquidos. La impedancia bioeléctrica por medio del análisis vectorial (BIVA) permite la valoración de la composición corporal, especialmente la distribución de líquido corporal en el agua extracelular (ECW), tercer espacio y agua corporal total (TBW). La sobrecarga de líquidos en otras poblaciones se ha identificado como predictor de mortalidad. Sin embargo, pocos estudios han analizado el efecto de esta distribución sobre la mortalidad de los pacientes con IC. Objetivos: Evaluar si existe asociación entre la distribución del líquido corporal y la mortalidad en pacientes con IC. Material y métodos: Estudio de cohorte prospectivo. Se incluyeron pacientes mayores de 18 años de edad, con diagnóstico de IC estable, se excluyeron pacientes con cáncer, infarto al miocardio $<3$ meses e IC descompensada. La composición corporal se evaluó mediante impedancia bioeléctrica con análisis vectorial (BIVA). Resultados: Se enrolaron 130 pacientes, la edad fue de $65.96 \pm 14.85$ años. La edad de los sujetos que no sobrevivieron fue mayor $(82 \pm 7.53$ vs. $65.61 \pm 14.57, \mathrm{p}=0.007)$. Al comparar la composición corporal de los sujetos que murieron contra los que sobrevivieron se observó que los que murieron tuvieron mayor agua corporal total (ACT: 60.75 \pm 4.52 vs. $53.06 \pm 8.03, \mathrm{p}=0.022)$, agua extracelular (AEC: $27.73 \pm 2.61$ vs. 24.01 $\pm 2.63, \mathrm{p}=0.001)$, índice de impedancia $(0.86 \pm 0.04$ vs. $0.81 \pm 0.05, \mathrm{p}=0.016)$ tercer espacio (1.56 [0.46-2.09] vs. 0.21 [-0.31-0.877], $\mathrm{p}=0.007)$, así como menor fuerza de mano $(18.33 \pm 10.03$ vs. $26.87 \pm$ $8.88, \mathrm{p}=0.046)$ y ángulo de fase $(3.68 \pm$ 1.47 vs. $5.46 \pm 1.45, \mathrm{p}=0.004)$. Conclusión: En los pacientes con IC, la cantidad y distribución del líquido corporal es un marcador de riesgo de mortalidad. Aporte a la práctica clínica diaria: La evaluación de distribución de líquido corporal por medio del BIVA puede permitir un mejor manejo del paciente con IC.

\section{Experiencia en} toracoscopia por puerto único en Centro Médico ISSEMYM Toluca del período enero del 2015 a diciembre del 2016

\section{Moreno TJA, Escobedo SE, Martínez AMA, Téllez BJL, Loyola GU, Farah OSI, FGallardo F, Romero DF}

Centro Médico ISSEMYM Toluca

Introducción: La práctica de la cirugía torácica ha evolucionado a lo largo del tiempo; en los inicios de la cirugía torácica se usaba la toracotomía como único abordaje. El avance tecnológico y de las nuevas técnicas quirúrgicas así como de videoasistidas ha permitido el progreso de la toracoscopia, convirtiéndola en la actualidad en el método de elección para el diagnóstico y tratamiento de muchas de las enfermedades torácicas, permitiendo una recuperación rápida de los pacientes aminorando el trauma quirúrgico, así como el estrés metabólico y el uso de los analgésicos. Objetivos: Sustentar la práctica efectiva y segura de la cirugía videotoracoscópica asistida con puerto único de trabajo ya que existe poca 
evidencia y documentación bibliográfica a nivel nacional e internacional de este tipo de cirugía. Material y métodos: $P o$ blación: Todos los pacientes del Servicio de Cirugía de Tórax sometidos a toracoscopia con puerto único en el período enero 2015 y diciembre 2016. Método: Se revisaron expedientes electrónicos y del archivo clínico. Criterios de inclusión: Pacientes sometidos a toracoscopia con puerto único en el período enero 2015 a diciembre 2016. Criterios de exclusión: Pacientes sometidos a toracoscopia en la que se utilizaron 2 o más puertos de trabajo. Pacientes que requirieron toracotomía. Pacientes fuera del período de estudio (enero 2015 a diciembre 2016). Pacientes con toracoscopia como manejo de hemotórax traumático. Presentación del caso: Se revisaron los expendientes de pacientes sometidos a toracoscopia por puerto único durante el período enero del 2015 a diciembre del 2016. En todos nuestros procedimientos se realizó una incisión en tórax de aproximadamente 1.5 a $2 \mathrm{~cm}$ por la que se introduce una cámara de $5 \mathrm{~mm}$ y las pinzas de trabajo; incialmente se realizaba una toracoscopia diagnóstica en la que se valoraba la viabilidad del procedimiento por puerto único. Los diagnósticos por los que se realizaba el procedimiento van desde toma de biospias pulmonares y pleurales hastas drenaje de absceso hepático y simpatectomía, se revisó así mismo el tiempo quirúrgico del procedimiento y los días de estancia posterior a la cirugía. Resultados: Se realizó un total de 42 toracoscopias por puerto único, dentro de los procedimientos realizados se realizó toma de biopsia pulmonar en 14 pacientes, 7 decorticaciones por derrames pleurales complicados así mismo se realizaron tomas de biopsia pleurales, simpatectomías, bullectomías, drenaje de absceso hepático, entre otros. De los 42 procedimiento realizados 16 tuvieron un tiempo quirúrgico entre 60 y 120 minutos, en 13 de nuestros procedimientos se tuvo un tiempo quirúrgico inferior a una hora. El tiempo de estancia en nuestro servicio posterior al procedimiento fue de 4 a 6 días. De nuestras 42 toracoscopias realizadas no se presentó alguna complicación derivada de la cirugía.
Conclusión: La toracoscopia con puerto único como parte de la cirugía torácica de mínima invasión es un procedimiento seguro, confiable, con baja morbilidad y que en manos adiestradas brinda beneficios al paciente; por lo que es un procedimiento ampliamente recomendado para ciertas patologías; sin embargo, se requiere de mayor estudio para su aplicación en diferentes procedimientos de la misma área. Aporte a la práctica clínica diaria: Se ha demostrado que la cirugía toracoscópica por un solo puerto es tan efectiva como la videotoracoscópica convencional que genera menor morbilidad a los pacientes durante el posoperatorio y que realizada por cirujanos expertos en la materia cuenta con un mínimo de complicaciones y es un procedimiento seguro para el paciente. Las principales ventajas de esta técnica son la disminución del dolor posoperatorio y recuperación rápida.

\section{Evaluación de función endotelial entre pacientes con enfermedad pulmonar obstructiva crónica causada por tabaco y humo de biomasa}

\section{Pérez-Bautista O, Pérez-Cortés \\ GK, González ID, Orea-Tejeda A, Hernández-Zenteno $R$, Jiménez-Cepeda $A$, Velázquez-Montero $A$, Verdeja-Vendrell $L$ Navarrete-Penaloza $A$, Sánchez-Santillán $R$}

INER Ismael Cosío Villegas

Introducción: La función endotelial (FE) favorece el desarrollo de aterosclerosis y se considera un predictor independiente de eventos cardiovasculares. La disfunción endotelial (DE) tiene alta prevalencia en los pacientes con enfermedad pulmonar obstructiva crónica (EPOC) por humo de tabaco (HT) o de biomasa (HB), principales etiologías de EPOC en México. Sin embargo, no se conoce si existe una diferencia en la DE entre ambos grupos. Objetivos: Evaluar la diferencia en la FE entre los pacientes con EPOC por HT o HB.
Material y métodos: Estudio transversal en pacientes ambulatorios, mayores de 18 años, con diagnóstico de EPOC GOLD IIII. Aquellos con EPOC por etiología mixta se excluyeron. Se dividió a los pacientes según su etiología (HT o HB), y se realizó historia clínica y exploración física. La FE se evaluó mediante fotopletismografía de pulso. Se consideró DE con un índice de tiempo de amplitud máxima/tiempo total $(\mathrm{TAM} / \mathrm{TT})>0.30$. Se realizó una regresión lineal múltiple para determinar el efecto de la etiología de EPOC sobre la FE, ajustado por edad y sexo. Resultados: Se evaluaron 97 pacientes, con una edad de $72.16 \pm 9.95$ años, $53.6 \%$ fueron mujeres. En el grupo de HB hubo más mujeres $(90.7 \%$ vs. $24.1 \%$, $\mathrm{p}<0.001)$, mayor edad (76.1 \pm 9.1 vs. 69.0 \pm 9.5 años, $\mathrm{p}<0.001)$, mayor prevalencia de reflujo hepatoyugular positivo $(50 \%$ vs. $20.7 \%, \mathrm{p}=0.022)$, e insuficiencia cardíaca (30.2\% vs. $16.7 \%, \mathrm{p}=0.113$ ) comparados con aquellos del grupo de HT. La prevalencia general de DE fue $78.9 \%$. El grupo HB tuvieron un índice TAM/TT mayor (0.04) que aquellos del grupo HT ( $\beta$ : 2.5, CI $95 \%$; 1.2-3.7, p < 0.001) ajustado por edad y sexo. Conclusión: La DE es mayor EPOC por HB que en aquellos por HT. El grupo HB tuvieron mayor prevalencia de insuficiencia cardíaca derecha. Aporte a la práctica clínica diaria: Poder identificar de forma temprana a los pacientes con riesgo cardiovascular.

Gasometría arterial a 2,240 $\mathrm{m}$ por encima del nivel del mar: El efecto de la edad, género y el índice de masa corporal

Cid JS, Marte SA, Pérez PR, Gochicoa RL, Torre-Bouscoulet $L$

INER Ismael Cosío Villegas

Introducción: La gasometría arterial es una prueba mínimamente invasiva estándar que puede evaluar el estado de oxigenación, ventilación y ácido-base, por lo que es importante conocer los valores de referencia en población sana que reside en la CDMX. Objetivos: Objetivo principal: Estimar los valores de referencia de los 
valores gasométricos en una población sana que radica en la Ciudad de México. Comparar los valores obtenidos con los valores estimados mediante fórmulas estandarizadas (por ejemplo del Dr. PérezPadilla). Material y métodos: El estudio fue realizado en el Departamento de Fisiología del INER. Los participantes llenaron un formulario de consentimiento para una prueba de esfuerzo máximo que incluye un catéter intraarterial, éstos residían en el Valle de México o Ciudad de México área metropolitana durante al menos 2 años, eran mayores de 15 años de edad, con cuestionario de hábito tabáquico negativo y sin síntomas respiratorios. Los individuos con obesidad (IMC > 30) con tabaquismo activo en los últimos 6 meses y/o índice tabáquico mayor 10 años/paquete y aquéllos con muestras de sangre inadecuadas para la cuantificación fueron excluidos del análisis. Resultados: Un total de 217 sujetos (63\% de la población que participó en la prueba de valores de referencia de PECP) aceptaron la colocación de línea arterial, todos ellos contaron con gasometría en reposo. El 52.5\% (114 sujetos) fue del sexo masculino. Existieron diferencias significativas en la mayoría de las variables antropométricas y de espirometría esperadas a la diferencia de género, el $6 \%$ de la población fue menor de 20 años de edad, el $48 \%$ (104 sujetos) tenía una edad entre 20-40 años y el $46 \%$ de la población tuvo más de 40 años. Se evaluó la asociación de las variables gasométricas con la edad y se observó que conforme la población envejece la $\mathrm{PaO}_{2}$, la $\mathrm{SaO}_{2}$ y el lactato en reposo descienden, mientras la $\mathrm{PaCO}_{2} \mathrm{y}$ el gradiente alvéolo-arterial (Gradiente A-a) incrementan (p: < 0.005). A 2,240 $\mathrm{m}$ de altitud, la $\mathrm{PaCO}_{2}$ media fue de 30.7 $\mathrm{mmHg}$ y tendió a aumentar con la edad, especialmente en las mujeres, conduciendo a un exceso de base negativo $(-2,5)$. La saturación de oxígeno fue cercana al $90 \%$ y por lo tanto, aunque la oxigenación se mantiene, fácilmente puede caer por debajo de la rodilla de la curva de disociación oxihemoglobina. Conclusión: La altitud debe tenerse en cuenta para la correcta interpretación del estado de oxigenación y ventilación. El estado de oxigenación se mantiene a 2,240 metros sobre el nivel del mar, pero cerca del $90 \%$ de saturación arterial y con más riesgo de hipoxemia. El conocer los valores de referencia de la gasometría arterial nos permite tomar decisiones clínicas adecuadas en pacientes que se encunetran a una altitud de 2,240 metros sobre el nivel del mar y su repercusión en esta población. Aporte a la práctica clínica diaria: El conocer los valores normales de la gasometría arterial nos permite tomar decisiones clínicas en sujetos que se encuentran a una altitud de 2,240 metros sobre el nivel del mar y su repercusión en esta población y establecer valores de referencia.

\section{Prevalencia de hipertensión pulmonar y comorbilidades asociadas en pacientes mexicanos hospitalizados en un Centro Hospitalario de Tercer Nivel}

Orea-Tejeda A, Pérez CG, González ID, Espinosa de los MC, VerdejaVendrell L, Flores-Trujillo F, JiménezCepeda A, Navarrete-Penaloza AG, Sánchez-Santillán R, Ernesto JuárezLeón E

INER Ismael Cosío Villegas

Introducción: La hipertensión pulmonar (HP) está asociada con una pobre calidad de vida y menor sobrevida, la cual varía según su etiología. Sin embargo, existen pocos reportes acerca de su incidencia, prevalencia y etiología subyacente. Objetivos: Determinar la prevalencia de HP y principales comorbilidades en pacientes mexicanos hospitalizados en un centro hospitalario de tercer nivel. Material y métodos: Estudio transversal en pacientes hospitalizados entre los años 2014 y 2016 en un centro de tercer nivel. Las comorbilidades se clasificaron de acuerdo a la Clasificación Internacional de Enfermedades, décima versión. Se incluyeron sujetos mayores 18 años; se excluyeron aquellos con defectos cardíacos congénitos. Resultados: Se incluyeron 8,681 pacientes (edad $49.85 \pm$ 17.90 años). La prevalencia de HP fue de $3.43 \%$ ( $\mathrm{n}=298)$. En los sujetos con HP, el
$60.7 \%$ fueron mujeres. Al comparar a los sujetos con HP contra los sujetos sin HP encontramos que tuvieron mayor edad (57.46 \pm 15.19 vs. $49.58 \pm 17.93$ años, $\mathrm{p}$ $<0.001)$, mayor cor pulmonale $(19.8 \% \mathrm{vs}$. $1.4 \%, \mathrm{p}<0.001)$, EPOC (13.8\% vs. $6.5 \%$, $\mathrm{p}<0.001)$, exacerbación aguda $(56.09 \%$ vs. $39.29 \%, \mathrm{p}<0.001)$, prevalencia de tromboembolia pulmonar $(12.8 \% \mathrm{vs}$. $1.9 \%, \mathrm{p}<0.001)$; apnea del sueño $(11.1 \%$ vs. $2.9 \%, \mathrm{p}<0.001)$; neumonitis por hipersensibilidad $(8.7 \%$ vs. $1.8 \%, \mathrm{p}<$ $0.001)$; fibrosis pulmonar (6.7\% vs. $1.5 \%, \mathrm{p}$ $<0.001)$; trombosis venosa profunda $(3.7 \%$ vs. $1.0 \%, \mathrm{p}<0.001)$; cardiopatía isquémica ( $2.3 \%$ vs. $1.0 \%$, p 0.042); lupus eritematoso sistémico $(2.0 \%$ vs. $0.4 \%, \mathrm{p}<0.001)$, así como mayor estancia intrahospitalaria (13.62 \pm 8.58 días vs. $11.90 \pm 12.16$. Conclusión: La HP es una condición asociada con múltiples comorbilidades, las cuales están relacionadas con una mayor morbilidad y mortalidad, por lo que es necesaria su detección y tratamientos tempranos para reducir su impacto económico y mortalidad. Aporte a la práctica clínica diaria: Describe las principales comorbilidades de la población con HP.

Relación entre la función endotelial y el volumen espiratorio forzado en el primer segundo en los pacientes con enfermedad pulmonar obstructiva crónica

Espinosa de los MC, SánchezSantillán R, González ID, Orea-Tejeda $A$, Velázquez-Montero $A$, NavarretePeñaloza AG, Jiménez-Cepeda A, Pérez-Cortés G, Verdeja-Vendrell L, Flores-Trujillo $F$

INER Ismael Cosío Villegas

Introducción: La enfermedad pulmonar obstructiva crónica (EPOC) se caracteriza por una inflamación crónica de vías aéreas de pequeño calibre y alvéolos, que genera limitación al flujo de aire no reversible. Las enfermedades cardiovasculares en especial la insuficiencia cardíaca (IC) representa una alta morbilidad y mortalidad, siendo causa de peor pronóstico 
en estos pacientes. El daño al endotelio puede contribuir al enfisema y a la EPOC e indirectamente el daño en la vasculatura pulmonar puede desarrollar tanto enfisema como EPOC. Objetivos: Evaluar la relación entre la función endotelial (FE) y la función respiratoria en los pacientes con EPOC e IC. Material y métodos: Estudio transversal, con 117 pacientes con diagnóstico de EPOC e IC. La FE se determinó mediante fotopletismografía, se evaluó la relación del tiempo de amplitud (TAM) y tiempo total (TT) de la curva considerando una disfunción endotelial (DE) un valor > 0.30 TAM/TT. Resultados: Se evaluaron 117 pacientes, la edad fue de $71.4 \pm 11.09$, el $60.7 \%$ presentaba disfunción endotelial (DE) y de ellos $56.8 \%$ eran del sexo femenino. Los sujetos con DE tuvieron mayor prevalencia de enfermedades cardiovasculares $(47.9 \%$ vs. $9 \%, \mathrm{p}=0.005)$, hipertensión arterial pulmonar $(21.6 \%$ vs. $3 \%, \mathrm{p}=0.05)$, en comparación con aquéllos sin DE. No se encontraron diferencias significativas en sexo, edad, peso, talla, hipertensión arterial, diabetes, obesidad. Los pacientes con DE tienen un $11 \%$ menos de $\mathrm{FEV}_{1}$ comparado con aquéllos sin DE. ( $\beta$ :-11.25, $\mathrm{p}=$ 0.05). Conclusión: Los pacientes con DE tienen $\mathrm{FEV}_{1}$ menor en comparación con aquéllos sin DE. En aquéllos con EPOC y DE tendrán el grado de EPOC más severo lo que permite especular que DE no es sólo a nivel capilar y local, sino de la unidad capilar /alveolar y de tipo sistémica. Aporte a la práctica clínica diaria: La disfunción endotelial en los pacientes con EPOC se asocia a disminución de la función respiratoria.

\section{Inducción in vitro de NETosis y apoptosis} de neutrófilos mediante sueros de pacientes con tuberculosis pulmonar activa

Hernández SA, Landa APD, Juárez OM, Arce PP, Islas TS, Rojas-Espinosa O, Muñiz SR

Hospital General de México; Escuela Nacional de Ciencias Biológicas, IPN; Universidad Autónoma de Baja California, Ensenada, Baja California
Introducción: La respuesta de los neutrófilos frente a Mycobacterium tuberculosis ha sido poco explorada, éstos son reclutados de manera temprana y cuentan con un mecanismo microbicida que es la liberación de trampas extracelulares (NETs), el proceso que conduce a su formación se conoce como NETosis que es un mecanismo de muerte celular diferente a la apoptosis y necrosis. Objetivos: Evaluar si los sueros de pacientes con tuberculosis activa inducen la formación de NETs en los neutrófilos de donadores sanos. Material y métodos: Se obtuvieron neutrófilos de donadores sanos y fueron sometidos in vitro durante 3 y $6 \mathrm{~h}$ al efecto de los sueros de pacientes con tuberculosis y sueros de convivientes, el DNA fue teñido y cuantificado con Hoechst, la medición de cambios nucleares se realizó con microscopia de fluorescencia se tomó en cuenta el número de células con núcleos intactos, picnóticos o en NETosis. Resultados: Se examinaron 46 sueros, 9 de pacientes con tuberculosos activa, 21 de convivientes y 16 no convivientes. A las $3 \mathrm{~h}$ todos los sueros de los pacientes con tuberculosis indujeron cambios consistentes en NETs, picnosis y edema nuclear. En $43 \%$ de convivientes se indujeron cambios en menor grado y ninguno de los no convivientes genero alteraciones nucleares. A $6 \mathrm{~h}$ los sueros de los pacientes con tuberculosis indujeron la liberación de vesículas similares a los cuerpos apoptóticos y 3 sueros de los convivientes tuvieron el mismo efecto. Conclusión: Los sueros de los pacientes con tuberculosis inducen alteraciones en la cromatina nuclear de los neutrófilos sugerentes de una muerte por NETosis y apoptosis, los estímulos que pueden estar involucrados son la IL8 y TNF alfa. Aporte a la práctica clínica diaria: Desarrollar nuevos métodos diagnósticos para identificar infecciones por micobacterias, los cuales tengan mayor sensibilidad y especificidad, para implementar un tratamiento oportuno.

\section{Manejo quirúrgico de hemoptisis}

Carranza MI, Narciso DE, Morales GJ INER Ismael Cosío Villegas
Introducción: El rol de la cirugía en el tratamiento de la hemoptisis está poco estudiada, porque representa $1 \%$ de los pacientes admitidos. Existen opciones no quirúrgicas: la embolización vascular identificando el vaso sangrante; por broncoscopia utilizando irrigación con soluciones hemostáticas; empero, éstas tienen alta recidiva. Por lo anterior, surge la necesidad de identificar factores de riesgo de recidiva que orienten a tomar decisiones terapéuticas quirúrgicas desde su ingreso hospitalario. Material y métodos: 50 pacientes encontrados con diagnóstico de hemoptisis que fueron sometidos a resección anatómica mayor o menor, donde el procedimiento fue indicado para tratamiento o control de hemoptisis, desde junio 2007 a abril 2015. Resultados: De 50 pacientes revisados, $30(60 \%)$ son masculinos y $20(40 \%)$ femeninos, la edad promedio fue 51 años (16-78 años). La cantidad expectorada fue franca (44\%), mayor (22\%) y hemoptoica (18\%). El 38\% (19) de los casos eran sanos y la comorbilidad más frecuente fue diabetes mellitus en $28 \%$ (14) de la población. Como etiología encontramos predominantemente: secuelas de tuberculosis $14(28 \%)$, lesiones cavitadas no relacionadas a tuberculosis $10(20 \%) \mathrm{y}$ bronquiectasias 7 (14\%). Del tratamiento: $26(52 \%)$ se realizó $\mathrm{FBC}+$ cirugía, $4(8 \%)$ embolización+cirugía, 8 (16\%) FBC+embolización+cirugía y 12 (24\%) cirugía como primera opción terapéutica. Los pacientes con más episodios de hemoptisis $(>6)$ pertenecen al grupo de FBC+cirugía. Al ingreso 14 casos presentaron inestabilidad hemodinámica; con promedio de 2.5 episodios, $43 \%$ requirieron intubación selectiva. El sangrado transoperatorio en pacientes con comorbilidades ( $\mathrm{p}=0.027$ ), así como el IMC ( $\mathrm{p}$ $<0.01$ ) son significativos en comparación con población sana. No hubo significancia en la mortalidad entre tipo de tratamiento. Conclusión: La tuberculosis es la causa más frecuente de hemoptisis. Aquéllos que al ingreso presenten inestabilidad hemodinámica con necesidad de intubación selectiva y/o >200 mL/24h con dos o más episodios son pacientes beneficiados de resección quirúrgica como manejo definitivo a su ingreso hospitalario. 
Identificación de micobacterias no tuberculosas en muestras clínicas de pacientes con tuberculosis HIV negativos en el Hospital General de México

Cicero-Sabido R, Landa APD, Hernández-Solís A, González-Villa M, González-González H, MartínezRivera I, Mandujano-Martínez $A P$, Torres-Mazadiego BP, WongArámbula E, Rodríguez-Maldonado AP, Hernández-Rivas L, RamírezGonzález JE

Hospital General de México; Instituto de Diagnóstico y Referencia Epidemiológicos

Introducción: Existe un aumento progresivo de micobacterias no tuberculosas (MNT) en infecciones pulmonares y extrapulmonares que pueden confundirse con el complejo Mycobacterium tuberculosis. Objetivos: Conocer la frecuencia de MNT en muestras clínicas de pacientes inmunocompetentes con diagnóstico clínico de tuberculosis activa, con bacilos ácidoalcohol resistentes (BAAR) negativos, en el laboratorio de micobacterias de un hospital de referencia de tercer nivel de especialidades de enero del 2012 a diciembre del 2014. Material y métodos: Estudio prospectivo, descriptivo, se estudiaron cepas aisladas de material biológico en cultivos Löwestein-Jensen y MGITI960. La identificación de las especies de las micobacterias aisladas se realizó mediante PCR-secuenciación a partir de la obtención de una ampliación de 441 pb del gen hsp65 y su posterior análisis filogenético. Resultados: Se estudiaron 120 muestras clínicas de pacientes HIV negativos. Muestras pulmonares 99/120 (82\%) y especímenes biológicos extrapulmonares 21/120 (18\%). En 37/120 (30.8\%) se identificaron MNT, 16 pulmonares, 13 genitourinarias, tres en médula ósea y cinco en diversos especímenes. Se identificó M. avium en 20 aislamientos, M. intracellulare en 7 y diferentes especies de MNT en las 10 muestras restantes. Conclusión: Se señala la importancia de identificar la presencia de MNT en las muestras clínicas de los casos de tuberculosis activa con BAAR negativo que pueden confundirse con el complejo M. tuberculosis siendo esencial para decidir un tratamiento adecuado. Aporte a la práctica clínica diaria: Identificar la epidemiología de infecciones por micobacterias, e implemetar un tratamiento adecuado, sin demoras.

\section{Micetoma pulmonar por Aspergillus y hongos filamentosos emergentes (hialohifomicosis). Reporte de caso}

\section{Fuentes JJC, Júarez GA, Hernández $T V$, Villaseñor $D E$}

IMSS; Unidad Médica de Alta Especialidad, Hospital General «Dr. Gaudencio González Garza», CMN «La Raza»

Introducción: El micetoma pulmonar es una masa de elementos micóticos libre dentro de una cavidad pulmonar. La causa más común es Aspergillus sp.; sin embargo, han tomado auge las hialohifomicosis, entre los cuales se encuentran Scedosporium sp. y Beuveria sp. Objetivos: Reporte de caso. Material y métodos: Se presenta el caso de paciente inmunocompetente que presenta micetoma por aspegillus e hialohifomicosis. Presentación del caso: Femenino de 25 años con exposicionales negados, quien ingresa por hemoptisis intermitente de 6 años, fiebre, pérdida de $20 \mathrm{~kg}$ en 9 meses, tos, con signo de media luna en tomografía. Resultados: Se realizó broncoscopia con lavado con desarrollo de Beauveria bassiana y cultivo biopsia de bronquio de lóbulo medio con desarrollo de Scedosporium apiospermum, realización de lobectomía inferior con reporte histológico de Aspergillus $s p$. Conclusión: Las hialohifomisosis han adquirido creciente protagonismo como causante de infección, los casos por Scedosporium han ido creciendo; sin embargo, son muy pocos los casos de micetoma por Beauveria sp, como principal forma de presentación en inmunocompetentes, por lo que además del genero Aspergillus se deben considerar desde el primer contacto con el paciente estos nuevos hongos emergentes, aunque con cuadro clínico indistinguible de Aspergillus, el cultivo de muestras obtenidas por biopsia quirúrgica o aspiración del hongo dan sustento al diagnóstico etiológico. La resección pulmonar es el tratamiento de elección. Aporte a la práctica clínica diaria: La causa de infección más común es el género Aspergillus sp, aunque varias especies de hongos oportunistas pueden ser responsable de la infección suponiendo alrededor de $10 \%$ de las micosis, el término hialohifomicosis denomina las infecciones por hongos raros filamentosos de los cuales Scedosporium apiospermun y Beuveria bassiana son algunos de sus representantes. La infección en el caso de nuestro paciente fue consecuencia de la inhalación de aire con conidias por lo que el micetoma es la forma de presentación más común en inmunocompetentes.

\section{Neumomediastino espontáneo. Serie de casos en un hospital de tercer nivel y revisión de la literatura}

García HS, Palacios LFJ, Saldívar MDE, Pérez RE, Muñoz MG, Wong JM

Hospital Universitario «Dr. José Eleuterio González». Universidad Autónoma de Nuevo León

Introducción: El neumomediastino espontáneo se define como la presencia de aire en mediastino no asociado a trauma, lesión iatrogénica o enfermedad pulmonar conocida. Es una entidad poco frecuente con una incidencia de 1 en 800 a 1 en 42,000 consultas en urgencias. Objetivos: Reportar una serie breve de casos clínicos de neumomediastino espontáneo dada su baja incidencia y mostrar evolución, tratmiento y pronóstico de nuestros pacientes. Material y métodos: Se revisó la casuística de pacientes con neumomediastino espontáneo del Hospital Universitario «Dr. José Eleuterio González» del 2016. Presentación de los casos: Se presentan 3 casos clínicos, uno asociado a un episodio de estornudo y los otros dos con paciente en reposo. 2 presentan antecedentes de patología respiratoria. Se realizaron estudios de 
imagen evidenciando el neumomediastino y se decidió su ingreso para tratamiento conservador en el $100 \%$ de los pacientes a base de oxigenoterapia, evolución clínica favorable, egresando a los 3 días promedio. Resultados: Se presentaron 3 pacientes, 2 masculinos y 1 femenino con síntomas de disnea, dolor torácico y aumento de volumen en cuello-tórax, se observó saturación de oxígeno a su ingreso de $95 \%$ en taquicárdicos; con promedio de 6 horas de evolución desde inicio de los síntomas. Se requirió radiografía de tórax así como TAC, en dos pacientes se realizó broncoscopia sin datos patológicos. El $100 \%$ de los pacientes recibió tratamiento conservador con un promedio de estancia hospitalaria de 2.6 días. Conclusión: El neumomediastino espontáneo es una patología infrecuente de evolución clínica favorable. Los métodos diagnósticos son la radiografía de cuello, tórax y TAC. El tratamiento se basa en reposo absoluto, oxigenoterapia y control radiográfico, siendo éste el utilizado con nuestros pacientes con resultados favorables. Aporte a la práctica clínica diaria: Es fundamental el reconocimiento de esta patología debido a su baja incidencia así como el abordaje diagnóstico y terapéutico con la finalidad de disminuir los días de estancia hospitalaria y costos para el paciente.

\section{Mesotelioma epitelial subtipo tubulopapilar de aspecto sarcomatoide, reporte de un caso}

\section{Hernández HMA, Pérez RA,} Coronel MJ

Hospital General de México

Introducción: Mesotelioma pleural maligno, rara forma de cáncer derivado de las células mesoteliales de membranas serosas, principalmente pleura y peritoneo. Presenta una asociación en el $80 \%$ de los casos con exposición a asbestos. Existen tres tipos histológicos principales: Epitelial (representando alrededor del $50 \%$ de los casos y con mejor pronóstico), sarcomatoide y mixto. Los mesoteliomas epiteliales presentan clásicamente un patrón tubulopapilar, papilar, trabecular, entre otros. Siendo un reto su adecuada clasificación histológica. Objetivos: Reportar un caso de mesotelioma epitelial subtipo tubulopapilar, con aspecto macroscópico de mesotelioma sarcomatoide. Presentación del caso: Hombre de 45 años sin exposición a asbestos, con cuadro de 1 año de evolución, caracterizado por dolor pleurítico en hemitórax derecho, disnea progresiva de grandes a pequeños esfuerzos y pérdida de $15 \mathrm{~kg}$, ingresa con síndrome de dificultad respiratoria severo y radiografía de tórax tomada 10 días previos a su ingreso donde se observa opacidad periférica de aspecto festonado, disminución del volumen de hemitórax derecho e infiltrado sugerente de diseminación linfohematógena en ambos campos pulmonares, de manera súbita presenta paro cardiorrespiratorio, no reversible a maniobras. Se envía el cuerpo a unidad de patología reportando mesotelioma sarcomatoide por aspecto macroscópico, pero reportando como resultado final mesotelioma epitelial subtipo tubulopapilar. Conclusión: Una opacidad periférica de aspecto festonado, aunada a disnea, dolor pleurítico y pérdida de peso son datos que nos sugieren fuertemente la presencia de mestotelioma. Aporte a la práctica clínica diaria: Si bien la variedad epitelial del mesotelioma pleural es la más común y con mejor pronóstico, continúa siendo una forma agresiva con un pronóstico desfavorable debido a su alta mortalidad pese a las diferentes opciones de tratamiento, por lo que se vuelve importante documentar este tipo de patologías con la finalidad de crear reportes que nos permitan identificar si un subtipo del tumor puede favorecer o empeorar el pronóstico de estos pacientes.

Factores asociados en la calidad del diagnóstico de enfermedad pulmonar obstructiva crónica (EPOC) en pacientes referidos a la consulta externa de neumología en un hospital de segundo nivel
Toledo EJ, Palma VM, García GA, Serrano MM

Introducción: Las guías clínicas existentes recomiendan que el diagnóstico de la EPOC sea confirmado mediante espirometría. La realidad demuestra que esto no se cumple. En múltiples estudios se nota una alta prevalencia tanto del infra- como del sobrediagnóstico de la EPOC, así como la poca utilización de la espirometría. El diagnóstico errado de EPOC está directamente relacionado con la prescripción de tratamientos inadecuados. Objetivos: Determinar los factores asociados y la calidad en el diagnóstico de la EPOC en pacientes referidos a la consulta externa de neumología del Hospital General de Zona \#20 (HGZ 20) del IMSS en Puebla. Material y métodos: Estudio descriptivo, prolectivo, longitudinal, homodémico. Realizado en la consulta externa de neumología del HGZ 20, de septiembre de 2015 a febrero de 2016. Se reclutaron pacientes referidos con diagnóstico de envío de EPOC. La calidad del diagnóstico se evaluó de acuerdo con los resultados de la espirometría que documentara el diagnóstico de obstrucción fija al flujo aéreo. Resultados: Un total de 162 pacientes, $48 \%$ hombres y mujeres 52\%. Edad más frecuente de envío entre 70 a 79 años, $38 \%$. El 75\% enviados por medicina interna. Recibían broncodilatadores el $49 \%$ y oxígeno domiciliario un $28 \%$. Sólo en 19 pacientes, 12\%, se confirmó el diagnóstico de EPOC. Conclusión: La EPOC está siendo diagnosticada de forma imprecisa, por una valoración inadecuada de los factores de riesgo y sobre todo la inconveniente apreciación de la espirometría, lo que conlleva a una prescripción no óptima de tratamiento. Aporte a la práctica clínica diaria: El estudio refleja un conocimiento limitado de la EPOC entre los médicos de primer contacto, urge la difusión del conocimiento de la patología, así como de la importancia del diagnóstico certero de una de las enfermedades respiratorias con mayor prevalencia. Fomentando el apego a las guías de práctica clínica para el diagnóstico, prevención y tratamiento de la EPOC.

Hallazgos broncoscópico en pacientes con estridor atendidos en el Hospital 


\section{del Niño Morelense en el período comprendido enero 2010-mayo 2016}

Urbina MME, Gómez JÁl

Secretaría de Salud; Hospital del Niño Morelense

Introducción: El estridor es un ruido respiratorio musical de tonalidad variable que se presenta predominantemente durante la inspiración, aunque también se puede presentar de manera bifásica. La obstrucción de la vía aérea puede ubicarse a nivel supraglótico, glótico o infraglótico. Objetivos: Objetivo general: Describir los hallazgos broncoscópicos en pacientes con el diagnóstico de estridor en el período comprendido de enero 2010 a mayo 2016. Objetivos específicos: 1. Caracterizar los aspectos demográficos en pacientes con estridor. 2. Conocer los diagnósticos broncoscópicos en pacientes con estridor. 3 . Conocer el abordaje terapéutico brindado a estos pacientes. Material y métodos: Se diseñó un estudio de tipo descriptivo, restrospectivo en pacientes de 1 mes a 17 años de edad con el diagnóstico de estridor que se les hubiese realizado broncoscopia en el período enero 2010-mayo 2016. Se tomaron los datos del expediente electrónico Histoclin. Resultados: Se realizó un total de 385 broncoscopias, de las cuales 54 (14.2\%) de los pacientes tenían el diagnóstico de estridor. De éstos el $66.6 \%$ fueron masculinos y $33.3 \%$ (18) femeninos. El 51.7\% de la población fueron menores de 2 años y el $35 \%$ de entre 2 a 4 años, $38.8 \%$ de 6 a 10 años, $9.3 \%$ mayores de 10 años. La primera causa de estridor fue la estenosis subglótica con $38.8 \%$, el $47.6 \%$ fueron estenosis grado II, $38 \%$ grado III, $14.2 \%$ grado I. Laringomalacia en $24 \%, 19.2 \%$ papilomatosis laríngea, $9.2 \%$ cuerpo extraño, y de éstos el $80 \%$ fue de tipo orgánico y el 20\% inorgánico (metálico). Con respecto al período de intubación el $37.5 \%$ tenían menos de 7 días. El 75\% de pacientes con estenosis subglótica requirió traqueotomía. Conclusión: La causa más frecuente de estridor fue la estenosis subglótica y ésta no se asoció con el tiempo de intubación; el tratamiento de elección fue la traqueostomía.

\section{Linfoma de la zona gris con compromiso mediastinal, reporte de un caso}

Hernández HMA, Hernández SA, Silva $C A$

Hospital General de México

Introducción: Linfoma de zona gris, neoplasia rara descrita por el reconocimiento de un subgrupo agresivo de linfoma mediastinal de células $\mathrm{B}$, reconocido por la OMS hasta 2008 como linfoma de células $\mathrm{B}$, inclasificable, con características intermedias entre linfoma difuso de células B grandes y linfoma de Hodgkin clásico, la rareza de esta combinación y la heterogeneidad de la enfermedad hacen del manejo de esta enfermedad un reto. Objetivos: Reportar un caso de linfoma de zona gris, cuya presentación clínica fue un tumor de mediastino anterosuperior. Presentación del caso: Hombre de 27 años con cuadro clínico de 1 mes de evolución caracterizado por dolor en hemitórax izquierdo, disnea de medianos esfuerzos, tos no productiva en accesos, picos febriles vespertinos y pérdida de $6 \mathrm{~kg}$. Ingresa con radiografía de tórax tomada al inicio de los síntomas observándose opacidad de bordes bien definidos, en región intercleidohiliar interna izquierda, paralela a tráquea sugiriendo tumor de mediastino, se realiza nueva radiografía donde observamos aumento de la opacidad, con volumen mayor al doble de la imagen inicial, se realiza biopsia por minitoracotomía anterior. Linfoma de zona gris con características intermedias entre linfoma de Hodgkin y linfoma difuso de células B grandes. Conclusión: Una opacidad mediastinal en un paciente joven nos obliga a descartar la presencia de linfoma, teratoma o tumor germinal como principales diagnósticos diferenciales. Aporte a la práctica clínica diaria: $\mathrm{La}$ presentación clínica del linfoma de zona gris es similar a la del linfoma de Hodgkin mediastinal, frecuente en hombres de la tercera y cuarta década; sin embargo, a diferencia del linfoma de Hodgkin y el linfoma de células B mediastinales tiene un curso clínico más agresivo con menor respuesta a tratamiento. Dado su reciente reconocimiento y relativa escasez de casos, se justifica su descripción con la finalidad de mejorar el diagnóstico temprano y estimular el desarrollo de mejores tratamientos.

\section{Factores predictores de mortalidad en pacientes con mediastinitis necrotizante descendente}

Cervantes $Y$, Rueda VP, Téllez BJL, Izunza SS, Gómez GR, Berrios MJA

INER Ismael Cosío VIIlegas;

Hospital Regional General 220, Toluca

Introducción: La mediastinitis necrotizante descendente es un padecimiento de origen infeccioso potencialmente letal, su evolución es rápidamente progresiva a sepsis y falla orgánica múltiple, su mortalidad oscila entre el 11 y 40\%. Objetivos: Evaluar los factores pronósticos de mortalidad en pacientes con mediastinitis necrotizante descendente. Material y métodos: Se hizo una revisión retrospectiva de pacientes con mediastinitis necrotizante descendente del 2006 al 2016, atendidos en el Instituto de Enfermedades Respiratorias se incluyeron 37 pacientes, evaluando variables demográficas y de riesgo contrastadas con variables de evolución posquirúrgica. Se realizó análisis de regresión logística utilizando programa IBM SPSS Statistic 20. La mediastinitis necrotizante descendente es una enfermedad altamente letal, el conocimiento de los factores de riesgo asociados a mortalidad permitirá establecer medidas terapéuticas eficacesy tempranas. Resultados: Se incluyeron 37 pacientes, 8 mujeres (21.6\%) y 29 hombres (78.4\%), la edad promedio fue 43.8 , la media de tiempo de evolución fue de 12 días, el $91.8 \%$ fueron clasificación ENDO IIB, al ingreso el SOFA fue de $9.89 \pm 5.92$ y APACHE de $19.43 \pm 9.57$. La mortalidad fue de $37.8 \%$. Como factores pronósticos de mortalidad se encontró que el $80 \%$ de los pacientes con hipertensión arterial fallecieron, en cambio sólo el $31 \%$ de los pacientes sin hipertensión arterial fallecieron con una p significativa de 0.03 , el 
$60 \%$ de los pacientes con diabetes mellitus falleció; sin embargo, no fue significativo estadísticamente $(\mathrm{p}=0.09)$, para los pacientes que fallecieron la media de SOFA fue de 14.36 OR 7.18 (rango 3.86-10.49) $\mathrm{p}<0.001$ y APACHE de 26.07 OR 10.68 (rango 5.09-16.26) $\mathrm{p}<0.001$. Conclusión: En este estudio la mortalidad en nuestra población es similar a la encontrada en otras series, los factores identificados como predictores de mortalidad fueron hipertensión arterial y el puntaje de SOFA y APACHE al ingreso. Aporte a la práctica clínica diaria: Estratificar los pacientes con mediastinitis necrotizante descendente en grupos de riesgo para individualizar manejo.

\section{Factores de riesgo asociados a mortalidad en pacientes sometidos a traqueostomía percutánea guiada por broncoscopia durante el período 2014- 2015 en el Instituto Nacional de Enfermedades Respiratorias}

\section{Jaquez CMA, García IIR, López GB, Enseñat FM, Martínez MD, Sánchez CO}

INER Ismael Cosío Villegas

Introducción: La traqueostomía percutánea es un procedimiento mínimamente invasivo en el que el abordaje traqueal se efectúa con técnica de Seldinger, presenta baja tasa de morbilidad atribuible a que expone menor cantidad de tejido y la preservación del anillo cartilaginoso traqueal, comparado con la TQ. Objetivos: Analizar e identificar factores de riesgo asociados a mortalidad en pacientes con TP guiada por broncoscopia durante el 2014-2015 en el INER. Objetivos específicos: Calcular medidas de impacto potencial asociadas a mortalidad. Material y métodos: Estudio de investigación clínica, observacional, retrospectivo y transversal. Análisis estadístico: Para todas las variables clínicas, diagnósticas y de intervención se utilizó estadística descriptiva, se utilizaron proporciones, medidas de tendencia central y de dispersión. Se calculó la tasa de mortalidad en la población de estudio, se identificaron factores de riesgo asociados a mortalidad se calculó la razón de incidencia acumulada (RIA) para estimar la incidencia del grupo expuesto a un factor de riesgo entre la incidencia del grupo no expuesto. Resultados: Se incluyó un total de 165 pacientes, el $67.1 \%$ fue de sexo masculino, edad 51.5 años. Las comorbilidades más importantes en los pacientes que fallecieron fueron la HP y la EPI con diferencia estadísticamente significativa respecto a los que sobrevivieron, $\mathrm{p}<0.026$ y $\mathrm{p}<$ 0.02 . El diagnóstico de ingreso que más frecuentemente se presentó en los que murieron fue choque séptico $(\mathrm{p}<0.011)$. No se reportaron muertes asociadas directamente al procedimiento; sin embargo, $44.5 \%$ de los pacientes fallecieron por otras causas, siendo la más frecuente neumonía intrahospitalaria y comorbilidades asociadas. Conclusión: La TP es un procedimiento seguro y útil en pacientes críticamente enfermos, realizado de forma temprana y por personal experto, sin embargo, la tasa de mortalidad mostrada en esta cohorte fue de $44.5 \%$, ninguna atribuible directamente al procedimiento, sino más bien a neumonía nosocomial por ventilación mecánica prolongada y comorbilidades asociadas.

\section{Tumor de células granulares de localización traqueal. Reporte de un caso}

\section{Cervantes SY, Iñiguez GMA, Aguirre $P T$, Briseño $H A$}

INER Ismael Cosío Villegas

Introducción: El tumor de células granulares es un tumor infrecuente su nombre, inicialmente fue acuñado por la semejanza que poseía con las células granulares musculoesqueléticas, actualmente se atribuye un origen neural en las células de Schwann, la mayoría son benignos, pero un porcentaje pequeño tienen comportamiento agresivo, la localización en vía aérea respiratoria, particularmente tráquea y bronquios es extremadamente rara, por lo que existe gran dificultad diagnóstica. Objetivos: Reportar un caso de tumor de células granulares de localización traqueal. Material y métodos: Se describirá brevemente la evolución clínica de una paciente de 16 años con un tumor de células granulares traqueal, algoritmo diagnóstico y tratamiento quirúrgico. Presentación del caso: Mujer de 16 años con cuadro de 5 meses de evolución con disnea progresiva, tos con expectoración blanquecina, fiebre y malestar general, tratamientos diversos sin mejoría, la radiografía de tórax muestra neumonía bilateral en la tomografía de tórax, lesión en tercio distal de la tráquea, que ocluye el $80 \%$ de la luz.Se realizó broncoscopia, criobiopsias y citorreducción del tumor, con permeabilidad traqueal del $100 \%$, el reporte de patología revela tumor de células granulares (tumor de Abrikossoff) con inmunohistoquímica positiva para PS100, vimentina y NSE. Se sometió a resección y anastomosis traqueal. Resultados: A 15 meses de seguimiento, la paciente se encuentra asintomática, la espirometría sin datos de obstrucción de la vía aérea, la videobroncoscopia de seguimiento y tomografía de control no muestran recidiva tumoral, ni estenosis en sitio de anastomosis. Conclusión: El tumor de células granulares es un tumor raro, ocurre entre la cuarta y sexta décadas de la vida, habitualmente en mujeres, son pocos los casos reportados en niños. La localización en vía aérea es poco común, $2 \%$ tienen potencial maligno. Se requiere un alto índice de sospecha para su dianóstico. El tratamiento quirúrgico más efectivo es la resección de la lesión con márgenes negativos. La recurrencia es del 8 al 12\% posterior a la cirugía. Aporte a la práctica clínica diaria: Reconocerel tumor de células granulares traqueal como diagnóstico diferencial de otras neoplasias.

\section{Ácaros en polvo casero}

\section{Badillo AJI, Martínez FM, Garza VI, Díaz GVA}

Hospital General Zacatecas; Universidad Autónoma de Zacatecas 
Introducción: Los ácaros son pequeños arácnidos (200-500 micras) forman parte del grupo más antiguo, diverso y numeroso de animales que ha existido en el planeta. Habitan en medios con condiciones óptimas de calor, humedad, altura, habitualmente en alfombras, colchones, almohadas y sillones donde se alimentan de escamas dérmicas humanas. Sus principales componentes alergénicos implicados como causa de enfermedades alérgicas respiratorias son sus partículas fecales. Objetivos: Identificar especies de ácaros prevalentes en polvo casero en la Ciudad Zacatecas. Material y métodos: Se realizó estudio descriptivo, previo consentimiento informado por escrito, se recolectaron 90 muestras de polvo casero de 60 domicilios diferentes, en diferentes épocas del año, mediante aspiradora doméstica se tomaron muestras de 1-2 g del polvo de colchones, almohadas y sillones; se procesaron según método de flotación de Hart y Fain que utiliza la diferencia de densidad específica entre los ácaros y las soluciones de etanol $70 \%$ y cloruro de sodio saturada, tal mezcla de soluciones es decantada a caja de Petri y observada al estereomicroscopio. Los ácaros que resultasen se aspirarían mediante micropipeta para identificarse y cuantificarse por gramo, mediante microscopio óptico. Igualmente se tomaron igual cantidad de muestras mediante cinta adhesiva transparente y posterior observación directa al microscopio óptico, para identificarse y cuantificarse. Técnica ideada por nosotros. Resultados: De 90 muestras de polvo casero colectadas TODAS resultaron NEGATIVAS para ácaros. Se observaron diferentes estructuras de material inorgánico. Conclusión: Es conocido que la humedad relativa baja es el principal factor limitante del crecimiento y desarrollo de los ácaros seguido de bajas temperaturas $y$ altitud, condiciones que coexisten en nuestra ciudad para una inadecuada proliferación de ácaros. En consecuencia, el número tan disminuido de ácaros más que su inexistencia es el principal factor que nos impidió encontrarlos. Aporte a la práctica clínica diaria: Se requiere mayor número de muestras.

\section{Amiloidosis intersticial difusa. Reporte de un caso}

Márquez GC, Fuentes JJC, Hernández TV, Cabrera RMDA, Flores GCA, Flores IAA

IMSS CMN «La Raza»; CMN Siglo XXI

Introducción: Las enfermedades por depósito presentan una baja incidencia, así como una evolución fatal. Pueden afectar cualquier órgano y sistema, por lo que los pulmones pueden resultar afectados en estas enfermedades. Objetivos: Describir las características clínicas de la afección pulmonar en la amiloidosis. Material y métodos: Presentación de un caso de amiloidosis pulmonar intersticial que fue hospitalizado en nuestra unidad hospitalaria. Presentación del caso: Hombre de 54 años de edad. Diabetes mellitus tipo 2 diagnóstico hace 26 años, tratamiento con insulina. Tabaquismo activo, 40 paquetes/ año. Cuadro clínico de 3 años de evolución: tos productiva, cianozante, emetizante, con esputo verdoso y posteriormente gris; disnea progresiva incapacitante y dolor torácico de tipo pleurítico derecho. Múltiples internamientos, evidencia de derrame pleural bilateral, predominio derecho, exudado por criterios de Light, colocación de sonda endopleural. BAAR, estudio bacteriológico de esputo negativos. Broncoscopia: estenosis concéntrica del $50 \%$ del bronquio de lóbulo medio por tejido liso de tipo exofítico, histopatológico no concluyente. Se decide realizar biopsia pulmonar y pleural por toracotomía: pulmón atrapado, con la presencia de abundante tejido gelatinoso en lóbulo inferior derecho. Reporte histopatológico: infiltración multifocal intersticial y perivascular de material hialino amorfo correspondiente a amiloide. Resultados: La amiloidosis se caracteriza por el depósito de la proteína amiloide. Las manifestaciones pulmonares pueden ser diversas. Este caso se trata de una amiloidosis instersticial en la que se afectan los septos alveolares así como los vasos de pequeño calibre. La afección cardíaca en la enfermedad sistémica se asocia a la morbimortalidad de la misma. La identificación histopatológica es clave para establecer el diagnóstico. Conclusión: Las enfermedades por depósito poseen una incidencia y prevalencia muy baja e incluso desconocida en muchas regiones.
Debido a la morbimortalidad tan elevada que conllevan es importante su sospecha inicial para su diagnóstico y tratamiento oportunos. Aporte a la práctica clínica diaria: Información sobre una entidad desconocida, cuya incidencia y prevalencia se subestima y cuya evolución se ignora.

\section{Hemofilia A adquirida como síndrome paraneoplásico de adenocarcinoma pulmonar. Reporte de un caso}

\section{Márquez GC, Cabrera RMDA, Alberto Alejandro Flores IAA}

IMSS, CMN «La Raza»

Introducción: El cáncer de pulmón ocupa el primer lugar en incidencia por cáncer a nivel mundial. La patobiología del mismo es compleja, así como su diagnóstico y tratamiento. Es el tipo de cáncer que se asocia a más síndromes paraneoplásicos. Objetivos: Dar a conoce las características de un síndrome paraneoplásico hematológico por adenocarcinoma de pulmón. Material y métodos: Presentación de un caso de adenocarcinoma de pulmón con síndrome paraneoplásico hematológico, como causa de muerte en un paciente. Presentación del caso: Hombre, 68 años. Hipertensión arterial sistémica en tratamiento; tabaquismo 70 paquetes/ año, suspendido. Hemotórax traumático izquierdo (diciembre de 2015), ameritó manejo quirúrgico, biopsia negativa. El 05 de mayo de 2016 presenta aumento de volumen en cara posterior de hemitórax derecho, dolor de tipo pleurítico y disnea progresiva. Se realiza TC de tórax: paquipleuritis, derrame pleural y hematoma de pared torácica derechos. Presenta aumento progresivo del hematoma de pared, ameritando toracotomía derecha con drenaje y toma de biopsia pleural. Gasto $>1,000 \mathrm{~cm}^{3}$, hemático por sonda endopleural. Diagnóstico de hemofilia A secundaria, manejo con FEIBA. Defunción 24 de mayo, reporte de necropsia: adenocarcinoma pulmonar micropapilar poco diferenciado de lóbulo inferior derecho, mestástasis ganglionares, glo- 
meruloesclerosis focal y segmentaria, hemofilia A adquirida. Resultados: Las coagulopatías por inhibidores adquiridos son mediadas por factores inmunitarios humorales, cuyo blanco son diversos factores de la coagulación, siendo el más común el factor VIII. Se asocian a causas subyacentes; sin embargo, las neoplasias son más comunes. Afecta a adultos de edad avanzada y su diagnóstico es complejo. Su tratamiento mediante factores recombinantes e inmunomoduladores es clave, sin embargo, su mortalidad es elevada. Conclusión: Los síndromes paraneoplásicos son entidades bien descritas cuyo conocimiento es primordial para un diagnóstico y tratamiento oportunos. Los síndromes hematológicos son raros, con bajo índice de sospecha y se asocian a una elevada mortalidad. Aporte a la práctica clínica diaria: Conocimiento sobre un síndrome hematológico asociado al cáncer que conlleva mortalidad.

\section{Detección de}

\section{mycobacterium}

\section{tuberculosis en pacientes con VIH/SIDA por lavado bronquial con fibrobroncoscopia}

\section{Luis ME, Núñez PRC, Hernández SA, Martínez ChRA, Cicero SR}

Hospital General de México «Dr. Eduardo Liceaga»; Facultad de Medicina, UNAM

Introducción: La infección por VIH/ SIDA sigue siendo un problema de salud pública y continúa en aumento, las infecciones oportunistas pulmonares son la principal causa de morbimortalidad, la tuberculosis representa la principal comorbilidad asociada siendo un factor contribuyente para la alta mortalidad. La OMS recomienda realizar búsqueda intencionada de tuberculosis en pacientes con recién diagnóstico de VIH con la finalidad de reducir la mortalidad, garantizar la seguridad del tratamiento antirretroviral y facilitar el uso de tratamiento preventivo. Objetivos: Objetivo general: Determinar la frecuencia diagnóstica de tuberculosis por lavado bronquial con fibrobroncoscopia en pacientes con VIH/SIDA. Material y métodos: Se realizó fibrobroncoscopia a los pacientes con VIH/SIDA y síntomas pulmonares durante más de 2 semanas en el último mes, que no expectoraban o que tenían baciloscopias negativas pero con alta sospecha clínica de tuberculosis. Se realizó un estudio observacional, descriptivo y prospectivo. Resultados: Se estudiaron 82 pacientes, de todos los casos 26 pacientes expectoraban y 56 no a éstos se realizó fibrobroncoscopia. De los pacientes con expectoración la tinción Ziehl Neelsen fue positiva en 5 pacientes, en 12 pacientes se aislaron otros agentes infecciosos y en 9 se realizó fibrobroncoscopia con tinción Ziehl Neelsen, cultivos Löwenstein Jensen, cultivos MGIT 960 y XpertMTB/RIF, se confirmó el diagnóstico en 18 pacientes. La tasa de complicaciones del lavado bronquial fue mínima. Conclusión: En pacientes con probable tuberculosis el BAAR negativo no implica necesariamente la ausencia de TB. En este estudio por lavado bronquial se confirmó la presencia de $M$. tuberculosis en $21 \%$ de pacientes con alta sospecha clínica, lo que demuestra la utilidad del lavado bronquial en casos dudosos. La implementación de biología molecular es importante porque el resultado se obtiene de inmediato. Aporte a la práctica clínica diaria: La broncoscopia debe ser considerada como un estudio diagnóstico en cualquier paciente con enfermedad pulmonar grave y cuando no se ha podido llegar al diagnóstico con los métodos menos invasivos.

\section{Incidencia de}

complicaciones en

pacientes sometidos a traqueostomía percutánea guiada por broncoscopia en el Instituto Nacional de Enfermedades Respiratorias Ismael Cosío Villegas. Cohorte retrospectiva

García IIR, Altagracia JM, López GB, Enseñat FM, Martínez MD, Sánchez CO

INER Ismael Cosío Villegas
Objetivos: Calcular tasa de incidencia de complicaciones en pacientes sometidos a traqueostomía percutánea guiada por broncoscopia en el INER. Material y métodos: Diseño: Estudio de investigación clínica, observacional, retrospectivo, realizado en la unidad de Neumología Intervencionista del INER. Criterios de inclusion: Pacientes de género indistinto mayores de 18 años a quienes se les realizó traqueostomía percutánea (TP) con guía broncoscópica en el período comprendido entre 1ro enero de 2014 y 31 de diciembre de 2015 y que cuenten con expediente completo. Metodología: Se revisaron expedientes clínicos para recabar las variables demográficas, clínicas, de técnica quirúrgica y sus complicaciones, estancia intrahospitalaria. Análisis estadístico: Para todas las variables clínicas, diagnósticas y de intervención se utilizó estadística descriptiva; para variables categóricas se utilizaron proporciones y para variables numéricas medidas de tendencia central y de dispersión. Se calculó la incidencia de complicaciones en la población de estudio, se identificaron factores de riesgo para el desarrollo de complicaciones por su temporalidad (inmediatas, intermedias y tardías) y por su gravedad (menores, intermedias y graves), se calculó la razón de incidencia acumulada (RIA) para estimar la incidencia del grupo expuesto a un factor de riesgo entre la incidencia del grupo no-expuesto a ese factor con sus intervalos de confianza al $95 \%$ y prueba $\chi^{2}$. Resultados: 165 pacientes cumplieron los criterios de inclusión. La incidencia de complicaciones fue de $6 \%$ (10 pacientes), 8 pacientes fueron inmediatas, siendo la más frecuente hipoxemia. No se reportaron muertes asociadas al procedimiento, sin embargo, el $44 \%$ de los pacientes fallecieron por otras causas, siendo la más frecuente neumonía intrahospitalaria. Conclusión: Nuestro estudio confirma que la traqueostomía percutánea presenta una baja tasa de complicaciones en pacientes críticamente enfermos, sin dejar secuelas permanentes ni limitación funcional. La obesidad y sobrepeso fueron los factores de riesgo asociados a complicaciones de la traqueostomía percutánea. Aporte a la práctica clínica diaria: Seguridad de la traqueostomía percuntánea. 
Índice arteria pulmonar/ aorta como predictor de exacerbaciones graves en pacientes con EPOC secundario a tabaquismo y humo de leña atendidos en el Instituto Nacional de Enfermedades Respiratorias

Rodríguez RYG, Velázquez UM, Sansores MR, Ramírez VA

HMG Coyoacán; Hospital de La Mujer, Morelia, Michoacán; Centro Respiratorio de México; INER

Introducción: Las exacerbaciones agudas de la EPOC son eventos críticos asociados con pérdida acelerada de la función pulmonar, empeoramiento de la calidad de vida y mortalidad. El índice arteria pulmonar/ aorta (Ap/Ao) medido por TAC ha sido validado como predictor de exacerbaciones en pacientes con EPOC por tabaco en población anglosajona. Objetivo: Evaluar la asociación entre el índice Ap/Ao medido por TAC y las exacerbaciones graves en pacientes con EPOC y población mexicana atendida en el INER pertenecientes a la cohorte DITABE. Material y métodos: Estudio observacional, transversal, retrolectivo, descriptivo y comparativo. Muestra consecutiva de pacientes con EPOC pertenecientes a la Cohorte del DITABE, reclutados en el período enero 2012 a marzo del 2013. Resultados: Se incluyeron 43 pacientes con mayor proporción de hombres $(62.8 \%)$ que mujeres $(37.2 \%)$, con una media de edad de 68.02 años (DE 9.60). El factor causal de EPOC predominante fue la exposición a humo de tabaco (76.7\%). La media de VEF1 48.16 $\%$ (DE 20.30). El 62.8\% de los pacientes tuvieron al menos una exacerbacion grave, siendo el $39.5 \%$ de los pacientes exacerbadores frecuentes. Del total de la muestra únicamente 6 pacientes $(13.9 \%)$ tenían índice Ap/Ao mayor a 1 y no se asoció a exacerbaciones graves ( $p$ 0.832). No se encontraron variables predictoras (índice de disnea, gravedad de obstrucción, estado funcional) del índice de Ap/Ao mayor a 1.
Los pacientes con índice Ap/Ao > 1 difieren de los pacientes con índice Ap/Ao ? 1 en la frecuencia de sobrepeso $(28.42 \mathrm{~kg} /$ $\mathrm{m}^{2}$ vs. $25 \mathrm{~kg} / \mathrm{m}^{2}$, p .049) y de apnea obstructiva del sueño e insuficiencia cardíaca ( $\mathrm{p}=0.012$ y $\mathrm{p}=0.012$, respectivamente). Conclusión: El índice Ap/Ao no parece ser un buen predictor de exacerbaciones graves en población mexicana. Se requieren estudios longitudinales para conclusiones definitivas a este respecto.

\section{Neumonía intersticial con patrón usual como complicación tardía de radioterapia}

Bassol AC, Vega SÁ, Belmontes BJR, Juárez LJE, Vargas SJL, Flores $F$, Hernández ZR

INER Ismael Cosío Villegas

Introducción: La radioterapia es la principal terapia adyuvante para neoplasias torácicas. La radiosensibilidad del pulmón lo hace susceptible a manifestaciones inflamatorias. Objetivos: Describir las complicaciones pulmonares de radioterapia. Presentación del caso: Masculino 78 años, con antecedente de tabaquismo inactivo e índice tabáquico 15 paquetes-año, en 2016 laríngeo escamoso moderadamente diferenciado estadío II. Recibió tratamiento durante 18 meses con cordectomía láser, quimioterapia y 40 sesiones de radioterapia. Tres meses posteriores es valorado por cambios inusuales en placa de tórax y por tos seca con disnea. La tomografía de tórax documentó una neumonía intersticial difusa con un patrón usual y estenosis subepiglótica. A su ingreso recibió soporte mecánico ventilatorio no invasivo por falla respiratoria hipercápnica crónica agudizada con hipoxemia, esteroide sistémico y terapia inhalada. Por persistencia del estridor laríngeo a pesar del tratamiento, se realizó broncoscopia que corroboró estenosis subepiglótica grave por lesión vascularizada y cambios cicatrizales. El reporte de biopsia fue carcinoma escamoso de laringe moderadamente diferenciado, invasor. Se realizó traqueostomía percutánea sin complicaciones. Egresó con seguimiento por oncología. Resultados: La tolerancia de los tejidos a la radioterapia depende de la radiosensibilidad intrínseca, la relación dosis-volumen y factores de riesgo que son: edad > 60 años, tabaquismo, afección de lóbulos inferiores, clase funcional baja, $\mathrm{PaO}_{2}$ basal $<80$, aumento del TGF- $\alpha$ posradiación, dosis altas de radiación, quimioterapia con platinos, taxanos y gemcitabina. La hipoxemia crónica estimulará reacciones proinflamatorias y profibrinógenas que ocasionarán daño pulmonar crónico. Los síntomas se presentan tras 3 meses de la radioterapia. El LENT SOMA permite graduar la gravedad del cuadro y dirigir la terapia de soporte con esteroides, antibióticos en exacerbaciones y broncodilatadores, oxígeno suplementario y nintedanib en neumonías con patrón usual. Conclusión: La detección temprana y el uso de nintedanib puede disminuir la progresión funcional (CVF) y morfológica en neumonía intersticial por radiación. Aporte a la práctica clínica diaria: Debe existir un cribado en pacientes sometidos a radioterapia para detección temprana de este tipo de complicaciones.

\section{Evaluación de la producción de IP-10 como indicador de tuberculosis latente en contactos cercanos de pacientes con tuberculosis pulmonar}

Arreaga FGL, Muñoz TM, Salazar
LMÁ, Espinosa SR, Cruz-Lagunas A,
Márquez GJE, Jiménez ÁL, Zúñiga J

INER Ismael Cosío Villegas

Introducción: La tuberculosis (TB) es un problema de salud pública mundial que afecta a 9.2 millones de personas anualmente y se ha estimado que un tercio de la población mundial podría tener TB latente (TBL). Se ha sugerido que algunas quimiocinas podrían ser de utilidad para establecer con mayor precisión la presencia de TBL. Objetivos: Analizar la producción de IP-10 en respuesta de antígenos de M. tuberculosis (Mtb) como indicador de 
TBL en contactos estrechos de pacientes con TB pulmonar. Material y métodos: Se estudiaron 30 individuos contactos domiciliarios de pacientes con TB pulmonar. Se realizó la prueba de Quantiferon TB Gold In Tube estimulando células mononucleares de sangre periférica con antígenos de Mtb como ESAT-6, CFP-10 y TB7.7 y los niveles de IFN- $\boldsymbol{\gamma}$ se cuantificaron por ELISA. También se cuantificaron los niveles de IP-10 por Luminometría en los sobrenadantes de estímulos con antígenos de Mtb. Se realizaron pruebas de PPD en todos los sujetos y radiografía de tórax. Las diferencias se evaluaron por U de MannWhitney y correlación de Spearman. Resultados: Los ensayos de Quantiferon fueron positivos en 21/30 (70\%) de los contactos de pacientes con TB pulmonar mientras que PPD fue positivo en 18/30 (60\%). El 43\% de los contactos tuvo ambas pruebas, Quantiferon y PPD positivas. Se observó un aumento significativo en la producción de IP-10 en los contactos Quantiferon positivo en relación con los negativos $(\mathrm{p}=0.0003)$ y donadores sanos ( $\mathrm{p}=0.002)$; sin embargo, 2/12 (16.6\%) de los contactos Quantiferon negativos (con niveles limítrofes de IFN- $\gamma$ ) tuvieron niveles altos de IP-10 (mayores a 500 pg/ $\mathrm{mL}$ ). Se observó una correlación positiva $(\mathrm{r}=0.82, \mathrm{p}=0.0001)$ entre niveles altos de IP-10 e IFN- $\boldsymbol{\gamma}$. Conclusión: La quimiocina IP-10 podría ser un marcador útil en el diagnóstico de TBL ya que correlaciona con los niveles de IFN- $\gamma$ después del estímulo con antígenos de Mtb.

\section{Aspecto clínico, radiográfico y de funcionamiento pulmonar en el síndrome combinado fibrosis pulmonar y enfisema: reporte de un caso}

\section{Rivera UCP, Moreno JF, Villegas JF, Roberto Mercado $R$}

Hospital Universitario José Eleuterio González; de Hoyos Abril; Elizondo; Longoria

Introducción: El enfisema pulmonar, las enfermedades intersticiales incluyendo la fibrosis pulmonar idiopática son entidades definidas por pruebas clínicas, funcionales, radiográficas y criterios histopatológicos. Objetivos: Describir un caso de fibrosis pulmonar y enfisema, su aspecto clínico, radiográfico y fisiológico. Presentación del caso: Masculino de 68 años con tabaquismo (40 paquetes/año), presenta disnea de 10 meses de evolución, tos irritativa ocasional, oximetría de pulso $80 \%\left(\mathrm{PaO}_{2} 51 \mathrm{mmHg}\right)$, acropaquia, crepitantes bibasales en velcro, hemoglobina de $13.6 \mathrm{~g} / \mathrm{dL}$, espirometría patrón restrictivo leve, con CPT 5.06 (75\%) y volumen residual 2.15 (91\%), DLCO 11\% del predicho, $\mathrm{FEV}_{1} 2.41 \mathrm{~L}, \mathrm{FVC} 2.78 \mathrm{~L}_{\text {, FEV }} / \mathrm{FVC}$ 87\%. TAC AR con áreas de enfisema paraseptal y centrilobulillar enlóbulos superiores y zonas de transición con bullas subpleurales y panalización bibasal. Prueba de ejercicio cardiopulmonar con tolerancia severamente disminuida, respuesta presora normal e hipoxemia severa. Resultados: Las manifestaciones del síndrome combinado fibrosis pulmonar y enfisema son inespecíficas. Algunos hallazgos son: áreas de enfisema en lóbulos superiores, panalización y fibrosis basal. A pesar de no tener un patrón espirométrico específico la función pulmonar con $\mathrm{CVF}, \mathrm{FEV}_{1}$ y CPT son inesperadamente normales o ligeramente anormal, con DLCO severamente disminuidas e hipoxemia en ejercicio, dichas características explicadas por presentar correlación con los hallazgos por imagen, traducidos a una hiperinflación y aumento de la complianza pulmonar que compensa la pérdida de volumen dada por la fibrosis pulmonar. Conclusión: Se describe un síndrome infrecuente subdiagnosticado, el cual presenta características distintivas dentro del diagnóstico diferencial de las causas de enfisema y la fibrosis pulmonar idiopática las cuales pueden sobreponerse. Aporte a la práctica clínica diaria: $\mathrm{Al}$ ser un síndrome infrecuente, con alto impacto pronóstico y calidad de vida, cobra importancia al identificarse rápidamente por tratamiento y evitar complicaciones, la información en la literatura puede ser confusa por la limitación de los datos, se describe los hallazgos más importantes y claves diagnósticas para su correcto abordaje e interpretación de los datos obtenidos.
Disfunción endotelial y temperatura periférica ante estrés psicológico en pacientes con insuficiencia cardiorrespiratoria. Resultados preliminares

Pérez CE, Torres MSC, Peláez HV, Figueroa HFA, Robles UB, Orea TA, Domínguez TB, González ID, Pérez CGK, Sánchez SRN, Navarrete PAG, Verdeja VL, Jiménez CAG

INER Ismael Cosío Villegas

Introducción: La disfunción endotelial es frecuente en las enfermedades cardiorrespiratorias, sin embargo, ha sido menos estudiada en pacientes con cor pulmonale. Por otro lado, el estrés psicológico afecta el endotelio y produce una menor vasodilatación, como resultado los pacientes presentan menor capacidad de termorregulación periférica y son más vulnerables a experimentar estrés psicológico, el cual afecta el pronóstico de estos pacientes. Objetivos: Determinar la relación entre la función endotelial y la temperatura periférica ante estrés psicológico en pacientes con insuficiencia cardiorrespiratoria. Material y métodos: Participaron 11 pacientes con insuficiencia cardiorrespiratoria (edad media $70.09 \pm 12,80$ años, $55.5 \%$ hombres, dominancia lateral diestra). Se evaluó la temperatura periférica bilateral de ambas manos durante un perfil psicofisiológico ante estrés psicológico de tres fases de cinco minutos cada una (línea base, estresor aritmético y recuperación). La función endotelial se evaluó mediante fotopletismografía, la cual consistió de: línea base, isquemia por cinco minutos e hiperemia reactiva, se tomaron los índices TAM/TT a los 30, 60, 90 y 120 segundos luego de la isquemia. Debido al tamaño de la muestra se realizó un análisis correlacional no paramétrico usando la $\mathrm{r}$ de Spearman. Resultados: Se encontraron principalmente correlaciones negativas entre el índice TAM/TT de la onda pulso a los 60 segundos y la temperatura periférica izquierda $(\mathrm{r}=-0.603 ; \mathrm{p}<0.05)$ y derecha $(\mathrm{r}=-0.616 ; \mathrm{p}<0.05)$ durante el estresor aritmético; así como con la temperatura 
periférica izquierda en recuperación $(\mathrm{r}=$ -0.603; $\mathrm{p}<0.05)$. Conclusión: Existe relación entre una mayor disfunción endotelial y una menor regulación autonómica de la temperatura periférica frente al estrés psicológico en estos pacientes. Sin embargo, estos datos son preliminares y se continuará trabajando en ellos para incrementar el tamaño de la muestra y buscar resultados más sólidos. Aporte a la práctica clínica diaria: Debe considerarse el tratamiento interdisciplinario de la disfunción endotelial y la mala regulación de la temperatura periférica, indicadores de peor pronóstico.

\section{Tumor neuroectodérmico primario de pulmón}

\section{Martínez OVA, Renpenning CEW}

Hospital Universitario UANL

Introducción: El sarcoma de Ewing intraóseo es el segundo tumor primario de hueso más frecuente después del osteosarcoma. En el momento del diagnóstico, un $24 \%$ de los casos presenta enfermedad metastásica, localizada fundamentalmente, por orden de frecuencia, en el pulmón, en otros huesos o en la médula ósea. Se origina fundamentalmente en huesos largos del esqueleto axial y afecta de forma preferente a las diáfisis, la edad media de presentación es de 15 años y se observa un ligero predominio masculino; en el tórax se localiza sobre todo en las costillas (tumor de Askin) y la localización pulmonar primaria es extremadamente rara, salvo en el marco de enfermedad metastásica, y con una edad de presentación un poco más tardía, en torno a los 20 años. Objetivos: Reportar caso de tumor neuroectodérmico primario de pulmón. Presentación del caso: Masculino de 19 años de edad, sin antecedentes heredofamiliares y personales patológicos de importancia, acude con un cuadro clínico de 1 mes de evolución, caracterizado por disnea, pérdida de peso, diaforesis y limitación en la clase funcional, radiografia de tórax muestra gran tumoración en hemitórax derecho. Resultados: Se realizan biopsias con tru cut guiadas por ultrasonido, observando células pequeñas, redondas, azules que se acumulan entre sí, con escaso citoplasma.
Conclusión: Tumor neuroectodérmico primario de pulmón, sin involucro a pared torácica y sin metástasis. Aporte a la práctica clínica diaria: Tener en mente los posibles diagnósticos diferenciales de los tumores en tórax, realizar el abordaje diagnóstico adecuado.

\section{Enfermedad pulmonar difusa asociada a artritis idiopática juvenil. Reporte de caso}

Rodríguez SIN, Velázquez SJR, Rojas SJ, Avilés RBA

INER Ismael Cosío Villegas

Introducción: La artritis idiopática juvenil (AIJ) engloba a todas las artritis de causa desconocida y comúnmente asociada a autoinmunidad de inicio antes de los 16 años de edad, existen diferentes variantes de presentación, articular o sistémica propiamente, siendo la afección pulmonar en $4 \%$ de inicio grave, con una mortalidad hasta del 10\%. Objetivos: Presentar el caso de un paciente con AIJ y afección pulmonar. Presentación del caso: Masculino de 14 años, madre con artritis reumatoide tratada con metrotexate. Sano previamente. Inició padecimiento actual 3 meses previos a su ingreso con accesos cortos de tos seca asociada a disnea, se agrega además mialgias, artralgias y mal estado general, es tratado con ciprofloxacino y paracetamol sin mejoría, por lo que es referido a nuestro Instituto. Ingresa con saturación de $70 \%$ con taquicardia, afebril, palidez de piel, taquipnea, dificultad respiratoria, estertores crepitantes diseminados bilaterales y acropaquias en extremidades. Radiografía con patrón intersticial difuso bilateral. TCAR con engrosamiento interlobulillar, patrón nodular, vidrio deslustrado y panal de abeja bilateral. Factor reumatoide positivo, anticuerpos anti-CCP positivos, anti-Ro positivos y reactantes de fase aguda positivos. Pruebas de función pulmonar con patrón restrictivo grave y disminución en la difusión de gases. Broncoscopia sin alteraciones. ECOT: HAP de $40 \mathrm{mmHg}$. Se concluye como enfermedad pulmonar difusa asociada a artritis idiopática juvenil. Se inicia tratamiento con metilprednisolona, leflunomida, metrotexate, rituximab, sildenafil y oxígeno suplementario. Conclusión: La afección intersticial difusa en niños representa una entidad poco frecuente en el espectro de la AIJ. Su incidicencia es baja; sin embargo, se debe sospechar de manera oportuna en pacientes con síntomas respiratorios, ya que su evolución conlleva a fibrosis pulmonar. Aporte a la práctica clínica diaria: Es importante el diagnóstico precoz del paciente con AIJ, que en su presentación con afección pulmonar como primera manifestación es infrecuente, se debe iniciar tratamiento inmunosupresor que disminuye la morbimortalidad.

\section{Laceración traqueal en traumatismo cerrado de tórax en un paciente pediátrico}

\section{Espinoza ESL, González MCY, Ruiz $P M D$, Rivas $M A$ \\ IMSS, UMAE Hospital de Cardiología 34, Monterrey, Nvo. León}

Introducción: La laceración traqueal traumática es una lesión poco frecuente que requiere intervención quirúrgica en casi todos los casos. Pequeñas laceraciones pueden ser manejadas sin cirugía, pero grandes desgarros requieren reparación quirúrgica. La historia natural es hacia la curación (90\%) pero puede haber estenosis. La broncoscopia preoperatoria es útil para determinar la extensión de la lesión y en el posoperatorio para asegurar una adecuada cicatrización y detectar estenosis. Presentación del caso: Femenino 6 años, traumatismo cerrado de tórax con pared de cemento. Sin dificultad respiratoria, pulsioximetría $>93 \%$ e hipoaereación apical derecha. TCAR tórax neumomediastino e hiperdensidad en ápice derecho compatible con hemorragia y atelectasia. Broncoscopia flexible hallazgo de laceración longitudinal de la pars membranosa de aprox. $5 \mathrm{~cm}$ desde el tercio medio hasta la carina. Traqueoplastía con parche de pericardio ameritando bomba de circulación 
extracorpórea por fuga aérea importante durante la disección. Broncoscopia posquirúrgico inmediato con reparación exitosa sin fuga u obstrucción dinámica. Se extubó al 3er. día posquirúrgico. Esofagograma sin fuga. Broncoscopia posoperatoria a los 15 días sin estenosis. Conclusión: La laceración traqueal traumática es poco frecuente, posibles mecanismos son hiperextensión traqueal contra la columna vertebral o aumento súbito de la presión intratraqueal por compresión torácica con una glotis cerrada. La mayoría ocurren alrededor de la carina. La broncoscopia determina la extensión y facilita la intubación evitando mayor lesión. La toracotomía posterolateral derecha expone mejor la tráquea y carina. Laceraciones longitudinales se reparan con cualquier forma de sutura, las circunferenciales con sutura interrumpida para evitar estenosis. Todas las reparaciones deben reforzarse con malla, músculo, colgajo pericárdico para limitar fugas o fístulas. El manejo posoperatorio sugiere extubación precoz, la broncoscopia posoperatoria debe realizarse dos semanas después de la cirugía para evaluar cicatrización y estenosis de la vía aérea.

\section{Tumor gigante fibroso solitario de pleura}

García TR, Torres VRA, Villarreal ZMA, Gómez BMF, Sánchez GJ

\section{IMSS}

Introducción: El tumor solitario pleural es una neoplasia rara, descrita por primera vez en 1870 por Wagener. En 1931, Klemperer y Rabin lo describieron como una lesión localizada y benigna. En 1942, Stout y Murray sugirieron un origen mesotelial. Posteriormente investigaciones con microscopio electrónico describen células epiteliales, confirmando el origen mesotelial. En 1979, Sharifker estudió 18 casos de tumor fibroso solitario y concluyó que las células mesoteliales halladas estaban atrapadas entre el tumor y que el origen real era el tejido fibroso submesotelial. Objetivos: Conocer al respecto de patología infrecuente en nuestro medio. Presentación del caso: Presentamos el caso de un paciente de sexo masculino de 62 años que ingresó con el diagnóstico de tumor de hemitórax izquierdo. Tras la realización de TAC y cirugía se hace el hallazgo de tumor torácico benigno fibroso solitario de pleura. Estos tumores son neoplasias infrecuentes de origen mesotelial de crecimiento lento y localizado. Su hallazgo suele ser incidental mediante radiografías de tórax, ya que más del $50 \%$ son asintomáticos, hasta que se presentan como masas de hasta 15 cm o más llegando a causar derrame por la compresión de estructuras aledañas. El tumor solitario fibroso de pleura es una entidad rara en nuestro medio, lo inusual de este caso fue el tamaño del tumor en nuestro paciente, ocupaba casi $90 \%$ del hemitórax izquierdo, siendo de los pocos casos que se han reportado en la literatura, recordando que no se ha asociado ningún factor ambiental y que la sospecha clínica es la principal arma para diagnosticar este padecimiento, apoyado con las técnicas de imagen, recomendándose la cirugía para obtener el diagnóstico anatomopatológico, así como tratamiento obteniéndose un buen pronóstico. Conclusión: El tumor solitario fibroso de pleura es una entidad rara en nuestro medio, lo inusual de este caso fue el tamaño del tumor en nuestro paciente, ocupaba casi $90 \%$ del hemitórax izquierdo, siendo de los pocos casos que se han reportado en la literatura, recordando que no se ha asociado ningún factor ambiental y que la sospecha clínica es la principal arma para diagnosticar este padecimiento, apoyado con las técnicas de imagen, recomendándose la cirugía para obtener el diagnóstico anatomopatológico, así como tratamiento obteniéndose un buen pronóstico. Aporte a la práctica clínica diaria: Sospecha de patología descrita, siendo infrecuente en nuestro medio.

\section{Complicaciones}

\section{cardiopulmonares agudas tras neumonectomía en enfermedad no maligna}

Vega SÁE, Bassol CAC, Belmontes BJR, Juárez LJE, Téllez NNA, Flores TFF, Hernández ZR

INER Ismael Cosío Villegas
Introducción: Más de la mitad de los pacientes sometidos a neumonectomía presentan complicaciones tempranas o tardías. La principal indicación en patología benigna son causas infecciosas. Objetivos: Describir las complicaciones de la neumonectomía. Material y métodos: Revisión de expediente clínico. Presentación del caso: hombre de 54 años de edad con antecedente de tabaquismo activo y DMT2. Ingresado por desnutrición, derrame pleural, absceso pulmonar e hidroneumotórax derecho con choque séptico. Se programó para neumonectomía derecha de urgencia. Se manejó con ventilación unipulmonar y sonda endopleural derecha, a las 72 horas presentó hemotórax que fue resuelto por reintervención. A los 9 días se extuba, y tras otros 5 días desarrolló neumomediastino y hemoptisis masiva. Con tomografía y broncoscopia se documentó dehiscencia del muñón derecho. Se reintervino para cierre de muñón y lavado de cavidad. De los cultivos de líquido pleural se aisló Streptococcus constellatus y del aspirado traqueal Stenotrophomona maltophillia, recibió tratamiento dirigido con resolución de la infección. La neumonectomía tiene una morbimortalidad elevada. Entre las complicaciones agudas encontramos edema agudo pulmonar, herniación cardíaca, arritmias cardíacas, fístula broncopleural, neumonía del pulmón contralateral, empiema y SIRA, que pueden ocurrir de manera separada o en combinación. Los factores asociados a mal pronóstico son: edad avanzada, PFR precirugía, EPOC, enfermedad cardiovascular y procedimiento urgente que confiere un riesgo hasta 10 veces mayor para complicaciones. La neumonectomía derecha se asocia a mayor mortalidad. Sólo un 50\% de los pacientes son evaluados con PFR. Conclusión: La morbimortalidad asociada a este procedimiento afecta a un $30 \%$ de pacientes, y aumenta en intervenciones urgentes en las que, además, no es posible evaluar los factores de riesgo mencionados. El tratamiento y seguimiento temprano de enfermedades infecciosas puede reducir la morbilidad asociada. Aporte a la práctica clínica diaria: La correcta selección de pacientes sometidos a neumonectomía de urgencia puede disminuir la morbimortalidad del procedimiento. 


\section{Análisis del derrame pleural en el sureste de México. Enfoque en presentación clínica y morbilidades}

\section{Cortés TA, Villarreal VAD, Che MJL, Vargas $M G$}

Hospital Regional de Alta Especialidad de la Península de Yucatán

Introducción: La etiología del derrame pleural (DP) puede presentar variaciones según el ámbito geográfico, temporal o de ubicación. En México, la frecuencia del DP se ha descrito en dos estudios que derivan del centro y norte del país. Los resultados no necesariamente se pueden aplicar a otras regiones o instituciones. Objetivos: Conocer la frecuencia y etiologías del DP, asimismo, diferencias clínicas y morbilidades entre las diversas etiologías en un hospital regional del sureste de México. Material y métodos: Estudio observacional, prospectivo que incluye la totalidad de casos con DP que ingresaron al hospital en un período de 4 años. Para objetivos del estudio, se excluyeron los casos con diagnóstico parcial o incluso que fueron derivados al hospital para continuar su abordaje. Del mismo modo, los casos con información clínica no suficiente para definir la etiología o características clínicas. Resultados: Se incluyeron 178 casos. Tomando como referencia 1,600 consultas de primera vez atendidas en el Departamento de Neumología en el período del estudio, la frecuencia del DP fue $11.1 \%$. La etiología más común fue infecciosa $(n=60,34 \%)$. Disnea fue el síntomas más común $(91 \%)$ y no mostró diferencias entre las etiologías. Por otro lado, tos, dolor torácico, fiebre, expectoración fueron más frecuentes en los casos de etiología infecciosa (bacteriana y tuberculosis). Finalmente, es destacable que los síntomas, diferentes a disnea, fueron expresados con la menor tasa en los trasudados al compararlos con los otros grupos. La morbilidad a destacar fue mala higiene oral asociado con causas infecciosas. Conclusión: La etiología del DP en un hospital regional contrasta con lo previamente publicado, posiblemente estas diferencias radiquen en el sistema de atención de los hospitales. Las diferencias en la expresión clínica pueden orientarnos a posibles causas del DP. Aporte a la práctica clínica diaria: Complementar el conocimiento de la etiología del DP con énfasis en el sureste de México, asimismo, describir la expresión clínica de cada etiología.

\section{Infecciones de la articulación esternoclavicular}

\section{López GJJ, Cazares CC, Preciado AN, López TJG}

Hospital Civil «Fray A. Alcalde» de Guadalajara

Introducción: La articulación esternoclavicular es una unión sinovial. La articulación incluye la clavícula medial, el manubrio superior y el primer cartílago costal. Ramas de la arteria torácica interna y supraescapulares son fuente primaria de irrigación de la articulación. Como en otras articulaciones sinoviales, la esternoclavicular es susceptible de artritis, subluxación e infección. La artritis séptica de la articulación esternoclavicular es una rara condición con incidencia no reportada. Dentro de las causas se encuentran diseminación hematógena de la bacteria a la articulación, extensión directa de una articulación cercana, e inoculación directa. El tratamiento más efectivo de la infección de la articulación esternoclavicular continúa siendo el quirúrgico con tasas de curación del $100 \%$ en pacientes tratados con resección de la articulación y colgajo pectoral. Objetivos: El objetivo de dicha presentación es avalar la buena respuesta obtenida con resección de la articulación, siendo radicales al momento de realizarla, concordando con la literatura consultada. Material y métodos: Presentación de caso clínico. Se trata de un paciente masculino de 55 años de edad, comórbidos de hipertensión arterial y diabetes mellitus tipo 2. Inicia su padecimiento cinco días previos a la consulta por presentar dolor, tumor y calor en la región de la articulación esternoclavicular derecha, que incrementó los síntomas progresivamente, presentan- do episodios febriles los últimos días. Al ingreso se realizó tomografía de tórax observando colección periarticular esternoclavicular derecha con ocupación hacia el opérculo torácico. Se inicia tratamiento con antibiótico, meropenem-linezolid, previa toma de cultivos, mediante punción aspiración, que se reportaron negativos. Se decide ingreso a sala operatoria, donde se realiza resección de tercio medial de la clavícula, hemimanubrio y extremo medial de la primera costilla. Se debrida tejido necrótico e inflamado y realizan lavados profusos con solución antiséptica. Se observa infección hacia opérculo torácico por lo que se coloca drenaje hacia cavidad formada y se deja herida abierta para permitir aseo diario. Se empaqueta cavidad con gasas embebidas en solución salina. El paciente evoluciona favorablemente y se egresa diez días posteriores. Resultados obtenidos en concordancia con la literatura consultada. Conclusión: La infección de la articulación esternoclavicular es rara y no se conoce su incidencia precisa. $\mathrm{La}$ enfermedad como la diabetes es un importante factor de riesgo predisponente. El dolor es el síntoma inicial predominante seguido de edema localizado y fiebre. La tomografía es un método sensible y útil para establecer el diagnóstico. La resección quirúrgica de la articulación esternoclavicular es el tratamiento establecido con mayor tasa de éxito reportada. Aporte a la práctica clínica diaria: Por tratarse de una enfermedad poco frecuente, es importante presentar la experiencia obtenida en dicho caso para permitir un abordaje diagnóstico y terapéutico inmediato y definitivo.

\section{Diferencias en el rendimiento durante la prueba de caminata de seis minutos entre pacientes con insuficiencia cardiorrespiratoria y sus cuidadores primarios informales}

Robles UB, Orea TA, Torres MS, Figueroa HA, Pérez CE, Verdeja VL, 
Peláez HV, Jiménez CA, González ID, Sánchez SR, Pérez CGK, Navarrete $P A$

INER Ismael Cosío Villegas

Introducción: Los pacientes con insuficiencia cardiorrespiratoria (ICR) presentan elevados índices de discapacidad y morbimortalidad. A su vez, el cuidador primario informal (CPI), a lo largo del proceso de la enfermedad, aumenta de manera progresiva la carga física y psicológica, con el riesgo consecuente de desarrollar problemas de salud. Objetivos: Comparar el desempeño durante la prueba de caminata de seis minutos (P6CM) entre pacientes con ICR y sus CPI. Material y métodos: Participaron 18 pacientes con ICR (G1, edad media $70.94 \pm 14.67$, $50 \%$ mujeres) y 18 CPI (G2, edad media $56.83 \pm 13.28,83.3 \%$ mujeres), quienes realizaron la P6CM. Se registraron presión arterial sistólica (PAS) y diastólica (PAD), frecuencia cardíaca (FC) y frecuencia respiratoria (FR) en las fases: 1) Línea base, 2) al término de la caminata y 3) recuperación al minuto. Se realizó $\chi^{2}$ para variables nominales y U de Mann-Whitney para variables continuas, usando SPSS 23. Resultados: Existieron diferencias estadísticamente significativas en edad y distribución de sexo $(\mathrm{p}<.05)$ entre ambos grupos. No se encontraron diferencias en el desempeño durante la P6CM ( $\mathrm{p}>.05)$, excepto en la FR durante las fases 2 y 3 ( $\mathrm{p}<$ $\left..05^{*}\right)$ : Distancia (G1/G2): $304.06 \pm 163.13$ $\mathrm{m} / 348 \pm 108.82 \mathrm{~m}$. Tiempo (G1/G2): $291.31 \pm 96.84 \mathrm{~min} . / 336.50 \pm 68.41 \mathrm{~min}$. Los datos se presentan en el orden: Línea base | Final | Recuperación. Pulso (G1/ G2): $70.44 \pm 11.86 / 68.06 \pm 10.37 \mid 80.00 \pm$ $17.25 / 72.06 \pm 11.62 \mid 72.56 \pm 10.88 / 68.39 \pm$ 11.21. PAS (G1/G2): $143.38 \pm 33.58 / 144.78$ $\pm 22.14|144 \pm 33.44 / 144.78 \pm 28.72|$ $136.31 \pm 28.14 / 142.35 \pm 26.06$. PAD (G1/ G2): $75.94 \pm 15.27 / 78.61 \pm 12.03 \mid 76.50 \pm$ $12.37 / 78.61 \pm 11.90 \mid 75.06 \pm 13.27 / 77.41$ \pm 11.46. FR (G1/G2): $17.94 \pm 3.99 / 17.00$ $\pm 2.93|21.00 \pm 3.67 / 17.72 \pm 3.02 *| 18.25$ $\pm 3.37 / 16.33 \pm 2.87 *$ Conclusión: Los resultados muestran que los CPI presentan un desempeño y una respuesta físiológica similar a la de sus pacientes. Destacando que los valores de PAS son hipertensivos y factor de riesgo para el desarrollo de enfermedades cardiovasculares, aunado a los factores que comparten como los estilos de vida. Lo anterior hace evidente la necesidad de cuidar a los CPI. Aporte a la práctica clínica diaria: Realizar un abordaje preventivo.

\section{Valores de referencia de presiones máximas inspiratorias y espiratorias en población mexicana}

\section{Cid JS, Leal AT, Gochicoa RLG, Torre-Bouscoulet $L$}

INER Ismael Cosío Villegas

Introducción: Las presiones máximas inspiratorias y espiratorias contribuyen a evaluar la fuerza de los músculos respiratorios, proporcionando una herramienta útil en el diagnóstico y manejo de pacientes con enfermedades neuromusculares $\mathrm{u}$ obstructivas crónicas. Objetivos: Conocer los valores de referencia en la población mexicana para las presiones máximas inspiratorias y espiratorias. Comparar los valores obtenidos en nuestro estudio con los valores estimados mediante fórmulas estandarizadas. Establecer las ecuaciones de predicción para PIM/PEM en la población mexicana. Material y métodos: Se realizó un estudio descriptivo, observacional, prospectivo en sujetos sanos de entre 18 y 80 años mexicanos durante el período comprendido de mayo a noviembre del 2016 en el Departamento de Fisiología Respiratoria del INER. Resultados: Se reclutaron 123 sujetos, de éstos se excluyó el 20\% (24 sujetos) por no cumplir criterios de inclusión. En total se estudiaron 99 sujetos sanos respiratorios, residentes de la Ciudad de México y sin obesidad (IMC $25.0 \pm 3.1 \mathrm{~kg} / \mathrm{m}^{2}$ ) de los cuales el $61.6 \%$ de la población $(n=61)$ eran mujeres, la edad promedio de la población fue de 39.8 años (min-máx: 18-77 años). Los valores de las presiones máximas fueron significativamente mayores en hombres (Pimax $104.7 \pm 28.3 \mathrm{cmH}_{2} \mathrm{O}$ y Pemax $133.2 \pm 34.9$ $\mathrm{cmH}_{2} \mathrm{O}$ ), respecto a las mujeres (Pimax $79.6 \pm 23.5 \mathrm{cmH}_{2} \mathrm{O}$ y Pemax $101.0 \pm 24.5$ $\mathrm{cmH}_{2} \mathrm{O}$ ), con un coeficiente de variación entre las maniobras realizadas de 0.04 en
Pimax y 0.05 en Pemax, respectivamente. En el análisis univariado, las variables que más se asociaron a Pimax fueron talla, peso e IMC, pero cuando se analizaron estas variables por género, las únicas variables que se asociaron significativamente fueron peso e IMC, también se valoraron transformaciones al cuadrado, al cubo, logarítmica y raíz cuadrada, siendo significativa la edad en mujeres, la talla y el peso en hombres. Las ecuaciones propuestas en nuestro estudio para Pimax tienen un coeficiente de determinación del 30-38\%. En el análisis univariado, las variables que más se asociaron a Pemax en la población fueron talla y peso; sin embargo, cuando se analizaron estas variables por género, ninguna de las variables antropométricas se asoció de manera significativa a Pemax, por lo que se analizó la variable Pimax y se encontró una asociación significativa (Rs $>0.3$ en hombres y $>0.5$ en mujeres), por lo que la ecuación de predicción que proponemos se basa en esta variable, con un coeficiente de determinación del $41 \%$ en mujeres y apenas del $14 \%$ en hombres. Conclusión: Las ecuaciones internacionalmente recomendadas (Black y Haytt) sobreestiman los valores esperados en nuestra población mexicana que radica a una altitud de $2,240 \mathrm{~m}$, por lo que se recomienda utilizar valores locales para la medición de las presiones inspiratoria y espiratoria máximas. Aporte a la práctica clínica diaria: Se propone utilizar los valores de referencia obtenidos para la población mexicana con mayor predicción que el resto de ecuaciones previamente utilizadas.

\section{Factores de riesgo para asma casi fatal en un servicio de urgencias}

\section{Juárez LJE, González ID, Orea TA, Sandoval GJL, Miguel RJL}

INER Ismael Cosío Villegas

Introducción: El asma es una de las enfermedades respiratorias más prevalentes del mundo. Muchos individuos con asma leve-moderada tienen características de una enfermedad más grave. Objetivos: 
Determinar la prevalencia de factores de riesgo para asma casi fatal (ACF) en un servicio de urgencias. Material y métodos: Realizamos un estudio transversal a pacientes con diagnóstico de asma que visitaron el Servicio de Urgencias del INER por crisis asmática durante enero 2017. Utilizamos la definición sintomática de GINA para identificar casos de asma. Resultados: Un total de 150 pacientes con asma completaron la encuesta, 100 (66\%) pacientes fueron mujeres. La media de edad fue $42 \pm 15$. El $26 \%$ recibió vacuna contra influenza. Hasta un $31.5 \%$ eran exfumadores, y un $4.7 \%$ fumadores activos. El 20\% de pacientes tuvo exposición a biomasa. El $78 \%$ de pacientes visitaron un servicio de urgencias en el año previo. La prevalencia de un diagnóstico previo de ACF fue del $4 \%$ y hasta un $8.6 \%$ de los pacientes recibió intubación orotraqueal por crisis asmática. Para controlar el asma durante el último año, un tercio (34\%) de los pacientes consumió esteroides sistémicos y el $28 \%$ reportó el consumo de $>12$ viales de salbutamol. El $94.6 \%$ de pacientes catalogó al invierno como la peor temporada para el control de su enfermedad. Las comorbilidades reportadas: rinitis alérgica (56.6\%), ERGE (46\%), obesidad (25.3\%), ansiedad-depresión (10\%), VIH (1.3\%). Más de la mitad (63\%) de los pacientes reportó mal apego al tratamiento médico. Sólo un $9.3 \%$ contaba con un plan de acción y el 3.3\% conocía la terapia SMART. Ningún paciente reportó antecedente de insuficiencia cardíaca derecha. Conclusión: Los factores de riesgo para ACF deben ser considerados como factores prevenibles ante las muertes por asma. La educación del paciente para ajustar su tratamiento, prevenir exacerbaciones, cómo reconocer una exacerbación, cómo y cuándo iniciar el tratamiento ha demostrado mejorar sus desenlaces. Aporte a la práctica clínica diaria: Las visitas a urgencias de pacientes con factores de riesgo para $\mathrm{ACF}$ es prevalente. El seguimiento en clínicas especializadas es deseable.

\section{Resección de tumor} germinal extragonadal en mediastino. Reporte de un caso
Hernández-Arenas LÁ, Farah OSI, Escobedo SE, Menjivar ROM, Díaz MJL, Moreno TJA, Loyola GU, Téllez $B J L$

\section{Centro Médico ISSEMYM Toluca}

Descripción: Reportamos el caso de un hombre de 37 años con una historia de 2 años de evolución con disnea de medianos esfuerzos y se le detecta un tumor mediastinal, el cual es resecado de manera quirúrgica. Introducción: Los tumores germinales son una entidad rara, la cual se manifiesta en forma extragonadal en el 5-7\% de los casos, el mediastino es el sitio de presentación que predomina, $10 \%$ de estos tumores son malignos y más de un tercio son seminomas puros, afectando exclusivamente a hombres de entre 30 y 35 años. Objetivos: Presentar un cartel donde se demuestren los aspectos clínicos, radiológicos, histopatológicos y terapéuticos de un seminoma de localización mediastínica. Presentación del caso: Reporte de un caso con metodología descriptiva. Masculino de 37 años de edad, sin antecedentes crónico-degenerativos. Antecedentes quirúrgicos negados. Con historia de 2 años de evolución con disnea de medianos esfuerzos, dolor retroesternal, de predominio en hemitórax derecho, con tomografía de tórax contrastada en la cual se observa tumor en mediastino de aproximadamente 20 x 15 cm de bordes irregulares. Resultados: Con protocolo preoperatorio, se realiza esternotomía media, identificando la tumoración mediastinal de aproximadamente 20 x $15 \mathrm{~cm}$ encapsulada, bordes irregulares, con invasión de nervio frénico derecho, ambas pleuras parietales, lóbulo superior derecho y vena cava superior. Se realiza disección de tumoración en bloque, preservando el nervio frénico derecho, lobectomía atípica del lóbulo superior derecho, requiriendo plastía de vena cava superior con extirpación completa de masa mediastínica capsulada en bloque. Conclusión: El diagnóstico temprano y el tratamiento oportuno son la clave para el manejo de tumores mediastinales; el seminoma confiere un mejor pronóstico combinando la terapia quirúrgica con la quimiorradioterapia. Aporte a la práctica clínica diaria: La descripción de este caso clínico es de importancia para el abordaje y decisión terapéutica en el grupo de pacientes que presentan este tipo de tumores.

\section{Factores de riesgo que contribuyen a la hipertensión arterial pulmonar en el síndrome Down y su intervención en el manejo médico}

\section{Jamaica BL \\ Hospital Infantil de México «Federico Gómez»}

Introducción: El síndrome de Down (SD) tiene riesgo de presentar hipertensión arterial pulmonar (HAP). Por problemas cardiopulmonares múltiples a obstrucción de las vías respiratorias superiores e inferiores, reflujo gastroesofágico, cardiopatía congénita, entre otras. Objetivos: Evaluar factores de riesgo que contribuyen a la HAP y su intervención en el manejo médico de los pacientes con SD referidos al Servicio de Neumología, Hospital Infantil de México «Federico Gómez» (HIMFG) en el período comprendido de enero 2011 a abril 2016. Material y métodos: Estudio cohorte, longitudinal, observacional, retrospectivo. 54/369 expedientes cumplieron criterios de inclusión. Tamaño de muestra se calculó de acuerdo en el estudio de Banjar (75\% de los SD con HAP). La información se analizó en el software, estadístico SPSS para Windows versión 19.0. Resultados: HAP se diagnosticó con una media de 49.3 meses, a través del ecocardiograma, reportándose con mayor frecuencia HAP moderada y severa. Las comorbilidades más frecuentes asociadas fueron cardiopatía congénita, hipotiroidismo, infecciones de vías respiratorias recurrentes, prematurez, reflujo gastroesofágico. El PCA (17/54), la reparación del defecto cardíaco (15/49 pacientes) con una media de edad (25) meses. El esquema de tratamiento más utilizado la combinación de furosemida, espironolactona y captopril, al persistir con HAP se le añadió sildenafil y bosentan. Oxígeno domiciliar 21/54 pacientes. Los pacientes con HAP leve y moderada obtuvieron mejoría en el $85 \%$, 
a los 12 meses de iniciado el tratamiento, HAP severa y suprasistémica mejoría en el $45 \%$. Sin mejoría (9/54) tenían defecto cardíaco (8/9) y sin reparación del mismo. Conclusión: Pacientes con SD tienen asociaciones con otras comorbilidades que incrementan la HAP y que el defecto cardíaco sin reparación quirúrgica es causante de la persistencia de la misma. Aporte a la práctica clínica diaria: Crear conciencia sobre los factores de riesgo que incrementan la HAP para su manejo integral y así mejorar la calidad de vida de los pacientes.

\section{Utilidad de las criobiopsias endobronquiales y pulmonares en enfermedades no intersticiales}

Sánchez CO, Perea TPC, LópezGonzález B, Martínez MD

INER Ismael Cosío Villegas

Antecedentes: Las criobiopsias pulmonares (crio-BTB) se desarrollaron en un inicio para el abordaje diagnóstico de enfermedades pulmonares intersticiales (EPI) pero existe poca información sobre su utilidad en otros padecimientos pulmonares. Objetivos: Evaluar la utilidad de las criobiopsias en enfermedades pulmonares benignas y malignas. Material y métodos: Estudio de investigación clínica, observacional, transversal, retrospectivo y descriptivo. Población: Pacientes mayores de 18 años en quienes se realizó broncoscopia diagnóstica con toma de crio-BTB y lavados bronquioloalveolares (LBA). Se aplicó estadística descriptiva, se comparó el rendimiento diagnóstico según el tipo de muestra y grupos diagnósticos, utilizando ?2 y valores de $\mathrm{p}$ (considerados estadísticamente significativos $<0.05$ ).

Resultados: Se realizaron criobiopsias a 120 pacientes sin evidencia de enfermedad intersticial pulmonar. El 62.5\% (75/120) correspondieron al sexo masculino, la media de edad fue de $51.9(\mathrm{DE} \pm 18.3)$ años. El rendimiento diagnóstico global en la población de estudio fue de $91.7 \%$ (110/120), independientemente del tipo de muestra. El rendimiento en las criobiopsias fue de $75.0 \%(90 / 120)$ y en LBA de $37.7 \%$ (43/114) $(\mathrm{p}=0.001)$. De acuerdo con los grupos diagnósticos, el 39.2\% (47/120) correspondió a neoplasia, el 32.5\% (39/120) tuvo un diagnóstico infeccioso, el $2.5 \%$ (3/120) tuvo un diagnóstico mixto. El rendimiento diagnóstico de las criobiopsias fue superior en diagnósticos malignos (95.7\% vs. $19.5 \%, \mathrm{p}<0.001$ ) mientras que LBA fue superior en infecciosos $(84.6 \%$ vs. $56.4 \%, \mathrm{p}<0.001)$. Respecto a la relación con los patrones tomográficos no hubo diferencia estadísticamente significativa entre el rendimiento diagnóstico de LBA y crio-BTB; sin embargo, se observa mayor rendimiento en el diagnóstico de lesiones localizadas por criobiopsias que por LBA. Conclusión: Las criobiopsias demostraron su utilidad en patología pulmonar no intersticial, logrando la identificación de agentes etiológicos, con una tasa baja de complicaciones.

\section{Polimorfismos en} TNF se asocian con susceptibilidad a enfermedad respiratoria exacerbada por aspirina pero son independientes de los niveles de la citosina

Falfán VR, Pavón-Romero GF, Reséndiz-Hernández JM, RamírezJiménez F, Terán LM

INER Ismael Cosío Villegas

Introducción: La enfermedad respiratoria exacerbada por aspirina (EREA), es una entidad caracterizada por asma, sinusitis eosinofílica hiperplásica, pólipos nasales e intolerancia a la aspirina, se presenta quimiotaxis de células inflamatorias y liberación de citocinas proinflamatorias como el factor de necrosis tumoral alfa (TNF- $\alpha$ ) y la linfotoxina alfa (LT- $\alpha$ ); estudios previos indican la participación de factores genéticos involucrados en la susceptibilidad a la EREA. Objetivos:
Evaluar la asociación de tres SNP en TNF (rs361525, rs1800629 y rs1800750) y uno en LTA (rs909253) en pacientes con EREA y su correlación con los niveles séricos de TNF- $\alpha$. Material y métodos: Se realizó un estudio de casos controles, con 133 pacientes con EREA, 135 pacientes con asma (ATA) y 182 sujetos sanos (HC), la caracterización de genotipos fue realizada por discriminación alélica y la cuantificación proteica por ELISA. Resultados: El genotipo GA del rs1800629 se encuentra asociado a riesgo de desarrollar EREA (EREA vs. GC; $\mathrm{p}<0.05 \mathrm{OR}=2.36 \mathrm{IC} 95 \%$ $=1.04-5.54)$, esta asociación se mantiene al analizar en un modelo recesivo ( $\mathrm{p}<$ 0.05 OR $=2.51$ IC $95 \%=1.11-5.85)$; no se encuentra asociación con el resto de los polimorfismos evaluados. En relación con los niveles séricos, hubo una diferencia estadísticamente entre el grupo de asmáticos en comparación al resto de los grupos. Conclusión: El genotipo GA del rs1800629 se encuentra asociado con la susceptibilidad genética de EREA, pero no correlaciona con los niveles séricos de la proteína. Los niveles séricos de TNF- $\alpha$ se encuentran incrementados en los grupos de EREA y asma en relación al grupo control. Aporte a la práctica clínica diaria: Caracterización de fenotipos de riesgo en base a características genéticas.

\section{Hábitos de autocuidado de la salud de cuidadores primarios informales de pacientes con insuficiencia cardiorrespiratoria}

Robles UB Orea TA Peláez HV Torres MS, Figueroa HA, Pérez CE, González ID, Verdeja VL, Navarrete $P A$, Jiménez CA, Pérez CGK, Sánchez SR

INER Ismael Cosío Villegas

Introducción: La vulnerabilidad de los cuidadores primarios informales (CPI) está relacionada con el proceso de la enfermedad de sus pacientes. Las desventajas del CPI incluyen falta de apoyo, tiempo invertido y esfuerzo físico, repercutiendo en su salud física y mental. Objetivos: 
Describir los hábitos de autocuidado de la salud de los CPI de pacientes con insuficiencia cardiorrespiratoria (ICR). Material y métodos: Participaron 19 CPI de pacientes ICR (edad media 56.79 $\pm 2.89,78.9 \%$ mujeres). Se utilizó la encuesta de salud del CPI que identifica las características psicosociales del cuidador. Se seleccionaron los reactivos relacionados con las conductas de cuidado de la salud. Los datos se analizaron con SPSS 23. Resultados: Los resultados muestran que $52 \%$ son hijos de los pacientes y $36.6 \%$ cónyuges. El $84.2 \%$ comparten la misma casa y sólo cuidan a una persona. En cuanto a las actividades, cuidar a su paciente $(36.8 \%)$ y realizar labores del hogar $(31.6 \%)$ ocupan la mayor parte de su tiempo. El $73.1 \%$ no asistieron a revisión médica y $84.2 \%$ no acudieron al psicólogo en los últimos 6 meses, $26.3 \%$ acuden al médico al sentirse «muy mal». El $63.2 \%$ realiza alguna actividad física, $94.7 \%$ no fuma, $73.7 \%$ no consume alcohol y $57.9 \%$ no siguen alguna dieta. El 57.9\% de los CPI reportó haber experimentado síntomas de sus pacientes. Falta de tiempo (26.3\%), no tener quien cuide de su paciente $(15.8 \%)$ y falta de dinero (15.8\%) son los motivos que les impiden cuidar su salud. Finalmente, los CPI no recibieron información acerca del cuidado de su paciente $(57.9 \%)$, su papel de cuidador $(78.9 \%)$ o sobre cuidar su propia salud (63.2\%). Conclusión: Los datos revelan desatención tanto propia como del equipo de salud hacia los CPI, quienes empiezan a reportar sintomatología cardiorrespiratoria. Lo cual los puede llevar a deterioro físico y mental. Aporte a la práctica clínica diaria: Previniendo los factores de riesgo de enfermedades cardiorrespiratorias.

\section{Derrame pleural infeccioso una rara presentación de fístula esófago pleural más mega esófago. Reporte de caso}

Castañeda BAM, Machuca VNJ, Arias PMY

INER Ismael Cosío Villegas
Introducción: El derrame pleural infectado por lo regular es una complicación de la neumonía, otras posibles causas poco frecuentes se encuentran las comunicaciones fistulosas esofagopleurales. La vecindad de estos órganos es fundamental para que los procesos esofágicos afecten el mediastino, el espacio pleural, el árbol traqueobronquial o el pulmón de manera individual o asociada. Así, la posibilidad de mediastinitis, empiemas pleurales, neumotórax, fístulas, etc., son condiciones que pueden aparecer con punto de partida en el esófago. Objetivos: Presentar un derrame pleural con cuadro de evolución típico, originado por una fístula esofagopleural secundaria a mega esófago. Presentación del caso: Masculino, de 40 años, del centro del país, soltero, mesero, negó viajes recientes, sin enfermedades crónicas degenerativas conocidas. Se presenta al INER por disnea y dolor torácico tipo pleurítico de 3 semanas de evolución más fiebre en la última semana. Se valora en triage con FC 124 lpm, FR 26 RPM, TA 95/65, TEMP 36.6, SAT $89 \%$ AA, signos pleuropulmonar compatible con derrame pleural corroborado por radiografía de tórax, se ingresa a cama de urgencias para abordaje diagnóstico y tratamiento, se realiza ultrasonido torácico encontrando derrame pleural derecho septado, más heterogeneidad no compatible con pulmón ni derrame pleural en cara posterior ipsilateral, se realiza toracocentesis diagnóstica. Encontrando exudado complicado, tomografía de tórax con esófago dilatado en sus tres porciones, se comunica con cámara gástrica en cavidad torácica. Cultivo de líquido pleural reporta Candida krusei más Lactococcus lactis cremoris. Conclusión: Endoscopia reporta fístula esófago pleural y esófago, es intervenido por cirugía de tórax y se le realiza esofagectomía, esofagostoma, gastrostomía más lavado y decorticación pleural. Aporte a la práctica clínica diaria: Las patologías esofágicas no neoplásicas pueden debutar con cuadro clínicos iniciales en procesos infecciosos pleurales, éstos caracterizados por agentes saprófitos u oportunistas.

Linfocitos Th17 y control de asma en niños mexicanos, resultados preliminares
Moreno CV, Berra RR, Reyes LJ, Flores MLK, Jiménez CV

IMSS/Hospital Puebla; Benemérita Universidad Autónoma de Puebla; Centro de Investigación Biomédica de Oriente, IMSS

Introducción: Tradicionalmente se ha descrito en los niños con asma un desbalance entre la respuesta Th1 y Th2; sin embargo, se ha identificado la participación de la respuesta Th17 en la fisiopatogenia de enfermedades autoinmunes y alérgicas como el asma. Los linfocitos Th17, junto con inflamación de tipo neutrofílica y no así eosinofílica, se presentan en formas mucho más severas de la enfermedad y tienen pobre respuesta a los tratamientos con esteroides inhalados. Existe poca información sobre este tema en la edad pediátrica por lo que resulta interesante esta investigación. Objetivos: Determinar la proporción de linfocitos Th17 de niños con asma y relacionarlo con el control de la enfermedad. Material y métodos: Estudio comparativo, analítico, transversal, prospectivo. Mediante citometría de flujo se determinó la población de linfocitos Th17 (con fenotipo CD3+, CD4+, ROR-+) en niños con diagnóstico de asma del HGR36 IMSS, Puebla, que se dividieron en tres grupos de acuerdo al nivel de control. Se realizó análisis estadístico descriptivo y coeficiente de correlación de Spearman. Resultados: Se incluyeron 35 niños, 26 hombres y 9 mujeres y el promedio de edad fue de 9.09 años $+2.71,77 \%$ presentaron índice predictor de asma positivo y $23 \%$ negativo. El puntaje promedio en Asthma Control Test fue 22, el promedio de linfocitos Th17 fue de $9.65 \%+9.91 \%$, con un rango entre 0 y $36 \%$. La correlación de Spearman fue de-0.002 ( $p=0.89)$. Conclusión: En los niños con asma al igual que en los adultos se encuentran presentes los linfocitos Th17. Se observó que no existe correlación entre su proporción y el nivel de control. Si bien es cierto que existen grandes avances en el tratamiento para el asma, algunos pacientes no logran alcanzar el control. Resulta interesante investigar en los niños algunos aspectos moleculares que contribuyan a nuevos conocimientos de esta enfermedad.

\section{Monitorización del volumen circulante (VC) mediante}


una serie de medias tetrapolares de impedancia bioeléctrica. Ecuaciones de calibración

Balleza OJM, Romero MTJ, Estrella CRA, García PM, Vargas LFM, Huerta FMR, Kashina $S$

Universidad de Guanajuato

Introducción: Actualmente en neumología no existe equipo o técnica que permita monitorizar el volumen circulante (VC) de manera no invasiva y por largos períodos de tiempo. En el presente trabajo se propone el uso la impedancia bioeléctrica (IB) a 4 hilos -una técnica libre de radiaciones y de fácil uso- para monitorizar el VC. Objetivos: El principal objetivo es encontrar la posición óptima de electrodos y factores de calibración para estimar el VC. Material y métodos: Para ello se evaluaron 20 voluntarios sanos (H:13 y M:7), de edad de $22( \pm 5)$ años. A todos ellos se les midieron 29 parámetros antropométricos y se utilizaron dos configuraciones de 4 electrodos (2 de inyección (EI) y 2 de detección (ED)): 1) Los EI fueron colocados en el nivel del sexto espacio intercostal en la línea axilar media y los ED en el segundo espacio intercostal por debajo de la clavícula; 2) Los EI se colocaron a un costado del ángulo inferior de la escápula y los ED a cada costado del ángulo superior de la escápula. Simultáneamente se registraron las variaciones de volumen pulmonar con un neumotacómetro (gold estándar) y los cambios de impedancia con cada configuración de electrodos. Resultados: La correlación obtenida de ambas señales fue superior a 0.9. A cada voluntario se le estimó un coeficiente de calibración definido por el cociente del promedio de las determinaciones de impedancia y de volumen de cada señal. Este coeficiente fue determinado en términos de los parámetros antropométricos mediante un análisis lineal multivariante, obteniendo una ecuación de calibración. Los errores de volumen obtenidos con el equipo de impedancia, usando la configuración 1 y 2, en el grupo de hombres y mujeres fueron del $1.0 \%$ y $4.5 \%$, y $0.36 \%$ y $0.50 \%$, respectivamente. Conclusión: Los resultados sugieren que la mejor configuración de electrodos para estimar VC con IB es 1 . Aporte a la práctica clínica diaria: Tener un dispositivo de bajo coste, libre de radiaciones y fácil uso que permita monitorizar y analizar la señal de volumen pulmonar.

\section{Diferencias en los niveles de presión arterial ante estrés psicológico entre pacientes con enfermedad cardiopulmonar con expresión interna o externa de la IRA}

Figueroa HFA, Pérez CE, Peláez HV, Robles UB, Torres MS, Orea TAE, González ID, Navarrete PAG, Verdeja VL, Jiménez CAG, Pérez CGK, Sánchez RN, Domínguez TB

INER Ismael Cosío Villegas; Universidad Nacional Autónoma de México

Introducción: La ira crónica produce tensión psicológica que impacta al sistema cardiorrespiratorio. Dos formas de manejar la ira son: 1) expresión interna (EII), supresión; y 2) expresión externa (EIE), manifestación hacia personas y objetos. La supresión crónica se asocia con mayor presión arterial, mientras la expresión es positiva para la salud. Pese a esto se desconoce cómo el tipo de manejo de la ira influye en la presión arterial ante estrés psicológico. Objetivos: Comparar la presión arterial sistólica y diastólica ante estrés psicológico entre pacientes con enfermedad cardiopulmonar (EC) con expresión de la ira interna o externa. Material y métodos: Participaron 26 pacientes con EC. Clasificados según el inventario STAXI-2, en dos grupos: 1) EII $(\mathrm{n}=11$, edad media $72.18 \pm 17.14$, $63.63 \%$ mujeres) y 2$)$ EIE $(n=15$, edad media $67.67 \pm 10.17,53.33 \%$ mujeres). Se aplicó un perfil de estrés psicofisiológico de tres fases de 5 min cada una 1) Línea base (LB), 2) Estresor aritmético (EA) y 3) Recuperación (R). Se registraron y promediaron tres mediciones de presión arterial sistólica (PAS) y diastólica (PAD) en cada fase del perfil. Los datos se analizaron con U de Mann-Whitney. Resultados: Los pacientes con EIE presentaron mayor PAS y PAD en todas las fases, comparado con los clasificados en EII. PASLB. EII: $119.51 \pm 19.18$; EIE: $132.31 \pm 24.29(\mathrm{z}=$ -1.532, p > 0.05). PADLB. EII: $67.51 \pm 9.01$; EIE: $78.35 \pm 10.74(\mathrm{z}=-2.336, \mathrm{p}<0.05)$. PASEA. EII: $121.30 \pm 18.19$; EIE: 132.58 $\pm 19.18(\mathrm{z}=-1.636, \mathrm{p}>0.05)$. PADEA. EII: $70.06 \pm 10.71$; EIE: $82.42 \pm 12.10(\mathrm{z}$ $=-2.544, \mathrm{p}<0.05)$. PASR. EII: 118.03 \pm 18.19 ; EIE: $128.26 \pm 22.11(\mathrm{z}=-1.272, \mathrm{p}>$ 0.05). PADR. EII: $66.33 \pm 9.20$; EIE: 77.95 $\pm 9.78(\mathrm{z}=-2.751, \mathrm{p}<0.05)$ Conclusión: Contrario a lo reportado en otras investigaciones, la PAS y la PAD son mayores en pacientes clasificados con EIE. Pero es necesario considerar la intensidad de la expresión de ira en futuras investigaciones. Aporte a la práctica clínica diaria: Un adecuado manejo de la ira del paciente aumenta su pronóstico de salud.

\section{Neumotórax espontáneo resuelto con bullectomía por toracoscopia uniportal con anestesia regional en paciente despierto}

Hernández-Arenas LÁ, Gameros MLA, Menjivar ROM, Díaz MJL, Gallardo GJF, Loyola GU, Téllez BJL

Centro Médico ISSEMYM Toluca

Introducción: Actualmente existen mejoras en cuanto a las nuevas técnicas mínimamente invasivas para procedimientos en cirugía de tórax. Los avances en anestesiología incluyen procedimientos sin intubación y con paciente despierto mediante anestesia regional con la finalidad de disminuir la agresividad de los procedimientos. En este trabajo se presenta un video en el que se realiza resección de bullas enfisematosas por VATS (cirugía torácica videoasistida) mediante esta técnica anestésica obteniendo resultados posoperatorios exitosos, disminuyendo la morbimortalidad en este tipo de procedimientos. Objetivos: Evaluar la viabilidad y seguridad de procedimientos toracoscópicos sin 
intubación endotraqueal. Presentación del caso: El paciente que presentamos es un paciente de 18 años con neumotórax espontáneo, protocolizado con radiografía y tomografía axial computarizada de tórax, con diagnóstico de enfermedad bullosa en hemitórax derecho. Se decide abordaje toracoscópico uniportal para resección de bullas por VATS, usando técnica anestésica epidural y con el paciente no intubado, con bloqueo vagal intratorácico, sedación y apoyo ventilatorio con oxígeno por puntas nasales. Se realiza incisión en sexto espacio intercostal en línea axilar anterior, se diseca por planos hasta ingresar a cavidad torácica. Se realiza toracoscopia exploratoria identificando bullas de 2 x $3 \mathrm{~cm}$ y se realiza segmentectomía apical con endoengrapadora y descartan bullas en otras localizaciones, se realiza pleurodesis mecánica por abrasión. Se coloca sonda endopleural, se afronta tejido celular y piel. El colapso pulmonar transoperatorio fue satisfactorio en el paciente no intubado, con adecuado bloqueo vagal. La evolución fue favorable, con dolor mínimo, y con menor riesgo de comorbilidades asociadas a intubación y anestesia general. Tiempo de estancia hospitalaria 48 horas, buena evolución en posquirúrgico tardío. Conclusión: La resección de bullas por toracoscopia es una técnica factible de realizar mediante cirugía mínimamente invasiva, aunado a una técnica anestésica con bloqueo epidural y sin necesidad de intubación del paciente, demuestran la amplia gama de procedimientos innovadores que existen hoy en día.

\section{Manejo toracoscópico del empiema con abordaje uniportal}

\section{Hernández-Arenas LÁ, Menjivar ROM, Díaz MJL, Gameros MJA, Loyola GU, Téllez BJL}

Centro Médico ISSEMYM Toluca

Introducción: El empiema es una infección pleural que se presenta de manera más común como complicación de neumonía, pero también se puede presentar como complicación de un proceso infeccioso de etiología fúngica o micobacteriana, como complicación de un proceso infeccioso abdominal, secundario a un trauma o evento quirúrgico. Esta entidad sigue tres fases: exudativa, fibrinopurulenta y fibroblástica o de organización. En el tratamiento del empiema es determinante el diagnóstico de la fase de progresión de la enfermedad. Objetivos: Presentar un cartel en el que se muestre la factibilidad del acceso uniportal toracoscópico para el manejo seguro de empiema, así como los resultados obtenidos con esta técnica. Material y métodos: Reporte de tres casos con metodología descriptiva. Se reporta el caso de tres pacientes quienes fueron diagnosticados y tratados de manera quirúrgica por abordaje toracoscópico uniportal debido a empiema. Presentación del caso: Se reporta el caso de tres pacientes quienes fueron diagnosticados y tratados de manera quirúrgica por abordaje toracoscópico uniportal debido a empiema. Resultados: Se realizó toracoscopia con acceso uniportal en tres pacientes que presentaron empiema como complicación de proceso neumónico. Posterior al procedimiento quirúrgico se continúa vigilancia de gasto de sondas endopleurales, control radiológico y continuó manejo antimicrobiano. Disminuyó el dolor posquirúrgico y tiempo de estancia hospitalaria posterior a cirugía (4 días) en comparación a pacientes sometidos a toracotomía (7 días), ningún paciente requirió reintervención. Conclusión: La protocolización adecuada, diagnóstico temprano y abordaje apropiado son la clave para el manejo videoasistido del empiema. Aporte a la práctica clínica diaria: $\mathrm{El}$ tratamiento del empiema por toracoscopia con acceso uniportal es una técnica útil, viable, reproducible, la cual logra reducir considerablemente la estancia hospitalaria así como la disminución de complicaciones posoperatorias y dolor crónico por la baja manipulación de tejidos blandos.

\section{Reparación de hernia diafragmática postraumática crónica derecha con abordaje toracoscópico uniportal y laparoscópico}

Hernández-Arenas LÁ, Menjivar RM, Pérez PY, Escobedo SE, Loyola GU

Centro Médico ISSEMYM Toluca

Introducción: Las hernias diafragmáticas postraumáticas crónicas, secundarias a trauma abdominal cerrado, son poco comunes y aún más raras del hemidiafragma derecho (10\%). Su diagnóstico implica un alto índice de sospecha. El mecanismo fisiopatológico consiste en impacto de alta energía con aceleración y desaceleración que implica un aumento de la presión intraabdominal. La tendencia actual para el manejo de este padecimiento es la reparación por medio de cirugía laparoscópica. Objetivos: Presentar un cartel donde se demuestre la factibilidad del acceso toracoscópico y laparoscópico para la realización de reparación de hernia diafragmática. Presentación del caso: Femenino de 54 años de edad, enfermedad renal crónica de 15 años de evolución sin tratamiento sustitutivo. Antecedentes quirúrgicos instrumentación de columna vertebral secundario a trauma abdominal hace 25 años con secuelas de vejiga neurogénica. Historia hace dos años de disnea, de medianos esfuerzos, a la exploración física con ruidos respiratorios disminuidos en hemitórax derecho. Se solicita radiografía de tórax y TAC simple de tórax y abdomen en el cual se observa presencia de asas intestinales e hígado en hemitórax derecho, por lo que se decide exploración quirúrgica mediante toracoscopia y laparoscopia. Se realizó la reparación de una hernia diafragmática postraumática crónica derecha con reparación del defecto y colocación de malla por laparoscopia asistida por toracoscopia, con los beneficios de la cirugía mínimamente invasiva. El apoyo de la visión toracoscópica permite corroborar ausencia de afección del hiato esofágico, corroborar ausencia de adherencias hepatopulmonares y enteropulmonares, observar comportamiento pulmonar durante su reexpansión y permite mayor seguridad durante la reparación del defecto diafragmático. Conclusión: La protocolización adecuada, diagnóstico temprano y abordaje apropiado son la clave para el manejo videoasistido de la hernia diafragmática. Aprovechando los 
beneficios de cirugía de mínima invasión como menor incidencia de complicación con herida quirúrgica, mejor resultado cosmético, reducción de dolor posoperatorio, movilización y reinserción laboral precoz, mejor respuesta inmunológica a estrés quirúrgico, menor estancia hospitalaria.

\section{Pleurodesis en derrame pleural maligno tratado con sonda endopleural vs. catéter endopleural}

\section{Hernández GD, Gardea de la OEE, Contreras-Rodríguez FJ, Mendoza $T L A$, Guerrero-Rodríguez A, Ballesteros-Pallares R, Fernández- Figueroa NF}

Hospital de Especialidades CMNO; Hospital de Especialidades CMN «La Raza»

Introducción: El derrame pleural maligno (DPM) es una complicación frecuente en cáncer de pulmón y mama, el tratamiento siempre es paliativo, la colocación de sonda endopleural (SEP) más pleurodesis química es el tratamiento de primera elección, una alternativa es el catéter endopleural de pequeño calibre (CEP). Objetivos: El objetivo fue evaluar SEP vs. CEP en DPM, como desenlace principal pleurodesis exitosa, complicaciones y días de estancia hospitalaria (DEH). Material y métodos: Estudio clínico observacional prospectivo en la que se incluyeron pacientes consecutivos, mayores de 18 años, con DPM. Resultados: En 12 meses se incluyeron 39 pacientes con DPM, 24 (61.5\%) fueron mujeres, la media de edad fue de 58 años, la mínima de 23 años y la máxima de 85 años, las neoplasias más frecuentes fueron mama (38\%) y pulmón $(36 \%)$. A $11(28 \%)$ se les colocó SEP y CEP en 28 (72\%). Se realizó pleurodesis con yodo en 28 casos, fue exitosa en 21 (75\%). El éxito de la pleurodesis con yodopovidona a través de la SEP en 7/10 pacientes y con CEP en 14/18 pacientes. En 10 pacientes con CEP no se administró yodopovidona, de estos 5 pacientes (50\%) presentaron pleurodesis espontánea dentro del mes de seguimiento. Los DEH para SEP con media de $14 \pm 6.8$ IQ25-75(8-20) y en CEP 7.21 \pm 6.1 IQ25-75(2-10), con $p=0.004$. La complicación más frecuente en CEP fue la infección en 4/28 casos (14\%). En un caso requirió la colocación de SEP, el resto fue exitosamente tratada con antibiótico vía oral de forma ambulatoria. Conclusión: La pleurodesis con yodopovidona a través del CEP y por SEP fue exitosa en el $75 \%$ de los casos de DPM. No hubo diferencias en cuanto al éxito entre CEP y SEP, complicaciones de la pleurodesis y existe una diferencia significativa en cuanto a los DEH, con menor número de días en los tratados con CEP.

\section{Lobectomía superior derecha videoasistida con abordaje uniportal subxifoideo}

\section{Hernández ALÁ, Menjivar ROM, Loyola GU, Lei J}

Centro Médico ISSEMYM Toluca; Shangai Pulmonary Hospital

Introducción: Las resecciones mayores pulmonares videoasistidas con abordaje subxifoideo uniportal es una nueva técnica, cuya evidencia clínica y seguridad están en controversia aún. La necesidad de reducir el riesgo de daño intercostal asociado con los puertos o la incisión ha llevado a desarrollar la técnica por abordaje subxifoideo, descrita por primera vez en 2014. Objetivos: Presentar un caso donde se demuestre la factibilidad y seguridad de la realización de una lobectomía superior derecha con abordaje uniportal subxifoideo. Material y métodos: Con paciente bajo anestesia general, intubación selectiva. En decúbito lateral derecho con una inclinación de 60$70^{\circ}$. Incisión transversa en línea media de 4 cm por debajo de triángulo esternocostal, el recto abdominal fue dividido, exponiendo proceso subxifoideo y resecando el mismo. Óptica de $10 \mathrm{~mm}$ con $30^{\circ}$; fue introducida y se completó la lobectomía superior derecha haciendo disección con endoengrapadora de arteria, vena y bronquio. Presentación del caso: Se presenta el caso de un masculino de 50 años de edad, sin antecedentes de importancia. Historia de tos recurrente 4 semanas previas. Sin hallazgos patológicos a la exploración física, laboratorios y broncoscopia flexible sin alteraciones. La tomografía de tórax contrastada muestra una lesión en lóbulo superior derecho de $2 \times 1 \mathrm{~cm}$ aproximadamente. Resultados: Tiempo medio de cirugía fue de 120 minutos, el sangrado intraoperatorio de $80 \mathrm{~mL}$ y el drenaje fue retirado al tercer día posquirúrgico y egresado al cuarto. Resultado histopatológico muestra un adenocarcinoma pulmonar estadío T1a N0 M0. Conclusión: El abordaje subxifoideo ha sido utilizado en los últimos 20 años en procedimientos menores tanto torácicos como cardiovasculares. Este tipo de abordaje ha mostrado ser seguro y eficaz en las últimas series de casos publicados. Aporte a la práctica clínica diaria: Algunas de las ventajas de este abordaje es que reduce el riesgo de daño del nervio intercostal o parestesias debido a que la incisión se encuentra inferior al margen costal y disminuye las limitaciones que ocurren cuando hay espacios intercostales reducidos.

\section{Trastornos del sueño detectados en pacientes en unidad de cuidados intensivos}

\section{Hernández GD, Flores-Santiago PJ, Contreras-Rodríguez FJ, Mendoza- Topete LA, Orozco-González BN, Valencia-Fraire MÁ}

Hospital de Especialidades CMNO

Introducción: Los pacientes críticos son susceptibles de múltiples afectaciones no solamente por la enfermedad en estado crítico, sino por complicaciones que se pueden desarrollar durante su estancia en la UCI incluyendo trastornos del sueño, que en múltiples ocasiones estos trastornos pasan desapercibidos. Estos trastornos tienen afectación con desregulación simpática y parasimpática, alteraciones cortisol, inmunitarias, alteración del catabolismo. Las principales alteraciones descritas son sueño fragmentado y distribución anormal de la arquitectura del sueño con mayor sueño N1 y N2. Objetivos: Describir los 
trastornos del dormir en pacientes de UCI. Material y métodos: Estudio transversal descriptivo, donde se realizó estudio de sueño mediante dispositivo ALICE PDx $\left(\mathrm{C} 4, \mathrm{O}_{2}\right)$ a pacientes en terapia intensiva y evaluar la existencia de trastornos del sueño. Resultados: Se incluyeron diez pacientes, nueve hombres $(90 \%)$, con IMC $28 \pm 3.6$, mediana de edad (IQ2575) 59.5(53/65) años, SACS promedio fue 44.8 puntos, $8(80 \%)$ con somnolencia excesiva, definida por Epworth 10 puntos, presentaban múltiples microdespertares con promedio de $26.7 /$ hora, la saturación promedio fue $84 \% \pm 29 \%$, el T90 $8.7 \pm$ $15.6 \%$ se documentó la presencia de apnea obstructiva durante el dormir (SAOS) en el $50 \%(\mathrm{n}=5)$. Cuatro pacientes con SAOS tenían bruprenorfina y uno dexmedetomidina. El T90 en pacientes sin SAOS promedio $17 \pm 19 \%$. Conclusión: Los pacientes en área crítica en su totalidad presentan algún trastorno del dormir, sueño fraccionado en su totalidad, y aunque se monitoriza la saturación la hipoxemia intermitente genera T90 mayores a 15\% en el grupo de pacientes sin SAOS. Además, el riesgo es alto previo a su ingreso y la frecuencia de SAOS fue de $50 \%$ por lo que el sueño y el SAOS debe considerarse en el manejo de cuidados intensivos. Finalmente, la UCI no es un área adecuada para la realización de estudios del sueño, se perdieron el $30 \%$ de los estudios por grabación incompleta y $10 \%$ de las señales.

\section{Utilidad clínica de los índices pronósticos multidimensionales en una cohorte internacional de pacientes con enfermedad pulmonar obstructiva crónica en atención primaria}

Gonzálvez RJ, Anta AB, Pere TM, Espantoso RM, Gerasimovska KB, Lingner $H$

\footnotetext{
Centro de Salud de Matamá-Eoxi VigoSergas; C.S. Barrio La Salud-Santa Cruz de Tenerife-España; Instituto para la Investigación en Atención Primaria Jordi Gol-Barcelona-España; Atención Primaria-
}

Eoxi Vigo-Sergas-España; Department of Family Medicine, University of Sts. Cyril and Methodius, Skopje, Macedonia; Hannover Medical School, Centre for Public Health And Healthcare, Hannover, Germany

Introducción: Los índices pronóstico ADO, BODEx y DOSE podrían facilitar la estratificación del riesgo de EPOC y la toma de decisiones clínicas. Para realizar un análisis comparativo entre ellos, en los mismos pacientes y con criterios comunes de reclutamiento, se inició una cohorte europea en atención primaria (estudio PROEPOC/COPD) con un seguimiento previsto de cinco años. Objetivos: Comparar los fenotipos de EPOC con los datos basales de la cohorte. Material y métodos: Diseño: Validación externa de escalas, estudio de cohorte abierto y prospectivo en atención primaria. Ámbito: 36 centros de salud en 6 países europeos de alta, mediana y baja renta. Sujetos: Los resultados se refieren a los primeros 250 pacientes del estudio PROEPOC/COPD, registrados en la visita clínica por su médico de familia/enfermera. Se espera la inclusión de 477 pacientes al final del reclutamiento. Variables: Historial clínico del paciente, exacerbaciones, pruebas de función pulmonar, cuestionarios basales, escalas multidimensionales. Análisis: Análisis bivariante, cualitativo (prueba de Fisher) y cuantitativo (correlación y regresión lineal). Multivariante con modelo lineal generalizado con fenotipo como variable de resultado, seleccionando el modelo paso a paso, siguiendo el criterio de menor BIC (Criterio Bayesiano de Información). Se usa boostrap para calcular el intervalo de confianza al $95 \%$ mediante el paquete estadístico R. Resultados: En el análisis multivariante, solamente el índice ADO tiene un efecto independiente significativo en el fenotipo. El RRR (IC95\%) en el fenotipo agudizador con enfisema es 3.02 (1.69-5.38) respecto al no agudizador, y 1.84 (1.32-2.56) en el fenotipo agudizador con bronquitis. Conclusión: La relación del índice ADO con el fenotipo sugiere su superior utilidad para la toma de decisiones, a diferencia de la propuesta actual basada en el BODEx. Deberá confirmarse con el análisis de supervivencia en fases posteriores de este estudio. Aporte a la práctica clínica diaria: Utilidad de los índices pronósticos multidimensionales en pacientes EPOC en atención primaria.

\section{Apego a las recomendaciones para la prevención de neumonía asociada a ventilador}

\section{Hernández GD, Álvarez-Pinto J, Esparza-Quezada AL, Kastrinakis- Sarabia KA, López-González JA, Contreras-Rodríguez FJ}

Hospital de Especialidades CMNO

Introducción: La ventilación mecánica, aunque es un procedimiento ampliamente utilizado y existen recomendaciones para la prevención de neumonía asociada a ventilación, desconocemos el apego fuera de terapia intensiva. Objetivos: Evaluar recomendaciones básicas para la prevención de neumonía asociada a ventilación en un hospital de tercer nivel. Material y métodos: Estudio trasversal. Derechohabientes del IMSS, bajo algún modo de ventilación mecánica fuera de terapia intensiva y se evaluaron los parámetros de protección pulmonar y aquéllos que disminuyen el riesgo de neumonía asociada a ventilación. Resultados: Se revisaron 100 pacientes bajo ventilación mecánica fuera de la terapia intensiva en un hospital de 456 camas durante un período de dos meses, de los cuales se encontraban: o presión plateau < $30 \mathrm{cmH}_{2} \mathrm{O}(100 \%)$ o presión media del globo de cánula orotraqueal $28 \pm 10.3 \mathrm{mmHg}$ : presión óptima $69.44 \%$, sobreinflados $25 \%$, desinflados $5.5 \%$ o prueba espontánea diaria $(61 \%)$ o Rass entre $2-3(61 \%)$ o cabecera a 30 o $(50 \%)$ o ventilación mecánica $>6$ días (39\%) y de éstos sólo 38.5\% con traqueostomía o higiene de manos $(25 \%)$ o humidificador $(20 \%)$ o circuito sucio $(15 \%)$ o aspiración cerrada (10.77\%). Conclusión: De las diez recomendaciones evaluadas, se cumplen en más del $70 \%$ las que están en relación a la programación del ventilador, cuidados de cánula orotraqueal y sedación, mientras que acciones sencillas como la posición semirrecumbente, higiene de manos y cuidado del circuito se cumplen en menos del 30\% de los casos. 


\section{Metastasectomía pulmonar, experiencia de 8 años en el Instituto Nacional de Ciencias Médicas y Nutrición Salvador Zubirán}

Herrera ZJJ, Bolaños MFV, Argote GLM, Domínguez OD, Santillán DPJ

\section{INCMNSZ}

Introducción: El pulmón es uno de los órganos más afectado por metástasis, aproximadamente $30 \%$ de los pacientes con cáncer van a desarrollar metástasis pulmonares. Objetivos: Describir el tratamiento quirúrgico, evolución, resultados y seguimiento a largo plazo de una serie de pacientes con metástasis a pulmón. Material y métodos: Estudio retrospectivo, descriptivo, observacional de 8 años (enero 2007-diciembre 2014) cuya población fueron 50 pacientes con enfermedad metastásica a pulmón. Se evaluaron las variables: sexo, edad, histología del primario, tratamiento, abordaje, recidiva pulmonar y sobrevida a 5 años. Resultados: Seguimiento a 50 pacientes sometidos a metastasectomías pulmonar en un período de 8 años, $56 \%$ de ellos hombres $(n=28)$ y $44 \%$ mujeres $(n=22)$ con edad promedio de $49.9 \pm 17$ años. La histología del tumor primario fue $68 \%(\mathrm{n}=34)$ epitelial, $18 \%(\mathrm{n}=9)$ células germinales y $14 \%(n=7)$ sarcoma. De los tumores epiteliales, el $26.4 \%$ fue carcinoma de células claras de riñón $(\mathrm{n}=$ 9), seguidas de adenocarcinoma de colon moderadamente diferenciado $23.5 \%(\mathrm{n}=$ 8) y otros. El manejo del tumor primario fue cirugía $46 \%(n=23)$, cirugía + quimioterapia $32 \%(n=16)$, cirugía + radioterapia $12 \%(n=6)$, quimioterapia $6 \%(n=3) y$ cirugía + quimioterapia + radioterapia $4 \%$ $(n=2)$. El período libre de enfermedad promedio fue de 6.6 años. La metástasis apareció en el lado derecho en el 54\% (n $=27)$, izquierdo $42 \%(\mathrm{n}=21)$ y bilateral $4 \%(\mathrm{n}=2)$. El abordaje fue toracoscópico en todos los casos, requiriendo hacer una mini toracotomía en el $20 \%$ de ellos. Se resecó metástasis única en el 60\% $(\mathrm{n}=30)$, dos lesiones $26 \%(\mathrm{n}=13)$, tres lesiones
$10 \%(\mathrm{n}=5)$ y cuatro lesiones $4 \%(\mathrm{n}=2)$. La recidiva pulmonar $18 \%$ y la sobrevida a 5 años fue del $55.5 \%$. Conclusión: La toracoscopia es un abordaje seguro para el manejo de metástasis pulmonares en pacientes con condiciones de tolerar la resección pulmonar. Aporte a la práctica clínica diaria: Mejorar el manejo oncológico de metástasis pulmonares.

\section{Tratamiento multidisciplinario en fracturas costales múltiples}

\section{Díaz HR, Ramírez D, Ortega A, Esparza E}

IMSS Centro Médico Nacional de Occidente; Islas

Introducción: Las fracturas costales múltiples representan un desafío médicoquirúrgico, teniendo evoluciones tórpidas ya sea con manejo conservado o con cirugía, requiriendo ventilación mecánica y estancias intrahospitalarias prolongadas. Objetivos: Obtener la mejor y más rápida evolución en los pacientes con fracturas costales múltiples. Material y métodos: Paciente con múltiples fracturas en el que se decide manejo multidisciplinario para su tratamiento. Presentación del caso: Masculino de 79 años con fracturas múltiples desde C5-C10 por caída desde escaleras. Antecedentes: Cardiopatía isquémica en tratamiento con ASA y clopidogrel y colocación de un stent año previo. Procedimiento quirúrgico: Bajo anestesia endovenosa total (TIVA), bloqueo paravertebral derecho en T4-T8 con ropivacaina $7.5 \%$ con $60 \mathrm{mg}$ de metilprednisolona, Dynastat y buprenorfina. Se realiza toracotomía posterolateral derecha. Se localiza lesión pulmonar en lóbulo inferior derecho, se realiza reparación y lavado de cavidad torácica. Se fijan las fracturas antes mencionadas con placas-tornillos de titanio y con grapas STRACOS, según la posición de la fractura. Tratamiento analgésico posquirúrgico: tratamiento con parches de buprenorfina, pregabalina, celecoxib y paracetamol. Resultados: Paciente sale extubado de quirófano, requiriendo menos de 48 horas de terapia intensiva. Logrando movilización fuera de cama en las pri- meras 24 horas. Se continúa tratamiento con analgesia a base de buprenorfina en parche subdérmico, pregabalina, celecoxib y paracetamol dándose de alta al quinto día de EIH. Conclusión: El tratamiento multidisciplinario es la mejor opción para el paciente con múltiples fracturas costales. La literatura en general recomienda el tratamiento quirúrgico sobre el tratamiento conservador ya que disminuye la estancia en terapia intensiva y la necesidad de ventilación mecánica. Nosotros agregamos que para una recuperación, aún más rápida, además de la fijación de las fracturas se debe incluir un tratamiento analgésico especializado mejorando así la mecánica respiratoria y la rápida movilización de los pacientes fuera de cama. Se requieren más estudios para confirmar nuestra teoría. Aporte a la práctica clínica diaria: Un tratamiento multidisciplinario en todos estos casos representaría un avance al tratamiento para disminuir estancias en terapia intensiva y estancias intrahospitalarias.

\section{Fístula biliopleural como complicación de síndrome de Mirizzi}

Herrera ZJJ, Rivera LDA, Bolaños MFV, Domínguez OD, Santillán DPJ

INCMN «Salvador Zubirán»

Introducción: El síndrome de Mirizzi (SM) es una complicación que ocurre en aproximadamente $1 \%$ de los pacientes con colelitiasis caracterizado por ictericia obstructiva debido a impactación de litos en el infundíbulo de la vesícula o conducto cístico, comprimiendo el conducto hepático común y pudiendo originar una fístula colecisto-coledociana. El biliotórax es una complicación rara secundaria en la mayoría de los casos a fístula biliopleural de origen traumático. El diagnóstico presuntivo rápido seguido de una reparación quirúrgica precoz es esencial para un manejo exitoso. Objetivos: Dar a conocer un caso clínico raro. Presentación del caso: Femenino de 71 años de edad con dolor repentino en hipocondrio derecho, irradiando a epigastrio, asociado con anorexia, ictericia y acolia. Laboratorios 
con un patrón colestásico y la ecografía hepática con colección perivesicular, se pautó tratamiento conservador y CPRE. La CPRE reporta vía biliar común dilatada indicativa de SM. Tres días después la paciente presenta cefalea, fiebre, náuseas y dolor pleurítico derecho. RX torácica compatible con derrame pleural derecho, se realiza toracocentesis con biliotórax (BT: 4,9, DHL: 974, proteína: 3,21, pH: 7,44 , glucosa: 100 y albúmina $<3$ ). Al día siguiente se presenta acidosis respiratoria (pH: 7.29, $\mathrm{CO}_{2}$ : 78) deterioro clínico y se somete a intubación endotraqueal. Se realizó una TC de tórax que muestra recidiva de derrame, se realiza VATS con decorticación, adherenciolisis y reparación de defectos diafragmáticos que; sin embargo, no puede realizarse de forma completa por dificultad quirúrgica y se deja tubo torácico posteriormente removido. Alta hospitalaria sin complicaciones. Conclusión: A pesar de los avances en cirugía, no existe un consenso sobre la estrategia óptima para tratamiento de las fístulas biliopleurales, aunque un abordaje quirúrgico transtorácico parece reducir la morbimortalidad de esta entidad poco frecuente ante el fracaso con manejo conservador (tasa de fracaso 38\%). Aporte a la práctica clínica diaria: Dar a conocer un caso con buen manejo de una fístula biliopleural.

\section{Tumor fibroso solitario de pleura: Reporte de caso}

\section{Herrera ZJJ, Boyer DE, Bourlon de los RMT, Bolaños MFV, Catrip TJM, Santillán DPJ}

INCMN «Salvador Zubirán»; Hospital Ángeles Pedregal; INC «Ignacio CháveZ»

Introducción: Los tumores fibrosos solitarios representan el $4 \%$ de todas las neoplasias pleurales, $80 \%$ son benignos, principalmente ocurren en la sexta década de la vida, no tienen predominio por un género. Usualmente son de pleura visceral, la mayoría cursan asintomáticos y se diagnostican de forma incidental. Objetivos: Presentar un caso de un tumor poco común. Presentación del caso: Femenino de 41 años, sin antecedentes de importancia que inicia 6 meses previos a su ingreso con disnea de grandes esfuerzos que incrementa hasta volverse de pequeños esfuerzos, acompañada de tos productiva con expectoración hialina, diaforesis nocturna y pérdida de peso de $5 \mathrm{~kg}$. A la exploración física campos pulmonares tórax izquierdo silencio respiratorio generalizado, sin transmisión de la voz, con matidez a la percusión, derecho con rudeza respiratoria generalizada. Se realiza TAC de tórax donde se evidencia masa pulmonar izquierda de características heterogéneas, derrame pleural y desplazamiento de mediastino a la derecha. Durante la estancia hospitalaria presentó hipoglucemia («síndrome Doege Potter»). Se realizó biopsia por Tru-Cut donde se reporta tumor fibroso solitario por lo que se programa para cirugía. Se realizó toracotomía, esternotomía, resección de tumor fibroso de pleura de 3,274 g, lingulectomía. Se egresa 22 días posteriores a cirugía, sin complicaciones, sin dificultad respiratoria. Conclusión: Los tumores fibrosos solitarios son tumores pleurales muy raros que requieren alta sospecha para el diagnóstico, el tratamiento es quirúrgico. No tienen buen resultado a radioterapia o quimioterapia. Deben tener seguimiento al menos por 20 años porque se han reportado recurrencias. Aporte a la práctica clínica diaria: Manejo de tumores de pleura.

\section{Neumonía eosinofílica crónica}

\section{Martínez OVA, Sánchez SSS}

Hospital Universitario UANL

Introducción: Las eosinofilias pulmonares son un grupo heterogéneo de enfermedades que tienen en común la presencia de infiltrados radiológicos y eosinófilos aumentados en sangre periférica y/o parénquima pulmonar. Son enfermedades poco frecuentes y de diagnóstico complejo, por lo que generalmente es el neumólogo quien realiza el diagnóstico y tratamiento. En algunas de ellas hay aumento de eosinófilos en sangre periférica pero no en tejido pulmonar, en otras palabras, puede haber eosinofilia importante en tejido pulmonar sin haberla en sangre periférica
Objetivos: Identificar el cuadro clínico, saber relacionar la eosinofilia sérica y conocer el abordaje adecuado de los distintos tipos de neumonía eosinofílica. Material y métodos: Se presentará el caso de un paciente femenino con eosinofilia sérica marcada, disnea y alteraciones en tele de tórax. Presentación del caso: Femenino de 32 años de edad, la cual inicia su padecimiento actual 3 meses previos a su ingreso con accesos de tos con expectoración mucosa y fiebre de $38.6{ }^{\circ} \mathrm{C}, 2$ meses previos se agrega pérdida de peso de 10 $\mathrm{kg}$ y diaforesis nocturna, el último mes se agrega disnea de medianos esfuerzos que evoluciona a pequeños esfuerzos, por lo que acude. Eosinofilia sérica de 9,170, tele de tórax con infiltrados alveolares difusos de predominio subpleural, se realiza broncoscopia con lavado bronqueoalveolar resultando $69 \%$ de eosinófilos en el recuento celular, se inicia tratamiento con esteroides orales presentando una rápida respuesta favorable. Conclusión: La neumonía eosinófila crónica es una entidad poco frecuente, cuya etiología en muchas ocasiones es desconocida. Incluida en un grupo de enfermedades que asociaban alteraciones pulmonares y eosinofilia, el diagnóstico requiere de recuento de eosinófilos en lavado broncoalveolar y la piedra angular del tratamiento son los esteroides. Aporte a la práctica clínica diaria: Mencionar la necesidad de reconocer precozmente esta entidad así como resaltar la utilidad del lavado broncoalveolar en el diagnóstico con el fin de instaurar un tratamiento adecuado con esteroides.

\section{Manejo toracoscópico del derrame pericárdico en el Instituto Nacional de Ciencias Médicas y Nutrición Salvador Zubirán}

\section{Bolaños MFV, Herrera ZJJ, Saucedo CJ, Domínguez OD, Catrip TJM, Santillán DPJ}

INNSZ; INC «Ignacio CháveZ»; INER Ismael Cosío Villegas

Introducción: Actualmente la ventana pericárdica es el tratamiento para el derrame 
pericárdico, en pacientes con estabilidad hemodinámica el abordaje de elección se realiza con técnicas de mínima invasión. Objetivos: Estandarizar el abordaje toracoscópico con ventana pericárdica 4 x 4 $\mathrm{cm}$ en pacientes con derrame pericárdico y estabilidad hemodinámica. Material y métodos: Estudio prospectivo, descriptivo, observacional de un año (enero-diciembre 2016) cuya población fueron 17 pacientes con derrame pericárdico presentados al Servicio de Cirugía de Tórax de nuestra institución. Se evaluaron las variables: sexo, edad, tiempo de estancia posoperatoria, morbilidades y resultados cultivos y patología. Resultados: En un período de 12 meses se realizaron 17 ventanas pericárdicas toracoscópicas de 4 x $4 \mathrm{~cm}$. En el preoperatorio todos los pacientes presentaron alteraciones electrocardiográficas y cardiomegalia grado III/IV en la radiografía de tórax. De los 17 pacientes, 10 fueron mujeres y 7 hombres, la edad promedio fue de $44 \pm 20$ años. El diagnóstico preoperatorio de derrame pericárdico se hizo en el $70.6 \%$ de los casos. Todos los pacientes fueron sometidos a anestesia general con intubación selectiva, el abordaje fue derecho en el $91.6 \%$ y sólo hubo una conversión. El promedio de volumen evacuado fue de $481 \mathrm{~cm}^{3}\left(50-1600 \mathrm{~cm}^{3}\right)$, teniendo el diagnóstico de pericarditis crónica en el $70.58 \%$ de los casos. Los drenajes se retiraron a los $7.2 \pm 6.5$ días posquirúrgico, con gasto menor a $150 \mathrm{~mL}$ en 24 horas. Sólo un paciente presentó complicaciones posquirúrgicas (TEP). Conclusión: En pacientes con inestabilidad hemodinámica se debe realizar pericardiocentesis de urgencia. En pacientes con estabilidad hemodinámica, la ventana pericárdica vía toracoscópica es un procedimiento factible, seguro y reproducible que otorga los beneficios de la cirugía de mínima invasión, disminuyendo las complicaciones posoperatorias. Aporte a la práctica clínica diaria: Técnica segura de manejo del derrame pericárdico en pacientes con estabilidad hemodinámica.

\section{Caso reporte de quilotórax en edad pediátrica en síndrome nefrótico}

\section{Sandoval RNN, Vargas BEE,}

García RJL, Aguilar AA, Ruiz GHH, Hernández RR, Irissont DJA, Oregón AAl, Velázquez GMV, Saucedo TJL, Martínez BMC

\section{IMSS}

Introducción: El quilotórax se define como la salida de quilo desde el conducto torácico hacia el espacio pleural. Las causas más frecuentes son secundarios a trauma directo $(60 \%)$, obstrucción o aumento de presión de vena cava superior. Objetivos: Presentar caso de quilotórax en edad pediátrica en síndrome nefrótico y revisión de bibliografía. Presentación del caso: Paciente masculino de 8 años, diagnóstico de síndrome nefrótico corticorresistente (glomerulonefritis focal y segmentaria variante celular) diagnosticado a los 2 años, antecedente de peritonitis aguda primaria. Sin patologías respiratorias previas. Ingresa por tos productiva de cuatro días de evolución, dolor dorsolumbar izquierdo que mejora con analgésico, niega fiebre y datos de dificultad respiratoria. A la exploración física saturación 97\%, palidez de piel y tegumentos, edema palpebral, tórax con disminución de murmullo vesicular basal izquierdo, matidez a la percusión, disminución de vibraciones vocales, abdomen con ascitis, no irritación peritoneal, edema escrotal, godette positivo ++. Radiografía de tórax: radiopacidad homogénea en base de hemitórax izquierdo, sin broncograma, que borra ángulos costofrénico y cardiofrénico ipsilateal, sin desplazamiento de mediastino. U1trasonograma de tórax: Derrame pleural izquierdo de $150 \mathrm{~cm}^{3}$, septos incompletos y móviles. Toracentesis diagnóstica: análisis de líquido confirmatorio para quilotórax. En este caso la presencia de quilotórax no tiene causa directa, por lo que ser potador de un síndrome nefrótico no controlado con descompensación del mismo, ascitis, sea causa del desarrollo del quilotórax, recibiendo manejo médico de quilotórax y control de síndrome nefrótico con remisión. Conclusión: Los síndromes nefróticos y quilotórax en pediatría son escasos a nulos, están relacionados a ascitis quilosa por posibilidad de una comunicación, con paso de líquido de cavidad peritoneal al espacio pleural ya que la presión negativa intratorácica durante la inspiración favorece el paso de la cavidad peritoneal al espacio pleural. Aporte a la práctica clínica diaria: Conocer la asociación de quilotórax y síndrome nefrótico en paciente de pediatría.

\section{Síndrome de Goodpasture}

\section{Espeso RMF, Basaldua ZPX, Navarro $V D$}

IMSS

Introducción: El síndrome de riñónpulmón se define como una combinación de hemorragia alveolar difusa y glomerulonefritis, siendo las vasculitis sistémicas primarias y el síndrome de Goodpasture las etiologías más frecuentes. Objetivos: Dar a conocer un caso de síndrome de Goodpasture con presentación de neumonía organizada criptogénica. Presentación del caso: Masculino, 22 años; antecedente de enfermedad renal crónica, con diálisis peritoneal. Cuadro en febrero 2016 caracterizado por tos productiva esputo hialino, hemoptoicos, disnea progresiva, ataque al estado general. Recibe múltiples antibióticos con cuadros intermitentes de mejoría. Presenta evolución estacionaria, cultivos negativos. Se decide realizar biopsia pulmonar: infiltrados alveolares por neutrófilos y neovascularización, tabiques interalveolares engrosados por fibrosis y hemorragia con reporte de neumonía organizada criptogénica. Broncoscopia: Árbol bronquial con mucosa pálida y muy vascularizada. Inmunológicos con Ac. antimembrana basal glomerular: positivo 1:10. P-ANCA, C-ANCA, anticardiolipina, ac. antifosfolípidos: Negativos. Espirometría: FEV $/$ FVC: $77 \%$, FEV $_{1}$ : 74\%, FVC: $82 \%$. TLC 73\%. Caminata de 6 minutos: $\mathrm{SPO}_{2}$ inicial 94\%, final de 95\%. DLCO $102 \%$. Síndrome mediado por factores inmunológicos dirigidos contra elementos antigénicos localizados a nivel de la membrana basal, comunes a nivel de pulmón y riñón. La lesión inducida por inmunocomplejos es la clave patogénica de la enfermedad. Manifestaciones como hemoptisis y hematuria caracterizan a esta enfermedad. El síndrome nefrítico es un hallazgo de esta 
enfermedad y debe despertar la sospecha diagnóstica su hallazgo en el contexto que se planteó. Conclusión: Diagnóstico de síndrome de riñón-pulmón (Goodpasture) considerándose trastorno autoinmune raro, enfermedad por hipersensibilidad, en seguimiento por neumología y manejo conjunto con nefrología ya que el objetivo del tratamiento está orientado a la disminución de la cantidad de anticuerpos circulantes con inmunomodulares y plasmaféresis, sin embargo, el pronóstico es variable. Aporte a la práctica clínica diaria: Información sobre una entidad desconocida, cuya incidencia y prevalencia se subestima y cuya evolución se ignora.

\section{Evaluación de la calidad de vida en los pacientes con fibrosis quística de la UMAE pediatría CMNO}

\author{
Aguilar AA, Sandoval-Romero NN, \\ Pérez OA, Hernández ChE, Ruiz- \\ Gutiérrez HH, Hernández-Raigoza \\ $R$, Velázquez GMV, Saucedo TJL, \\ Martínez BMC
}

IMSS

Introducción: La fibrosis quística (FQ) es una trastorno autosómico recesivo causado por mutaciones en el gen CFTR (regulador de conducción transmembranal de la fibrosis quística). Objetivos: Determinar la calidad de vida de los pacientes pediátricos con FQ. Material y métodos: Estudio transversal analítico, pacientes de 2-16 años con FQ se aplicó cuestionario Pediatric Quality of Life Inventory (PedsQL) y el Cystic Fibrosis Questionnaire Revised (CFQ-R). Resultados: Se incluyeron 30 pacientes, 16 fueron del sexo masculino (53.3\%) y 14 del sexo femenino (46.7\%). La edad con una mediana de 8.9 años ( \pm 3.9 DE). Al evaluar la escala genérica PedsQL y específica CFQ-R se obtuvo una puntuación promedio del cuestionario PedsQL de 69.24 puntos ( $\pm 15.73 \mathrm{DE})$ en los pacientes y 62.69 puntos $( \pm 19.10 \mathrm{DE})$ en los tutores. Resultados de la calidad de vida en pacientes con fibrosis quística (CFQ-R). veintidós encuestas del CFQ-R a pacientes y 17 a tutores. En los pacientes la menor puntuación fue la percepción de la salud con 44.44 puntos ( $\pm 22.25 \mathrm{DE})$, seguido de imagen corporal con 47.60 puntos ( $\pm 28.62 \mathrm{DE})$. En las encuestas de los tutores el área que presentó menor puntuación fue la percepción de la salud con 39.86 puntos ( $\pm 29.42 \mathrm{DE})$, seguido de área de peso con 43.14 puntos $( \pm 32.85 \mathrm{DE})$, carga de tratamiento con 46.39 puntos $( \pm$ 17.69 DE). Conclusión: Las puntuaciones de calidad de vida de los pacientes con fibrosis quística, fueron menores a las reportadas en otros estudios, reflejando deterioro en la misma; el área de menor puntuación reportada por los niños fue la de escolar, mientras que por los tutores fue el área social en la escala genérica. El área de calidad de vida de menor puntuación reportada por los niños al igual que sus tutores fue la percepción de la salud en la escala específica. Aporte a la práctica clínica diaria: Experiencia clínica en paciente con fibrosis quística.

\section{Presentación atípica de coccidioidomicosis pulmonar}

\section{Martínez OVA, Herrera GAS}

Hospital Universitario UANL

Introducción: La coccidioidomicosis es una infección sistémica causada por el hongo Coccidioides immitis. Constituye una enfermedad endémica en el norte de México y el sureste de los Estados Unidos. Las manifestaciones radiológicas de este desorden son variables. La ruptura de una cavitación pulmonar con subsecuente neumotórax es infrecuente, inclusive en áreas endémicas de coccidioidomicosis. Objetivos: Dar a conocer las posibles presentaciones clínicas de la coccidioidomicosis, así como esta presentación atípica. Material y métodos: Presentamos un caso de neumotórax espontáneo secundario a ruptura de caverna pulmonar originada por coccidioidomicosis. Presentación del caso: Masculino de 55 años de edad, inicia su padecimiento 6 meses previos a su internamiento con accesos de tos sin expectoración, fiebre, diaforesis nocturna y pérdida de peso $8 \mathrm{~kg}$, tres días previos a su ingreso inicia con dolor opresivo en hemitórax anterior izquierdo, intensidad 5/10, con irradiación a región escapular ipsilateral, tos productiva, expectoración hialina, el día de su ingreso se exacerban los síntomas y se agrega disnea, motivos por los que decide acudir a este hospital. Se realiza broncoscopia con lavado broncoalveolar y biopsias pulmonares transbronquiales reportando proceso inflamatorio crónico granulomatosa asociado a la presencia de estructuras micóticas morfológicamente compatibles con Coccidioides immitis, tinción de PAS reporta la presencia de estructuras micóticas morfológicamente compatibles con Coccidioides immitis. Cultivo de lavado broncoalveolar: Coccidioides immitis, cultivo de líquido pleural: Coccidioides immitis. Conclusión: La infección por coccidioidomicosis es endémica en el norte del país, la mayor parte de las infecciones son benignas y autolimitadas debido a la eficiente respuesta de la inmunidad mediada por células, es poco frecuente que se presente como neumotórax espontáneo. Aporte a la práctica clínica diaria: Conocer las diferentes presentaciones clínicas de la infección por Coccidioides immitis, no descartar la infección por coccidioidomicosis ante un caso de neumotórax espontáneo y clínica de infección por coccidioidomicosis.

\section{Efecto Macklin secundario a influenza a H3N2. Reporte de caso}

\section{Martínez VLF, Leal AT, Castillo VMC, Salcedo ChM}

INER Ismael Cosío Villegas

Introducción: El neumomediastino espontáneo es una entidad rara, con una incidencia de 1/44,000 en el servicio de Urgencias. Causado por cualquier situación que desarrolle maniobra de Valsalva o asociado a infección en un $43 \%$. A la visualización tomográfica de aire en las vainas perivasculares y peribronquiales se le denomina efecto Macklin. Objetivos: Describir el caso y abordaje de una paciente con efecto Macklin por influenza 
H3N2. Presentación del caso: Femenino de 12 años, previamente sana. Padecimiento de 2 semanas con tos emetizante; 3 días previo a consultar se exacerba la tos, presenta dolor torácico y refiere impacto en tórax por compañero de escuela. Se agrega fiebre, dificultad respiratoria y cianosis. $\mathrm{Al}$ ingreso FC 120 lpm, FR 50 rpm, SpO aa $51 \%$, afebril, dificultad respiratoria, enfisema subcutáneo paraesternal derecho, sibilancias bifásicas bilaterales. Ingresa a UTIP con tratamiento: ceftriaxona, claritromicina y oseltamivir; esteroide sistémico, aminofilina, nebulizaciones y aporte de oxígeno. Se coloca catéter venoso central, presenta neumotórax derecho y colocación de sonda endopleural. Al octavo día presenta deterioro clínico posterior a esfuerzo, aumenta enfisema subcutáneo, se escala tratamiento antibiótico. Broncoscopia evidencia cambios inflamatorios del árbol bronquial; y TAC reporta efecto Macklin. Paciente con mejoría clínica, alta con esteroide inhalado. Resultado de PCR positivo para influenza A H3N2. Paciente en seguimiento por rehabilitación pulmonar con indicación de limitación de actividad física. El neumomediastino espontáneo es provocado por eventos que aumentan la presión de la vía aérea. Se ha asociado a procesos infecciosos, reportándose en la literatura dos casos asociados a influenza H1N1. En el caso de nuestra paciente se documenta influenza A H3N2. Conclusión: El neumomediastino espontáneo y el efecto Macklin, son entidades raras, autolimitadas, causadas por diferentes patologías, desde el esfuerzo por actividad física, traumatismos, crisis asmáticas $(0.3 \%)$ o infecciones $(43 \%)$. El tratamiento es sintomático, con reposo y oxígeno suplementario. Aporte a la práctica clínica diaria: Conocer causas, abordaje y tratamiento de la patología.

\section{Reporte de un caso enfermedad de Erdheim- Chester con sobrevida mayor de 9 años}

$$
\begin{aligned}
& \text { Rivera RJ, Basaldúa ZPX, Armenta } \\
& R R \\
& \text { IMSS }
\end{aligned}
$$

Introducción: La enfermedad de Erdheim-Chester es una rara histiocitosis de células no Langerhans. Se han reportado menos de 600 casos a nivel mundial. La mortalidad es variable, reportándose $26 \%$ a los 27 meses hasta el $80 \%$ a los 5 años. Objetivos: Dar a conocer una enfermedad rara y con ello poder incrementar la sospecha diagnóstica. Material y métodos: Se reporta el caso de una mujer diagnosticada con enfermedad de Erdheim-Chester desde el 2007, con deterioro del estado funcional por hipertensión pulmonar. Presentación del caso: Mujer de 38 años de edad. Diagnosticada en el 2007 con enfermedad de ErdheimChester. Tratamiento con interferón pegilado $100 \mu \mathrm{g}$ semanales, prednisona $5 \mathrm{mg}$ cada $24 \mathrm{~h}$ por los últimos 4 años. Oxígeno suplementario 3 1/min. Presenta con aumento de disnea, astenia, adinamia y pérdida de peso de $5 \mathrm{~kg}$, deterioro de estado funcional; se realiza ecocardiograma reportando PSAP $143 \mathrm{mmHg}$, se realiza cateterismo. Gasometría pH 7.44, $\mathrm{PCO}_{2} 28, \mathrm{PO}_{2} 67, \mathrm{HCO} 3-19, \mathrm{SaO}_{2} 94 \%$ con $\mathrm{FiO}_{2} 40 \%$. Cateterismo cardíaco: Presión media de arteria pulmonar 60 $\mathrm{mmHg}$, con respuesta negativa a prueba de vasorreactividad con oxígeno, presión media de arteria pulmonar $56 \mathrm{mmHg}$, reducción de 9\%. DLCO 18\%. Capacidad pulmonar total 65\%. Espirometría: FVC: $1.39 \mathrm{~L} ; 42 \%, \mathrm{FEV}_{1}: 0.96 \mathrm{~L} ; 35 \%, \mathrm{FEV}_{1} /$ FVC: $69 \%$. Posbroncodilatador: FVC: $1.35 \mathrm{~L} ;-3 \%, \mathrm{FEV}_{1}: 1.060 \mathrm{~L} ; 10 \%, \mathrm{FEV}_{1}$ I FVC: $79 \%$. Enfermedad rara con tratamiento con eficacia no comprobada por el poco número de casos. Conclusión: Se presenta caso de una paciente con enfermedad de Erdheim-Chester, con afección a nivel pulmonar, con sobrevida de 9 años, mayor a la esperada, debido a rareza es de gran interés su conocimiento. Aporte a la práctica clínica diaria: El conocer una enfermedad sumamente rara incrementará la sospecha diagnóstica, por lo tanto, el reporte de casos de la enfermedad es lo que abrirá camino para entender su patogenia y a las posibilidades terapéuticas.

\section{Reporte de dos casos}
Silva CTM, Santa María AJ, del Razo RR, Rocha DMC, Tona AG, Aguirre $P T$, Herrera $M$

INER Ismael Cosío Villegas

Introducción: Las estenosis menos frecuentemente encontradas $(10 \%$ de los casos) se deben a causas como Wegener, sarcoidosis, infecciones granulomatosas, traumatismos laríngeos externos y algunas son consideradas idiopáticas. Objetivos: Reportar el caso de dos pacientes con estenosis subglótica de tipo inflamatoria y probablemente infecciosa. Material y métodos: Revisión de expedientes e imágenes broncoscópicas. Presentación de los casos: Femenino de 10 años y masculino de 3 años que llegaron al Instituto con cuadro de dificultad respiratoria importante, estridor bifásico con estenosis subglótica grave que requirió intubación con cánulas menores a las destinadas por la edad, estimándose estenosis del 40 y 50). La niña tenía antecedente de atopia (ajo, sauce, ácaros, artemisa), cuadro de 2 meses de evolución con sibilancias intermitentes, disnea, una hospitalización durante 3 días por laringotraqueítis en hospital pediátrico. El niño, previamente sano, con cuadro de 1 mes de evolución con estridor intermitente, ameritando atención en urgencias en múltiples ocasiones, remitiendo parcialmente. Se realizaron tomografías descartándose compresiones extrínsecas, con edema de tejidos blandos a altura del cricoides. Recibieron tratamiento antiinflamatorio y antibiótico con cefalosporina de tercera generación. Los pacientes presentaron fuga de la cánula al séptimo y quinto día, se realiza broncoscopia, encontrándose con estenosis subglótica residual del $20 \%$, con inflamación y fibrina en la zona, sin requerir tratamiento quirúrgico. El paciente de 3 años tuvo una tercera revisión a las 2 semanas de alta, encontrándose sin alteraciones, permeabilidad al $100 \%$. Conclusión: Las estenosis inflamatorias deben ser sospechadas en pacientes con cuadro de estridor persistente, incluso intermitente ya que pueden progresar de forma tórpida y requerir apoyo mecánico ventilatorio. En el caso 
de nuestros pacientes el tratamiento con esteroide y antibiótico probó tener un resultado exitoso, sin requerir traqueostomía. Aporte a la práctica clínica diaria: Aunque no existen reportes de esta patología en la edad pediátrica, es importante considerarla como un diagnóstico posible en aquellos pacientes previamente sanos con estridor persistente, intermitente progresivo y grave.

\section{Variabilidad de la función pulmonar en niños asmáticos de 6 a 14 años medida por espirómetro portátil (PIKO-6)}

Martínez VLF, Cano SMC, Garrido GC, Miguel RJL, Leal AT

INER Ismael Cosío Villegas

Introducción: El asma es la enfermedad crónica más frecuente en niños, siendo de vital importancia el adecuado control de la enfermedad para disminuir su morbimortalidad. El asma sigue un ritmo circadiano, presentando exacerbaciones durante la mañana o síntomas nocturnos. El estudio está dirigido a determinar la variabilidad de la función pulmonar utilizando el espirómetro portátil PIKO-6, que es un aparato electrónico que mide el volumen espiratorio en el segundo $1\left(\mathrm{FEV}_{1}\right)$ y 6 (FEV6), así como el cociente $\mathrm{FEV}_{1} / \mathrm{FEV6}$. No se cuenta con estudios previos de dicha variabilidad. Objetivos: Evaluar la variabilidad de la función pulmonar en niños asmáticos de 6 a 14 años utilizando el PIKO-6. Material y métodos: Estudio observacional longitudinal en 37 pacientes asmáticos de 6 a 14 años, en seguimiento por consulta externa de Neumología Pediátrica. Se evaluó a los pacientes en 2 visitas, realizando en cada una de ellas: espirometría, cuestionario ACQ-7 y PIKO-6. De forma ambulatoria realizaron mediciones de PIKO-6 durante 1 mes. Resultados: Aplicando el cociente de correlación se encontró una adecuada correlación entre los valores obtenidos de la relación $\mathrm{FEV}_{1} / \mathrm{FEV} 6$ por PIKO-6 y la relación $\mathrm{FEV} / \mathrm{FVC}$ de la espirometría basal (R2 0.2390, p=0.395), y los valores posbroncodilatador $(\mathrm{R} 20.25, \mathrm{p}=0.03)$. Se encontró correlación entre las mediciones de $\mathrm{FEV}_{1}$ y FEV6 obtenidas por PIKO-6, en comparación con $\mathrm{FEV}_{1}$ y $\mathrm{FVC}$ medidos por espirometría: R2 de $0.74, \mathrm{p}=0.0000 \mathrm{y}$ $\mathrm{R} 2$ de $0.83, \mathrm{p}=0.0000$, respectivamente. Con la regresión de los promedios se encontró que la variabilidad diaria del $\mathrm{FEV}_{1}$ (PIKO-6) fue menor al 20\%. Conclusión: Los valores de $\mathrm{FEV}_{1}$, FEV6 y FEV $/ \mathrm{FEV}_{1}$ obtenidos por PIKO-6 correlacionan con

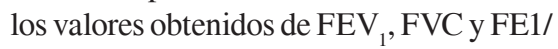
FVC por espirometría. En nuestro estudio la variabilidad diaria de $\mathrm{FEV}_{1}$ medida por PIKO-6 fue menor al 20\%. Aporte a la práctica clínica diaria: Utilizar el PIKO6 como una herramienta para monitorizar el adecuado control del asma de forma ambulatoria.

\section{Lesión quística pulmonar. Diagnósticos diferenciales}

\section{Lechuga TI, del Razo RR, Velázquez SR, Alejandre GA, Salcedo ChM, Castillo VMC}

INER Ismael Cosío Villegas

Introducción: El quiste pulmonar es un espacio anormal, con aire y pared $<3$ $\mathrm{mm}$, bordes definidos y tamaño variable. Las enfermedades con lesiones quísticas son histiocitosis de células de Langerhans (HCL), linfangioleiomiomatosis, esclerosis tuberosa, neumonía intersticial linfoide. Otras que simulan quistes como bronquiectasias quísticas son de causas infecciosas o enfermedades quísticas congénitas como malformación adenomatoide quística y quiste broncogénico. Objetivos: Revisar los hallazgos clínicos y tomográficos de enfermedades quísticas. Presentación de los casos: Revisión de expedientes de pacientes con diagnóstico de quistes pulmonares de 2015 a 2016. Caso 1: Femenino de 1 año, antecedente de 2 neumotórax espontáneos izquierdos, neumonía y neumotórax espontáneo derecho. TACAR: quistes bilaterales, destrucción del parénquima. Biopsia: HCL. Caso 2: Femenino de 3 años, deformidad de hemitórax derecho, disnea y dolor torácico, presenta neumotórax derecho. TACAR: quistes de gran tamaño, predominio derecho, confluentes, desplazamiento de mediastino. Pequeños quistes izquierdos. Áreas de parénquima sano. Biopsia: Malformación congénita de la vía aérea. Caso 3: Masculino de 5 años, antecedente de neumonía, con disnea y tos productiva, desnutrición. TACAR: destrucción del parénquima con quistes diseminados. Electrolitos en sudor positivos, mutación genética G542x. Caso 4: Masculino de 3 años, trisomía 21, tos de 2 meses. TACAR: Quistes subpleurales de predominio apical, bilaterales; se realiza resección de quistes subpleurales asociados a síndrome de Down. Caso 5: Masculino de 6 meses, neumonía grave y síndrome de dificultad respiratoria, a las 3 semanas con quistes bilaterales que confluyen, 1 con nivel hidroaéreo mostrando neumatoceles. Resultados: Se revisaron 5 expedientes de pacientes con lesiones quísticas: fibrosis quística, histiocitos, enfermedad congénita de la vía aérea, quistes subpleurales y neumatocele. Conclusión: El diagnóstico diferencial se basa en el número, tamaño, forma y distribución de los quistes junto a la evaluación de los hallazgos parenquimatosos. Aprendizaje: Identificar las enfermedades pulmonares que cursan con lesiones quísticas y aprender los datos clínicos y radiológicos que orientan hacia cada patología.

\section{Lesión pulmonar cavitada única del lóbulo superior derecho como presentación atípica de la granulomatosis con poliangeítis. Reporte de un caso}

Annetty ML, Castro LCJ, Bernabé SJC, Espinosa de los MC, Arroyo HM, Sánchez RCP

INER Ismael Cosío Villegas

Introducción: La granulomatosis con poliangeítis es una enfermedad que suele manifestarse a nivel pulmonar como nódulos cavitados múltiples diseminados, siendo la afección de un lóbulo pulmonar completo una forma de presentación rara. Objetivos: Describir una presentación 
atípica de la granulomatosis con poliangeítis a nivel pulmonar, con afectación de la totalidad del lóbulo superior derecho, con el objetivo de considerarlo un diagnóstico diferencial con otras enfermedades que frecuentemente producen este tipo de lesión pulmonar. Presentación del caso: Hombre de 56 años de edad, con diabetes mellitus e hipertensión arterial sistémica, con cuadro clínico de dos meses de evolución de pérdida ponderal, diaforesis y fiebre, quien en la radiografía de tórax presentaba opacidad pulmonar completa de localización apical derecha, motivo por el cual se hospitalizó para abordaje diagnóstico, reportándose negativos todos los resultados de bacteriología y cultivos de lavado bronquioloalveolar; resultados de biopsias transbronquial y biopsia transtorácica guiada por imagen reportaron tejido necrótico. Durante su estancia se apreció incremento de tamaño de lesión pulmonar en el transcurso de dos semanas. Fue sometido a lobectomía superior derecha, con reporte histopatológico de necrosis de toda la pieza quirúrgica. Al reinterrogar paciente el mismo refirió cuadros de sinusitis y otitis a repetición en la adultez temprana. Se recabaron estudios de anticuerpos, documentándose antiproteinasa 3 positivo, por lo cual se realizó el diagnóstico de granulomatosis con poliangeítis como causa de destrucción necrótica de lóbulo superior de pulmón derecho. Conclusión: La granulomatosis con poliangeítis es una enfermedad rara cuya manifestación clínica, en el caso de este paciente, resulta atípica, pudiendo ser confundida con tuberculosis pulmonar, cáncer de pulmón, entre otras. Conocer esta presentación clínica permitirá considerarla como un diagnóstico diferencial ante futuros casos de similares manifestaciones clínicas. Aporte a la práctica clínica diaria: $\mathrm{Co}$ nocer presentaciones atípicas de vasculitis con afección pulmonar.

\section{Mecánica pulmonar de pacientes con ventilación mecánica por síndrome de insuficiencia respiratoria aguda debida al virus de influenza}

Castro LCJ, Marcano de La RLA, García TRA, Sandoval GJL, Arroyo HM, Báez SR

INER Ismael Cosío Villegas

Introducción: En 2009 una nueva cepa del virus de la influenza AH1N1 (AH1N1pdm09) causó la primera pandemia del siglo XXI. Este virus ocasiona síndrome de insuficiencia respiratoria aguda (SIRA) en el 1 a 5\% de los casos, con una mortalidad que oscila entre el 35 y el $60 \%$. Dado que el SIRA por influenza es una condición médica grave que genera alta mortalidad a quien la padece, un tratamiento agresivo y oportuno es necesario para mejorar el pronóstico de estos pacientes. Las intervenciones que han demostrado que disminuyen la mortalidad en SIRA por influenza se pueden dividir en dos grupos: terapia antiviral específica y estrategias de ventilación en SIRA. Sin embargo, para lograr implementar estrategias de ventilación debemos conocer cómo es la mecánica pulmonar de estos pacientes sometidos a ventilación con presión positiva. Objetivos: Los objetivos específicos fueron: describir las características sociodemográficas de los pacientes con SIRA por influenza hospitalizados en el INER de enero a mayo de 2016; describir el cuadro clínico de presentación y describir la estrategia de ventilación. Material y métodos: Diseño del estudio: Estudio observacional, analítico, transversal y retrospectivo. $b$. Población de estudio: El universo de estudio contempló 56 expediente de pacientes sometidos a ventilación mecánica con SIRA por influenza probable o confirma$\mathrm{da}$, que fueron atendidos en el Instituto Nacional de Enfermedades Respiratorias de enero a mayo de 2016. El grupo de estudio fue conformado por 34 expedientes de pacientes con ventilación mecánica invasiva con SIRA por influenza, obtenidos por muestreo a conveniencia que cumplieron con los criterios de inclusión. a. Los criterios de inclusión fueron: expedientes de pacientes con SIRA por influenza probable o confirmada sometidos a ventilación mecánica invasiva, cuya edad fuera igual o mayor a 16 años, con estancia hospitalaria en VMI de al menos tres días atendidos en el INER en el pe- ríodo del 1 de enero al 31 de mayo de 2016. b. Criterios de exclusión: Los criterios de exclusión fueron: expedientes de pacientes en quienes se documentó una causa de SIRA diferente a influenza, con manejo avanzado de la vía aérea realizado en otro lugar distinto al INER o que fueron trasladados a otro hospital. c. Criterios de eliminación: El criterio de eliminación fue: expedientes de pacientes con información incompleta. Presentación del caso: Los pacientes con SIRA debido al virus de influenza tienen una alta mortalidad. En 2009 la pandemia de infección por el virus AH1N1pdm09 nos enseñó que la terapia antiviral específica temprana (primeros 2 días) con inhibidores de la neuraminidasa (INA) junto al soporte ventilatorio de protección pulmonar son parte importante en el manejo de estos pacientes, lo cual permite mejorar los resultados clínicos. Sin embargo, pese a que dichas estrategias han demostrado reducir la mortalidad, es de llamar la atención que a nivel mundial, su uso no es generalizado en el tratamiento de los pacientes con SIRA por influenza, implementando la ventilación de protección pulmonar sólo en el $60 \%$ de los casos, realizando la medición de la presión meseta en el $40 \%$, e instaurando la ventilación en posición prono y el bloqueo neuromuscular en SIRA grave en las primeras 48 horas en el $16 \%$ y $37 \%$ de los casos respectivamente. En México de acuerdo a un estudio realizado por Veguilla et al. la mitad de la población mexicana permanece susceptible a infectarse por el virus de la AH1N1pdm09, y esto podría ser la causa por la que en el INER, en época invernal se atienden varios casos de SIRA por influenza que ameritan soporte mecánico ventilatorio, con altas tasas de morbilidad y mortalidad. Dado que el INER es el centro de referencia nacional en enfermedades respiratorias en México, y dado el gran volumen de pacientes con SIRA por influenza que se tratan, se desea conocer las estrategias de ventilación empleados en este tipo de pacientes y la mecánica pulmonar durante el apoyo mecánico ventilatorio. Resultados: Durante el período del 1 de enero al 31 de mayo de 2016 se atendieron en el Servicio de Urgencias Respiratorias del INER un 
total de 7,165 consultas, de las cuales 1,374 fueron reportadas con el diagnóstico de enfermedad similar a influenza. De éstas se decidió la hospitalización de 93 pacientes con diagnóstico de neumonía adquirida en la comunidad por probable virus de la influenza, de los cuales 56 pacientes requirieron asistencia mecánica ventilatoria invasiva (VMI) por presentar síndrome de insuficiencia respiratoria aguda (SIRA). Se revisó un total de 56 expedientes de pacientes con neumonía por enfermedad similar a influenza y SIRA, atendidos en el INER en el período de enero a mayo de 2016, de los cuales 15 fueron excluidos por tener datos faltantes y tres por haberse trasladado a otro hospital. Cuatro fueron eliminados por corroborarse otro agente infeccioso diferente al virus de la influenza (tres con infección por metapneumovirus y uno por coronavirus, todos confirmados por estudio de PCR en muestra de isopado nasal). De esta manera se incluyeron al estudio un total de 34 expedientes. Por sexo, el 48\% ( $\mathrm{n}=16)$ fueron mujeres y se tuvo una media de edad general de 49 años (DE \pm 14$)$. La prevalencia de obesidad fue del $47 \%$ ( $\mathrm{n}=$ $16)$, el $50 \%(\mathrm{n}=17)$ tuvo al menos una comorbilidad y la mortalidad general por SIRA por el virus de la influenza fue del $42 \%$ a 60 días $(\mathrm{n}=14)$. El tiempo de evolución promedio fue de 10 días ( $\mathrm{DE} \pm 4.7$ ) y la presentación clínica por orden de frecuencia fue: tos $(94 \%)$, disnea $(88 \%)$, fiebre (82), expectoración $(70 \%)$, artralgias $(67 \%)$, mialgias $(64 \%)$, cefalea $(52 \%)$, rinorrea y odinofagia (47\%), hemoptoicos (35\%) y dolor pleurítico (11\%). Se confirmó la infección por el virus de la influenza a través de estudio de PCR en muestra proveniente de vía respiratoria: el 18\% (n =6) de los pacientes tuvo influenza A, el $12 \%(\mathrm{n}=4)$ influenza AH1N1, el 12\% (n =4) influenza AH1N1pdm09, el 8\% ( $\mathrm{n}=$ 3) influenza B y el $50 \%(n=17)$ restante no se pudo confirmar el agente etiológico, pero el cuadro clínico fue compatible con probable infección por el virus de la influenza. Con respecto a la estrategia de ventilación a la que fueron sometidos los pacientes durante la asistencia mecánica ventilatoria, se observó que el volumen corriente programado calculado por peso predicho (VtePP) fue superior a $8 \mathrm{~mL} /$
$\mathrm{kgPP}$ en ambos grupos de pacientes sin existir diferencia significativa entre sobrevivientes y fallecidos $(\mathrm{p}<0.05)$. Sobresale el hecho que ningún paciente del grupo de sobrevivientes tuvo una ventilación de protección pulmonar con un VtePP programado menor a $6 \mathrm{~mL} / \mathrm{kgPP}$. La ventilación en decúbito prono fue empleada en sólo 2 pacientes $(6 \%)$ del total, ambos fueron realizados en la UCIR y sobrevivieron. En ningún paciente se instauró la infusión temprana con bloqueadores neuromusculares (cisatracurio). También se observó que a los pacientes fallecidos se les programó mayores niveles de PEEP y de $\mathrm{FIO}_{2}$ en comparación con el grupo de sobrevivientes $(\mathrm{p}<0.05)$. Con respecto a la mecánica pulmonar, el grupo de pacientes fallecidos tuvo un mayor valor en las presiones de la vía aérea (presión pico, presión meseta y presión media) comparado con el grupo de sobrevivientes $(\mathrm{p}<$ 0.05 ); asimismo, los fallecidos tuvieron menor distensibilidad pulmonar y mayor presión de distensión $(\mathrm{p}<0.05)$. No hubo diferencia en la resistencia de la vía aérea entre grupos ( $p>0.05)$. Conclusión: Pese a que el SIRA por influenza es un padecimiento con alta mortalidad, existe poco uso de las estrategias que disminuyen la mortalidad. Más del $80 \%$ de los pacientes con SIRA por influenza no reciben ventilación de protección pulmonar. Existe poco uso de la ventilación en decúbito prono y nulo empleo de la infusión de bloqueadores neuromusculares, en pacientes con indicaciones para estas intervenciones. El inicio del tratamiento antiviral es tardío, aproximadamente de 10 días, debido al retraso de los pacientes en buscar atención médica. Habrá que emplear la presión de distención como una herramienta más a considerar en el manejo de los pacientes con SIRA por influenza, tratando de obtener valores < $15 \mathrm{cmH}_{2} \mathrm{O}$. Existieron diferencias en la estrategia de ventilación empleada y la mecánica pulmonar entre los pacientes que sobrevivieron y los que fallecieron, encontrándose en los fallecidos mayores presiones positivas en la vía aérea y una mecánica pulmonar más deteriorada. Aporte a la práctica clínica diaria: Conocer las alteraciones en la mecánica pulmonar que sufren los pacientes con SIRA por el virus de la influenza y el grado de apego a las estrategias de ventilación recomendadas a nivel internacional que impactan en la mortalidad, con el fin de entender la importancia de apegarse a las estrategias de protección pulmonar en este grupo de pacientes.

\section{Hemotórax derecho como una complicación inusual de disección aórtica. Presentación de un caso}

Castro AEF, Marcano de La RLA, Rodríguez LIS, Arroyo HLJ, Juárez HF, Hernández ZRJ

INER Ismael Cosío Villegas

Presentación del caso: Masculino de 86 años con hipertensión arterial sistémica sin tratamiento. Acudió por cuadro de dolor intenso en región costolumbar derecha, súbito, irradiado a región torácica anterior ipsilateral de un día de evolución acompañado de disnea. A su llegada con FC 90 lpm, TA 90/60 mmHg y ruidos respiratorios disminuidos en región subescapular derecha. Con hemoglobina $9.3 \mathrm{~g} / \mathrm{dL}$, hematocrito $28.5 \%$ y gasometría arterial con hiperventilación aguda e hipoxemia leve. Radiografía de tórax con presencia de derrame pleural bilateral de predominio derecho confirmado tomográficamente, mostrando densidades promedio de 47 Unidades Hounsfield (UH), así como engrosamiento irregular de la pared de la aorta descendente con extravasación del medio de contraste. Dos días después presentó disminución de la hemoglobina a $6.4 \mathrm{~g} / \mathrm{dL}$ y, tras hemotransfusión, se realizó toracentesis obteniendo líquido hemático con hematocrito $26.9 \%$. La integración diagnóstica confirmó un hemotórax derecho secundario a disección aórtica. A las 72 horas la radiografía mostró aumento del derrame pleural y el paciente presentó deterioro respiratorio con inestabilidad hemodinámica, posterior a lo cual, tras no aceptar tratamiento quirúrgico falleció. Aporte a la práctica clínica diaria: El hemotórax tiene una prevalencia de $10 \%$ como complicación de un síndrome aórtico agudo. Se presenta usualmente en hemitórax derecho, contrario a lo expuesto en el 
presente caso. El contar con hipertensión arterial —el principal factor de riesgo para desarrollar una disección aórtica — aunado al dolor súbito e intenso en tórax posterior como síntoma principal, nos orientó a corroborar el diagnóstico buscando extravasación del medio de contraste y un engrosamiento circunferencial de la aorta con densidad de 50 UH. Este último hallazgo se denomina hematoma intramural aórtico, considerado una variante establecida de la disección aórtica prevalente en ancianos y usualmente localizado en aorta descendente. La proximidad de la hemorragia intramural a la adventicia conlleva un mayor riesgo de rotura aórtica con el consecuente derrame hemorrágico.

\section{Evaluación de la función pulmonar en pacientes en vigilancia de leucemia}

Saucedo TJL, Aguilar AA, Barrera de LJC, Martínez BMC, Vargas BEE, Velázquez GMV, Sandoval RNN, Ruíz $G H H$, Hernández RR, Irissont DJA, Oregon AAI, Aguilar $R$

IMSS. Hospital de Pediatría CMNO

Introducción: La leucemia representa un 25 a 30\% de las neoplasias en menores de 14 años, siendo el cáncer más frecuente en la infancia. El incremento en la sobrevida de estos pacientes ha identificado secuelas derivadas de la enfermedad y sus tratamientos. Dentro de los efectos tardíos del tratamiento de leucemia se encuentran las alteraciones de la función pulmonar que pueden iniciar durante el tratamiento, o bien hacerse evidentes hasta 25 años después. Aunque se ha reportado que hasta el 40\% de los niños sobrevivientes de cáncer tienen alteraciones en las pruebas de función pulmonar, sólo el 25\% tiene síntomas respiratorios crónicos. Objetivos: Evaluar la función pulmonar en pacientes pediátricos en vigilancia de leucemia. Material y métodos: Se trata de un estudio transversal descriptivo en donde se incluyeron pacientes de 6 a 16 años en vigilancia de leucemia, sin otras comorbilidades. Se les realizó espirometría, pletismografía y capacidad de difusión de monóxido de carbono para evaluar su función pulmonar.
Resultados: Se incluyó un total de 50 pacientes, en los que se encontró alguna alteración en las pruebas de función pulmonar en $46 \%$, con presencia de síntomas respiratorios en $26 \%$. En espirometría se reportó patrón sugestivo de restricción en $12 \%$, mientras que en pletismografía hubo restricción en $8 \%$ y atrapamiento aéreo en $22 \%$; la DLCO estuvo disminuida en $2 \%$ y aumentada en $18 \%$. El tiempo de vigilancia tuvo diferencia estadística significativa para presentar alteración funcional pulmonar. Conclusión: Se demostró alteración en la función pulmonar en pacientes en vigilancia de leucemia a pesar de una baja frecuencia de síntomas respiratorios. Es necesaria la realización de pruebas de función pulmonar en la vigilancia y seguimiento de estos pacientes.

\section{Síndrome de Loeys-Dietz como causa de aneurisma pulmonar. Reporte de caso}

\section{Rodríguez SIN, Avilés RBA}

INER Ismael Cosío Villegas

Introducción: El síndrome de LoeysDietz es una entidad patológica de herencia autosómica dominante con alteración del tejido conectivo y clínicamente se presenta con aneurismas aórticos o pulmonares, anormalidades arteriales, hipertelorismo, paladar o úvula bífida. La prevalencia no se conoce con exactitud. Cuenta con expresiones variables en las mutaciones del factor de crecimiento B. No hay pruebas específicas para el diagnóstico, pero la asociación de la mutación de dicho factor y la historia de aneurisma o disección arterial sugiere el diagnóstico Objetivos: Presentar la asociación del síndrome con malformaciones vasculares. Presentación del caso: Masculino de 4 años, sin antecedentes heredofamiliares y perinatales sin importancia. Cuenta con antecedentes de hernioplastía inguinal y valvuloplastía mecánica aórtica con ventilación mecánica, antecedente de neumonía recurrente en tres ocasiones. Diagnóstico de pectus excavatum clínico. En tratamiento con acenocumarina y antihipertensivos. Presenta tos diurna y nocturna todos los días así como disnea de medianos esfuerzos de larga evolución, por lo que es referido. A su ingreso con oximetría normal, hipertelorismo, pectus excavatum, tiraje intercostal, cicatriz paraesternal, murmullo vesicular audible, precordio hiperdinámico, no soplos, extremidades con aracnodactilia. Radiografía de tórax: radiopacidad circular paracardíaca derecha, abombamiento de ventana aortopulmonar, con artefactos quirúrgicos. Angio-TAC con dilatación importante de ambas ramas pulmonares y del arco aórtico con aneurisma pulmonar asociado a síndrome de Loeys-Dietz. Conclusión: El diagnóstico diferencial con otras colagenopatías hereditarias como el síndrome de Marfan y la disección aórtica pura, tiene como denominador la mutación de factores de crecimiento. El tratamiento va encaminado a disminuir la presión de la aorta y de arterias pulmonares con pronóstico es sombrío. Aporte a la práctica clínica diaria: Es importante conocer la asociación de aneurismas de grandes arterias con las enfermedades hereditarias del colágeno, a pesar de su pronóstico es importante iniciar tratamiento médico de manera oportuna.

\section{Tumor pulmonar secundario a enfermedad relacionada con IgG4. Reporte de un caso}

Arias PMY, Marcano de La RLA, Juárez VI, Rodríguez BH, Castro LCJ, Rumbo NU

INER Ismael Cosío Villegas

Introducción: Las enfermedades relacionadas con IgG4 se caracterizan por infiltrado linfoplasmocitario de células IgG4+, elevación sérica de IgG4 y lesiones inflamatorias pseudotumorales que pueden afectar varios órganos, entre éstos el pulmón, por lo cual debe considerarse el diagnóstico diferencial con cáncer de pulmón, reciben distinto tratamiento con buen pronóstico, a diferencia del cáncer. Presentación del caso: Hombre de 74 años de edad, con antecedente de diabetes mellitus, hipertensión arterial sistémica y cáncer de próstata, 
con padecimiento de tres meses de ataque al estado general, astenia, pérdida ponderal de $10 \mathrm{~kg}$; estudio de imagen evidenció tumoración en lóbulo inferior izquierdo, se realizó broncoscopia diagnóstica observándose por EBUS lineal adenopatías mediastinales a nivel de 11L y 7 , biopsia transbronquial sin evidencia de células neoplásicas, posteriormente se realizó biopsia transtorácica guiada por ultrasonografía con reporte histopatológico de células fusiformes de significado biológico incierto. Se realizó lobectomía inferior izquierda encontrando tumor dependiente de lóbulo inferior izquierdo de 3.9 x $3.5 \mathrm{~cm}$, color café claro, con aspecto sólido de consistencia pétrea, parénquima antracótico con adherencias laxas de segmentos apicales a pared. En histopatología marcadores positivos: CD138, kappa, lambda e IgG4. Se reporta enfermedad pulmonar esclerosante de tipo sólido nodular asociada a IgG4. Tamaño de la lesión: 3.9 cm de eje mayor. Sin tumor en borde quirúrgico a $1.2 \mathrm{~cm}$. Conclusión: Las enfermedades relacionadas con $\mathrm{IgG} 4$ se caracterizan por infiltrado linfoplasmocitario de células IgG4+, elevación sérica de IgG4 y lesiones inflamatorias pseudotumorales, por lo que debe hacerse diagnóstico diferencial con cáncer pulmonar. Entre los diagnósticos diferenciales también se pueden citar la enfermedad de Mikulicz y síndrome de Sjögren, infecciones (virales, bacterianas, micobacterianas y fúngicas), siendo usualmente un diagnóstico de exclusión.

\section{Prioridades ante una} urgencia respiratoria: tiempos de atención en el Instituto Nacional de Enfermedades Respiratorias Ismael Cosío Villegas

García GML, Regalado PJ, Reveles ZL, Barrales M, García TR, Guadarrama PC, Lugo GG, Serna SHI, Rodríguez LIS, Solís BD, Muñiz $P M$, Sandoval GJL

INER Ismael Cosío Villegas
Introducción: Los servicios de urgencias a nivel global reportan un aumento de consultas. En el Instituto Nacional de Enfermedades Respiratorias (INER), centro de referencia nacional fue del 100\%: 10,497 en 1995, a 21,454 en 2015. Lo que puede repercutir en la calidad. Los tiempos de espera en la consulta de urgencias son indicadores de la calidad percibida en salud, oportunidad, seguridad y un componente de la satisfacción. Objetivo: Conocer los tiempos de atención en la unidad de urgencias del INER desde el ingreso al término de la evaluación médica. Material y métodos: Estudio descriptivo, prospectivo y transversal, realizado en la unidad de Urgencias del INER de octubre 2015 a septiembre 2016. Análisis estadístico: Se realizó estadística descriptiva e inferencial. Se usaron pruebas paramétricas. ANOVA y no paramétricas (Kruskal-Wallis). Programa SPSS V. 21. Resultados: Se incluyeron 555 pacientes con edad promedio de 46 años. Cincuenta y dos punto ocho por ciento hombres, de nivel socioeconómico bajo (75.02\%). El 79.5\% fueron urgencias de neumología. Las tres causas principales de atención fueron: crisis de asma (14\%), neumonías (10.6\%) y exacerbación de EPOC (6.3\%). El tiempo desde la llegada hasta su atención en recepción fue de 5 $\min$ (0.0-60). Tiempo de espera para triage 10 min (0.0-90). Duración de la consulta $40 \mathrm{~min}$ (5-425). Espera para pagar $10 \mathrm{~min}$ (0.0-90). Espera al camillero 5 min (1.0120). Espera para estudios de imagen: 5 min (0-120). Tiempo total de permanencia en urgencias fue de 90 min (5.0-654). El $5.8 \%$ estuvo insatisfecho. Conclusión: Las publicaciones sobre este tópico son escasas en la literatura nacional. Consideramos que esta información ayudará a fortalecer el modelo organizacional actual de la unidad. Éste es uno de los múltiples indicadores de calidad, por lo que se requiere seguimiento y la aplicación de otros en busca de una mejora continua.

\section{Terapia con oxígeno de alto flujo en pacientes con patologías respiratorias agudas}

Rojas SGA, Mora CJ, Morales RF,
Solís BEL, Rosas CJE, Tobarez ÁJ, Váldez CF, Rico JHU, Lepe VLF

Antiguo Hospital Civil de Guadalajara Fray Antonio Alcalde

Introducción: La terapia con oxígeno de alto flujo es un sistema que permite administrar al paciente un mayor flujo de oxígeno sin incrementar demasiado la presión positiva dentro de la vía aérea, esto reduce el espacio muerto debido a que elimina el $\mathrm{CO}_{2}$ y en consecuencia también reduce el trabajo respiratorio. De igual forma mantiene una $\mathrm{FiO}_{2}$ constante durante el flujo inspiratorio máximo y aumenta el volumen pulmonar al final de la espiración. El oxígeno administrado es húmedo y cálido, por lo que da mayor comodidad al paciente y disminuye la inflamación de la vía aérea, con lo que se reduce la cantidad de secreciones. Múltiples estudios se han realizado para comparar el sistema de alto flujo contra el sistema convencional de administración de oxígeno y se han demostrado sus ventajas sobre éste en pacientes con EPOC, falla respiratoria aguda de diversos orígenes, pacientes posextubados, etcétera. Objetivos: Determinar la eficacia de la administración de oxígeno mediante sistemas de alto flujo $v s$. sistemas de administración de oxígeno convencionales, en la mejora de parámetros respiratorios y disnea subjetiva en pacientes con patologías respiratorias agudas. Material y métodos: Se realizó un estudio analítico cuasiexperimental de ensayo antes-después. Para éste se eligió una muestra de 13 pacientes del Hospital Civil de Guadalajara FAA. Siendo $10 \mathrm{mu}-$ jeres y 3 hombres, el rango de edad fue de 9 a 93 años y los pacientes pertenecían a las áreas de urgencias, unidades de cuidados intensivos y hospitalización de adultos y pediátricos. Se incluyeron pacientes con distintos trastornos respiratorios agudos (exacerbación de EPOC, AHRF, neumonía, posextubación, etc.), que estuvieran recibiendo soporte con oxígeno a través de mascarilla o puntas nasales con un flujo máximo de $10 \mathrm{~L} / \mathrm{min}$ y cumpliendo con los siguientes criterios: $=$ Saturación de $\mathrm{O}_{2}<90 \%$. $=\mathrm{FC}>100$ lpm. $=\mathrm{FR}>30$ rpm. $=$ Disnea. $=$ Sin indicación franca de intubación endotraqueal. De manera 
inicial se registraron los siguientes parámetros de cada paciente: $\mathrm{SaO}_{2}, \mathrm{FC}$, FR, TA y disnea medida por la escala de Borg. Posterior al registro se cambió el suministro de oxígeno por un sistema de alto flujo (Airvo2, Optiflow Fisher \& Paykel) a $35 \mathrm{~L} / \mathrm{min}$, ajustando $\mathrm{la} \mathrm{FiO}_{2}$ para alcanzar un objetivo de $\mathrm{SaO}_{2}$ de $92-97 \%$, se programó una temperatura inicial de 37\&ordm; C ajustándose en algunos casos para mayor comodidad del paciente. Tras 2 horas de terapia con oxígeno de alto flujo se midieron nuevamente las variables antes mencionadas. Los datos obtenidos se analizaron por prueba de Shapiro-Wilk, posterior a esto se realizó una T de Student para aquellas variables con distribución normal. En las variables con Shapiro-Wilk significativo se empleó la prueba de Wilcoxon. Presentación del caso: La terapia con oxígeno de alto flujo es un sistema que permite administrar al paciente un mayor flujo de oxígeno sin incrementar demasiado la presión positiva dentro de la vía aérea, esto reduce el espacio muerto debido a que elimina el $\mathrm{CO}_{2}$ y en consecuencia también reduce el trabajo respiratorio. De igual forma mantiene una $\mathrm{FiO}_{2}$ constante durante el flujo inspiratorio máximo y aumenta el volumen pulmonar al final de la espiración. El oxígeno administrado es húmedo y cálido, por lo que da mayor comodidad al paciente y disminuye la inflamación de la vía aérea, con lo que se reduce la cantidad de secreciones. Resultados: Se encontró mejoría significativa en la $\mathrm{SaO}_{2}$ siendo la media basal de $89.3 \%$ (DE \pm 7.6$)$ y posterior a la aplicación del sistema de alto flujo fue de $96.7 \%$ (DE $\pm 2.4)$ (p 0.005), igualmente para la FR con una media basal de $30.3(\mathrm{DE} \pm 6.6)$ y posterior de $24.9(\mathrm{DE} \pm 4.7)(\mathrm{p} 0.001) \mathrm{y}$ finalmente para la disnea obteniendo una mediana basal en la escala de Borg de 7 y posterior de 4 (p 0.005). La FC y la TA no presentaron cambios estadísticamente significativos. Conclusión: Se encontró mejoría significativa en los parámetros respiratorios $\left(\mathrm{SaO}_{2}, \mathrm{FR}\right.$ y disnea) de los pacientes, tras 2 horas de manejo con oxígeno de alto flujo. Estudios posteriores son necesarios empleando muestras de mayor tamaño, aplicadas a patologías y grupos de edad específicos. Aporte a la práctica clínica diaria: El aporte de oxígeno de alto flujo disminuye el riesgo de intubación y re-intubación en pacientes con patologías respiratorias agudas, así como la disminución del trabajo respiratorio administrando un mayor flujo de volumen sin aumentar la presión positiva dentro de la vía aérea encontrando mejora significativa de la $\mathrm{SaO}_{2}$, entre otros.

\section{Enfermedad de Castleman mediastinal. Reporte de caso}

\section{Fuentes JJC, Márquez GC, Armentar RRM, Flores GCA, Arellano EO}

\section{IMSS; Unidad Médica de Alta Especialidad, Hospital General «Dr. Gaudencio González Garza», CMN «La Raza»; \\ Hospital de Cardiología, CMN Siglo XXI}

Introducción: La enfermedad de Castleman, entidad infrecuente, de incidencia desconocida enmarcada dentro de los trastornos linfoproliferativos con etiopatogenia aún no del todo dilucidada. Objetivos: Reporte de caso por sus características clínicas, radiológicas e histológicas de entidad poco descrita en nuestra país. Material y métodos: Se presenta un caso de enfermedad de Castleman de localización mediastinal anterior, en un paciente de 38 años de edad por lo infrecuente de la enfermedad. Presentación del caso: Masculino sin factores exposicionales de importancia, con tos en accesos, disnea leve progresiva, fiebre y con hallazgo de tumor de mediastino anterior de $7.6 \times 6$ cm con densidades desde 90 hasta 161 unidades Hounsfield en hemitórax derecho. Con resección quirúrgica de la lesión que macroscópicamente reportó un tumor multinodular, vascularizado, con cápsula bien definida, y microscópicamente con centros germinales con vasos de paredes hialinizadas con signo de la «paleta», y con linfocitos en capas concéntricas con apariencia en «capas de cebolla», con diagnóstico de enfermedad de Castleman tipo hialino vascular. Conclusión: La enfermedad de Castleman mediastinal es una entidad patológica bien descrita en la literatura científica, y aunque son pocos los casos reportados en nuestro país, es una entidad rara que debe ser considerada en el diagnóstico diferencial de tumores mediastinales. Aporte a la práctica clínica diaria: También llamada hiperplasia ganglionar angiofolicular benigna o hiperplasia gigantonodular linfoide benigna, clínicamente puede presentarse de forma localizada o multicéntrica. La forma localizada aparece más frecuente en tórax, con edad media de presentación a los 35 años, de curso asintomático siendo frecuente su diagnóstico como hallazgo casual. Se clasifica en 3 subtipos, de los cuales el vascular hialino es el más frecuente. Su tratamiento es la extirpación quirúrgica sin recurrencias en la mayoría de las series.

\section{Características clínicas de los pacientes pediátricos con exacerbación asmática hospitalizados en un tercer nivel de atención}

Aguilar AA, Velázquez-González MV Orozco AEG, Hernández ChE, RuizGutiérrez HH, Sandoval-Romero NN, Irissont DJA

IMSS

Introducción: El asma es la enfermedad crónica con mayor prevalencia en la edad pediátrica, es la principal causa de ausentismo escolar, de visitas al servicio de urgencias y principal causa de hospitalizaciones por enfermedad crónica en la infancia. Objetivos: Describir las características clínicas de los pacientes pediátricos con exacerbación asmática que requirieron ingreso hospitalario en un tercer nivel de atención. Material y métodos: Estudio descriptivo y retrospectivo pacientes de entre 2 y 16 años que hayan sido hospitalizados en esta unidad por presentar una exacerbación asmática. Resultados: Cincuenta y seis pacientes que requirieron ingreso hospitalario, 27 pacientes (53\%) del género masculino y 24 pacientes $(47 \%)$ femenino, con promedio de edad de 7.5 años. El grupo etario más afectado fueron los escolares con un $41.2 \%$, seguido de los preescolares con un $27.4 \%$. 
Encontramos que el $33.3 \%$ de los pacientes padecían de tabaquismo pasivo, siendo el padre el fumador en el $64.7 \%$. Otro factor que incrementa el riesgo de presentar una exacerbación asmática es el ser dueño de una mascota, en nuestro estudio se reporta que el $45.1 \%$ de los pacientes tenían mascotas. Las hospitalizaciones en los últimos 6 meses reportaron que el $11.8 \%$ (6 pacientes) había requerido ingreso hospitalario previamente, con una mediana de 1 hospitalización por paciente. Sin embargo, el $41.2 \%$ de los pacientes había requerido acudir al Servicio de Urgencias en los últimos 6 meses, 14 pacientes $(27.5 \%)$ presentaron alguna de las complicaciones estudiadas (atelectasia, neumotórax, neumomediastino y/o neumonía nosocomial). Conclusión: Las exacerbaciones asmáticas se registran sólo 10.2 casos por año, en nuestro hospital por ser unidad de tercer nivel de atención es importante remarcar que hasta un $10 \%$ de los pacientes pediátricos con una exacerbación asmática grave presentaron secuelas neurológicas. Aporte a la práctica clínica diaria: Conocimiento del manejo de los pacientes con crisis asmática severa.

\section{Tasa de falla a ventilación mecánica no invasiva en pacientes con neumonía adquirida en la comunidad que ingresan a urgencias: La experiencia de un tercer nivel}

Rodríguez LIS, Arroyo HLJ, Castro AEF, Hernández CCM, Sandoval GJL, Reveles ZL, García TR, Barrales LM, Guadarrama MC, García GML

INER Ismael Cosío Villegas

Introducción: El uso de ventilación mecánica no invasiva (VMNI) en pacientes con falla respiratoria aguda hipoxémica es controversial. Se ha demostrado que la falla a VMNI aumenta la mortalidad hasta en $30 \%$. En el Instituto Nacional de Enfermedades Respiratorias (INER), las neumonías adquiridas en la comunidad (NAC) son la segunda causa de ingreso a la Unidad de Urgencias Respiratorias
(UUR) ocupando el $10.6 \%$ de la carga endémica de la Unidad. Hoy por hoy, no se ha estudiado la conveniencia de instaurar VMNI en esta entidad, y por tanto no existe en el INER un protocolo clínico establecido que defina su uso en NAC. Objetivos: Determinar el porcentaje de falla a VMNI en pacientes que ingresan a la UUR del INER con diagnóstico de NAC. Material y métodos: Este estudio transversal retrospectivo analizó descriptivamente la base de datos de los pacientes que ingresaron a la UUR del INER de septiembre 2015 hasta agosto 2016. Por medio de rangos y porcentajes se estimaron las magnitudes y porcentajes de intubación, uso de VMNI y tasa de fallo a la misma. Resultados: De los 2,540 pacientes ingresados a la UUR en el período de estudio, 461 pacientes (18.4\%) requirieron apoyo de ventilación mecánica. De éstos, 224 (48.6\%) fueron candidatos a intubación orotraqueal (IOT) de manera directa, mientras que 237 (51.4\%) recibieron VMNI, fallando a esta última un total de 50 pacientes $(21.1 \%)$. Las NAC fueron la principal causa de IOT $(74 ; 33.3 \%)$ y de VMNI (58; 24.5\%). Específicamente en esta patología, 24 pacientes (41.4\%) fallaron a la VMNI requiriendo posterior IOT dentro de la UUR. Conclusión: El porcentaje de falla a VMNI en la UUR del INER es igual e incluso mayor a la presentada por la literatura. Aporte a la práctica clínica diaria: Ello hace imprescindible generar un protocolo de manejo clínico específico que dicte la conducta terapéutica en los pacientes con NAC grave.

Percepción de la calidad de vida evaluada por cuestionario CFQ-R y su relación con el $\mathrm{FEV}_{1}$ en pacientes pediátricos con diagnóstico de fibrosis quística en un hospital de tercer nivel

Leija EG, Ramírez DO, Furuya MMEY, Vargas $\mathrm{BMH}$

IMSS Hospital de Pediatría CMN Siglo XXI
Introducción: La morbimortalidad de la fibrosis quística (FQ) está relacionada con la afectación pulmonar. El estándar de oro para medir función pulmonar es $\mathrm{FEV}_{1}$. La progresión de la enfermedad y los tratamientos para su control condiciona la calidad de vida (CV). $\mathrm{FEV}_{1}$ y $\mathrm{CV}$ traducen el estado general del paciente. En México no existían reportes con cuestionarios validados de la relación de CV con la función pulmonar. Objetivos: Conocer la percepción de la CV evaluada por cuestionario de FQ revisado (CFQ-R) y su relación con $\mathrm{FEV}_{1}$. Material y métodos: Estudio transversal, descriptivo, analítico, realizado en el Hospital de Pediatría de CMN Siglo XXI. Se aplicó el cuestionario CFQ-R y se obtuvo el $\mathrm{FEV}_{1}$, se compararon los resultados de los dominios del cuestionario con la espirometría y se determinó mediante prueba de Pearson si existía correlación. Resultados: Se incluyeron 18 pacientes, se obtuvieron 29 cuestionarios de CV, 18 de pacientes y 11 a padres, se compararon los dominios con el $\mathrm{FEV}_{1}$ y se obtuvo correlación en los dominios: físico: $p=0.05$, corporal: $p=0.03$, carga del tratamiento: $p=0.02$, el resto de los dominios incluyendo el respiratorio no alcanzaron significancia estadística. Se analizaron de manera independiente los cuestionarios aplicados a los padres y se obtuvo correlación con el $\mathrm{FEV}_{1}$ en los dominios: físico: $\mathrm{p}=0.03$ y percepción de la salud: $\mathrm{p}=0.003$, el resto de los dominios no obtuvo correlación. Conclusión: Se

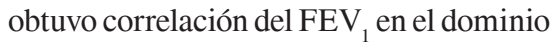
capacidad física, imagen corporal y carga del tratamiento, el dominio respiratorio no mostró asociación. En cuanto a la comparación de los cuestionarios entre padres y pacientes se obtuvo correlación en los dominios objetivos, no así en los subjetivos. Aporte a la práctica clínica diaria: Estamos obligados no sólo a dar tratamiento médico, sino trabajar las áreas relacionadas con la $\mathrm{CV}$ del paciente con $\mathrm{FQ}$, sin dejar que las limitaciones económicas, de infraestructura y farmacológicas de nuestro sistema de salud sean justificación para no hacerlo.

\section{Diferencias en el} desempeño en la prueba 


\section{de caminata de los 6 minutos entre pacientes con enfermedad cardiopulmonar con expresión interna o externa de la IRA}

Figueroa HFA, Peláez HV, Pérez CE, Torres MS, Robles UB, Orea TA, González ID, Pérez CGK, Sánchez SRN, Jiménez CAG, Verdeja VL, Navarrete $P A G$

INER Ismael Cosío Villegas

Introducción: La forma de expresión de la IRA es tanto factor de riesgo como protector, dependiendo de la siguiente clasificación: 1) Expresión interna (EII), la ira se suprime; y 2) Expresión externa (EEI), que es la manifestación de la ira hacia personas y objetos. La EII afecta negativamente el funcionamiento fisiológico y psicológico de pacientes con enfermedad cardiopulmonar (EC). No se ha reportado el efecto de la forma de expresión de esta emoción sobre la respuesta fisiológica durante una prueba de caminata de los seis minutos en estos pacientes. Objetivos: Comparar indicadores de la prueba de caminata de los seis minutos (C6M) entre pacientes con enfermedad cardiopulmonar con expresión interna o externa de la ira. Material y métodos: Participaron 23 pacientes con EC (edad media 69.08 $\pm 13.74,56 \%$ mujeres). Se clasificaron en 1) expresión interna (EII, $\mathrm{n}=11$ ) y 2) externa (EEI, $\mathrm{n}=12$ ) según el inventario STAXI-2. Se realizó la C6M registrando distancia recorrida y tiempo, además de presión arterial sistólica (PAS) y diastólica (PAD), pulso y frecuencia respiratoria (FR) en cada una de las siguientes fases: 1) Línea base, 2) Final y 3) Recuperación. Resultados: Los pacientes con EEI tienen mayor PAS y PAD que los clasificados EII. Línea base | Final | Recuperación. PAS (EII/EEI): $140.50 \pm$ $20.53 / 148.08 \pm 32.70(\mathrm{z}=.985, \mathrm{p}>0.05) \mid$ $145.10 \pm 23.29 / 148.41 \pm 31.89(\mathrm{z}=.400, \mathrm{p}$ $>0.05) \mid 135.20 \pm 23.72 / 135.33 \pm 30.89(\mathrm{z}$ $=.185, \mathrm{p}>0.05)$. PAD (EII/EEI): $70.40 \pm$ $12.66 / 86.25 \pm 13.36(\mathrm{z}=2.310, \mathrm{p}<0.05)$ | $72.40 \pm 11.90 / 85.83 \pm 10.10(\mathrm{z}=2.558$, $\mathrm{p}<0.05) \mid 73.60 \pm 8.69 / 89.58 \pm 19.73(\mathrm{z}$
$=2.095, \mathrm{p}<0.05)$. FR $($ EII/EEI $): 17.10 \pm$ $5.97 / 18.83 \pm 3.15(\mathrm{z}=.866, \mathrm{p}>0.05) \mid 22.20$ $\pm 7.55 / 21 \pm 3.83(\mathrm{z}=.617, \mathrm{p}>0.05) \mid 18 \pm$ $4.80 / 19.16 \pm 2.94(\mathrm{z}=.155, \mathrm{p}>0.05)$. Distancia (EII/EEI): $189.60 \pm 105.19 \mathrm{~m} / 276 \pm$ $149.23 \mathrm{~m}(\mathrm{z}=1.47, \mathrm{p}>0.05)$. Tiempo (EII/ EEI): $277.30 \pm 92.08 \mathrm{seg} / 306.33 \pm 99.58$ seg $(\mathrm{z}=1.292, \mathrm{p}>0.05)$. Conclusión: $\mathrm{La}$ forma de expresión de la ira marca una diferencia en los indicadores de la C6M $\mathrm{y}$, a pesar de no tener diferencias significativas, sí lo son clínicamente como se observa en distancia, que es indicador de pronóstico de salud. Aporte a la práctica clínica diaria: Identificar la regulación de las emociones del paciente puede ser un factor para pronosticar el desempeño físico de éste.

\section{Perfil clínico y demográfico} de pacientes en una clínica de anticoagulación de un servicio de medicina respiratoria

Contreras FJ, Morett-Vera F, Mendoza-Topete LA, GonzálezOrozco BN, Hernández-Gordillo D, Herrera-Jiménez LE

Centro Médico Nacional de Occidente, IMSS

Introducción: Los anticoagulantes antagonistas de la vitamina $\mathrm{K}$ aún son ampliamente utilizados en la práctica clínica, son altamente susceptibles a interacciones con otros medicamentos y es difícil mantener un índice de anticoagulación óptimo. Se han reportado mejores resultados con la implementación de clínicas de anticoagulación. Objetivos: Conocer las características clínicas y demográficas de los pacientes que requieren anticoagulación oral con acenocumarina y la proporción en niveles óptimos durante sus visitas médicas. Material y métodos: Se trata de una serie de casos en el Departamento de Neumología del CMNO-IMSS que requieren de anticoagulación oral; muestreo no probabilístico de casos consecutivos. A los pacientes incluidos se les realizó seguimiento estricto con INR, el ajuste de dosis semanal y el seguimiento fue de acuerdo a algoritmos estandarizados. El INR óptimo se definió de 2-3.2. Se utilizó estadística descriptiva, se compararon medianas con U de Mann Whitney y proporciones con c $\chi^{2}$. Resultados: Se incluyeron 57 pacientes, $69 \%$ mujeres, la mediana de edad 55 años. El $61.5 \%$ se anticoagularon por enfermedad tromboembólica venosa, $27.7 \%$ por hipertensión pulmonar. Apnea del sueño estuvo presente en $21 \%$, hipertensión arterial sistémica en $15 \%$, obesidad en $14 \%$. A la primera visita $23 \%$ tenían INR terapéutico y $64 \%$ sobreanticoagulados, a la sexta visita se alcanzó la mayor proporción de INR óptimo 59\% con 33\% sobreanticoagulados. En la visita 6, no hubo diferencias significativas al comparar dosis semanal, edad, género, peso o proporción de pacientes con SAOS en grupo con INR óptimo vs. INR no óptimo. Las complicaciones fueron del 7\%, sin compromiso vital. Conclusión: Implementar clínicas de anticoagulación, mejora la proporción de pacientes con INR óptimo, a partir de pacientes con niveles supraóptimos, evitando complicaciones graves asociadas a sangrado. No hubo diferencias estadísticas entre las variables analizadas, sin embargo, podría ser efecto de tamaño de muestra.

\section{¿Son las enfermedades intersticiales causantes de colapso del cuidador?}

\section{Alarcón DEA, López CAC, Buendía RI, Selman M, Martínez EKP}

INER Ismael Cosío Villegas

Introducción: Dentro de los principales retos de padecer una enfermedad crónica se encuentra el incremento de la discapacidad y dependencia, que requiere contar con un cuidador informal que se define como la persona que provee apoyo físico, emocional o financiero y se caracteriza por tener un vínculo afectivo y no recibir remuneración económica por sus cuidados. Estos cuidadores requieren modificar sus estilos de vida para adaptarse a las necesidades específicas que deben proveer, lo que en ocasiones favorece una dinámica negativa entre el cuidador y el paciente. Objetivos: Identificar si los cuidadores primarios de pacientes con enfermedades 
intersticiales sufren colapso del cuidador primario. Material y métodos: Se realizó en el INER el cuestionario de Zarit para evaluar la sobrecarga del cuidador a aquéllos que acompañan a pacientes con enfermedades intersticiales que acuden a citas de protocolo en la Unidad de Investigación en el período de octubre 2016-enero 2017. Resultados: Se analizaron 7 familiares de pacientes con FPI, 15 de neumonitis y 11 de enfermedad intersticial secundaria a enfermedad autoinmune. Los familiares en cada grupo fueron: 4 cónyuges y 3 hijos en FPI, 11 cónyuges, 2 hijos y 2 padres en neumonitis y en autoinmunes 3 cónyuges, 7 hijos y 1 padre. El promedio de tiempo de enfermedad en el grupo de FPI fue 33 \pm 12 meses, neumonitis $49 \pm 40$ meses y autoinmunes $18 \pm 17$ meses. El nivel de sobrecarga de cuidadores de FPI y neumonitis fue leve, autoinmune no presentó. Conclusión: En este estudio preliminar los cuidadores presentaron colapso del cuidador en nivel leve en las enfermedades que presentaron mayor tiempo de evolución; sin embargo, cuando se aplicaban los cuestionarios se sorprendían de las preguntas porque nadie les había sensibilizado este tema y consideramos que es un tema a seguir estudiando ya que puede influir en calidad de vida no sólo del paciente sino del cuidador. Aporte a la práctica clínica diaria: Cobra la misma importancia el identificar y tratar al cuidador primario ya que su papel es de suma importancia en el bienestar y cuidado del paciente.

\section{Fusariosis diseminada: Reto diagnóstico y terapéutico}

\section{Contreras RFJ, Guerrero-Rodríguez A, Mendoza-Topete LA, Hernández- Gordillo D, Gardea-De La O EE}

Centro Médico Nacional de Occidente, Instituto Mexicano del Seguro Social

Introducción: Fusarium causa amplio espectro de infecciones superficiales y localizadas así como invasivas y diseminadas. Hongo ubicuo cuya infección y manifestación depende del estado inmune, la mortalidad se reporta hasta del $75 \%$ en infecciones diseminadas. Objetivos:
Informar de un caso poco frecuente. Presentación del caso: Mujer de 44 años, previamente sana, vive cerca de canal de aguas negras, presentó queratitis ulcerativa periférica de ojo derecho, asociado a ANCA+, se inició tratamiento con metilprednisolona y ciclofosfamida, con pobre respuesta local, suspendiéndose cuando se aisló Fusarium sp de secreción escleral, recibió tratamiento con itraconazol/natamicina, sin mejoría en medio privado, dos meses después presenta tos y expectoración hialina se documentó lesiones pulmonares abscedadas, sinusitis maxilar, absceso hepático, nódulos y ulceraciones dérmicas, cultivos posteriores negativos de múltiples sitios. A pesar de voriconazol/anfotericina requirió enucleación ocular derecha presentando afección ocular izquierda por queratitis ulcerativa y aumento de zonas de consolidación pulmonar, persistiendo lesiones dérmicas, hepáticas y rinosinusales, en la histopatología ocular sin presencia de microorganismos, por lo cual se reconsideró la participación inmunológica. Sin documentar autoinmunidad ni déficit inmunitario. Ha presentado mejoría clínica y radiológica con posaconazol. Fusariosis diseminada es la tercera infección fúngica más frecuente en pacientes inmunocomprometidos. Se encuentra afección pulmonar hasta en el $50 \%$ como sitio primario o secundario manifestada como consolidación, nódulos y cavitaciones además de afección en piel, senos paranasales y ojos. Los hemocultivos son apenas positivos en $40 \%$. La diseminación fue atribuida a la infusión de esteroides y ciclofosfamida. Conclusión: La fusariosis diseminada tiene alta tasa de mortalidad, la afección multisistémica supone reto diagnóstico clínico a descartar principalmente afecciones inmunológicas, con pobre respuesta a anfotericina/voriconazol, documentados los antifúngicos de mayor utilidad en estos casos, la llamada «terapia salvamento» con posaconazol mostró ser efectiva en este caso. No se demostró inmunodeficiencia permanente, ni autoinmunidad asociada a queratitis ulcerativa. Aporte a la práctica clínica diaria: Caso poco frecuente con alta mortalidad.

\section{Evaluación del GenoType MTBDRsI para detección}

de resistencias a fármacos antituberculosis de segunda línea

Mohedano MMJ, Muñoz TM

INER Ismael Cosío Villegas

Introducción: La tuberculosis extremadamente resistente (TB-XDR, resistencia concomitante a isoniacida, rifampicina, una fluoroquinolona y un inyectable de segunda línea), plantea un riesgo considerable para el control mundial de la tuberculosis. Durante la última década han surgido pruebas moleculares que detectan mutaciones específicas de genes relacionados con la resistencia a diversos fármacos, ofreciendo resultados con mayor rapidez, siendo una de ellas GenoType ${ }^{\circledR}$ MTBDRsl (Hain Lifescience GmbH, Nehren, Germany). Objetivos: El objetivo de este trabajo es evaluar el desempeño de esta prueba para el diagnóstico de resistencia a fluoroquinolonas e inyectables de segunda línea (comparación de la eficacia de pruebas de genotipificación vs. fenotipificación). Material y métodos: Se evaluaron retrospectivamente cultivos de pacientes que contaban con pruebas de farmacosensibilidad (PFS) a primera y segunda línea y en los que además se realizó genotipificación por GenoType ${ }^{\circledR}$ MTBDRsl. El cultivo y PFS se realizaron utilizando el sistema BACTEC MGIT960 TbExist siguiendo los lineamientos establecidos por la OMS. Resultados: En el período 2015-2016 se encontraron 42 cultivos con desarrollo de M. tuberculosis con resistencia a isoniacida y/o rifampicina y con genotipificación. La concordancia entre las PFS y la genotipificación para fluoroquinolonas (gen gyrA) fue 0.932 (95\% CI 0.8-1.0), sin encontrar diferencia significativa entre ofloxacino y moxifloxacino. La concordancia para inyectables de segunda línea (gen rrs) resultó moderada [Kappa $0.4(95 \%$ CI 0.004-0.8)], siendo muy variable dependiendo del fármaco: $0.8(95 \% \mathrm{CI}$ $0.4-1.0), 0.54$ (95\% CI 0.09-0.98), y 0.4 (95\% CI -0.2-0.9)] para amikacina, kanamicina y capreomicina, respec- 
tivamente. Adicionalmente, la prueba evalúa la presencia de mutación en el gen embB, siendo buena la concordancia con la prueba fenotípica de resistencia a etambutol [Kappa $(95 \%$ CI $)=0.7(0.4-$ 0.9)]. Conclusión: La prueba GenoType MTBDRsl es un estudio confiable para el diagnóstico de TB-XDR. Aporte a la práctica clínica diaria: Diagnóstico y tratamiento oportuno de pacientes con tuberculosis farmacorresistente.

\section{Hernia de Morgagni. Reporte a propósito de un caso}

\section{Domínguez EMG, Suárez NJE, Morett $O E$, Ayala PCG}

HRAEB

Introducción: La hernia de Morgagni es un defecto diafragmático localizado en mediastino anterior, resultando en una herniación directa del contenido abdominal dentro de la cavidad torácica. La fisiopatología exacta de la hernia de Morgagni no está clara, el pequeño agujero de Morgagni se agranda con aumento prolongado o repentino de la presión intraabdominal que permite que los órganos abdominales se hernien a la cavidad torácica. Su incidencia es baja (2-3\%), la hernia de Morgagni es una patología poco común a cualquier edad, siendo diagnosticada frecuentemente como hallazgo radiográfico. Objetivos: Reporte de caso. Presentación del caso: Femenino de 2 años antecedentes inmunizaciones completas. Internamiento al año por neumonía, infecciones de vías respiratorias superiores 3-4 episodios por año asociados a hiperreactividad bronquial. Inicia 7 días previos a ingreso con tos seca-húmeda, no emetizante, cianosante, disneizante, rinorrea hialina y fiebre $39^{\circ} \mathrm{C}$ se agrega dificultad respiratoria, se interna con diagnóstico de neumonía adquirida en la comunidad. Hallazgo en radiografía de tórax asas intestinales intratorácicas por delante de silueta cardíaca, a exploración campos pulmonares con murmullo vesicular presente, ruidos peristálticos cara anterior de hemitórax izquierdo, ruidos cardíacos rítmicos, saturación al medio ambiente al 94\%. TAC de tórax imagen retroesternal sugestiva de víscera hueca, epiplón. Ecocardiograma desplazamiento del corazón a la derecha, anatomía segmentaria normal. Gammagrama pulmonar perfusorio normal. Se realiza plastía diafragmática por laparoscopia. Estado actual asintomática. Identificación paciente con hernia Morgagni oportuna, con resolución vía laparoscópica. Conclusión: El hallazgo incidental de hernia de Morgagni en la edad pediátrica se asocia en su mayoría a eventos de infecciones respiratorias bajas, la tomografía es el método más sensible para el diagnóstico, el tratamiento es quirúrgico en todos los casos debido al riesgo de obstrucción intestinal o estrangulación visceral. La laparoscopia disminuye la morbimortalidad. Se deben descartar malformaciones asociadas como cardiopatía congénita y cromosomopatías. Aporte a la práctica clínica diaria: Identificación oportuna para evitar complicaciones abdominales.

\section{Anillos vasculares. Experiencia en una unidad de tercer nivel del noreste del país}

González CY, Espinoza ESL, Ruiz $P M D$, Rivas MA, de La Fuente L

IMSS

Introducción: Los anillos vasculares completos son anomalías del arco aórtico y estructuras vasculares asociadas debidos a un fallo de la fusión e involución de los arcos aórticos embrionarios. Objetivos: Relación de patología respiratoria con la presencia de anillos vasculares. Material y métodos: Se revisó en forma retrospectiva los antecedentes de pacientes ingresados en el Servicio de Neumología Pediátrica de la UMAE 34 de la Ciudad de Monterrey NL con síntomas respiratorios crónicos, en el período enero 2007 a enero 2012 buscando la presencia de un anillo vascular que podría justificar la evolución no satisfactoria de síntomas. Presentación del caso: Caso 1. Masculino de 2 años con sospecha de neumopatía por reflujo, SEGD imagen compatible con anillo vascular, an-
gioTAC con presencia de arteria subclavia aberrante que comprime a esófago. Cursa con persistencia de tos encontrando por endoscopia alteración en la segmentación con bronquio traqueal prominente. Caso 2. Masculino de 2 años con patología respiratoria crónica, angioTAC con arteria subclavia derecha aberrante. Caso 3. Masculino de 1 año con estridor laríngeo en estudio, SEGD compresión extrínseca en tercio medio de esófago, angioTAC de tórax con trayecto de arteria subclavia izquierda posterior al esófago, exploración endoscópica con presencia de pulsaciones vasculares $1 \mathrm{~cm}$ arriba de carina, disminución de calibre endotraqueal a la derecha de la tráquea. Caso 4. Femenino 1 año en estudio por tos crónica, angioTAC con persistencia de arco aórtico posterior con involución de porción proximal del arco anterior formando anillo vascular. Caso 5. Femenino de 6 años con diagnóstico de Sx Down y CIV, cuadros respiratorios repetición, angioTAC con arteria subclavia derecha aberrante comprimiendo esófago y tráquea. La malformación más común encontrada fue la presencia de una arteria subclavia derecha aberrante. Conclusión: Descartar anillo vascular ante la presencia patología respiratoria crónica. Aporte a la práctica clínica diaria: Estudiar la posibilidad de un anillo vascular en caso de sintomatología respiratoria que no responde a manejo convencional.

\section{Niveles séricos de malondialdehído (MDA) en niños con asma bronquial}

\section{Castillo VMC, Cano SMC}

INER Ismael Cosío Villegas

Introducción: El asma es un problema de salud pública que afecta a personas en todas las edades, pero predomina en etapas tempranas de la vida. Aproximadamente la mitad de los casos se desarrolla antes de los 10 años. El asma produce inflamación crónica de la vía aérea condicionando aumento en hiperreactividad bronquial, estrés oxidativo e hipoxemia. Se desconoce la relación de marcadores de estrés oxidativo como lo es MDA y si correlaciona con 
el control de asma. Objetivos: Conocer el comportamiento de los niveles séricos de MDA como parámetro de estrés oxidativo en niños con diagnóstico de asma de acuerdo al estado nutricional y control del asma (ACQ). Material y métodos: Estudio descriptivo, transversal, observacional, realizado en pacientes de consulta externa. Se proporcionó información acerca del estudio, los riesgos y beneficios y se firmó consentimiento informado. Posteriormente la realización de espirometría, se aplicaron cuestionarios de control de asma ACQ-7, se tomó la muestra sérica para medición MDA por el método de Gérard-Monnier. Resultados: Se incluyeron 31 pacientes con diagnóstico de asma en niños y niñas, la distribución por género 22 masculino (70.96\%) y 9 femenino $(29.03 \%)$. La mediana de edad de los pacientes 9 años (ICC 8-11); las espirometrías realizadas a todos los pacientes con grado de calidad A de acuerdo con los criterios de aceptabilidad y repetibilidad ATS encontrando los siguientes patrones: normal $51.6 \%$, obstrucción leve $45.2 \%$, obstrucción moderada 3.2\%. Los niveles séricos de MDA fue 2.3 a $8.13 \mathrm{mM}$, con una mediana de 4.25 (ICC 3.54-4.95). De la misma manera no hubo diferencia de los niveles de malondialdehído entre los pacientes controlados y no controlados $(\mathrm{p}=$ 0.8025). Conclusión: Los niveles séricos de malondialdehído encontrados no muestran relación con el índice de masa corporal y con el control del asma. Sin embargo, debido a la limitante del tamaño de muestra, continuamos reclutando pacientes. Aporte a la práctica clínica diaria: Herramienta nueva para el seguimiento de asma.

\section{Reconstrucción de pared torácica secundaria a metástasis de carcinoma hepatocelular} Bolaños MFV, López AS, Saucedo
CJ, Domínguez OD, Herrera ZJJ

INCMNSZ; Facultad de Medicina de la Universidad Popular Autónoma del Estado de Puebla

Introducción: Los tumores metastásicos del carcinoma hepatocelular a la pared cos- tal son poco frecuentes. Se ha encontrado una asociación en el desarrollo de metástasis de hepatocarcinoma en la pared costal posterior a la ablación por radiofrecuencia o quimioembolización del primario en hígado. Objetivos: Presentar caso de metástasis inusual en pared costal. Material y métodos: Revisión bibliográfica y reporte de caso. Presentación del caso: Paciente masculino de 70 años de edad que acude a consulta por dolor torácico y presencia de una tumoración mal definida en pared costal izquierda. Mediante TAC de tórax se confirma la presencia de una lesión intratorácica, extrapulmonar de 7 x $6 \mathrm{~cm}$ con extensión a plano extramuscular. Posteriormente se realiza TAC trifásica de hígado con imagen con tumoración de 2.3 $\mathrm{cm}$ con escaso reforzamiento durante la fase arterial en segmento 7 del hígado, se lleva a cabo biopsia percutánea de tumor con reporte histopatológico de carcinoma hepatocelular poco diferenciado. Un día después se realiza resección por toracotomía con apoyo videoasistido de tumoración y reconstrucción de los arcos resecados con un sistema de barras y grapas costales de titanio. El paciente evoluciona de forma satisfactoria en el posoperatorio, se retira drenaje y egresa al séptimo día posquirúrgico con seguimiento en la consulta externa sin complicaciones a la fecha. Paciente sin complicaciones seis meses posquirúrgicos. Conclusión: En este caso la metástasis tuvo una localización extremadamente inusual del cáncer hepatocelular. Los tumores de pared costal representan menos del 5\% de neoplasias malignas torácicas. El abordaje quirúrgico, resección en bloque del tumor de pared costal y la reconstrucción mediante sistema de barras y grapas costales de titanio han demostrado tener resultados satisfactorios en pacientes con este tipo de tumores. Aporte a la práctica clínica diaria: Exponer nuestra experiencia en el manejo de una metástasis inusual de pared costal.

Características clínicas de pacientes pediátricos con fibrosis quística y su asociación con el tipo de mutación
González MCY, Espinoza ESL, Ruiz $P M D$, Rivas MA, Alvarado RJE

IMSS

Introducción: La fibrosis quística es una enfermedad autosómica recesiva mortal más frecuente en población caucásica con una frecuencia de 1/2,000 a 3,000 recién nacidos vivos. En México con una incidencia de 1/8,500 nacidos vivos. El gen defectuoso está localizado en el cromosoma 7, la mutación DELTA F508 es la más común, con aproximadamente $70 \%$ de alelos defectuosos en la población mundial. Objetivos: Determinar las características clínicas de pacientes pediátricos con fibrosis quística y su asociación con el tipo de mutación. Material y métodos: Estudio descriptivo, transversal, retrospectivo, analítico. Se incluyeron pacientes menores de 15 años con diagnóstico de fibrosis quística diagnosticados durante 2006-2013 mediante cuantificación de electrolitos en sudor. Se revisaron expedientes clínicos documentando características clínicas y tipo de mutación. Los resultados fueron analizados con paquete estadístico SPSS v20, empleando medidas de tendencia central, $\chi^{2}$ y tablas de contingencia. Resultados: Se incluyeron 71 pacientes con una media de edad de $8.7 \pm 3.8$ años, correspondiendo $38(53 \%)$ al sexo femenino y $33(46 \%)$ al sexo masculino. La mutación más frecuente fue DELTA F508 (36\%), seguida de G542 XX (9\%) y 1079 xx (1\%). En el $52 \%$ la mutación no estaba consignada en el expediente clínico. La manifestación clínica predominante en los pacientes con DELTA F508 mutado fue la afección pulmonar $(46 \%)$ y pancreática $(19 \%)$. Conclusión: Las mutaciones detectadas y consideradas como severas fueron la mutación DELTA F508 y la G542 XX, siendo la primera la más frecuente y la que se correlacionó con un acentuado compromiso respiratorio y pancreático. Sin embargo, en un porcentaje elevado no fue posible documentar la mutación. Por lo que es importante confirmar la enfermedad con estudio genético, para establecer manejo multidisciplinario, evaluar pronóstico y en el futuro proponer nuevos tratamientos dirigidos a la clase de mutación identifica- 
da. Aporte a la práctica clínica diaria: Correlacionar características clínicas con mutación encontrada en fibrosis quística para evaluar pronóstico y tratamiento.

\section{Utilidad de broncoscopia flexible en fístula traqueoesofágica reparada}

\section{Castillo VMC, Martínez VLF, Lechuga TI, del Razo R}

INER Ismael Cosío Villegas

Introducción: La incidencia de las fístulas traqueoesofágicas (FTE) es de 1:3,000 a 1:5,000 nacidos vivos. Cincuenta por ciento de niños con antecedente de FTE reparadas presentan síntomas respiratorios recurrentes o persistentes debido a una hiperreactividad bronquial, traqueomalacia o aspiración debido a dismotilidad esofágica, estenosis esofágica, ERGE o recidiva de FTE reparada. Serie esofagogastroduodenal (SEGD) no permite en ocasiones identificar FTE recurrentes por lo que inyección de azul de metileno por endoscopia y broncoscopia son métodos auxiliares de importante diagnóstico. Objetivos: Describir los hallazgos broncoscópicos de dos casos de pacientes con antecedente de FTE reparadas, con neumonía complicada. Presentación de los casos: Dos pacientes de sexo femenino, uno de 14 otro de 7 años, con antecedente de FTE tipo III, ambos con historia de neumonía recurrente, llegan a nuestro Instituto con diagnóstico de neumonías complicadas. En uno de los casos con derrame pleural derecho, SEGD con tercio inferior del esófago con disminución de la luz. Broncoscopia con divertículo traqueal amplio, a 5 cartílagos traqueales antes de la carina. Durante la cirugía se realiza bilobectomía (medio e inferior) con bronquiectasias con resección del divertículo; reporte por patología de divertículo traqueal con metaplasia escamosa. El segundo caso, con derrame pleural izquierdo, tomografía computada de tórax con divertículo esofágico hacia hemitórax derecho, SEGD con imagen diverticular en la pared posterolateral derecha del esófago, en tercio medio, con trayectos fistulosos hacia parénquima pulmonar. Panendoscopia: divertículo esofágico con doble trayecto. Broncoscopia con fístula traqueoesofágica en unión de tercio medio y distal Conclusión: Importancia de broncoscopia flexible como método auxiliar para diagnóstico en casos presentados. Aporte a la práctica clínica diaria: $\mathrm{Re}$ saltar la importancia de la broncoscopia flexible en niños poscorrección de FTE, como parte del seguimiento para evitar neumopatías crónicas y complicaciones.

\section{Cierre asistido con presión negativa en el tratamiento de mediastinitis aguda. Reporte de un caso}

\section{Gallardo GJF, Menjivar ROM, Lara GVR, Díaz MJL}

\section{ISSEMYM}

Presentación del caso: Paciente masculino de 59 años de edad con los diagnósticos de estenosis aórtica, sometido a recambio valvular mediante esternotomía, quien desarrolló mediastinitis aguda posoperatoria. La mediastinitis es la inflamación o la infección del tejido conectivo que rodea a las estructuras mediastínicas. La mediastinitis posoperatoria ocurre principalmente tras esternotomía para cirugía cardíaca con una incidencia del 0.4-5\%. El tratamiento quirúrgico temprano es imprescindible, encaminado al desbridamiento amplio y eliminación de tejidos necróticos con adecuada evacuación de los fluidos infectados. El sistema de cicatrización asistido por vacío (Vaccum-Assisted Closure, VAC) se ha referido en la literatura médica en el empleo de la aspiración enérgica del espacio retroesternal y mediastinal, sin soluciones de irrigación. Este sistema disminuye la colonización bacteriana, favorece el cierre de la herida con aumento de la proliferación celular y la síntesis proteica, provee un ambiente húmedo propicio para la cicatrización y protege de contaminación externa. Está indicada en heridas agudas o subagudas, incluyendo quemaduras, heridas dehiscentes o infectadas. Se ha descrito su uso en el tratamiento de in- fecciones de tejidos blando incluyendo la mediastinitis, siendo una opción segura y ampliamente utilizada, cuya recomendación se extiende de manera gradual con resultados satisfactorios, seguros y eficaces. La terapia VAC (Vaccum-Assisted Closure) es una alternativa terapéutica para el tratamiento de la mediastinitis. Su uso en esta patología proporciona beneficio tal como un adecuado drenaje de los fluidos infectados, contribuyendo en una adecuada cicatrización y cierre de la herida, así como una recuperación más rápida. El objetivo de este trabajo es reportar el caso con metodología descriptiva de un paciente con presencia de mediastinitis anterior, la cual fue resuelta mediante terapia VAC, siendo ésta una opción terapéutica segura y eficaz.

\section{Influenza a H1N1: Reporte de caso y evolución tomográfica}

\section{Rodríguez AM}

Hospital Infantil de México «Federico Gómez»

Introducción: En la actualidad se conoce más sobre la patogenia de múltiples infecciones virales; sin embargo, aun relacionado a la clínica de los pacientes afectados con los mismos. En el 2010, el estudio de Möene Karla et al. se describen los hallazgos radiológicos encontrados en pacientes pediátricos que requirieron hospitalización, reportándose principalmente patrón intersticial, patrón mixto intersticial-alveolar, y patrón con relleno alveolar. El propósito de este caso es dar a conocer los hallazgos tomográficos que se encontraron en el momento inmediato a una neumonía grave por influenza $\mathrm{A}$ H1N1, así como la evolución a 3 años posterior al uso de esteroide inhalado. Objetivos: Presentar paciente con neumonía grave, requiriendo cuidados intensivos, como consecuencia de infección por virus de la influenza A H1N1, así como su evolución tomográfica. Presentación del caso: Femenino de 8 años 6 meses, sibilante temprano y con múltiples neumonías de repetición. Ingresa a nuestra institución por neumonía grave requiriendo intubación orotraqueal y alta frecuencia con 
aplicación de óxido nítrico. Fue aislado en panel viral, influenza A H1N1 y tras mejoría se egresa a domicilio con oxígeno suplementario. Dos meses después se reporta daño pulmonar secundario a neumonía, se inicia esteroide inhalado con reporte de tomografía consolidación en segmento anterior del lóbulo superior izquierdo, consolidación en segmento lateral de lóbulo medio y bronquiectasias cilíndricas, así como vidrio despulido en parches. Tras tres años se observa en tomografía únicamente vidrio despulido distribuido aleatoriamente. Se reporta evolución tomográfica con vidrio despulido en parches, sin evidencia de panal de abejas o enfisema. Paciente sin uso de oxígeno suplementario y con dosis mínimas de esteroide inhalado. Conclusión: Se observa evolución clínica y tomográfica favorable en paciente con influenza A H1N1 misma que es causa de daño pulmonar importante en pacientes con antecedente de neumonía grave. Aporte a la práctica clínica diaria: Conocer la gravedad del daño pulmonar y evolución tomográfica secundaria a Influenza A H1N1.

\section{Evaluación de la función pulmonar en pacientes pediátricos que viven con VIH}

De Borbón ABK, Hernández RR, Espinoza OMM, Barrera de LJC, Díaz PR, Aguilar AA, Ruíz GHH

\section{IMSS}

Introducción: Estudios en niños demuestran alteraciones en la función pulmonar de pacientes que viven con VIH con prevalencia entre el 21 a 45\%, múltiples factores como posibles causas desde el estado proinflamatorio de la propia infección, tabaquismo, colonización de vía aérea por gérmenes oportunistas, daño estructural por agentes oxidantes, entre otros. Objetivos: Evaluar la función pulmonar en pacientes pediátricos que viven con VIH. Material y métodos: Estudio transversal, incluimos pacientes de 6 a 16 años de edad de la UMAE Hospital de Pediatría, CMNO, IMSS de julio 2015 a enero 2016.
Se realizó cuestionario, somatometría, espirometría pre-posbroncodilatadora, pletismografía, DLCO, C6M y saturación de oxígeno, carga viral y cuenta de CD4+, previa aprobación por el comité local de investigación y firma del consentimiento informado por el tutor. El análisis estadístico con frecuencias y porcentajes para variables cualitativas, medianas y rangos para cuantitativas. Comparamos proporciones con prueba $\chi^{2}$ o medianas con $U$ de Mann Whitney y Kruskal Wallis. Resultados: Total de 15 pacientes con mediana de 12 años de edad, género masculino $67 \%$. Transmisión del VIH vertical en $100 \%$ de la población. Se encontraron alteraciones en las pruebas de función pulmonar en el $53 \%$, principalmente en pletismografía y DLco, relacionado a tenofovir, emtricitabina, tabaquismo, antecedente de neumonía y tuberculosis. Se identificó talla baja en el $27 \%$ de los casos. Conclusión: Es importante considerar dentro del seguimiento del paciente pediátrico con VIH la posibilidad de alteraciones en la función pulmonar, con una prevalencia del $53 \%$ en nuestra población, con antecedente de enfermedad respiratoria al diagnóstico, exposición a tabaquismo, uso de tenofovir y emtricitabina. Aporte a la práctica clínica diaria: Éste es el primer estudio sobre función pulmonar en México en pacientes pediátricos que viven con VIH. Considera el incluir en el protocolo de seguimiento de estos pacientes la revisión neumológica anual y la realización de pruebas de función pulmonar, evitando complicaciones futuras.

\section{Timoma e} (síndrome de Good): Una serie de casos

\section{Bolaños MFV, Herrera ZJJ, Carrera CR, Domínguez OD, Argote GLM, Santillán DPJ}

\section{INCMNSZ}

Introducción: El síndrome de Good es una afección rara caracterizada por la presencia de timoma, hipogammaglobulinemia e inmunodeficiencia humoral. Existe muy poca información de esta enfermedad y del pro- nóstico de los pacientes, así como cuál es el tratamiento óptimo. Objetivos: Describir el resultado de cuatro pacientes diagnosticados con síndrome de Good sometidos a timectomía toracoscópica. Material y métodos: Se hizo seguimiento prospectivo a los pacientes con diagnóstico de síndrome de Good sometidos a timectomía toracoscópica como tratamiento de primera línea. Se detectaron complicaciones posoperatorias y se siguió el resultado de cada caso. Presentación del caso: Cuatro pacientes con diarrea crónica, masa mediastínica e hipogammaglobulinemia fueron sometidos a timectomía. El primer paciente remitió los síntomas después de la cirugía y presentó neumonía en el posoperatorio que fue tratada con antibióticos. El segundo paciente comenzó un tratamiento antituberculoso debido a un bacilo positivo de ZiehlNeelsen en el cultivo de esputo y aspiración duodenal. El tercer paciente se recuperó de la cirugía con remisión de los síntomas. El cuarto paciente se asoció a gastrectomía total con anastomosis esófago-yeyunal para adenocarcinoma gástrico y requirió terapia complementaria. En nuestra experiencia se recomienda inmunoglobulina suplementaria y antibióticos como tratamiento de seguimiento en pacientes con persistencia de hipogammaglobulinemia después de la timectomía. Conclusión: Se debe sospechar el síndrome de Good en pacientes con presencia de timoma e inmunodeficiencia humoral asociados con infecciones oportunistas. En realidad, no se ha establecido un protocolo definitivo de tratamiento, la cirugía sigue siendo el tratamiento básico para el timoma. Aporte a la práctica clínica diaria: Compartir nuestra experiencia en el manejo del síndrome de Good.

\section{Evaluación de capacitación en enfermedades respiratorias en el personal de salud del primer nivel de atención, en México, 2016}

Camargo ÁR, Salas HJ, Castellanos
JM, Fernández VM, Flores BP, Reyes
HA, Hernández ZR

INER Ismael Cosío Villegas 
Introducción: La educación al personal de salud (PS) es el pilar fundamental de cualquier estrategia de prevención y control de enfermedades, con actividades que se incluyen como parte del Programa de Acción Específico para la Prevención y Control de las Enfermedades Respiratorias e Influenza (PAE-ERI). Objetivos: Mejorar las competencias del PS de Primer Nivel de Atención (PNA) en la prevención y control de las Enfermedades Respiratorias (ER). Material y métodos: En 2016, el PAE-ERI y el Instituto Nacional de Enfermedades Respiratorias (INER) diseñaron los contenidos de capacitación y evaluación del curso en prevención y control de las ER (asma, EPOC, neumonía e influenza), dirigido al PS del PNA de los 32 estados, incluyendo médicos y enfermeras. La evaluación consta de 32 ítems, dividida en grupos temáticos (prevención, diagnóstico, tratamiento y control). En cada evento de capacitación se realizó pre y posevaluación, se incluyó para su análisis al PS que presentó ambas pruebas y se excluyeron las evaluaciones incompletas. Resultados: Se realizaron 367 evaluaciones completas del PS, de las cuales el $77 \%$ corresponden a médicos y el 23\% a enfermeras, el promedio de respuestas correctas en la evaluación inicial fue de $62.2 \%$ y de la final con $73.7 \%$, teniendo una diferencia sustancial entre ambas pruebas. En las preguntas enfocadas a EPOC se obtuvo el mayor incremento de aciertos con $25.4 \%$ y el menor se registró para neumonía con $12.9 \%$. En 37 (94.8\%) de las 39 preguntas se registró un incremento de respuestas correctas. Conclusión: Para la mejora continua del quehacer institucional y para mejorar las competencias del PS se requiere implementar un programa de educación continua en salud respiratoria para el abordaje correcto de las ER en el PNA. Aporte a la práctica clínica diaria: El presente trabajo tiene como objetivo mejorar las competencias clínicas del personal de salud del primer nivel de atención.

\section{Quiste broncogénico esofágico: Reporte de caso} Herrera ZJJ, Pérez SR, Ponce de
León BG, Mata MYG, Bolaños MFV,

$\begin{array}{cl}\text { Santillán DPJ } & \begin{array}{l}\text { Manifestación pulmonar } \\ \text { de histiocitosis de células } \\ \text { de Langerhans }\end{array}\end{array}$

Introducción: El quiste broncogénico es una malformación broncopulmonar del intestino anterior. Sus localizaciones más comunes son el mediastino posterior, la región paratraqueal, la región hiliar o pericárdica, siendo el esófago una ubicación muy rara. Objetivos: Compartir nuestra experiencia en manejo de quiste broncogénico. Material y métodos: Revisión bibliográfica y reporte de caso. Presentación del caso: Paciente femenino de 68 años de edad que se presentó a nuestra consulta con quejas de dos meses de distensión abdominal, plenitud posprandial, dolor epigástrico tipo cólico 7/10 ardoroso irradiado hacia mesogastrio acompañado de eructos y pirosis. Negó disfagia, pérdida de peso o sangrado de tubo digestivo, en el examen físico y los laboratorios no hubo hallazgos de relevancia. Se realizó una TAC toracoabdominal que reveló una lesión de baja densidad en el esófago distal, por lo que se llevó a cabo una endoscopia superior, en la que se encontró una masa de $3 \mathrm{~cm}$ de diámetro cubierta por mucosa normal. Se decidió someter a cirugía toracoscópica videoasistida derecha. La masa se encontró por debajo del ligamento pulmonar derecho, y se realizó miotomía. El tumor se disecó circunferencialmente, se abrió y se encontró un área quística con zona epitelializada y formación de material mucoso sin comunicación con el lumen esofágico y se eliminó con seguridad el quiste broncogénico paraesofágico. El paciente fue dado de alta sin complicaciones. Los siguientes días el informe histopatológico dio como diagnóstico un quiste broncogénico. Este caso resalta el manejo de una entidad rara con enucleación de quistes broncogénicos esofágicos no comunicantes y cierre de las capas musculares esofágicas. Conclusión: El quiste broncogénico es una enfermedad rara diagnosticada incidentalmente. $\mathrm{La}$ indicación de tratamiento quirúrgico es controvertida en casos asintomáticos, pero el riesgo de infección, complicaciones por compresión y riesgo potencial de malignidad lo apoyan. En pacientes sintomáticos parece ser el tratamiento de elección. Aporte a la práctica clínica diaria: Manejo de quiste broncogénico en esófago.
Avilés RBA, Martínez VLF, Rodríguez
SNI

INER Ismael Cosío Villegas

Introducción: La histiocitosis de células de Langerhans es una enfermedad poco frecuente, caracterizada por el acúmulo y proliferación de histiocitos y eosinófilos, afectando órganos y sistemas de forma aislada o múltiple. A nivel pulmonar las células de Langerhans monoclonales CD1a-positivo infiltran los bronquiolos y el intersticio alveolar. Se desconoce la etiología, se presenta entre los 20 y 40 años y en fumadores. En niños es poco frecuente. Menos del 10\% tiene afección pulmonar. Objetivos: Describir el caso y abordaje de dos pacientes con manifestación pulmonar de histiocitosis de células de Langerhans. Presentación de los casos: Caso 1: Femenino de 1 año. Antecedente de hospitalización a los 8 meses por neumonía adquirida en la comunidad (NAC) con neumotórax a tensión espontáneo, requiriendo ventilación mecánica y colocación de sonda endopleural (SEP). A los 12 meses NAC requiriendo hospitalización. Se realiza TAC presentando imágenes quísticas bilaterales. Durante su estancia presenta 3 neumotórax espontáneos bilaterales con colocación de SEP. Se realiza biopsia pulmonar de lóbulo medio y pleurodesis química bilateral. Caso 2: Femenino de 2 años. Antecedente de 2 hospitalizaciones: neumotórax izquierdo requiriendo fase III de ventilación y neumotórax derecho. Sintomatología: tos crónica y limitación al ejercicio. Radiografía y TAC de tórax con lesiones quísticas bilaterales, predominio lóbulo inferior derecho, presencia de quistes subpleurales. Se realiza lobectomía inferior derecha y colocación de SEP. En ambos pacientes se descarta inmunodeficiencia, se obtiene alfa 1 antitripsina negativo y con radiografías de cráneo y fémur sin alteraciones. Histopatología 
de ambas: Histiocitosis de células de Langerhans con S100 positivo. Referidas a Oncohematología. Conclusión: A pesar de que la histiocitosis de células de Langerhans es una enfermedad rara en niños, es importante conocer sus manifestaciones clínicas, para poder brindar un abordaje adecuado y un tratamiento oportuno obtener mejor calidad de vida y mayor sobrevida. Aporte a la práctica clínica diaria: Diagnóstico oportuno y tratamiento adecuado.

\section{Implementación de una estrategia de prevención y control de las enfermedades respiratorias en México}

Camargo ÁR, García AMA, Castellanos JM, Reyes HA

Secretaría de Salud

Introducción: Las enfermedades que afectan el aparato respiratorio son diversas y se dividen en agudas y crónicas, ambas representan un serio problema de salud pública en México. Para dar respuesta mediante una política pública a los daños a la salud ocasionados por estas enfermedades respiratorias (ER), fue necesario priorizar los padecimientos con mayor impacto en la salud en la población: Enfermedad pulmonar obstructiva crónica (EPOC), asma, neumonía e influenza. Objetivos: Implementar en México una estrategia de prevención y control de las ER que impacte en la disminución de gastos de bolsillo, gastos en salud pública, uso de antibióticos y otros medicamentos innecesarios, así como el número de hospitalizaciones. Material y métodos: Se realizó un diagnóstico de salud y se priorizó el abordaje de las ER. Se identificaron necesidades de insumos médicos, capacitación, financiamiento y recursos humanos. Se diseñó una estrategia nacional proporcionando lineamientos para dar la atención a las ER desde el Primer Nivel de Atención (PNA), basado en prevención (manejo de determinantes sociales, vacunación, promoción, cribado de asma y EPOC) y control (diagnóstico oportuno, tratamiento, control periódico, manejo de comorbilidades y rehabilitación de secuelas), en cuatro fases: difusión, instrumentación, operación y supervisiónevaluación, todo ello con financiamiento del Seguro Popular. Resultados: Se implementó el Programa de Acción Específico para la Prevención y Control de las Enfermedades Respiratorias (PAE-ERI). Se realizó difusión sobre la estrategia en las dependencias públicas de Salud. Se Inició la fase de instrumentación en 2016. Se capacitó al personal de salud del PNA en la prevención y control de ER. En 2017 inició la fase de operación. Conclusión: Es necesario evaluar los alcances de las actividades de la operación del PAE-ERI, para tomar decisiones sobre el futuro de la estrategia en México. Aporte a la práctica clínica diaria: Ayudará a mejorar la atención de las enfermedades respiratorias.

\section{Segmentectomía apicoposterior derecha por abordaje toracoscópico uniportal}

Menjivar ROM, Díaz MJL, HernándezArenas LÁ, Loyola GU

Centro Médico ISSEMYM Toluca

Introducción: La necesidad de preservar el tejido pulmonar en pacientes cuya capacidad respiratoria imposibilita las resecciones extensas, como lobectomía y neumonectomía, obliga a recurrir a procedimientos tolerables. La segmentectomía en el cáncer de pulmón temprano ha sido el procedimiento de elección en los últimos 5 años para el estadío T1-N0-M0. Objetivos: Presentar un caso donde se demuestra la factibilidad y seguridad de la realización de segmentectomía apicoposterior derecha con abordaje toracoscópico uniportal para lesión preinvasora pulmonar. Presentación del caso: Se presenta el caso de un femenino de 55 años de edad, sin antecedentes de importancia. Tos recurrente 5 semanas previas, sin otras condiciones preexistentes. Sin hallazgos patológicos a la exploración física, laboratorios y broncoscopia flexible. Restricción en capacidad pulmonar. En tomografía de tórax contrastada, lesión en lóbulo superior derecho de $2 \mathrm{x}$ $2 \mathrm{~cm}$ y fibrosis en parénquima pulmonar. Con paciente bajo anestesia general e intubación selectiva, en decúbito lateral izquierdo con una inclinación de $80-90^{\circ}$, se realiza incisión transversa en línea media axilar de $3 \mathrm{~cm}$ en sexto espacio intercostal. Óptica de $10 \mathrm{~mm}$ con $30^{\circ}$ fue introducida y se completó la segmentectomía apicoposterior derecha haciendo disección con endoengrapadora. Se introdujo sonda endopleural de $28 \mathrm{fr}$. El tiempo de cirugía fue de 60 minutos, el sangrado de $50 \mathrm{~mL}$ y el drenaje fue retirado al tercer día posquirúrgico y egresado al cuarto. Resultado histopatológico muestra lesión preinvasora pulmonar. Conclusión: El abordaje toracoscópico uniportal ha mostrado ser seguro y eficaz para este procedimiento en las series de casos publicados. En este trabajo se demuestra la realización de una segmentectomía apicoposterior derecha y sin complicaciones asociadas. Aporte a la práctica clínica diaria: El tratamiento de las lesiones preinvasoras pulmonares con acceso uniportal es una técnica útil, viable y reproducible, la cual logra reducir considerablemente la estancia hospitalaria.

\section{Neumonía intersticial por virus sincitial respiratorio en lactante menor: Presentación de un caso}

Maldonado DA

IMSS

Introducción: El virus sincitial respiratorio (VSR) es el agente causal más común de infecciones respiratorias bajas en niños pequeños. Se estima que en México 66,000 a 199,000 niños menores de 5 años murieron por esta causa, $25-40 \%$ de los casos presenta síntomas de bronquiolitis en los primeros 5 días de exposición al virus. Objetivos: Presentar un caso de lactante menor con VSR. Presentación del caso: Masculino de 5 meses producto de segunda gesta, parto eutócico, de término, peso y talla normales, alimentado con seno materno, esquema de vacunación incompleto. Presenta tos productiva tratada con broncodilatador, mucolítico 
y antibiótico, 4 días después presenta fiebre y dificultad respiratoria, se atiende en urgencias con esteroide intravenoso, sulfato de magnesio, mucolítico y oxígeno; exploración: sibilancias, estertores crepitantes, distermias e incremento de dificultad respiratoria, acidosis respiratoria descompensada y normoxemia, amerita intubación endotraqueal con parámetros altos de ventilación, con datos de choque séptico, requirió soporte cardiovascular y antibiótico. Durante su evolución presentó complicaciones: neumotórax a tensión bilateral resuelto con sondas endopleurales. Rx inicial mostró infiltrado intersticial, consolidación parahiliar izquierda y apical derecha, panel viral positivo para virus sincitial respiratorio. Después de 24 días se extuba. Egresa a piso 3 días después. Conclusión: El caso descrito corresponde al grupo de edad más común que afecta el virus sincitial respiratorio; se presentó inicialmente de la forma característica y presentó la evolución de las infecciones graves, ameritó ventilación mecánica, desarrolló sobreinfección bacteriana con datos de choque séptico que ameritó manejo con cefotaxima y dicloxacilina además de adrenalina en infusión, presentó complicaciones como neumotórax a tensión dado el requerimiento de parámetros altos de ventilación. No existe vacuna para el VSR, la única forma de prevenirlo es el lavado de manos adecuado y evitar contacto con saliva y secreciones de las personas infectadas. Aporte a la práctica clínica diaria: Conocer la presentación de infección grave por virus sincitial respiratorio en niños.

\section{Nivel de adherencia e incumplimiento al tratamiento inhalado en pacientes con enfermedad respiratoria crónica}

Sánchez HJD, Mora SJR, Patiño LC

IMSS

Introducción: La falta de adherencia a los medicamentos es un problema de importancia internacional. En pacientes con enfermedad respiratoria crónica se estima que sólo el $50 \%$ tiene adecuado apego al tratamiento, con ello incrementa el número de exacerbaciones anuales, incrementando costos directos e indirectos. Objetivos: Identificar la prevalencia del nivel de adherencia al tratamiento inhalado en pacientes ambulatorios con enfermedad pulmonar crónica en el Hospital General de Zona No. 4, en Celaya, Guanajuato. Material y métodos: Estudio transversal. Se incluyeron 104 pacientes adultos que utilizaron cualquier tipo de tratamiento inhalado y que acudieron a la consulta externa de neumología de un hospital de segundo nivel. Los casos se incluyeron de forma consecutiva. Se realizó a todos los pacientes el test de adherencia a inhaladores (TAI) que permite identificar el cumplimiento y adherencia terapéutica. Se utilizó estadística no paramétrica para identificar frecuencias y porcentajes. Resultados: La mediana de edad fue de 67 (min-máx, 25-80) años de edad. El tiempo de diagnóstico fue de 6 años. El 76\% de los pacientes utiliza al menos 2 inhaladores y el $15 \%$ tres. Predominó el sexo femenino con un $52 \%$ y el $43 \%$ de los pacientes sólo contaba con primaria terminada. Se observó una mala adherencia terapéutica debido a mala técnica del uso de los dispositivos en un $33 \%$, errores críticos como no recordar dosis habitual en $12.5 \%$. Al comparar los grupos de asma y EPOC tienen una adhesión terapéutica similar (44\% vs. $47 \%$, $\mathrm{p}=0.12)$. Conclusión: Se debe capacitar al paciente sobre el uso adecuado de los inhaladores para obtener una adecuada adherencia terapéutica para mejor control de la enfermedad. Se requiere de más estudios para evaluar la adherencia terapéutica y su relación con el número de exacerbaciones y sobrevida. Aporte a la práctica clínica diaria: Informa con datos importantes sobre la instrucción adecuada que debemos otorgar a los pacientes sobre el uso de inhaladores, con ello lograremos mayor adherencia terapéutica y con ello disminuir riesgo de exacerbaciones.

Plasmocitoma traqueal. Presentación de un caso y revisión de la literatura
Narváez FS, Domínguez EMG, Ayala PCG, Hernández PY

HRAEB

Introducción: El plasmocitoma solitario es un tumor de células plasmáticas que se ha identificado en órganos y tejidos como hueso, riñón, ovario, tracto digestivo, pulmón y vía aérea superior, siendo los senos paranasales y la cavidad oral los sitios más frecuentes de presentación. Objetivos: La localización dentro de vía aérea central es rara y el propósito de este trabajo es la presentación de un caso y revisión bibliográfica del tema. Presentación del caso: Se trata de femenino de 21 años sin antecedentes. Enero 2016, cuadro de neumonía e intubación por 10 días, antes de realizar traqueostomía por fracaso en el destete. Enviada a este servicio con sospecha de estenosis traqueal para valoración y manejo. Broncoscopia abril 2016, confirmó la presencia de un tumor sólido localizado en la región subglótica, justo por debajo de las cuerdas vocales. Mayo 2016, se programó para broncoscopia rígida. Por medio de este procedimiento se pudo resecar el $80 \%$ del tejido tumoral con pinzas de biopsia y se cauterizó con láser la base del tumor, dejando la cánula. Reporte histopatológico: Proliferación monoclonal de células plasmáticas con restricción de cadenas kappa (plasmocitoma). Referida al Servicio de Hematología donde inicialmente se indicó radioterapia dirigida al sitio de la lesión, en 25 sesiones. Posteriormente y con la realización de estudios complementarios se corroboró el diagnóstico de mieloma quiescente (Smoldering Multiple Myeloma). Enero 2017, broncoscopia en la que se evidenció una tráquea permeable al $100 \%$ y sin recurrencia tumoral. No se pudo decanular debido a datos de infección. Conclusión: Si bien la presentación traqueal del plasmocitoma es rara, en la literatura se han encontrado reportes de por lo menos 10 casos en tres publicaciones. Una vez corroborado el diagnóstico histológico, es obligación el realizar los estudios complementarios para determinar si el hallazgo corresponde a un tumor solitario a mieloma múltiple. Aporte a la práctica clínica diaria: Presentación inusual. 


\section{Linfoma primario pulmonar tipo MALT: Presentación de caso}

\section{Rivera UCP, Renpenning CEW, Herrera GAS, Sánchez SSS, Mercado LR}

Hospital Universitario Dr. José Eleuterio González

Introducción: El linfoma primario de pulmón es infrecuente, con presentaciones desde formas indolentes hasta progresivas y agresivas. Por mencionar el linfoma no Hodgkin de células B es el tipo más frecuente $80 \%$ de todos los casos. Objetivos: Describir las características de un caso con presentación de linfoma primario pulmonar. Presentación del caso: Femenino de 53 años sin antecedentes, ingresa tras cuadro de 9 meses con síntomas B, tos irritativa y disnea progresiva hasta el reposo, 5 meses después aparece aumento progresivo de adenopatía. A la revisión oximetría $88 \%$ aire ambiente, adenopatía izquierda de $3 \times 1.5 \mathrm{~cm}$ no dolorosa, campos pulmonares con murmullo vesicular disminuido en tercio inferior bilateral con escasos crepitantes integrando un síndrome de condensación pulmonar así como hepato-esplenomegalia. Hemograma con hemoglobina $8.09 \mathrm{~g} / \mathrm{dL}$, sin otras citopenias, TAC contrastada con múltiples nódulos que confluyen, consolidaciones bilaterales peribroncovasculares de predominio basales, nódulos mediastinales, adenopatía de $3 \mathrm{~cm}$ cuello izquierdo. La biopsia excisional de adenopatía reportó linfoma de Hodgkin de la zona marginal (WHO 9699/3) inmunohistoquímica CD20, CD79 ALFA positivo, KI67, con índice de proliferación celular $20 \%$, FISH fusión para $\mathrm{t}(11: 14)$ negativo, la broncoscopia con LBA, cepillado y biopsias transbronquiales de segmentos 9 y 10 izquierdos reportó infiltración de tejido pulmonar con proliferación de células linfoides, invasión del epitelio bronquial y en tejido pulmonar CD20 positivo, CD79a positivo, KI67 20\%, se observaron translocaciones T(11:18)(q21:21). Este caso describe un linfoma tipo MALT, que puede ser no distinguible de formas secundarias, únicamente basados en patología y sus características morfológicas. Conclusión:
El linfoma primario de pulmón representa un reto diagnóstico para el neumólogo y patólogo, por lo cual, es necesario conocer la diversidad clínica de presentación. Aporte a la práctica clínica diaria: Tomar en cuenta en el abanico de diferentes patologías pulmonares el linfoma primario pulmonar, el cual es infrecuente y realizar un diagnóstico oportuno para el inicio de tratamiento.

\section{Megaesófago y perforación esofágica secundaria como causa infrecuente de empiema. Reporte de caso y revisión de la literatura}

\section{Sánchez RCP, Marmolejo TME,} Vázquez MJC, Berrios MJ

INER Ismael Cosío Villegas

Introducción: El megaesófago es una entidad de baja frecuencia que se define como la dilatación de las paredes esofágicas con disminución o ausencia de la peristalsis del órgano. Su tratamiento representa un reto, particularmente en los casos complicados con empiema, sepsis y/o perforación. Objetivos: Dar a conocer la importancia de la sospecha diagnóstica del megaesófago para evitar complicaciones graves. Material y métodos: Presentación del caso: Masculino de 40 años. Tabaquismo activo IT 5.5 paquetes año. Sin otros antecedentes. Padecimiento de un año caracterizado por disfagia a sólidos posterior a líquidos. Un mes previo a su ingreso hiporexia, fiebre, tos productiva de expectoración purulenta, diaforesis y palpitaciones. Se recibe taquicárdico, taquipneico e hipoxémico. Se integra síndrome de derrame pleural derecho. Con leucocitosis a expensas de neutrofilia. Tomográficamente se documenta megaesófago y derrame pleural. La toracocentesis reporta exudado polimorfonuclear y amilasa en $284 \mathrm{mg} / \mathrm{dL}$. Recibió tratamiento antibiótico, drenaje pleural y nutrición parenteral. La endoscopia documenta perforación esofágica. Debido al estado clínico se decide intervención quirúrgica en 2 etapas realizando inicialmente esofagectomía con lavado y decorticación, así como gastrostomía; posteriormente, restitución del tránsito esofágico. Conclusión: El megaesófago es una entidad poco frecuente en la actualidad, gracias al diagnóstico temprano y mejoras en el abordaje terapéutico. Principalmente se presenta secundario a acalasia primaria sin tratamiento o a la enfermedad de Chagas. Según la clasificación radiológica de Ferreira-Santos, hay IV etapas siendo la grado IV la etapa más severa con dilatación esofágica superior a los 10 centímetros. La complicación más temida es la perforación a nivel torácico con mediastinitis y/o empiema, como sucedió en el presente caso. Aporte a la práctica clínica diaria: El presente caso es de interés por la baja frecuencia de la enfermedad. Ante la presencia de un megaesófago, la importancia radica en el abordaje diagnóstico temprano, basado en las implicaciones pronósticas y terapéuticas, con el fin de prevenir la aparición de complicaciones.

\section{Pseudoquilotórax secundario a derrame pleural crónico, etiología poco común e insospechada. Presentación de caso}

\section{Toledo EJ, Hernández NIZ}

IMSS; Benemérita Universidad Autónoma de Puebla

Introducción: El pseudoquilotórax es una forma muy poco común de los derrames pleurales (DP), caracterizado por la presencia de un líquido quiloso, exudativo y lipídico con elevadas concentraciones de colesterol. Objetivos: Describir caso de pseudoquilotórax secundario a derrame pleural crónico postraumático y revisión de literatura. Presentación del caso: Masculino de 40 años, obrero cargador. Sin antecedentes patológicos. 4 meses de evolución, posterior a esfuerzo físico al cargar bultos de $50 \mathrm{~kg}$ sobre su costado, inició con dolor pleurítico derecho, progresivo, disnea hasta MMRC 2, se detectó derrame pleural (DP) derecho, multitratado por 
medicina interna, sin encontrar etiología ni mejoría. TAC toracoabdominal, sin alteraciones en parénquima pulmonar, pequeño derrame pleural basal derecho y plaquipleuritis. Toracocentesis, líquido de aspecto quiloso; DHL: 4223 UI/L, glucosa $70 \mathrm{mg} / \mathrm{dL}$, colesterol $263 \mathrm{mg} / \mathrm{dL}$, triglicéridos $21 \mathrm{mg} / \mathrm{dL}$, con cristales de colesterol +++, BAAR negativo, ADA 16U. Pleurostomía y biopsia pleural, se palpó engrosamiento notorio de pleura parietal, líquido quiloso, drenaje 600 mL, citopatológico sin células neoplásicas, plaquipleuritis. Evolución favorable, seguimiento hasta la actualidad asintomático, sin repercusión funcional ni recidiva del derrame. El pseudoquilotórax es una forma infrecuente de los DP, caracterizado por la presencia de un líquido lipídico con elevadas concentraciones de colesterol, lo cual le da el aspecto lechoso. Se asocia comúnmente con trastornos inflamatorios crónicos como la tuberculosis o la artritis reumatoide. Algunos exudados que permanecen durante mucho tiempo (meses o incluso años) en el espacio pleural tienen tendencia a enriquecerse de colesterol. El diagnóstico se realiza mediante el análisis del líquido corroborando la presencia de cifras elevadas de colesterol así como cristales y DHL elevada. Conclusión: El pseudoquilotórax es un tipo muy poco común de efusión pleural, suele presentarse en derrames crónicos con engrosamiento pleural. Aporte a la práctica clínica diaria: Se recalca la importancia del protocolo conveniente del derrame pleural quiloso y la sospecha del pseudoquilotórax y las patologías implicadas.

\section{Síndrome de}

hipoventilación alveolar central congénita.

Transición de

\section{traqueostomía a ventilación mecánica no invasiva. Reporte de caso}

Téllez NNA, Vega SÁE, Avilés RBA, Torres FMG, Carrillo AJL

INER Ismael Cosío Villegas
Introducción: El síndrome de hipoventilación alveolar central congénita (SHACC), es una enfermedad infradiagnosticada, la literatura universal reporta la incidencia 1:200,000 nacidos vivos, se asocia a mutaciones en el gen PHOX2B. El manejo ventilatorio y abordaje en estos casos es poco conocido, por tal motivo, se presenta un caso tratado en la Clínica de Sueño del INER para inicio de VMNI. Objetivos: Evaluación del paciente con SHACC para inicio de VMNI. Presentación del caso: Femenino de 9 años con SHACC diagnosticado en período posnatal, con traqueostomía y ventilación mecánica invasiva continua hasta los 3 años de edad y posteriormente uso de ventilación mecánica nocturno con parámetros PINSP $18 \mathrm{cmH}_{2} \mathrm{O}$ y PEPP $6 \mathrm{cmH}_{2} \mathrm{O}$. Acudió a la Clínica de Sueño en 2016, la gasometría diurna con $\mathrm{PaCO}_{2} 36 \mathrm{mmHg}$, se realizó polisomnografía con el ventilador que usaba la paciente, documentando hipoventilación con TnCO2 máximo de $67 \mathrm{mmHg}$ en fase NREM y períodos de asincronía. Se sugirió cambio de ventilador y realizar protocolo de decanulación. Se aceptó procedimiento y se realizó broncoscopia más prueba de deglución, sin contraindicación para cierre de traqueostomía. Se citó para realizar polisomnografía diurna donde se retiró la cánula traqueal, se colocó interfase oronasal y se tituló BiPAP-ST con IPAP 20, EPAP 8, FR 18, saturando al $92 \%$ (sin oxígeno suplementario) y $\mathrm{TnCO}_{2}$ de $36 \mathrm{mmHg}$. Fue egresada para seguimiento externo, sin complicaciones. La transición de traqueostomía a VMNI suele ser factible en niños de edad escolar. Las limitaciones que existen incluyen las interfaces adecuadas y cómodas para el niño. El modo ventilatorio debe ser capaz de dar frecuencia respiratoria de respaldo. La titulación periódica de la VMNI es pertinente en su seguimiento. Conclusión: El adecuado soporte ventilatorio permitirá mejorar el pronóstico y calidad de vida en estos pacientes. Aporte a la práctica clínica diaria: Indicación de VMNI en pacientes con hipoventilación central congénita.

\section{Monday effect: Análisis flujo-tiempo para disminuir}

los tiempos de espera en una unidad de urgencias respiratorias

Rodríguez LIS, Arroyo HLJ, Castro

AEF, Sandoval GJL, García GML

INER Ismael Cosío Villegas

Introducción: El tiempo de espera en consulta de urgencias es un indicador de calidad en la atención de los servicios de salud y constituye un componente vital en la satisfacción del paciente. El Institute for Healthcare Improvement (IHI) ha determinado que el primer paso para disminuir los tiempos de espera en los servicios de consulta consiste en entender el balance entre la oferta y la demanda de dichos servicios. Al ser la Unidad de Urgencias Respiratorias (UUR) del Instituto Nacional de Enfermedades Respiratorias (INER) un centro de referencia nacional atendiendo más de 15,500 consultas anuales, se vuelve prioritario iniciar un análisis flujotiempo que permita encontrar áreas de oportunidad para la modificación de procesos que conlleven a una mejora continua. Objetivos: Determinar el flujo de consulta por día de la semana en la UUR del INER. Material y métodos: Este estudio transversal retrospectivo analizó descriptivamente la base de datos de los pacientes que acudieron a consulta en la UUR del INER de septiembre 2015 hasta agosto 2016. Por medio de frecuencias y porcentajes se estimó la distribución de consultas proporcionadas por la unidad. Resultados: El promedio de citas por día es mayor en lunes (28 consultas), seguido de martes y jueves (25), miércoles (24), viernes (23), sábado y domingo (20). El análisis de frecuencias mostró que en las 44 semanas analizadas, el máximo de consultas semanales fue atendido principalmente en día lunes (18 semanas; 41\%), seguido de jueves (8; $18 \%)$, martes $(7 ; 16 \%)$, miércoles y viernes $(6 ; 14 \%)$, sábado $(3 ; 7 \%)$ y domingo (2; 5\%). Conclusión: La reasignación de la entrada de pacientes referidos al INER en los días menos saturados o la reasignación de recursos humanos en los días saturados, son áreas de oportunidad 
para disminuir el indicador de tiempos de espera en la UUR y así mejorar la calidad en la atención del paciente.

\section{Recidiva de hernia diafragmática en una lactante menor: Reporte de un caso}

\section{Maldonado DA}

IMSS

Introducción: La hernia diafragmática es una de las anomalías congénitas más comunes. La incidencia anual de 1 en 2500-5000 nacidos vivos. Mortalidad varía del $20-40 \%$ a pesar de los avances en la tecnología y las estrategias utilizadas para optimizar los resultados quirúrgicos. Objetivos: Presentar a un lactante con recurrencia de hernia diafragmática. Presentación del caso: Femenino de 4 meses, producto de gesta 2, cursó con amenaza de aborto y amenaza de parto prematuro. Nació por cesárea, Apgar 5-7 presentó dificultad respiratoria progresiva ameritó intubación endotraqueal, hernia diafragmática izquierda secundaria a agenesia de cúpula diafragmática además de hipoplasia de pulmón izquierdo del 80\%; se colocó malla a los 3 días de vida, encontrando intestino delgado, colon, lóbulo hepático izquierdo, bazos y omento en tórax; permaneció intubada 40 días y egresó a los 2 meses con diagnóstico de displasia broncopulmonar e hipertensión arterial pulmonar tratada con fluticasona y sildenafil. Un mes después presenta cianosis generalizada y flacidez durante la alimentación con dificultad respiratoria, en urgencias recibió manejó avanzado de la vía aérea y cefalosporina por sospecha de neumonía por aspiración, cardiología reportó insuficiencia tricuspídea de 23 mmHg. Radiografía mostró hernia diafragmática izquierda que se corroboró por tomografía toracoabdominal. Encontraron en tórax bazo, colon, estómago y omentos, se colocó nuevamente malla de polipropileno con expansión pulmonar del $80 \%$. Conclusión: La recurrencia de hernia diafragmática parece ser más frecuente y prevalente en niños, prin- cipalmente en aquéllos que requirieron colocación de parche para cerrar el defecto; se desconoce cuál es el mejor material ya que generalmente se debe fijar a las costillas y la recurrencia incrementa conforme el paciente crece. Este paciente fue intervenido quirúrgicamente en el período neonatal y a los 3 meses cuando ya hubo aumento de talla y peso y recidivó su hernia.

\section{Control de asma en niños de la consulta externa de Neumología pediátrica mediante el ACT}

\section{Ristori MKM, Moreno CV, Martínez HAJ}

\section{IMSS/Hospital Puebla}

Introducción: La importancia de evaluar el control de asma en niños mediante un instrumento validado como es la prueba de control de asma (ACT), nos permite determinar el nivel de control para poder realizar las modificaciones pertinentes al tratamiento o intervenir en el control ambiental en aquellos pacientes que no logran alcanzar el control. Objetivos: Determinar el nivel de control de asma de los pacientes tratados en la consulta externa de Neumología Pediátrica del Hospital Regional Número 36 a través del ACT. Material y métodos: Estudio descriptivo, observacional, transversal en pacientes pediátricos asmáticos de todas las edades que acudieron a consulta externa de Neumología Pediátrica del Hospital Regional número 36 del IMSS donde se les aplicó el ACT. Se utilizó estadística descriptiva y Chi cuadrada. Resultados: Un total de 100 niños con asma con alrededor de 2 años de evolución de la enfermedad y promedio de edad de 12 años fueron evaluados mediante ACT. El $82 \%$ proviene de zona urbana y el $18 \%$ de medio rural. Del total de la población el 53\% presentó control parcial de asma, $10 \%$ control total y $47 \%$ asma descontrolada. El 45\% del total correspondió a adolescentes, cuyo control en ese grupo de edad fue: total $31 \%$, parcial $4 \%$ y descontrol $10 \%$. Conclusión: El ACT es una herramienta útil para valorar el control en nuestros pacientes y nos permitió concluir que ni el género ni la edad son factores que influyan sobre el control del asma. La zona geográfica de procedencia tampoco mostró influencia sobre la puntuación ACT.

\section{Linfoma primario de pulmón, reporte de un caso}

\section{Hernández RJE}

\section{IMSS}

Introducción: Se realizó diagnóstico de una paciente con manifestaciones clínicas y hallazgos radiológicos inespecíficos mediante biopsia pulmonar, descartando la importancia de la misma en este tipo de pacientes en quienes es frecuente el retraso del diagnóstico siendo tratados de manera frecuente como neumonías. Objetivos: Diagnóstico temprano por confirmación histopatológica de linfoma primario de pulmón. Material y métodos: Estudio realizado en Hospital de Cardiología 34, unidad médica de alta especialidad. Paciente a cargo del servicio de Neumología, mayo 2016. Presentación del caso: Se presenta el caso de paciente femenino de 58 años de edad con antecedente de hipertensión arterial en control, sin otros antecedentes relevantes para padecimiento actual. Sintomatología de 4 meses de evolución que consta de fiebre, sin predominio de horario, tos productiva, astenia y adinamia y presencia de derrame pleural derecho en una ocasión, el cual fue drenado con características serohemáticas en una sola ocasión, así como pérdida de peso de aproximadamente 9 kilos en 5 meses. A la exploración con movimientos respiratorios normales, no se integra síndrome pleuropulmonar, con crepitantes de predominio subclavicular del lado izquierdo. Resto sin anormalidades saturando $96 \%$ al aire ambiente. En sus exámenes de laboratorio con hipoalbuminemia 2.9, deshidrogenasa láctica de 271, resto normal. Cultivos, baciloscopias y métodos moleculares negativos para enfermedades infecciosas. Tomografía de tórax, en ventana para parénquima se observa consolidación en lóbulo superior, así como vidrio despulido periférico, y en hemitórax derecho con 
presencia de vidrio despulido y con tendencia a consolidar por encima de cisura menor. Gammagrafía con galio 67 con área hipercaptante en sitio de lesión en LSI como primera sospecha diagnóstica de linfoma primario de pulmón, sin compromiso mediastinal. Finalmente se confirma sospecha mediante biopsia a cielo abierto. Conclusión: El linfoma primario de pulmón es infrecuente. Es importante ante un cuadro clínico inespecífico y hallazgos radiológicos inconsistentes tomar en cuenta como diagnóstico diferencial el linfoma primario de pulmón. Aporte a la práctica clínica diaria: Siendo una patología frecuentemente subdiagnosticada considerar siempre el diagnóstico histopatológico para reducir el retraso en el tratamiento definitivo y progresión de la enfermedad.

\section{Valores de referencia para la prueba de caminata de seis minutos en dos poblaciones latinoamericanas adultas, residentes de altitudes moderadas}

Velázquez UM, Vázquez-García JC, Franco-Marina F, Casas A, GochicoaRangel L, Torre-Bouscoulet $L$, VargasDomínguez $C$, Pérez-Padilla $R$

INER Ismael Cosío Villegas

Introducción: La prueba de caminata de seis minutos (PCSM) es una prueba sólidamente estandarizada y relevante en la evaluación funcional. Desde la publicación de las guías ATS 2002 se han publicado varias ecuaciones de referencia con una alta variabilidad en los términos incluidos, así como en las estrategias de modelado y su capacidad predictiva, lo cual puede relacionarse con diferencias en las poblaciones estudiadas. Objetivos: Generar la ecuación de referencia con la mayor capacidad predictiva incluyendo los predictores usuales e incorporando indicadores de esfuerzo durante la prueba, en dos poblaciones latinas residentes de altitudes moderadas. Material y métodos: Estudio descriptivo, transversal, comparativo. Muestra por conveniencia de hombres y mujeres $>25$ años, sanos respiratorios. Participaron 2 centros latinoamericanos, usando métodos estandarizados: Bogotá, Colombia (2,640 m) y la Ciudad de México (2,240 m). Todos firmaron un consentimiento informado y completaron un cuestionario de escrutinio estandarizado y se les realizó una espirometría con broncodilatador. Se realizó la PCSM de acuerdo a las guías ATS 2002. Resultados: Doscientos cincuenta y siete sujetos cumplieron el criterio de salud respiratoria y completaron la prueba (60.3\% mujeres, 134 colombianos y 123 mexicanos). Ambas poblaciones tuvieron talla (media 161.2, DE \pm 9.5), peso (media 64.9, DE \pm 10.8) e IMC (media 24.9, DE \pm 2.6) de similares. La distancia caminada fue similar en ambas poblaciones (media global de $625.9 \mathrm{~m}, \mathrm{DE} \pm 70.6$ ). La media global de FCMáxPP fue de $75.8 \%$. La R2 fue de 0.65 e incluyó las siguientes variables: género, edad, edad cuadrada, talla y FCMáxPP. Las variables con mayor impacto (considerando R2 semiparcial) fueron FCMáxPP, género y edad (término cuadrático). Conclusión: Las ecuaciones de referencia pueden tener mayor capacidad predictiva si se incluye un indicador de esfuerzo de la prueba (FCMáxPP) y se modela mejor la ecuación con el término cuadrático de la edad. Aporte a la práctica clínica diaria: Con esta ecuación de referencia latinoamericana podrán evaluarse desde la primera consulta los valores deseables de capacidad funcional submáxima del enfermo respiratorio. Además, agregar un indicador de esfuerzo mejora la predicción, lo cual puede ser un parámetro a medir para asegurar la calidad de la prueba, especialmente en estudios de investigación.

\section{Resección de liposarcoma invasor en tórax con reconstrucción torácica}

Martínez AM, Díaz MJL, Lara GVR, Gallardo GJF, Menjivar ROM, Romero DFN, Loyola GU, Téllez BJL, Martínez CT

ISSEMYM; Centro Médico ISSEMYM Toluca

Introducción: Los sarcomas de tejidos blandos comprenden un grupo heterogéneo de neoplasias malignas de origen mesenquimatoso y neuroectodérmico. Objetivos: Diagnosticar de manera temprana para reducir el índice de mortalidad y mejorar la sobrevida de los pacientes. Presentación del caso: Se realiza la presentación de una paciente con liposarcoma en tórax en Centro Médico ISSEMYM, con revisión de la literatura. Femenino 76 años de edad, hipertensión arterial crónica 2 años. Inicia sintomatología 1 año previo con aumento de tamaño en región costal izquierda posterolateral indurada no dolorosa de aproximadamente $3 \mathrm{~cm}$, biopsia excisional con resultado histopatológico de «liposarcoma desdiferenciado con componentes de células redondas/mixoide y con componente fusocelular». A la exploración física tumoración de aproximadamente $10 \times 8 \mathrm{~cm}$ a nivel de quinto arco costal izquierdo posterolateral. Se realizó exéresis de tumoración, el cual invadía 3 arcos costales y pleura, realizándose resección en bloque, con posterior colocación de arcos de titanio y colocación de injerto y colgajo cutáneo. Resultados: La experiencia quirúrgica demuestra que sin tratamiento adyuvante, la recurrencia local varía de acuerdo al tipo de resección: 90\% para resección marginal, $39 \%$ en resección amplia, $25 \%$ en compartamentectomía y de 7 a $18 \%$ en amputaciones. La radioterapia sola, utilizada comúnmente en forma paliativa, resulta en índices de control local del 29 al 33\%. Cuando la radioterapia se emplea de manera preoperatoria se logra un control local del 90 al 97\%. Conclusión: Los sarcomas de tejidos blandos continúan siendo un grupo de tumores de difícil manejo, debido a la gran diversidad en términos de grado, histología, potencial metastásico y localización anatómica. Aporte a la práctica clínica diaria: Mejorar la sobrevida de los pacientes. Establecer puntos claves en el diagnóstico, tratamiento y seguimiento de los pacientes.

\section{Eficacia de la cámara espaciadora vs. nebulizador en el manejo de la crisis asmática}

Alamilla LP, Moreno CV, Benítez CAI

IMSS/Hospital Puebla 
Introducción: Los agonistas $\beta^{2}$ adrenérgicos de acción corta son los medicamentos más usados en las crisis de asma y su mejor vía de administración es la inhalatoria. Se considera que la terapia broncodilatadora con inhalador de dosis medida (MDI), idealmente con un espaciador, produce una mejoría y un efecto farmacológico equivalente e incluso mejor a la vía nebulizada. Objetivo: Determinar la eficacia de la cámara espaciadora vs. nebulizador en el tratamiento de la crisis asmática. Materiales y métodos: Estudio prolectivo, comparativo, longitudinal, experimental, aleatorizado realizado en el servicio de Urgencias Pediátricas del Hospital General Regional de Puebla No 36 del IMSS. Se incluyeron 60 pacientes de entre 3 y 14 años con diagnóstico de crisis asmática leve y moderada con base en Score Pulmonar. Se aleatorizaron para recibir tratamiento a base de aerocámara o nebulización. Resultados: Se incluyeron 30 niños por grupo, $38.3 \%$ fueron mujeres y $61.6 \%$ hombres. El $23 \%$ ingresó con crisis asmática leve y $76.6 \%$ moderada. Hubo diferencia significativa en el tiempo de resolución de la crisis de 3.9 h vs. 3.1 h $(p=0.04)$ en los pacientes que recibieron nebulizaciones vs. los que se trataron con aerocámara respectivamente. El Score Pulmonar a las 3 horas con aerocámara fue de $0.3 \pm 0.4$ y con nebulizador $0.86 \pm$ 0.47 con $\mathrm{p}<0.002$. Conclusión: Tal como se refiere en la literatura el tratamiento de crisis asmática con aerocámara resultó más eficaz comparado con nebulización convencional, pues disminuyó el tiempo de resolución de la crisis y la mejoría clínica se observó en menor tiempo. Desde el punto de vista costo-beneficio, disminuyó el uso de oxígeno y la terapia fue más fácil de aplicar incluso por los propios padres. La aerocámara es un recurso útil para aplicación del tratamiento de mantenimiento como en exacerbaciones.

Cuantificación de proteína $C$ reactiva en pacientes con neumonía adquirida en la comunidad, al ingreso y 72 horas después de tratamiento antimicrobiano,

\section{en el Hospital General de México}

Saavedra de RSI, Pech AB, Cicero SR

Hospital General de México «Dr. Eduardo Liceaga»; Hospital General Naval de Alta Especialidad

Introducción: La neumonía adquirida en la comunidad (NAC) es la causa infecciosa más frecuente de muerte en el mundo. Estudios recientes reportan tasas de mortalidad del $8-15 \%$ aumentando hasta el $30 \%$ en pacientes que requieren UCI. La identificación temprana de pacientes con riesgo de mala evolución es importante. Las escalas CURB 65 y PSI estiman la mortalidad por NAC. Sin embargo, el uso complementario de biomarcadores se ha propuesto para mejorar la precisión de las escalas de gravedad. La Proteína C reactiva es un marcador de inflamación sistémica y daño tisular, denominado reactante de fase aguda. Justificación: Debido a la gravedad de NAC, y altos costos que conlleva, con el propósito de identificar de forma temprana a los pacientes con NAC e iniciar tratamiento antibiótico oportuno, considerando que no existe un nivel de cohorte de proteína $C$ reactiva en NAC. Objetivos: Determinar el comportamiento de Proteína $\mathrm{C}$ reactiva al ingreso y 72 horas después del tratamiento antimicrobiano, en pacientes con diagnóstico de NAC. Material y métodos: Estudio observacional, transversal y descriptivo en pacientes que ingresaron a Neumología con diagnóstico de NAC durante el año 2013. Se determinaron los niveles séricos de Proteína $\mathrm{C}$ reactiva al ingreso y 72 horas después del tratamiento antimicrobiano. Análisis estadístico. En programa SPSS B.20, con Prueba t para muestras pareadas. Resultados: Setenta y dos pacientes ingresados con NAC. Treinta y un pacientes cumplieron con criterios de inclusión. La media de Proteína $\mathrm{C}$ reactiva al ingreso fue 152.78 , y a las 72 horas de tratamiento antimicrobiano media de 84.25, con el análisis estadístico prueba t de muestras pareadas, se observó diferencia significativa. Conclusión: Los datos obtenidos en el presente trabajo coinciden con la literatura mundial, los biomarcado- res demuestran ser útiles en el diagnóstico de NAC, así como para evaluar la respuesta al tratamiento.

Utilidad de la solución salina hipertónica al $3 \%$ en comparación con salbutamol en el tratamiento de bronquiolitis aguda

Cruz LDL, Moreno CV, Benítez CAI

IMSS/Hospital Puebla

Objetivo: Determinar la utilidad de la solución salina hipertónica al 3\% en comparación con el salbutamol en el tratamiento de pacientes pediátricos con diagnóstico de bronquiolitis aguda. Material y métodos: Estudio prospectivo, longitudinal, experimental, aleatorizado, doble ciego. Se incluyeron 40 pacientes atendidos en el HGR No. 36, ambos sexos, edad entre 6 y 24 meses, diagnóstico de bronquiolitis aguda, clasificación moderada y severa, divididos en dos grupos, Grupo I: tratamiento con nebulizaciones con salbutamol; Grupo II: nebulizaciones con solución salina hipertónica al 3\%. Resultados: El 57.5\% $(\mathrm{n}=23)$ correspondió al sexo masculino, $42.5 \%(n=17)$ femenino, La clasificación Woods-Down es modificada por Ferres en el grupo I: fue moderada $85 \%(\mathrm{n}=17)$, $15 \%(\mathrm{n}=3)$ severa, en el Grupo II $70 \%$ $(n=14)$ moderada y $30 \%(n=6)$ severa. Al ingreso el Grupo I con puntaje de severidad promedio $6.35 \pm 1.08$, el Grupo II: $6.55 \pm 1.57(\mathrm{p}=0.643)$. Posterior a $24 \mathrm{~h}$ de tratamiento con nebulizaciones de solución hipertónica al 3\% hubo mejoría clínica significativa: $3.25 \pm 1.33$ vs. salbutamol $4.90 \pm 0.96,(\mathrm{p}=0.000)$, así como reducción significativa del número de horas de estancia hospitalaria: Grupo I: $89.70 \pm 23.12$ h, Grupo II: 57.60 \pm 20.37 h $(\mathrm{p}=0.000$; IC 18.14-46.05). Conclusión: El uso de solución salina al 3\% nebulizada para el tratamiento de la bronquiolitis moderada y severa tal como se refiere en la literatura redujo el tiempo de estancia hospitalaria y las ma- 
nifestaciones clínicas en las primeras 24 h, lo que puede impactar en la reducción de costos generados por hospitalización.

Índice predictor de asma en la consulta externa de Neumología Pediátrica del HGR No. 36, IMSS, Puebla

Martínez MM, Moreno CV, Méndez MS

IMSS/Hospital Puebla

Introducción: El asma es un proceso inflamatorio crónico de las vías aéreas, con diferentes fenotipos y edad de presentación. El índice predictor de asma (IPA) evalúa criterios mayores: eczema en los primeros 3 años y padre o madre con diagnóstico médico de asma y criterios menores: diagnóstico médico de rinitis alérgica en los primeros 3 años, episodios de sibilancias no asociadas a resfríos en los primeros 3 años y eosinofilia en sangre periférica mayor igual a $4 \%$, tiene una sensibilidad $16 \%$, especificidad $97 \%$, valor predictivo positivo $77 \%$ y valor predictivo negativo $68 \%$. Es una herramienta muy útil cuando nos enfrentamos a pacientes sibilantes recurrentes menores de 3 años de edad. Objetivo: Determinar el API en la consulta externa de Neumología Pediátrica del HGR No. 36, IMSS e identificar a los niños que tienen un alto riesgo de presentar asma atópica. Material y métodos: Estudio descriptivo, observacional, transversal, homodémico, realizado en la consulta externa de Neumología Pediátrica del HGR 36. Se incluyeron menores de 5 años con API positivo. Se usó estadística descriptiva e inferencial con pruebas $\chi^{2}$. Resultados: Se estudiaron 100 pacientes, con edad promedio de 2.4 años. El peso promedio de $12.0 \pm 4.85 \mathrm{~kg}, 55 \%$ hombres y $45 \%$ mujeres. El API positivo con criterios mayores fueron $28 \%$, y con criterios menores 4\%. Asma atópica con API positivo $65.6 \%$. Encontramos en nuestra población una sensibilidad del $65.6 \%$ y especificidad del $92 \%$, valor predictivo positivo $75.5 \%$, valor predictivo negativo $88.44 \%$. Conclusión: El IPA es una herramienta muy útil, rápida y fácil de aplicar en nuestra práctica clínica diaria. Logró identificar en nuestra población un $65.6 \%$ de los que tienen riesgo de presentar asma atópica y con ello instalar un tratamiento adecuado y prolongado para evitar remodelación de la vía aérea a largo plazo, permitió instalar medidas preventivas y ambientales adecuadas.

\section{Presentación de un caso fulminante de tuberculosis traqueobronquial}

\section{Rivera UCP, Mercado LR, Renpenning CEW}

Hospital Universitario Dr. José Eleuterio González

Introducción: La tuberculosis endobronquial (EBTB) ha aumentado su incidencia reportando de $10-40 \%$ de los casos de TBP. La presentación clínica es variable. El uso de la broncoscopia para el diagnóstico ha permitido un mayor diagnóstico. Objetivos: Describir la presentación atípica de un caso fulminante de tuberculosis traqueobronquial. Presentación del caso: Masculino de 76 años de edad con antecedentes de combe (+), DM de larga evolución, el cual presenta cuadro de 2 meses con tos con expectoración mucopurulenta, diaforesis vespertina, hiporexia y pérdida de peso de $10 \mathrm{~kg}$. Se agrega disnea de esfuerzos de instalación gradual hasta el reposo. A la revisión oximetría 97\%, campos pulmonares con murmullo vesicular disminuido, estertores difusos bilaterales bibasales con síndrome de consolidación derecha. TAC revela múltiples nódulos de diferente tamaño y distribución, predominio subpleural, así como consolidaciones peribroncovasculares y calcificaciones. Cultivos de expectoración negativos, broncoscopia con lesiones adheridas en la mucosa de coloración negruzca y placas blanquecinas sobre la superficie de las mismas en trayecto traqueal, con distorsión de la anatomía segmentaria predominante en língula y superior del lóbulo inferior, árbol traqueobronquial derecho en su primera división con lesión exofítica que ocluye en su totalidad luz de lóbulo intermediario de la cual se tomaron biopsias con repor- te BAAR positivo, citología y biopsias con detección de bacilos ácido-alcohol resistentes, GeneXpert positivo. Se inició tratamiento con antifímicos sin respuesta favorable por presentación fibroestenótica. Se presenta un caso clínico de TB Traqueobronquial con evolución tórpida por la rápida progresión e infiltración de la enfermedad. Conclusión: Caso descriptivo de los hallazgos imagenológicos y broncoscópicos sugerentes de la enfermedad. Aporte a la práctica clínica diaria: Las variedades broncoscópicas identificadas por método de Churg's pueden ser variables e incluir dentro del diferencial enfermedades de índole neoplásica, es importante identificarlas en el abordaje de los casos, ya que el desenlace diagnóstico puede ser desfavorable por la alta diseminación, pobre actividad antifímica y la modificación traqueobronquial.

\section{Reporte de caso: Angiosarcoma cardíaco diagnóstico mediante ventana pericárdica por toracoscopia}

\section{Payro HLE}

\section{Hospital Central Militar}

Introducción: El angiosarcoma cardíaco primario es un tumor poco común, representa el $2 \%$ de los sarcomas, surge del endotelio vascular/linfáticos, altamente agresivo, con sobrevida a 5 años: 10-35\%, sobrevida media: 18 meses, alto índice de recurrencia local después de tratamiento, la mayoría fallece por enfermedad metastásica. La relación hombre:mujer de 2-3/1, se presenta en < 65 años. Tiempo de sobrevida promedio: 4 meses. Objetivos: Dar a conocer la rareza del padecimiento y el mal pronóstico cuando se presenta esta entidad nosológica manifestada por el derrame pericárdico y la utilidad de la toracoscopia quirúrgica para el diagnóstico preciso del angiosarcoma cardíaco. Material y métodos: Antecedentes personales no patológicos: Originaria y residente de Tlaxcala, grupo sanguíneo O (+), esquema básico de vacunación completo, adecuados 
hábitos higiénicos y malos hábitos alimenticios, vive en casa-habitación que cuenta con todos los servicios, zoonosis: perros, gatos y pájaros, etilismo ocasional, tabaquismo y otras toxicomanías, niega exposición crónica a biomasas y asbesto, niega convivencia con tosedores crónicos, niega hemotransfusiones, ocupación ama de casa, escolaridad: preparatoria inconclusa. Antecedentes personales patológicos: Obesidad, parálisis facial en noviembre 2013, resuelta tratamiento médico; colecistectomía laparoscópica hace 6 años. G-O: menarca 12 años, IVSA 20 años ritmo catamenial irregular, PARA 63033, PAP y mastografía negativos para malignidad, salpingoclasia hace 11 años, 3 cesáreas, última hace 11 años. Padecimiento actual: Inicia con disnea de medianos a mínimos esfuerzos que progresa hasta la ortopnea y disnea paroxística nocturna, edema y dolor torácico de 2 meses de aparición ocasional, por el que acude al Ptn.Snd. 1er. Rgto. Mec., Panotla, Tlaxcala. El médico solicita estudios de laboratorio y radiográficos de tórax que demuestra cardiomegalia grado IV, USG de pelvis con reporte de miomatosis uterina intramural y subserosa, ECOTT reportando derrame pericárdico de aproximadamente 1,500 $\mathrm{cm}^{3}$, por el cual la paciente acude por sus propios medios al servicio de urgencias el día 6 de mayo de 2014, presentando datos clínicos de derrame pericárdico con ruidos cardíacos disminuidos y plétora yugular sin datos de choque, por lo que se ingresa para estudio y tratamiento del derrame pericárdico. A su ingreso a este nosocomio: talla: $1.65 \mathrm{~cm}$, peso: $106 \mathrm{~kg}$, IMC: 38.9, alerta, consciente, orientada en las 3 esferas, cooperadora a su estudio médico, palidez de la piel, mesaticéfala, pupilas isocóricas, reactivas a la luz, conjuntivas pálidas, mucosas orales bien hidratadas, cuello cilíndrico, tráquea central sin adenopatías, pulsos carotídeos presentes sin soplos, rítmicos, con plétora yugular, tórax en tonel, palpación normal, cinética ventilatoria con expansión bilateral simétrica estrecha, restrictiva por la obesidad, vibraciones vocales disminuidas, percusión mate hacia las bases, auscultación sin estertores, sin soplos, ni sibilancias, ruidos cardíacos sincrónicos, sin soplos con intensidad disminuida, tendiente a la taquicardia, abdomen globoso a expensas de panículo adiposo abundante, depresible sin presencia de circulación colateral, no doloroso no se palpan visceromegalias, extremidades superiores e inferiores con arcos de movimiento conservados, sin masas o puntos dolorosos, pulsos distales presentes, llenado capilar menor a $3 \mathrm{seg}$, con edema de miembros inferiores + . Glasgow 15. frecuencia cardíaca: $100 \mathrm{~L} /$ min, frecuencia respiratoria: $20 / \mathrm{min}$, tensión arterial: 116/70 mmHg, Temperatura: 36.5\&ordm; C Estudios de laboratorio: Leucocitos: 10.400 103/mL, hemoglobina $10.3 \mathrm{~g} / \mathrm{dL}$, plaquetas: 404,000 103/mL, VCM: 67.2 .8 fL, HCM: 21.1 pg, neutrófilos: 7,600 103/mL, glucosa: $101 \mathrm{mg} / \mathrm{dL}$, urea: $23.5 \mathrm{mg} / \mathrm{dL}$, BUN: $11.0 \mathrm{mg} / \mathrm{dL}$, creatinina: $0.59 \mathrm{mg} / \mathrm{dL}$, bilirrubina total: 2.02 $\mathrm{mg} / \mathrm{dL}$, bilirrubina directa $0.68 \mathrm{mg} / \mathrm{dL}$, TGP: 14 U/L, TGO: 17 U/L, fosfatasa alcalina: 105 U/L. Panel cardíaco: CK-MB: menor de 1, mioglobina 49.3, troponina I: menor de 0.05 , péptido natriurético tipo B: 33.5, dímero D: 3,830. Sodio: $138.5 \mathrm{mmol} /$ dL, potasio: $3.9 \mathrm{mmol} / \mathrm{dL}$, cloro: $95 \mathrm{mmol} /$ dL. Radiografía del tórax: Silueta cardiomediastinal con cardiomegalia grado III, bordes costodiafragmático derecho sin alteraciones izquierdo no valorable, sin presencia de consolidados. TAC: Presencia de tumor sólido expansivo que sustituye la totalidad de la grasa pericárdica de comportamiento hipovascular que rodea la silueta cardíaca sin infiltración de grandes vasos, descartándose metástasis a distancia. Electrocardiograma: ritmo sinusal, FVM:123, Eje QRS:50, PR: 130 mseg, DQRS:90 mseg, QT: 310, QTc: 440, sin datos de lesión isquemia o necrosis, derivaciones con bajo voltaje. ECOTT donde se corrobora derrame pericárdico crónico de aproximadamente 1,400 $\mathrm{cm}^{3}$. Dx de ingreso: derrame pericárdico de origen a determinar. Evolución: se pasa a unidad de cuidados coronarios vigilando el estado respiratorio y hemodinámico, apoyo ventilatorio, se le realiza ventana pericárdica por toracoscopia más toma de biopsia, el 8 de mayo 14, se toman muestras de líquido de derrame, estudios para descartar proceso inmunológico, infeccioso, inflamatorio: -VIH tipo 1 y 2 por técnica inmunoenzimática: no reactivo. ADA en líquido pleural: 8.39 U/L. Coombs directo
2+ // Coombs (título) 2+. VSG 49, reticulocitos 120.4, VDRL: negativo, anticardiolipinas IgG e IgM negativos. Anti B2GP IgG e IgM negativos. ANA: homogéneo. Toracoscopia quirúrgica: ventana pericardíaca y colocación de drenaje (cardia espiral): biopsia pericárdica (Q-3951-14): angiosarcoma. Ante los hallazgos se decide realizar pericardiectomía extensa. Hallazgos transquirúrgicos: tumoración extensa en pericardio y miocardio en aurícula y ventrículo derechos, con el siguiente reporte histopatológico (Q-4774-14): Angiosarcoma pasa a Unidad de Cuidados Coronarios con datos de síndrome de fuga capilar, es egresada a sala, debuta con neumotórax resolviéndose con drenaje torácico. En apoyo con oncología médica se inicia tratamiento con quimio y radioterapia. Conclusión: El abordaje habitual de este tipo de casos se realiza mediante incisión subxifoidea de $4 \mathrm{~cm}$, con toma de biopsia de pericardio y colocación de sonda pleural para drenaje a ciegas, por lo que se recomienda realizar el abordaje por toracoscopia y realización de la ventana pericárdica con mayores ventajas: se mantiene observación directa del estado de los tejidos, tamaño de la ventana suficiente para el drenaje del derrame pericárdico, toma de biopsia del pericardio en la cantidad necesaria y sitio adecuado, lo que permitió en este caso la identificación visual del tumor cardíaco. Aporte a la práctica clínica diaria: La rareza de la entidad y las ventajas que ofrece la cirugía de mínima invasión mediante la toracoscopia quirúrgica permiten tomar biopsias de pericardio y directas del tumor, así como citología de líquido pleural y del derrame pericárdico mediante pericardiocentesis y/o drenaje a través de la ventana pericárdica, la biopsia endomiocárdica tiene un $50 \%$ de efectividad en el diagnóstico.

\section{Incidencia y asociación entre rinosinusitis y enfermedades inflamatorias de la vía aérea en pacientes menores de 12 años del Hospital General Regional Número 36 del Instituto}




\section{Mexicano del Seguro Social}

\section{Chávez SR, Moreno CV, Méndez MS}

IMSS/Hospital Puebla

Introducción: La rinitis alérgica (RA) y el asma pueden ser relacionadas y consideradas como una manifestación de un síndrome común de inflamación de la vía aérea, cerca de $40 \%$ de los pacientes con RA tienen asma y de éstos $80 \%$ presentan síntomas nasales. Objetivo: Determinar la incidencia y asociación entre rinosinusitis y las enfermedades inflamatorias de la vía aérea en pacientes menores de 12 años. Material y métodos: Estudio descriptivo, observacional en menores de 12 años con diagnóstico de rinosinusitis. Se evaluaron: índice predictor de asma positivo (IPA), niveles séricos de $\mathrm{IgE}$, eosinófilos, y comorbilidades, así como factores ambientales. Muestreo no probabilístico y por conveniencia. Resultados: Se incluyeron 59 pacientes; $67.7 \%$ hombres y $23.3 \%$ mujeres, promedio de edad 2.34 años. El peso promedio fue de $21.4 \mathrm{~kg}$. Existieron antecedentes de atopia en el $22 \%$, mientras que $77.9 \%$ negó este historial. El promedio de IgE fue de 77.8 y de eosinófilos fue de $3.5 \%$. Catorce pacientes viven en zona rurales y 45 en zona urbana. Se encontró una incidencia de rinosinusitis de $1.5 \%$. La asociación entre rinitis alérgica y asma se presentó en 45 casos (76.2\%). Se asoció rinosinusitis con RA en un $20 \%$ y se encontró poliposis nasal en 2 casos $(3.38 \%)$. No se encontró relación entre la rinosinusitis y el asma $\mathrm{p}=0.288$. Conclusión: De nuestra población estudiada el $16.8 \%$ presentó enfermedades atópicas tales como dermatitis, rinitis alérgica y asma. Se observa una asociación en más de $70 \%$ de los pacientes entre RA y asma, muy similar a lo reportado en la literatura; sin embargo, no encontramos factores nasales que condicionen mal control de la enfermedad. Hubo baja incidencia de rinosinusitis en nuestra población. La relación estrecha entre rinitis alérgica y asma implica tratamiento adecuado y multidisciplinario para ambas enfermedades por Neumología Pediátrica, ORL y Alergología.

\section{Equivalencia del índice de masa corporal con resultados de bioimpedancia en una cohorte de envejecimiento pulmonar en el INER}

\section{Moreno HSR, Buendía RI, Sierra $P$, Selman LM, Martínez K}

INER Ismael Cosío Villegas

Introducción: La obesidad es una enfermedad compleja y de condición heterogénea que influye en el desarrollo natural de diversas enfermedades: problemas cardiovasculares, metabólicos, articulares y a nivel pulmonar. En los últimos años se ha implementado el análisis de composición corporal para establecer el diagnóstico de obesidad utilizando la bioimpedancia, que emplea una corriente alterna de baja intensidad y de frecuencias sobre los $100 \mathrm{KHz}$. Este tipo de análisis nos permite, en pocos minutos, estimar la distribución de la grasa corporal del paciente y nos da datos tan importantes como la cantidad de masa grasa, masa libre de grasa y líquido corporal. Sin embargo, el costo del equipo es elevado. Objetivos: Comparar la clasificación de obesidad con índice de masa corporal (IMC) y los valores de bioimpedancia. Material y métodos: Realizamos un estudio prospectivo, observacional, descriptivo, en una cohorte de pacientes $>40$ años del INER, período noviembre 2015 a agosto 2016. Variables de bioimpedancia: MME (masa muscular esquelética), MGC (masa grasa corporal), ACT (agua corporal total), IMG (índice de masa grasa), IMM (índice de masa magra) y se calculó el IMC = peso $(\mathrm{kg}) /$ talla $\left(\mathrm{m}^{2}\right)$. Clasificando el mismo de acuerdo a los criterios de la OMS. Además se realizó espirometría simple como parte de los protocolos en que participan estos pacientes. Resultados: Estudiamos 82 sujetos, utilizando ambos métodos: peso normal en 24, sobrepeso en 38 y obesidad en 20, con una correlación positiva del IMC con la masa grasa de la impedancia y negativa del IMC con la masa magra, se analizaron además estas variables con el \% de FVC y FEV, sin encontrar correlación. Conclusión: Sin duda la bioimpedancia brinda amplia información, sin embargo, debido a costos para clasificar a los pacientes, descartamos la toma de impedancias en esta cohorte y nos basaremos en el IMC. Aporte a la práctica clínica diaria: Reducir costos y tiempo antes de solicitar una bioimpedancia.

\section{Función pulmonar en niños con diagnóstico de asma en un hospital de concentración}

Lázaro TPA, Moreno CV, Benítez CAI

IMSS/Hospital Puebla

Introducción: La gravedad del asma puede ser subestimada por la presencia de síntomas aislados o por el contrario conducir al sobreuso de medicamentos, con incremento en costos y también de la morbilidad. Para obtener una adecuada vigilancia, deben realizarse medidas objetivas de la función pulmonar, por lo que se recomienda la espirometría como una medida valiosa en los niños capaces de realizarla. Objetivos: Conocer la función pulmonar en niños mayores de cinco años con diagnóstico de asma previo al inicio del tratamiento de mantenimiento con esteroides inhalados y 6 meses después. Material y métodos: Estudio observacional, prospectivo, comparativo, homodémico, longitudinal. Se analizaron las espirometría realizadas al diagnóstico inicial y 6 meses después de tratamiento. Los niños fueron capaces de realizar espirometría cumpliendo con los criterios de repetitividad y aceptabilidad, adecuado esfuerzo y curvas flujo volumen y volumen tiempo aceptable. Las variables estudiadas fueron $\mathrm{CVF}, \mathrm{VEF}_{1}$ y relación $\mathrm{VEF}_{1} / \mathrm{CFV}$ antes y después del tratamiento. El análisis estadístico es descriptivo, con medidas de desviación y tendencia central, así como $\chi^{2}$ y t de Student. Resultados: Se incluyeron 56 pacientes, $60 \%$ hombres y $40 \%$ mujeres, promedio de edad de 9.9 años. Se encontró mejoría 
significativa en el VEF1 a los 6 meses comparado con la espirometría basal, ( $\mathrm{p}=0.012$ ), la CVF también presentó un cambio significativo ( $\mathrm{p}=0.003$ ); asimismo, la relación VEF1/CVF también mostró mejoría significativa $(\mathrm{p}=0.000)$. Se demostró resolución de la obstrucción en el $100 \%$ de los pacientes. También se observó mejoría en la saturación de oxígeno ( $p=0.001$ ). Conclusión: Se encontró mejoría significativa en todos los parámetros espirométricos, posterior al tratamiento con esteroides inhalados durante un período de 6 meses, desconocemos si esta misma mejoría pueda alcanzarse en un período de tiempo menor. No hubo correlación entre la mejoría en la función pulmonar y el tipo de tratamiento utilizado. La espirometría es una herramienta valiosa y objetiva para evaluar la respuesta al tratamiento y el control de los niños con asma.

\section{Aplicación de un proyecto pedagógico basado en competencias a los tópicos educativos de las Guías de Rehabilitación Pulmonar de la ARS/ETS para mejorar la calidad de vida de pacientes con EPOC}

\section{Paredes GE, Hernández SA}

Hospital General de México

Introducción: En la actualidad son bien conocidos los beneficios de los programas de rehabilitación pulmonar, en publicaciones previas los resultados del componente educativo por sí solo han sido variables. Aunque es importante resaltar que las mismas no describen si se ha aplicado algún diseño que considere las características de la población adulta, lo cual es determinante en la obtención de resultados. En este trabajo se presentan los resultados de la intervención educativa motivo de la maestría en educación, basados en los principios de la andragogía que considera un clima educativo que favorezca las exigencias de la forma de aprendizaje del adulto, creando un perfil deseable en las características del profesor, del estudiante, del programa, de los objetivos, del contenido y las estrategias de aprendizaje. Objetivos: Evaluar los resultados de un programa de educación en pacientes con EPOC. Material y métodos: Se desarroló el diseño de un programa basado en competencias a los tópicos que señalan las Guías de Rehabilitación Pulmonar de la ARS/ERS, en pacientes con EPOC con la finalidad de conocer su impacto en los síntomas y calidad de vida para lo cual se aplicaron las siguientes evaluaciones antes y después del programa: Cuestionario CAT, Escala HAD, MRCm. Resultados: Se incluyeron 8 pacientes con EPOC, 4 hombres, edad promedio de 63 años, 7.5 años de escolaridad. Mejoría de puntaje CAT 1.87, mejoría de escala MRCm 0.45, Dominio ansiedad en escala HAD mejoría 1.8 puntos, dominio depresión mejoría de un punto. Conclusión: El aprendizaje en la adultez tiene una base teórica que articula las experiencias adquiridas con la experiencia momentánea y con una forma específica de conceptualización, es decir, que cuando el sujeto adulto aprende emplea las diferentes formas del pensamiento que ha construido con anticipación: motora, perceptiva, concreta, práctico-formal, por lo que la mejoría en la calidad de vida en los pacientes en este estudio piloto es reflejo de un diseño pertinente a esta población.

\section{Diferencias en la amplitud de respiración torácica y abdominal ante estrés psicológico entre hombres y mujeres con insuficiencia cardiorrespiratoria}

Figueroa HFA, Pérez CE, Peláez $H V$, Torres MS, Robles UB, Orea TA, Domínguez TB, González ID, Verdeja VL, Jiménez CAG, Navarrete PAG, Sánchez SRN, Pérez CGK

INER Ismael Cosío Villegas; Universidad Nacional Autónoma de México

Introducción: Pacientes con insuficiencia cardiorrespiratoria (ICR) presentan un patrón de respiración anormal. Para mejorar- lo, la respiración abdominal es usada para regular el sistema cardiorrespiratorio. $\mathrm{La}$ función respiratoria se comporta y modifica de forma similar ante estrés psicológico y físico igualmente este tipo de respiración. Pero difiere en mujeres sanas, presentando limitaciones pulmonares durante ejercicio intenso. Sin embargo, no se ha reportado si existen diferencias entre género y patrón respiratorio en pacientes con ICR. Objetivos: Comparar la amplitud abdominal y torácica de respiración entre hombres y mujeres con ICR ante estrés psicológico. Material y métodos: Participaron 32 pacientes con ICR, 20 mujeres (M) (edad media $69.10 \pm 13.47)$ y 12 hombres $(H)($ edad media $67.08 \pm 16.74)$. Se aplicó un perfil de estrés psicofisiológico de tres fases de 5 min cada una: 1) Línea base (LB), 2) Estresor aritmético (EA) y 3) Recuperación (R), en el que se midió la amplitud torácica (AmpTo), abdominal (AmpAb) y se calculó la diferencia entre éstas (AB-To). Se realizó U de Mann-Whitney. Resultados: Existen diferencias en mujeres con menor AmpTo, AmpAb y AB-To en comparación con hombres. AmpToLB: M: $0.466 \pm 0.250$; $\mathrm{H}: 1.316 \pm 0.949(\mathrm{z}=-3.231, \mathrm{p}<0.05)$. AmpToEA: M: $0.456 \pm 0.329$; H: $0.820 \pm$ 0.424 ( $\mathrm{z}=-2.647, \mathrm{p}<0.05)$. AmpToR: M: $0.442 \pm 0.227 ; \mathrm{H}: 1.214 \pm 0.994(\mathrm{z}=-2.413$, p < 0.05). AmpAbLB: M: $0.504 \pm 0.517$; $\mathrm{H}: 1.587 \pm 1.036(\mathrm{z}=-3.426, \mathrm{p}<0.05)$. AmpAbEA: M: $0.427 \pm 0.356 ; \mathrm{H}: 1.271$ $\pm 0.595(\mathrm{z}=-3.737, \mathrm{p}<0.05)$. AmpAbR: M: $0.494 \pm 0.504$; $\mathrm{H}: 1.467 \pm 0.813(\mathrm{z}=$ -3.464, p < 0.05). AB-ToLB: M:- $0.639 \pm$ $0.759 ; \mathrm{H}:-2.903 \pm 1.472(\mathrm{z}=-4.282, \mathrm{p}<$ 0.05). AB-ToEA: M: $-0.029 \pm 0.401$; H: $0.451 \pm 0.699(\mathrm{z}=-2.297, \mathrm{p}<0.05)$. ABToR: M: $0.017 \pm 0.441$; H: $0.253 \pm 1.298$ ( $\mathrm{z}=-1.985, \mathrm{p}<0.05$ ). Conclusión: Las mujeres tienen mayor respiración torácica y menor amplitud respiratoria que impacta la recuperación ante estrés psicológico y su salud. Aporte a la práctica clínica diaria: Identificar grupos vulnerables al estrés psicológico.

\section{Respuesta terapéutica existente entre la penicilina sódica cristalina y la cefotaxima en el}




\section{tratamiento de la neumonía en la edad pediátrica}

\section{García CNG, Moreno CV, Benítez CAI}

IMSS/Hospital Puebla

Introducción: La neumonía adquirida en la comunidad (NAC) es una de las causas infecciosas más frecuentes de morbimortalidad a nivel mundial. Se reportan entre 140 a 160 millones de episodios nuevos con un $8 \%$ de hospitalización; la tasa anual es de 270 por 100,000 , principalmente en la población de los lactantes menores de 2 años de edad y una letalidad promedio del $4 \%$ en los pacientes hospitalizados, y menos de $1 \%$ en los ambulatorios. Dentro del grupo de los antibióticos, la penicilina debe ser el antibiótico de primera elección en aquellos niños que previamente se encontraban sanos, con esquema de vacunación al corriente, con una neumonía de leve-moderada en quien se sospecha neumonía bacteriana, ya que este antibiótico tiene acción antibacteriana contra $S$. pneumoniae que es el patógeno que se encuentra como causante de la mayoría de las neumonías en menores de 5 años. Objetivos: Comparar la respuesta terapéutica que existe entre la penicilina sódica cristalina $v s$. cefotaxima en menores de 5 años en el tratamiento de la NAC. Material y métodos: El estudio se llevó a cabo en el Hospital General Regional No 36, IMSS, Puebla, dentro del área de Neumología Pediátrica. Es un estudio comparativo, prospectivo, experimental, homodémico, longitudinal. Se utilizó estadística descriptiva con medidas de tendencia central y estadística inferencial: $\mathrm{T}$ de Student para variables numéricas $\mathrm{y}$ $\chi^{2}$ para variables nominales. Se considera valor de $\mathrm{p}$ significativo $<0.05$. Criterios de inclusión: Derechohabientes, rango de edad de 1 mes-5 años, con diagnóstico de neumonía, en tratamiento con penicilina sódica cristalina o cefotaxima. Criterios de exclusión: Uso de antibióticos previamente, neumonía complicada, pacientes fuera de rango de edad. Resultados: En el período comprendido de noviembre de 2014 a marzo de 2015 se analizó un total de 60 pacientes hospitalizados en el Servicio de Neumología Pediátrica menores de 5 años portadores de NAC y se subdividieron para la administración de tratamiento antibiótico: $50 \%$ (30 pacientes) con penicilina sódica cristalina y $50 \%$ (30 pacientes) con cefotaxima. Al ingreso se encontró: En el grupo de penicilina sódica cristalina se encontró predominio de sexo masculino, mientras que en el de cefotaxima se encontró predominio de sexo femenino. Al ingreso: Fiebre: Grupo 1: 25 (83\%), grupo 2: 24 $(80 \%), p=0.23$. Oxemia anormal: grupo 1 : $29(97 \%)$, grupo 2: $27(90 \%) \cdot p=0.30 . \mathrm{DR}$ : $100 \%$ de ambos grupos. Taquipnea: grupo 1: 29 con taquipnea (97\%), grupo 2: 28 (93\%), $\mathrm{p}=0.30$. A las 48 hrs: Fiebre: grupo 1: 17 (57\%), grupo 2: 14 (46\%), p = 0.30. Oxemias en ambos grupos: 26 anormales (87\%), $\mathrm{p}=0.64$. DR grupo $1: 16$ con DR (54\%), grupo 2 con DR 19 (63\%), $\mathrm{p}=0.3$. Taquipnea: grupo 1: 13 (43\%), grupo 2: 12 (40\%), $\mathrm{p}=0.5$. Conclusión: De acuerdo al estudio que realizamos en nuestro hospital existió una buena respuesta terapéutica a la administración de penicilina sódica cristalina contra cefotaxima en mayores de 5 años en el manejo de las NAC. Definiendo como una buena respuesta la desaparición de los síntomas (fiebre y dificultad respiratoria). Por lo que dado su menor costo y efectividad se justifica su uso en este tipo de pacientes de primera instancia antes de optar por tratar con cefalosporina de tercera generación. Aporte a la práctica clínica diaria: En nuestra institución prevalece el uso de antibióticos en este caso penicilina sódica cristalina y cefotaxima de manera irracional en el manejo de las NAC debido a que se cree que la resistencia antimicrobiana se encuentra presente en la mayoría de los patógenos productores de esta enfermedad. En el presente trabajo se valoraron variables clínicas tales como fiebre, oxemia, dificultad respiratoria así como taquipnea y no se encontraron diferencias significativas en el análisis estadístico que se llevo a cabo.

\section{Simpatectomía toracoscópica tratamiento definitivo con sudoración compensatoria a otras áreas corporales,}

seguimiento a 2 años en el
Hospital Central Militar

Payro HLE

Hospital Central Militar

Introducción: La hiperhidrosis afecta casi al 3\% de la población en las actividades profesionales perjudican la calidad de vida, manifestándose como fobia social, el concepto de hiperhidrosis refiere la sudoración excesiva que el organismo produce por el calor o estímulos emocionales que superen los estímulos fisiológicos. Los síntomas asociados como la fiebre, sudoración nocturna excesiva, la pérdida de peso, las linfadenopatías, la cefalea o palpitaciones, debe alertar al médico clínico sobre la existencia de posibles causas secundarias, el examen físico debe estar dirigido para tratar de confirmar el patrón de distribución del sudor excesivo. La hiperhidrosis primaria o idiopática es típicamente focal y limitada a axilas, palmas de las manos y plantas de los pies, área cráneo-facial y tras regiones, específicas, acompañadas o no de infecciones cutáneas y mal olor. Objetivos: Dar a conocer las complicaciones inmediatas y tardías que se presentan en el posquirúrgico la simpatectomía o simpatectomía por toracoscopia. Material y métodos: Estudio prospectivo, descriptivo, observacional (enero 2014-enero 2017) en el Hospital Central Militar, de la Ciudad de México, en el Servicio de Cirugía Cardiotorácica, se realizaron 33 procedimientos de simpatectomía toracoscópica $(n=33)$ para tratamiento de la hiperhidrosis primaria, con seguimiento a dos años para conocer la sudoración compensatoria en forma permanente a otras áreas. Los procedimientos se realizaron de enero de 2014 a enero de 2015, y el seguimiento posoperatorio durante los dos años siguientes a su intervención, arrojando los siguientes resultados. Presentación del caso: 33 casos de hiperhidrosis tratados mediante toracoscopia quirúrgica bilateral para la sección de la cadena simpática de T2-T4, mediante seguimiento a dos años en el Hospital Central Militar detectándose las complicaciones de sudoración compensatoria a otras áreas del la superficie corporal. Resultados: De los 33 pacientes 
operados, 18 (54.5\%) fueron varones y 15 $(45.4 \%)$ mujeres. Presentando las siguientes complicaciones: Inmediatas: dolor incisional y retroesternal, exacerbado por la tos e inspiración profunda, en 18 pacientes (54\%). $10(55.5 \%)$ hombres y 8 mujeres $(53.3 \%)$, el cual reduce a los 14 días posoperatorios controlado con analgésicos y antiinflamatorios. Crónicas: sudoración compensatoria, $28(84.8 \%)$ pacientes, de los cuales 15 (53.5\%) hombres, 13 (46.4\%) mujeres presentaron sudoración excesiva en espalda y 3 de ellas presentaron adicionalmente en muslos y piernas. Una mujer presentó sudoración palmar izquierda, que remitió en 8 meses de manera espontánea. La complicación más importante de la simpatectomía es la sudoración refleja posquirúrgica severo. Sin embargo, en esta serie de casos no se presentó dicha complicación. Conclusión: Aun cuando se tenga determinado número de complicaciones controlables, es preferible elegir y recomendar este tratamiento definitivo y permanente para disminuir las molestias que dentro del Servicio de las Armas puede constituir, más allá de los problemas de relación social. La simpatectomía torácica mediante toracoscopia bilateral, se ha consolidado como una técnica efectiva, permanente y segura.

\section{Tumor fibroso solitario con invasión endobronquial, origen intraparenquimatoso}

\section{Lazcano HE, Zamora LD, Rayas RD, Vacio OAJ, Alamo HV, García BEM}

\section{CMN SXXI}

Introducción: El tumor fibroso solitario tiene una aparición $98 \%$ de origen pleural, la gran división otorga pronóstico en típicos y atípicos lo que otorga grado de malignidad cuyo pronóstico es directamente proporcional a su atipia influyendo en la resecabilidad por grado de invasión. Objetivos: Describir el infrecuente caso clínico de tumor fibroso solitario intraparenquimatoso con invasión bronquial. Presentación del caso: Femenino de 65 años de edad. Inicia en octubre del 2016 con disnea MMRcl a 3 en 4 meses, tos y sibilancias que no ceden a tratamiento. $L a$ exploración física: ruidos respiratorios disminuidos subescapulares. Radiografía de tórax evidencia de dos radiopacidades hiliares voluminosas con extensión basal de bordes definidos. Se corrobora con TAC imágenes sólidas en proyecciones de lóbulos inferiores, derecha de 6.6 x $6.7 \mathrm{~cm}$ con invasión hiliar, infiltración al bronquio intermediario, principal derecho y tráquea. La menor izquierda sólida de 2.6 x $2.3 \mathrm{~cm}$. Broncoscopia evidencia tumor en tercio inferior de la tráquea, obstruye $95 \%$, se reseca de urgencia con técnica combinada, rígida y flexible se deja permeabilidad de la tráquea $100 \%$, bronquio principal derecho $100 \%$, bronquio de lóbulo superior $100 \%$, bronquio intermediario $100 \%$. La porción de tumor extraída 5 x 1.5 x $1.5 \mathrm{~cm}$ longitudinal, irregular, lobulado, blanquecino. El reporte de patología evidencia tumor fibroso solitario intraparenquimatoso patrón hemangiopericitoide. Comentario: Es extremadamente escasa la literatura en relación al tumor fibroso solitario endobronquial origen parenquimatoso. Se han reportado tres casos, en UCLA por el Dr. Peter S et al. en 2010, en el Hospital Universitario de Shangai por Wenyong et al. en 2015 y en el Hospital Universitario Kunming en China por Quiong et al., también en 2015. Resecabilidad endobronquial y resolución de la urgencia de un tumor con comportamiento atípico. Conclusión: Un reporte de caso y primero en México descrito. Aporte a la práctica clínica diaria: La posible aparición de tumores voluminosos de aspecto pleural, pero origen pulmonar con capacidad de invasión endobronquial.

Prevalencia y asociación entre asma y obesidad en pacientes pediátricos del Hospital General Regional Número 36 del Instituto Mexicano del Seguro Social

Moreno CV, Anacleto VGJ, Méndez MS

IMSS/Hospital Puebla
Introducción: Encontramos una asociación entre asma y estado nutricional, los pacientes no controlados fueron aquéllos con un estado nutricional de obesidad grave. Por lo que estos pacientes deben llevar un seguimiento del estado nutricional para mejorar el control del asma. El asma es definida por sus características clínicas, fisiológicas y patológicas. La obesidad es el exceso de grasa acumulada que afecta a la salud. La obesidad y el asma constituyen serios problemas de salud pública. Objetivos: Determinar la prevalencia y asociación entre asma y obesidad en pacientes pediátricos del Hospital General Regional Número 36 del Instituto Mexicano del Seguro Social. Material y métodos: Diseño de estudio. Observacional, comparativo, prospectivo. Tipo de estudio: descriptivo. Período de estudio: del 1 de agosto al 31 de diciembre de 2014. Lugar donde se desarrolla el proyecto: IMSS HGR 36, Servicio de Neumología Pediátrica. Población: niños con y sin obesidad y asma, con edad de 6 a 15 años, cualquier género. Tamaño de muestra: por conveniencia. Variables: sexo, edad, índice de masa corporal, estado nutricional, control del asma, comorbilidades. Análisis estadístico: descriptivo en el programa SPPS v.21. Resultados: Se obtuvo un total de 150 pacientes, 62 de sexo femenino y 88 de sexo masculino. En cuanto al estado nutricional 41 pacientes con peso normal, 33 con sobrepeso, 57 con obesidad y 19 con obesidad grave. Con edad promedio de 9.01 años, peso promedio $35.94 \mathrm{~kg}$, talla promedio $1.33 \mathrm{~m}$, IMC promedio 19.27, no se encontraron diferencias significativas de acuerdo con el sexo ( $p=0.419)$. Control del asma: 55 pacientes bien controlados (41 no obesos y 14 obesos), 74 parcialmente controlados (30 no obesos y 44 obesos), 21 no controlados (3 no obesos y 18 obesos). Comorbilidades asociadas 98 pacientes con rinitis alérgica, 9 con alergia alimentaria y 44 con rinosinusitis. Conclusión: Encontramos una asociación entre asma y estado nutricional, los pacientes no controlados fueron aquéllos con un estado nutricional de obesidad grave. Por lo que estos pacientes deben llevar un seguimiento del estado nutricional para mejorar el control del asma. 


\section{Asociación de la disfunción ventricular derecha e izquierda en pacientes con enfermedad pulmonar obstructiva crónica}

Belmontes-Barraza JR, González $I D$, Jaime $P$, Orea-Tejeda A, SchalchPonce de León J, Verdeja-Vendrell

$L$, Jiménez-Cepeda A, Pérez-Cortés G, Sánchez-Santillán $R$, Peláez-

Hernández V, Robles-Uribe $B$, Figueroa-Herrera A, Torres-Montiel S

INER Ismael Cosío Villegas

Introducción: La disfunción del ventrículo derecho se asocia con la enfermedad pulmonar obstructiva crónica (EPOC) por sus efectos en la función cardíaca, afectaciones en la vasculatura pulmonar, además estos pacientes tienen mayor riesgo de desarrollar hipertensión pulmonar. Objetivos: Evaluar la asociación entre disfunción ventricular del ventrículo izquierdo y disfunción del ventrículo derecho en pacientes con EPOC. Material y métodos: Estudio trasversal realizado en 20 pacientes. Los criterios de inclusión: pacientes mayores de 18 años de edad, con diagnóstico confirmado de EPOC. Se excluyó a los pacientes son síndrome de sobreposición. Para la recolección de la información se revisó la historia clínica. La valoración de función biventricular se realizó mediante ventriculografía radioisotópica. El análisis estadístico se realizó mediante regresión lineal múltiple. Resultados: Del total de la población, 6 pacientes tuvieron disfunción del ventrículo derecho, la media de edad fue de 62.3 \pm 17.28 años. No se observaron diferencias estadísticamente significativas en las comorbilidades. Aquéllos con disfunción del ventrículo derecho tuvieron mayor volumen diastólico del ventrículo $(\beta=$ 38 milímetros 95\% IC 11.41 a 64.94, $\mathrm{p}=$ 0.009) que los sujetos sin disfunción del ventrículo derecho. Conclusión: Los pacientes con disfunción del ventrículo derecho tuvieron mayor volumen diastólico del ventrículo izquierdo que en los sujetos sin falla ventricular derecho. Aporte a la práctica clínica diaria: Permite espe- cular que el riesgo elevado de disfunción derecho en los pacientes con EPOC está íntimamente relacionado a la función del ventrículo izquierdo.

\section{Evaluación de la} composición corporal en los pacientes con hipertensión pulmonar en
pacientes con EPOC

González ID, Navarrete-Peñaloza

A, Orea-Tejeda A, Jiménez-Cepeda

$A$, Verdeja-Vendrell L, Pérez-Cortés

G, Castillo LF, Sánchez-Santillán R, Peláez-Hernández V,

Figueroa-Herrera A, Torres-Montiel S, Robles UB

INER Ismael Cosío Villegas

Introducción: Los sujetos con enfermedad pulmonar obstructiva crónica (EPOC), presentan de manera característica disminución de masa muscular la cual se relaciona a peor pronóstico. En los pacientes con EPOC la HP es un predictor de hospitalizaciones por exacerbación, así como de mortalidad. La evaluación de la composición corporal por medio de la bioimpedancia eléctrica por análisis vectorial (BIVA), permite identificar la resistencia $(\mathrm{R})$ y la reactancia $(\mathrm{Xc})$; la primera, tiene una correlación negativa con la masa muscular y/o agua corporal total, mientras que la segunda, correlaciona en forma positiva con la integridad de la membrana celular. Objetivos: Evaluar la composición corporal en los pacientes con EPOC e HP. Material y métodos: Estudio transversal, se reclutaron 102 pacientes mayores de 18 años con diagnóstico de EPOC, los pacientes con asma fueron excluidos. La HP se definió como presión arterial pulmonar de $40 \mathrm{mmHg}$, calculada por ecocardiograma. Resultados: El $51.43 \%$ de la población fueron hombres (edad 72.16 \pm 10.74 años), al comparar la composición corporal de los pacientes con EPOC e HP vs. EPOC sin HP se observó que los primeros tuvieron mayor peso $(89.14 \pm$ vs. 64.6, $\mathrm{p}<0.001)$, IMC $(36.4 \pm 14.2 v s$. $26.6 \pm 5.7, \mathrm{p}<0.001)$, cintura $(113.1 \pm 21$. vs. $94.8 \pm 16.1, \mathrm{p}<0.001)$, así como tercer espacio menor $(-1.18 \pm 3.3$ vs $0.05 \pm 1.5$, $\mathrm{p}=0.05)$, resistencia ajustada por talla $(237 \pm 145$ vs. $388.0 \pm 87.3, \mathrm{p}<0.001) \mathrm{y}$ reactancia ajustada por talla $(44.0 \pm 8.9$ vs. $58.4 \pm 63.4, \mathrm{p}=0.291)$. Conclusión: Los pacientes con EPOC e HP presentan mayor cantidad de tejido adiposo, así como una menor cantidad de masa muscular y una membrana celular con mayor deterioro que los pacientes con EPOC solo. Los cambios en la composición corporal de los sujetos con EPOC e HP podrían explicar una disminución aún mayor de la fuerza muscular, la capacidad funcional y un peor pronóstico de estos pacientes.

\section{Expresión in situ del factor de crecimiento endotelial vascular y de la enzima convertidora de endotelina-1 en un modelo experimental de perfusión pulmonar ex vivo}

Hernández JC, Jasso VR, Olmos ZJR, Vázquez JLF, Baltazares LM, Polo JA, Pérez LMT, Alonso GM, Martínez CJ, Jasso AJ, Martínez SA, Guzmán CA, Gaxiola GM, Silva MM, Patricio-Santillán DP, Rueda JER, Romero $R L$

INER Ismael Cosío Villegas

Introducción: El trasplante pulmonar es la última alternativa de tratamiento en pacientes con enfermedad pulmonar terminal, pero la falta de donadores por diferentes razones, como el edema pulmonar ocasionado por el daño en el endotelio pulmonar asociado a la liberación de mediadores de la inflamación, dificulta su realización. La perfusión pulmonar ex vivo (PPEV) es una técnica que después de la extracción del bloque pulmonar, mediante la reperfusión y ventilación controlada permite la recuperación y trasplante de esos pulmones dañados, pero no se ha estudiado el efecto que tiene sobre la cuantificación de la enzima convertidora de endotelina 1 (ECE-1) y el factor de crecimiento del endotelio vascular (VEGF) en pulmones con 
preservación prolongada. Objetivos: Evaluar el efecto de la PPEV por 4 horas sobre la expresión de ECE-1 y VEGF, cambios fisiológicos e histológicos en pulmones con preservación prolongada. Material y métodos: Se obtuvieron pulmones de 10 cerdos y se sometieron a PPEV por 4 horas de la siguiente manera: grupo I (n = 5): PPEV inmediatamente después de la procuración y grupo II $(n=5)$ : PPEV después de 12 horas de preservación. En todos los casos se evaluó la hemodinamia, gasometría, mecánica pulmonar, cambios macroscópicos, microscópicos, gravimétricos y en la cuantificación de ECE-1 y VEGF. Resultados: En ambos grupos la hemodinamia y gasometría se mantuvieron dentro de los parámetros normales. La distensibilidad disminuyó en ambos grupos ( $\mathrm{p}>0.05$ ANDEVA), Raw, Ppic, Pplateu, se incrementaron en los dos grupos (pero se encontraron dentro de los parámetros de referencia) y la Pmed se mantuvo normal en ambos grupos. Los dos grupos desarrollaron el mismo grado de edema macroscópico, microscópico y gravimétrico. En el grupo I hubo mayor expresión de ECE-1 (p > 0.05 ANDEVA), mientras que el VEGF fue similar en ambos grupos. Conclusión: La PPEV mantiene los parámetros fisiológicos, mecánica pulmonar e histológica, así como la expresión de ECE-1 y VEGF en pulmones sometidos a PPEV con preservación prolongada.

\section{Función hemodinámica, gasométrica y de mecánica pulmonar en} un modelo experimental de sepsis con tres modos ventilatorios como tratamiento único

\begin{abstract}
Guzmán CAE, Jasso VR, Olmos ZR, Hernández JC, Baltazares LM, García TR, González CR, Alonso GM, Gaxiola GM, Santillán DP, Zenteno GE, Vadillo OF, Jasso AJ, Martínez SA, Pérez LF, Cisneros J, Polo JAA, Silva MM, Luna FA
\end{abstract}

INER Ismael Cosío Villegas; UAM-I; UNAM; Inmegen
Introducción: En pacientes con sepsis no siempre se cumplen los criterios de un síndrome de dificultad respiratoria aguda (SIRA), por lo tanto la asistencia mecánica ventilatoria (AMV) es esencial en el manejo de la lesión pulmonar aguda (ALI) producida por la respuesta inflamatoria durante la sepsis; sin embargo, en los lineamientos para el tratamiento de sepsis, no se indica la aplicación preventiva de AMV. Por otra parte, en pacientes con SIRA se han utilizado los modos ventilatorios de ventilación controlada por volumen (VCV) y el modo controlado por presión (VCP), ambas con medidas protectoras, pero no se ha obtenido el éxito deseado ya que no evitan el daño pulmonar producido por sepsis, ni mejorar la supervivencia, por lo que hay que buscar otro modos de AMV que logren esto. El modo AMV de liberación por presión de la vía aérea (APRV) y de alta frecuencia oscilatoria (HFOV) son modos ventilatorios no convencionales que pueden lograr una protección pulmonar. Objetivos: Comparar el efecto que tiene la AMV en modo VCP, APRV y HFOV como único tratamiento sobre los cambios radiográficos, hemodinámicos, gasométricos, mecánica ventilatoria e histológica pulmonar en un modelo porcino con ALI temprano provocado por sepsis. Material y métodos: 15 cerdos con sepsis inducido con lipopolisacárido (LPS) de Escherichia coli, divididos al azar en tres grupos con diferente modo ventilatorio: Grupo I: con ventilación controlada por presión (VCP); Grupo II: con liberación de la presión de vía aérea (APRV). Grupo III: de alta frecuencia oscilatoria (HFOV). A partir de condiciones iniciales de lesión pulmonar, la evaluación de parámetros funcionales e histológicos durante VM como manejo único, se realizó con un análisis medidas repetidas durante seis horas considerando diferencias significativas con una $\mathrm{p}<$ 0.05. Resultados: Hemodinámicamente el grupo III mantuvo mayor estabilidad de la presión arterial media vs. los grupos I y II, mientras la presión media de la arteria pulmonar y la presión de oclusión se incrementaron en los grupos I y II (ANDEVA, p $<0.05)$. La mecánica pulmonar del grupo II mostró distensibilidad dinámica normal (ANDEVA $\mathrm{p}<0.05$ ). Los tres grupos presentaron gasometrías similares; no obstante, el grupo III manifestó mayor incremento en $\mathrm{PaO}_{2}$ y disminución de Lactato (ANDEVA, p < 0.05). Histológicamente los tres grupos desarrollaron congestión y hemorragia pero en menor grado para el grupo III (Kruskal-Wallis, p < 0.05). Conclusión: El modo HFOV muestra ventajas funcionales e histológicas sobre los modos APVR y VCP ya que mantiene mejores valores hemodinámicos, gasométricos y de lactato sérico, así como menor grado de lesiones histológicas, en este modelo experimental de sepsis. Con la evaluación de estos modos ventilatorios se ayuda a la clínica en la preparación y entrenamiento del personal del INER, así como presentar las bases para el tratamiento alterno de ventilación mecánica en el paciente con sepsis.

\section{Remodelación pulmonar y cambios hemodinámicos en un modelo experimental de hipertensión pulmonar: Apoptosis (expresión de caspasa-3act y survivina)}

Baltazares LM, Jasso VR, Baltazares LE, Soto AV, Olmos ZR, Hernández $J C$, Gaxiola GM, Guzmán CAE, Polo JA, Silva MM, Rueda JR, Alonso GM

INER Ismael Cosío Villegas; Instituto

Nacional de Cardiología «Ignacio Chávez»

Introducción: La hipertensión pulmonar (HP) se define como la elevación de la presión media de la arteria pulmonar (PMAP) $>25 \mathrm{mmHg}$ en reposo. Esta elevación es causada por vasoconstricción, trombosis in situ y remodelación vascular. Recién se conoce la relevancia del proceso anormal de la apoptosis en HP. La apoptosis es un mecanismo de muerte celular, donde participan marcadores como caspasa3act y survivina proteína antiapoptótica. Objetivos: Establecer un modelo de HP inducido (MCT), determinar los cambios hemodinámicos y el comportamiento de caspasa-3act y survivina. Material y métodos: Ratas Wistar 250-450 g. Grupo I controles: $\mathrm{n}=10$, Grupo II HP-MCT $\mathrm{n}$ $=10$. Dosis única $80 \mathrm{mg} / \mathrm{kg}$ MCT. Fin de 
estudio 6 semanas. Procedimiento anestesia general, ventilación mecánica y cateterismo. Extracción bloque cardiopulmonar para estudio histopatológico. Clasificación de Heath \& Edwars. Resultados: Hemodinamia: El grupo II mostró (PMAP) elevada $(42.90 \pm 9.04 \mathrm{mmHg})$, grupo I control $(21.2 \pm 4.51 \mathrm{mmHg})$ diferencia significativa entre grupos $(\mathrm{p}<.0003$, prueba t de Student). Histopatológicos: Grupo I control sin alteraciones. Grupo II-HP a) hiperplasia neumocitos tipo II con cambios regenerativos, b) hipertrofia de la media vascular de arterias de mediano calibre aspecto «tela de cebolla», c) pérdida de integridad de láminas elásticas entre fibras de músculo liso de la arteria pulmonar. Evaluación Heath \& Edwars. Grupo II HP con $\mathrm{n}=10$. Grado $0=20 \%$, Grado I $=50 \%$ Grado II $=20 \%$ y Grado III $=10 \%$. Inmunohistoquímica. a) Grupo II HP-MCT se observó sobreexpresión de survivina y disminución de la expresión de caspasa-3act en comparación al grupo I control. Conclusiones: 1. El modelo HP inducido-MCT es eficiente y permite determinar mecanismos fisiopatológicos para establecer nuevos esquemas terapéuticos que involucran la regulación de apoptosis. 2. Los valores de caspasa-3act sugieren que la función apoptótica en HP se encuentra disminuida. 3. La remodelación vascular está ligada a la expresión de survivina y los resultados sugieren su participación en etapas tempranas de HP.

\section{Linfangioleiomiomatosis: Dos casos con presentaciones distintas}

\section{Contreras RFJ, Ortiz-Romero J, Flores-Santiago P, Mendoza-Topete $L A$, Hernández-Gordillo $D$}

Centro Médico Nacional de Occidente, IMSS

Introducción: Linfangioleiomiomatosis (LAM), enfermedad neoplásica rara, predomina en mujeres premenopáusicas, caracterizada por proliferación hamartomatosa de células musculares lisas atípicas a lo largo de linfáticos del pulmón, tórax, abdomen y pelvis. Disnea es el síntoma más común, neumotórax en $80 \%$, recurre hasta 70\%, quilotórax 7-39\%. Esporádica o asociada a esclerosis tuberosa (ET), tiene curso indolente e inexorable, la sobrevida a 10 años es $92 \%$. Sirolimus mejora función pulmonar y calidad de vida. Objetivos: Informar la presentación simultánea de dos casos de LAM con manifestaciones clínicas distintas. Presentación de los casos: Caso 1. Mujer de 38 años, asintomática previa, presenta neumotórax bilateral, se documentó quistes pulmonares bilaterales grandes, difusos, el neumotórax izquierdo resolvió con catéter pleural, hemitórax derecho requirió bulectomía por fístula, histopatología confirmó LAM. Caso 2. Mujer de 49 años, asintomática respiratoria, por estudio abdominal se encuentra fortuitamente derrame pleural izquierdo menor, la toracentesis guiada por US demostró líquido lechoso, el estudio bioquímico confirmó quilotórax, la TAC mostró múltiples quistes pulmonares pequeños, bilaterales, difusos, no adenopatías mediastinales. Presentamos dos casos de LAM esporádica, que se presentan de forma simultánea, con manifestaciones clínicas y radiológicas diferentes, con grado 3 de afección en ambos casos, en el caso de neumotórax los quistes son grandes y más jóvenes comparados con el caso de quilotórax, en serie de diez casos mexicanos de dos instituciones INER-IMSS, el $40 \%$ presenta quilotórax y $60 \%$ neumotórax, afección tomográfica grado 3 en $60 \%$, el resto grado 2 . La asociación con ET fue en $20 \%$. Estos casos se suman a la casuística descrita. Se inició tratamiento con sirolimus, actualmente en seguimiento. Conclusión: LAM afecta a mujeres jóvenes, las manifestaciones clínicas y radiológicas son variadas, el neumotórax es la manifestación más frecuente, el diagnóstico es tardío cuando se mide por grado de afección tomográfica. Aporte a la práctica clínica diaria: Expone dos formas distintas de expresión clínica de la misma enfermedad.

\section{Histiocitoma fibroso} maligno en tórax infiltrante a pulmón, a propósito de un caso

Camacho FR, Gordillo MJA, Vargas

\section{$A B$, Pérez RA, Garduño BJ, López ZDF, Cicero $S R$}

\section{Hospital General de México «Dr. Eduardo Liceaga»}

Introducción: El histiocitoma fibroso maligno (HFM) es el segundo sarcoma de partes blandas más frecuente, comparado con los indiferenciados. Procede de las células mesenquimales pluripotenciales, capaces de diferenciarse hacia histiocitos, fibroblastos y miofibroblastos, con alto grado de malignidad. La edad promedio es 45 años. Se presentan en extremidades inferiores, en corazón derecho, causando síntomas y signos relacionados con congestión pulmonar, estenosis mitral y obstrucción de vena pulmonar. Es raro como neoplasia pulmonar. También pueden presentarse con metástasis pulmonares, linfáticas, renales y cutáneas. Presentación del caso: Masculino de 46 años de edad. Inició padecimiento en noviembre de 2015 con diaforesis nocturna y tos productiva, que posteriormente fue amarilla y hemoptoica. Un mes después con ataque al estado general, dolor torácico opresivo de intensidad 5 de 10 en hemitórax derecho. Perdió $8 \mathrm{~kg}$ en 4 meses. A la exploración física, síndrome de consolidación pulmonar derecho. Tomografía de tórax con tumor en lóbulo medio con comunicación hacia hemidiafragma ipsilateral. Gammagrama óseo normal. Se realizó lobectomía media y rafia diafragmática por defecto de $6 \mathrm{~cm}$. Histología con lesión fusocelular de alto grado. En parénquima pulmonar áreas extensas de necrosis e inflamación aguda abscedada, anticuerpo positivo CD68, vimentina. Conclusión: El HFM es raro en México, excepcionalmente localizado torácicamente, ya sea como metástasis o como primario. Resecarlos es el tratamiento más utilizado, en este caso lobectomía. La quimioterapia y radioterapia adyuvante son indicadas ocasionalmente. También llamado sarcoma pleomórfico de alto grado, tiene mortalidad entre $65-75 \%$ dentro de los 2 años siguientes al diagnóstico, tanto por enfermedad recurrente como metastásica. El indicador pronóstico más significativo es el estado avanzado de la enfermedad al momento del diagnóstico. 


\section{Efecto de la pirfenidona sobre la expresión de TGF- $\beta 1$, fibronectina y deposición de colágena en la cicatriz postraqueoplastía. Estudio experimental}

Olmos ZJR, Silva-Martínez M, Jasso-Victoria R, Baltazares-Lipp $M$, Briones-Torres D, Hernández-Jiménez C, Buendía-Roldan I, Calyeca-Gómez J, Gaxiola-Gaxiola M, Guzmán-Cedillo $A$, Santillán-Doherty $P$

INER Ismael Cosío Villegas; Facultad de Ciencias, UNAM

Introducción: La estenosis traqueal (ET) se produce por una inflamación prolongada que ocasiona incremento en la expresión del factor de crecimiento transformante beta 1 (TGF- $\beta 1$ ), fibronectina (Fibro) y deposición de colágena (DC). Su tratamiento es con procedimientos endoscópicos y resección y anastomosis terminoterminal del segmento afectado (traqueoplastía), solos o en combinación con la aplicación de moduladores de la cicatrización (MDC), pero no se ha logrado evitar la reestenosis, por lo que es necesario buscar MDC que la eviten. La pirfenidona (PIRFE) y colágeno polivinil pirrolidona (CPVP) disminuyen la fibrosis, por lo que su uso poscirugía podría evitar las ET. Objetivos: Evaluar los cambios en la expresión de TGF- $\beta 1$, Fibro y DC en la cicatriz postraqueoplastía de ratas tratadas con PIRFE y CPVP. Material y métodos: Cuarenta ratas Wistar con traqueoplastía cervical, divididas en 4 grupos $(\mathrm{n}=10)$, fueron tratadas con: Grupo I: SSF, Grupo II: CPVP, Grupo III: Mitomicina C, Grupo IV: 40 mg/kg PIRFE. Se valoró la cicatrización macroscópica y microscópica, expresión de TGF- $\beta 1$, Fibro y DC. Resultados: Los animales tratados con CPVP y PIRFE desarrollaron menor estenosis, inflamación y fibrosis que los otros grupos de estudio ( $\mathrm{p}<0.05$ Kruskal Wallis) y menor expresión de TGF- $\beta 1$, Fibro y DC que el grupo I ( $p<0.05$ ANDEVA, Tukey). Conclusión: La PIRFE y la CPVP disminuyen la inflamación, fibrosis, expresión de TGF- $\beta 1$, Fibronec- tina y deposición de colágena en la cicatriz postraqueoplastía de ratas.

Neumonitis grave secundaria a toxicidad por nivolumab en cáncer pulmonar avanzado. Presentación de caso y revisión de la literatura

\section{Herrera OMI, Sánchez RCP, Alatorre $A J$, Rodríguez CJ}

INER Ismael Cosío Villegas

Introducción: El cáncer de pulmón es la primera causa de muerte por cáncer a nivel mundial. El avance en el conocimiento de esta enfermedad ha permitido el desarrollo de nuevos tratamientos como la inmunoterapia. Nivolumab ha mostrado ser superior a la quimioterapia e incluso recién en pacientes que sobreexpresan PD-L1 en más del $50 \%$ del tumor con la clona 22-C3. Presentamos el caso de una mujer con diagnóstico de adenocarcinoma pulmonar estadío clínico IV (EC IV) con neumonitis grave con adecuada respuesta a esteroide. Objetivos: Describir el curso clínico de la neumonitis inmunomediada secundaria a nivolumab en cáncer pulmonar de células no pequeñas. Presentación del caso: Mujer de 41 años de edad. Tabaquismo y exposición a biomasa negados. Adenocarcinoma pulmonar EC IV. A las 72 horas posteriores a 2 do ciclo con nivolumab presenta astenia, progresión de la disnea y aumento de requerimiento de oxígeno. Requirió ventilación mecánica no invasiva. Paraclínicos con neutrofilia y procalcitonina negativa. Imágenes tomográficas de llenado alveolar bilateral. Broncoscopia con cultivos negativos. Ante la sospecha de neumonitis inmunomediada inicia manejo con esteroide. Se egresa por mejoría con suspensión de tratamiento anti PD1. El diagnóstico oportuno de la toxicidad pulmonar inmunomediada y el tratamiento temprano con corticoesteroides permite un control adecuado de la neumonitis secundaria a nivolumab. Conclusión: A pesar de que se han producido avances significativos en el tratamiento del CPCNP con estos nuevos tratamientos, las inmunoterapias cuentan con un perfil de toxicidad diferente a los otros tratamientos sistémicos oncológicos, cobrando importancia los efectos adversos «inmunomediados». De ellos, la neumonitis se ha reportado con frecuencia del $1 \%$ al $2 \%$ y aún más baja mortalidad. Aporte a la práctica clínica diaria: El diagnóstico oportuno de la toxicidad pulmonar inmunomediada y el tratamiento temprano con corticoesteroides permiten un control adecuado de esta complicación tal como se demostró en el presente caso.

\section{Manejo quirúrgico del cáncer de pulmón de células no pequeñas en un centro de referencia de tercer nivel}

Carranza MI, Carranza SJ, Iñiguez GM

INER Ismael Cosío Villegas

Introducción: El cáncer de pulmón es la primera causa de mortalidad mundial. En nuestro país según estadísticas del INEGI en el año 2015 se registraron 6,874 defunciones por cáncer de pulmón. La tasa de sobrevida disminuye conforme el estadío clínico (EC), siendo ésta hasta del $48 \%$ a cinco años para EC I-II contra el $4.8 \%$ para aquéllos no candidatos a manejo quirúrgico. Objetivos: Analizar la población con diagnóstico de cáncer de pulmón de células no pequeñas (CPCNP) que fueron intervenidos quirúrgicamente con intento curativo dentro del Servicio de Cirugía Torácica en el Instituto Nacional de Enfermedades Respiratorias. Material y métodos: Se revisaron los expedientes de aquellos pacientes con diagnóstico de CPCNP operados de resección anatómica mayor con intento curativo del 2010 al 2015, posteriormente se realizó un análisis demográfico y de sobrevida a mediano plazo de los mismos. El presente es reporte preliminar de hallazgos. Resultados: Cuarenta y cinco pacientes; $25(55 \%)$ femenino y 20 (45\%) masculino, con una edad promedio 59 años. El $48 \%$ (22) eran sanos y la comorbilidad más frecuente fue la hipertensión arterial $24 \%$ (11). El $48 \%$ eran fumadores activos con 
un índice tabáquico promedio 31.8 (1-108) cajetillas/año. El 22\% ingresó como nódulo pulmonar solitario y el síntoma principal que detonó buscar atención médica fue hemoptisis (35\%), tos crónica (15.5\%) y dolor torácico $(15.5 \%)$. Se realizó lobectomía en $71 \%$ (32) de los pacientes. Con una sobrevida global a los 3, 12 y 21 meses de $69 \%$, $58 \%$ y $38 \%$. La sobrevida por EC Ia, Ib, IIa, IIb, IIIa, IIIb y IV fue para los doce meses $50 \%, 25 \%, 60 \%, 55 \%, 75 \%, 50 \%$ y $80 \%$. Y para los 36 meses 16\%, 25\%, 20\%, 22\%, 0\%, 25\% y 0\%. Conclusión: El CPCNP es una patología de alto impacto para el país, no sólo por ser una enfermedad letal al diagnosticarse en estadíos avanzados, sino porque un adecuado tamizaje permite el diagnóstico temprano para ofrecer tratamientos quirúrgicos curativos.

\section{Presentación atípica de adenocarcinoma pulmonar en mujer no fumadora}

\section{Abundis CR, Castro RA \\ IMSS}

Introducción: El cáncer de pulmón se encuentra dentro de las principales causas de muerte en México, con incidencia de 224,390 casos nuevos. De todos los casos el adenocarcinoma es el $76 \%$ de los casos. Objetivos: Evaluar los diferentes factores de riesgo para adenocarcinoma fuera de tabaquismo. Presentación del caso: Se presenta paciente femenino de 35 años de edad que es enviado a nuestra unidad sin antecedentes de importancia, sin tabaquismo, dedicada al hogar y sin enfermedades conocidas. Inicia su cuadro hace 1 año con acceso de tos sin expectoración, no disneizante ni emetizante que se manejó de manera sintomática con mejoría parcial de su cuadro, 3 meses previos a su internamiento se agrega expectoración blanquecina y disnea, se envía con el diagnóstico de proteinosis alveolar por los hallazgos tomográficos de patrón intersticial vidrio despulido bilateral con áreas de mosaico así como engrosamiento septal interlobular e interlobulillar, se realiza broncoscopia con lavado bronquioalveolar y biopsias transbronquiales las cuales dan como diagnóstico adenocarcinoma pulmonar moderadamente diferenciado con patrón papilar. Resultados: Adenocarcinoma moderadamente diferenciado con patrón papilar napsina A y Ca15-3 (+). Conclusión: En los inicios el 90\% de los casos se atribuyeron al tabaquismo, actualmente se estima que el $25 \%$ de los casos ocurren en sujetos nunca fumadores, en quienes se considera una etiología multifactorial. De los factores más importantes actualmente se encuentran las mutaciones al receptor del factor de crecimiento epidérmico que más comúnmente se presente en no fumadores, ya que no se conoce por completo la fisiopatología del cáncer en pacientes sin factores de riesgo, será necesario en un futuro evaluación genética como parte de protocolo diagnóstico. Es el nuevo reto en la actualidad y la medicina del futuro. Aporte a la práctica clínica diaria: $\mathrm{La}$ necesidad de realizar estudios moleculares como parte del estudio a todo paciente con patología pulmonar como diagnóstico de exclusión.

\section{Hemangioendotelioma pulmonar: Reporte de un caso}

\section{Tabarez CE}

IMSS HG CMNR

Objetivos: Identificar datos clínicos como radiológicos del diagnóstico para mejorar oportunamente su diagnóstico. Presentación del caso: Masculino de 32 años, sin antecedentes de importancia. Posterior a traumatismo contuso de tórax en noviembre 2015 (garrafón de agua), el 16/12/16 (3 semanas posteriores), al estar laborando, durante un esfuerzo físico presenta dolor torácico súbito en hemitórax izquierdo (pleurítico), intenso 9/10, acompañado de disnea MMRC 3. Por lo anterior acude a su HGZ. Se administra AINE, sin mostrar mejoría. Se detecta derrame pleural izquierdo que se aborda con toracocentesis diagnóstica obteniendo líquido pleural de características hemáticas. Se coloca sonda endopleual (18/12/17), con un gasto de 2700, acompañado de disminución de hemoglobina 3 gr. Antecedente de síndrome febril el cual se adjudica a patología pleural manejado con: clindamicina/ceftriaxona (15 días), meropenem (5 días), la sonda se retira en forma incidental (02/01/16), persiste radiopacidad homogénea inicial en hemitórax izquierdo, se ingresa a tercer nivel para valorar tratamiento quirúrgico, el cual se realiza (25/01/16) con hallazgos: drenaje de cavidad, aseo quirúrgico y pleurotomía abierta y ventana pleuropulmonar izquierda, datos de carnificación diseminada en cavidad. Se toman biopsia, la cuales se reportan con neoplasia maligna de probable estirpe epitelial, probable hemangioendotelioma epitelioide. Durante su estancia intrahospitalaria persiste con evolución tórpida, síndrome febril, dolor torácico pleurítico. Resultados: Biopsia pleural quirúrgica con reporte de neoplasia maligna de probable estirpe epitelial, probable hemangioendotelioma epitelioide. Inmunohistoquímica TTF-1 NAPSINA A, MOC31 negativos, WT-1 positivo nucleal con intensidad de $+++/+++$ Calretinina negativo, CK5/6 negativo, mamoglobina negativo, CD31 positivo citoplasma con intensidad de +/+++, CD34 negativo, Hgc NEGATIVO, AFP negativo, Factor VII negativo. Conclusión: El caso clínico tiene un diagnóstico, se realiza en forma incidental, enmascarado por patología traumática, siendo una entidad no frecuente de difícil diagnóstico. Aporte a la práctica clínica diaria: Llevar una certeza diagnóstica con la experiencia mostrada en este paciente.

\section{¿La presencia de autoinmunidad confiere características clínicas diferentes al síndrome combinado (fibrosis pulmonar/enfisema)?}

Buendía-Roldán I, Alarcón DEA, Barreto RJO, Martínez-Espinosa KP, Mateos-Toledo H, Rojas-Serrano J, Estrada GA, Castillo PJ, Mejía ÁM

INER Ismael Cosío Villegas

Introducción: El síndrome combinado (SC) definido como asociación de fibrosis pulmonar/enfisema, entidad relacionada al tabaquismo, recién se ha asociado con 
la presencia de autoinmunidad. Objetivos: Identificar diferencias entre el SC con y sin autoinmunidad (SCCA y SCSA). Material y métodos: Estudio retrospectivo, observacional y descriptivo de la cohorte de pacientes referidos al INER para inclusión en protocolos de tratamiento compasivo, del 2012-2016, identificamos pacientes con $\mathrm{SC}$ a los cuales se les realizó un panel de autoinmunidad para descartar causas secundarias. Resultados: Se identificaron 14 sujetos con SC, 50\% presentaron marcadores de autoinmunidad sin cuadro sistémico inicial, 3 con factor reumatoide positivo a títulos altos, 2 con anticuerpos de esclerodermia, 1 anti-Ro positivo y 1 con IPAF; ambos grupos mostraron neumonía intersticial usual (NIU) en la tomografía, el grado de afección de fibrosis fue similar, no así la afección por enfisema que fue mayor en SCCA $(\mathrm{p}=0.04)$. El género masculino fue de $86 \%$ en SCCA vs. $100 \%$ en SCSA. La exposición al tabaco se presentó en el $100 \%$ en ambos grupos pero la intensidad del mismo no mostró diferencias significativas. En las pruebas de función respiratoria en SCSA 2 pacientes (29\%) presentaron obstrucción, el intercambio gaseoso fue similar en ambos grupos, sin embargo, en la caminata de 6 minutos en SCSA muestra una mejor recuperación al ejercicio ( $p=0.007)$. Conclusión: En el SC se han identificado diferentes grupos con pronósticos variables, se ha considerado que la presencia de autoinmunidad se asocia menos con NIU y en el género femenino. Nuestro grupo no mostró este comportamiento, posiblemente sea un sesgo de selección. Se ha reportado que la presencia de marcadores específicos de enfermedad colágeno vascular confiere mejor respuesta al tratamiento. Cuando se comparó la evolución del grupo tratado con antifibrosantes (SCSA) con el tratado con inmunosupresores (SCCA) observamos que la evolución no mostró diferencias. Aporte a la práctica clínica diaria: Optimizar diagnóstico-tratamiento.

\section{Discromatopsia asociada al tratamiento con sildenafil en paciente portadora}

\section{de hipertensión arterial pulmonar. Reporte de caso}

\section{Estrella HM, Ávila HJI, Váldez LHG}

\section{IMSS}

Introducción: La administración oral de los inhibidores de la fosfodiesterasa en el manejo de la hipertensión pulmonar puede producir a nivel retiniano vasoconstricción del músculo liso vascular, generar fibrosis y alteraciones permanentes, ya que es capaz de cruzar la barrera hematoretiniana. Objetivos: Describir la evolución clínica de una paciente en tratamiento con sildenafil, que presentó efecto adverso asociado. Material y métodos: Se recabó información del expediente clínico y gabinete. Presentación del caso: Femenino de 26 años de edad con diagnóstico de conducto arterioso persistente corregido al año 4 meses, sordera secundaria a secuelas de rubéola congénita diagnosticada a los 2 años, estrabismo diagnosticado desde los 3 años tratado con anteojos, portadora de hiperplasia suprarrenal tarda en tratamiento actual con deflazacort $3 \mathrm{mg}$ cada 12 horas diagnosticada a los 14 años, Ehlers Danlos diagnosticada a los 14 años sin tratamiento, hipertensión pulmonar diagnosticada en 2015 por cateterismo derecho, con presión media de la arteria pulmonar de $77 \mathrm{mmHg}$; gammagrama ventilación/perfusión negativo para tromboembolia, perfil reumatológico normal, eco transtorácico y transesofágico normal. Se inicia sildenafil a dosis de $25 \mathrm{mg}$ cada 8 horas, presentando a los 2 meses discromatopsia, por lo que se suspende el tratamiento, presentando deterioro de clase funcional evidenciado en prueba de caminata de 6 minutos; siendo valorada por oftalmología, los cuales descartan lesión vascular, estructural o afección permanente en retina, se reinicia tratamiento sin presentar nuevo evento. Resultados: Se observó efecto adverso transitorio, sin recurrencia. Conclusión: En el tratamiento de la hipertensión pulmonar, al ser los inhibidores de la fosfodiesterasa, como el sildenafil, uno de los medicamentos de prescripción, se deben considerar los efectos adversos asociados a su uso, a pesar de que el desarrollo de discromatopsia sea de baja incidencia, debe ser tomado en cuenta durante el tratamiento de esta enfermedad, y de presentarse continuar seguimiento y descartar afección permanente. Aporte a la práctica clínica diaria: Realizar interrogatorio dirigido a alteraciones visuales en pacientes en tratamiento con sildenafil.

\section{Biopsia pleural cerrada guiada por ultrasonido realizada por neumólogos: Serie de casos}

\section{Sánchez GJA, Sandoval GJL, Valencia RJ, Hernández RYC, Vargas SJL}

INER Ismael Cosío Villegas

Introducción: La ultrasonografía pulmonar es una herramienta que ha demostrado su utilidad en la actividad de los neumólogos. La biopsia pleural cerrada ha sido un procedimiento invasivo pulmonar, el cual ha sido desplazado en años recientes por la toracoscopia; la biopsia pleural, sin embargo, ha demostrado ser un estudio de bajo costo con un disponibilidad mucho más alta que la toracoscopia. El rendimiento reportado en la literatura mundial ha sido de entre un $48-56 \%$, por lo que su uso disminuyó con el advenimiento de la toracoscopia; sin embargo, la toracoscopia es un procedimiento invasivo que requiere un alto grado de preparación y un costo más elevado que el de la biopsia pleural cerrada con una disponibilidad menor en nuestro medio. La adyuvancia de la ultrasonografía pulmonar en la guía del sitio de biopsia pleural ha demostrado en estudios aumentar el rendimiento diagnóstico hasta un $80 \%$ en diversas series. Objetivos: Se presenta la serie de 24 de casos de derrame pleural diagnosticado por ultrasonografía pulmonar y las realizaciones de biopsia pleural cerrada guiada por ultrasonido. Material y métodos: Se obtuvieron 23 casos de derrame pleural con exudado linfocítico y candidatos a biopsia pleural, se eligió 
el sitio de biopsia con base en la región más inferior disponible manteniendo el margen de seguridad. Presentación del caso: Se obtuvieron 24 casos de derrame pleural exudado linfocítico de etiología desconocida, de los cuales se incluyen 9 mujeres y 15 hombres de entre 17 y 84 años. Resultados: Se obtiene resultado de malignidad en el $58 \%$ y de benignidad en el $16 \%$ con un rendimiento global del $75 \%$; en los casos de malignidad se obtiene una tipificación completa por medio de inmunohistoquímica. Conclusión: La biopsia pleural cerrada guiada por ultrasonido es un estudio útil y eficaz para el diagnóstico de derrame pleural de origen desconocido con un rendimiento mayor que la literatura internacional.

\section{Síndrome de Hermansky Pudlak a propósito de un caso}

\begin{abstract}
Jiménez COG, Oropeza LR, Gardea de la O EE, Estrada GA, Mejía ÁME
\end{abstract}

INER Ismael Cosío Villegas

Introducción: El síndrome de Hermansky Pudlak (SHP) es un trastorno autosómico recesivo no ligado al sexo, caracterizado por albinismo oculocutáneo, diátesis hemorrágica, colitis granulomatosa y enfermedad pulmonar intersticial. Afecta aproximadamente entre 500,000 a $1,000,000$ de personas en el mundo. Los genes SHP que codifican proteínas SHP, que forman el complejo de orgánulos relacionados con biogénesis de lisosomas (BLOCs, por sus siglas en inglés: biogenesis of lysosome-related organelles complexes). El SHP constituye un grupo heterogéneo de enfermedades hereditarias raras autosómica recesiva que se manifiesta como albinismo oculocutáneo tirosincinasa (+) y alteraciones hemorrágicas debido a la acumulación lisosomal de lipofuscina en el sistema reticuloendotelial de las células. Es una enfermedad muy rara y se conocen 10 subtipos diferentes, siendo el HPS-1 el subtipo más común y la variante más severa pudiendo causar múltiples comorbilidades como enfermedad pulmonar intersticial difusa (EPID) o enfermedad inflamatoria intestinal hasta en un $15 \%$ de los pacientes. Las pruebas genéticas se recomiendan para determinar el subtipo específico de la enfermedad ya que existen diferencias fenotípicas entre los diferentes subtipos que determinarán el seguimiento y pronóstico de los pacientes. Objetivos: Caracterizar a una paciente con Sx de Hermansky Pudlak. Presentación del caso: Presentamos un caso de paciente femenino de 40 años de edad con antecedente de albinismo ocular y cutáneo, colitis granulomatosa y neumopatía intersticial con patrón tomográfico tipo NINE. Con perfil inmunológico negativo, descartando alguna otra patología de origen autoinmune. Conclusión: Es una patología poco común y en cuanto al tratamiento, no existe uno efectivo para el SHP-EPI más que el trasplante pulmonar, se debe considerar de manera temprana con precaución por la predisposición al sangrado. En los pacientes con enfermedad avanzada se han administrado esteroides a altas dosis, sin embargo, su eficacia no ha sido comprobada. Aporte a la práctica clínica diaria: En el abordaje de este tipo de pacientes muchas veces se quedan sin diagnóstico oportuno.

\section{Aspiración de carbón activado, reporte de un caso}

\section{Hervert JM, Tapia ChI, Trejo KS, Juárez OC, García ÁJ}

Centro Médico Nacional «La Raza»

Introducción: Carbón activado: polvo de estructura porosa, capaz de adsorber sustancias durante su trayecto gastrointestinal, evitando su absorción sistémica (útil en intoxicaciones). La aspiración de carbón activado es una complicación, infrecuente, con alta morbimortalidad. Presentación del caso: Femenino, 12 años, con ingesta de gabapentina ante intento suicida (16.11.2016). Dos horas después se administra carbón activado mediante sonda nasogástrica, presentando disnea súbita, cianosis, dificultad respiratoria. Inician manejo avanzado de vía aérea, tratamiento: ceftriaxona/ clindamicina, envían a Centro Médico Nacional La Raza (25.11.2016). Realizan broncoscopia flexible y lavado broncoalveolar (28.11.16) evidenciando abundantes secreciones verdes espesas, hiperemia y partículas de material carbonáceo. Cursa con traqueobronquitis severa por Pseudomonas aeruginosa (extubada a los 11 días), tratada con piperacilina-tazobactam/vancomicina, metilprednisolona por 14 días, egresa 15.12.2016. El 21.12.2016 cursa con disnea de medianos esfuerzos, tos productiva, esputo blanquecino, pulsioximetría $84 \%$ (medio ambiente). Espirometría(18.12.2017): $\mathrm{FEV}_{1} / \mathrm{FVC}$ $52 \%, \mathrm{FEV}_{1} 36 \%$, FVC 61\% (obstrucción muy grave), gasometría: $\mathrm{pH}^{7.54}, \mathrm{pO}_{2} 55$, $\mathrm{pCO}_{2} 25, \mathrm{HCO}_{3} 21$, EB 1.1, saturación 92\%, clínicamente con sibilancias. Realizan broncoscopia, lavado y cepillado broncoalveolar seriado: o 27.12.2016: Estenosis traqueal concéntrica del 3er y 5to. anillos traqueales (menores a 20\%), impactación de material carbonáceo. 05.01.2017: Hiperemia y edema leve, libre de restos carbonáceos. Actualmente en tratamiento con fluticasona inhalada 200 $\mu \mathrm{g}$ cada $12 \mathrm{~h}$ y salbutamol en caso necesario. Conclusión: El carbón activado es altamente dañino para la vía respiratoria, condiciona insuficiencia respiratoria, hiperreactividad bronquial e incluso la muerte. La broncoscopia es un procedimiento diagnóstico/terapéutico esencial.

\section{Neumotórax espontáneo primario. Reporte de un caso}

Tapia Chl, Hervert JM, Trejo RKS, Juárez OC, García AJ

Centro Médico Nacional «La Raza»

Introducción: El neumotórax espontáneo primario es aquel que se presenta sin enfermedad pulmonar conocida; es una entidad rara en pediatría. Algunos de los factores de riesgo son el sexo masculino, jóvenes entre 15-34 años, consumo de tabaco y/o consumo de marihuana. Los signos y síntomas son de aparición súbita caracterizados por dolor torácico que incrementa con la respiración o tos, dificultad respiratoria, aumento del diámetro anteroposterior del tórax, timpanismo a la percusión y 
disminución de los ruidos respiratorios en el lado afectado. El estándar de oro para el diagnóstico es la tomografía pero por la factibilidad del estudio puede realizarse con radiografía de tórax. El manejo inicial es de soporte vital con aspiración con aguja y drenaje con catéter y debe realizarse escrutinio diagnóstico para descartar posibles etiologías. Presentación del caso: Masculino de 14 años, inicia el 30.06.16 posterior a baile, con dolor opresivo en hemitórax derecho, tos seca y disnea, manejado por tres días con ceftriaxona, con persistencia de sintomatología, por lo que acude a hospital 05.07.2016, se detecta aumento de hemitórax derecho, ausencia de ruidos respiratorios y timpanismo ipsilateral, radiografía con neumotórax completo derecho, se drena y coloca sonda pleural con succión $18 \mathrm{cmH}_{2}$ O. 8.07.16 se cierra succión, reincidiendo con neumotórax (reiniciado succión a $15 \mathrm{cmH}_{2} \mathrm{O}$ ), logrando retiro de sonda 13.07.2016. Se realizó protocolo de estudio, descartado las principales causas de neumotórax secundario (tomografía de tórax normal, cariotipo normal, se descarta síndrome de Marfan y cardiopatía). Conclusión: El neumotórax espontáneo primario es una entidad poco conocida, que debe sospecharse en todo paciente con el cuadro clínico y factores de riesgo, ya que el tratamiento inicial es de suma importancia para la supervivencia del paciente. Si no se recibe un tratamiento integral y oportuno el paciente puede llegar a presentar complicaciones como insuficiencia respiratoria aguda y colapso cardiorrespiratorio, con desenlace fatal.

\section{Metahemoglobinemia congénita como causa de cianosis persistente}

\section{Trejo RKS, Hervert JM, Tapia Chl, García AJ, Juárez OC}

Centro Médico Nacional «La Raza»

Introducción: La metahemoglobinemia se caracteriza por incremento de los niveles de metahemoglobina en sangre. Puede ser congénita, por cambios en la síntesis o metabolismo de la hemoglobina o adquirida por reacción adversa a sustancias. El rango normal es de $0-2 \%$; la metahemoglobina es inútil como transportador de oxígeno, por lo tanto su incremento provoca un grado variable de cianosis. Entre 10-20\% puede evidenciarse cianosis y sangre marrón, niveles de $30 \%$ presentan disnea, taquicardia y náusea, de $50 \%$ presentan alteraciones neurológicas con letargia, síncope y coma, niveles arriba de $70 \%$ son incompatibles con la vida. La hereditaria aparece poco después del nacimiento y debe ser sospechada cuando la cianosis no responde a prueba de hiperoxigenación y se descarta otra etiología. Presentación del caso: Caso 1: Masculino de 10 años, antecedente de 2 tías con coloración azulada de piel y tegumentos. Asintomático. A los 3 años notan cianosis bucal y ungueal, se descarta cardiopatía congénita. Ingresa programado para orquidopexia donde se detecta desaturación de $88 \%$ que no mejora a la administración de oxígeno. A la exploración física cianosis peribucal y ungueal. Nivel de metahemoglobina $31.9 \%$. Caso 2: Masculino de 10 años, primo hermano con probable metahemoglobinemia. Cursa con hiperactividad y déficit de atención. A los 2 años se observa cianosis peribucal y acrocianosis, se descarta cardiopatía congénita, cuadro de neumonía a los 4 años 5 meses. Sólo refiere disnea con grandes esfuerzos. Se descartan causas neumológicas y cardiológicas por cateterismo. A la exploración física con acrocianosis y cianosis bucal. $\mathrm{pO}_{2} 56$, metahemoglobina 39\%. Conclusión: La metahemoglobinemia es causa poco conocida de cianosis que no mejora a la administración de oxígeno. Cuando se han descartado otras posibles causas como cardiopatía, enfermedad pulmonar o intoxicaciones se debe sospechar y medir por niveles de metahemoglobina, para posterior estudio genético y manejo con antioxidantes como el ácido ascórbico.

Tiotropio es seguro y reduce el riesgo de exacerbaciones por asma en niños de edad preescolar

Bisgaard H, Vandewalker M, Graham $L R$, Moroni-Zentgraf $P$, Engel $M$,
El Azzi G, Vulcu SD, Finnigan H, Jle-Vrijlandt E (presentado por Waingarten $J$ y Uriostegui RD)

Departamento de Medicina Clínica, Universidad de Copenhagen, Hospital de Gentofte, Copenhagen, Dinamarca; Alergia e Inmunología, Investigación Clínica de los Ozarks,

Columbia, Missouri, Estados Unidos de América; Pulmunología Pediátrica, Centro de Cuidado Infantil de Atlanta, Atlanta, Georgia, Estados Unidos de América; Enfermedades Respiratorias TA, Boehringer Ingelheim Pharma GmbH \& Co. KG, Ingelheim am Rhein, Alemania; Medicina Traduccional y Farmacología Clínica, Boehringer Ingelheim Pharma GmbH \& Co. KG, Biberach an der Riss, Alemania; Desarrollo Clínico y Asuntos Médicos/Enfermedades Respiratorias TA, Boehringer Ingelheim Ltd, Bracknell, Reino

Unido; Departamento de Pulmonología y Alergia Pediátrica, Hospital Infantil de Beatrix Centro Médico Universitario Groningen, Universidad de Groningen, Groningen, Holanda; Boehringer Ingelheim México

Introducción: El asma es la enfermedad crónica más común de la infancia (GINA 2015). Para los niños de edad preescolar cuyos síntomas del asma no están bien controlados con corticosteroides inhalados, hay opciones limitadas disponibles como tratamiento adicional. Objetivos: Evaluar la seguridad de tiotropio respimat (tioR) una vez al día (QD) en pacientes de 1-5 años de edad con asma sintomática persistente. Material y métodos: Un estudio fase II/III, aleatorizado, doble ciego, controlado con placebo, de grupo paralelo (NCT01634113) de tioR 5 ?g, tioR 2.5 ?g o placebo Respimat ${ }^{\circledR}$ (pboR), administrado QD en la tarde por $12 \mathrm{se}$ manas, cada uno como complemento a la terapia de mantenimiento habitual. Datos de seguridad, incluyendo el análisis post hoc de una variable de exacerbación compuesta derivada de eventos adversos (EAs), son reportados. Resultados: No se reportaron EAs relacionados a la discontinuación del tratamiento o muerte. La proporción de los pacientes con cualquier EA fue mayor con pboR (73.5\%) que con tioR 5 ?g (58.1\%) y 2.5 ?g (55.6\%). Se reportaron EAs relacionados al medicamento en dos pacientes, uno en el grupo tioR 5 ?g (6.5\%) y otro en el grupo (5.9\%). Se reportaron EAs serios en 3 pacientes, todos en el grupo pboR. Exacerbación/empeoramiento de 
asma se reportó en un menor número de pacientes en el grupo tioR 5 ?g y tioR 2.5 ?g comparado con el grupo pboR. Conclusión: Tiotropium Respimat ${ }^{\circledR}$ administrado una vez al día como complemento a la terapia de mantenimiento es bien tolerado y puede reducir las exacerbaciones de asma sintomática persistente en niños de edad preescolar.

\section{Propuesta para educar al paciente en el correcto uso de su tratamiento inhalado}

\section{López MC, López EEC, Toral FS, del Río HR}

INER Ismael Cosío Villegas

Introducción: La terapia inhalada depende en gran manera de la correcta utilización de los dispositivos que existen para ella, lo que puede influir de manera significativa en el depósito pulmonar. Un estudio reporta que cerca del $20 \%$ de los pacientes presentan errores en el uso de IDMp y esto compromete casi totalmente la dosis efectiva. En otro estudio se observaron a 3,811 pacientes con EPOC o asma, encontrando que el $76 \%$ presentaba un error en la utilización del IDMp. En México una serie de estudios reflejan que la adherencia al tratamiento es sólo del 6070\%. Objetivos: Diseñar una aplicación para teléfono móvil en donde se le explica la técnica en lenguaje sencillo a través de un video en donde también la podrá ver en tiempo real, realizada por una persona adiestrada. Esta aplicación alertará al paciente en el momento que deba administrar su tratamiento. Material y métodos: Se realizó una búsqueda sistemática con el plan de búsqueda: Tratamiento de asma. Dispositivos de inhalación de medicamento. Apego y control del tratamiento
Inhalado en pacientes con asma Cámara Sony cybershot modelo mk340, o Cámara Canon modelo rgv 53896, o Editor Sony Vegas 3.5.7, o Audio Audicity 4.2.1. Los videos fueron avalados por un comité experto en el tema externo al grupo de trabajo. Resultados: Los dispositivos estudiados fueron: Aerolizer, Breezhaler, Diskus, Ellipta, Flujómetro, Genuair, IDM con cámara espaciadora, IDMp, Respimat, Turbohaler, Twisthaler. Cada uno de los videos de los dispositivos utilizados puede consultarse en la siguiente dirección electrónica: www.congresoneumologia2017.mx/videos. Conclusión: El consenso realizado de las técnicas y los videos grabados servirán para instruir a pacientes y personal de salud involucrado en el cuidado respiratorio. Aporte a la práctica clínica diaria: Ya que el médico no cuenta con el tiempo suficiente para explicarle al paciente la técnica correcta de administración, le puede pedir al paciente que descargue la aplicación en su celular y éste podrá aprender lúdicamente la técnica correcta.

\section{Tiotropio + olodaterol en pacientes con COPD moderada a severa con bronquitis crónica y/o enfisema}

Buhl R, Derom E, Bjermer L, Grönke $L$, Voss F, Fležar M (presentado por Waingarten FJ y Hernández ZR)

Departamento Pulmonar, Universidad del Hospital de Mainz, Mainz, Alemania; Departamento de Medicina Interna, Universidad del Hospital de Ghent, Ghent, Bélgica;

Departamento de Medicina Respiratoria y Alergología, Universidad de Lund, Lund, Suecia; Medicina TA de Enfermedades Respiratorias, Boehringer Ingelheim Pharma $\mathrm{GmbH} \& \mathrm{Co}$. KG, Ingelheim, Alemania; Bioestadística y Ciencia de Datos, Boehrin- ger Ingelheim Pharma GmbH \& Co. KG, Ingelheim, Alemania; Clínica Universitaria para Enfermedades Respiratorias y Alergias, Klinika Golnik, Golnik, Eslovenia; Boehringer Ingelheim México

Introducción: La bronquitis crónica y el enfisema son dos fenotipos de COPD que pueden afectar la decisión del tratamiento farmacológico. Objetivos: Tiotropio (T) + olodaterol (O) fue establecido para el tratamiento de EPOC en dos grandes estudios fase III. Este análisis post hoc evaluó el efecto de $\mathrm{T}+\mathrm{O}$ en la función pulmonar, sintomatología y calidad de vida relacionada a la salud en pacientes (pts) con bronquitis y/o enfisema definido por los investigadores. Material y métodos: TONADO ${ }^{\circledR} 1+2$ fueron estudios replicados, aleatorizados, doble ciego, de grupo paralelo. Pacientes con EPOC GOLD 2-4 (de acuerdo a la Global Initiative for Chronic Obstructive Lung Disease) fueron aleatorizados a una vez al día $\mathrm{T}+\mathrm{O} 2.5 / 5$ o 5/5 ?g, T 2.5 o 5 ?g, u O 5 ?g vía inhalador Respimat ${ }^{\circledR}$. Las variables incluyeron volumen espiratorio forzado en 1 segundo $\left(\mathrm{VEF}_{1}\right)$ área bajo la curva de 0 -3 horas (AUC0-3), cuestionario respiratorio St. George's (SGRQ) e índice de disnea de transición Mahler (TDI). Mostramos resultados para $\mathrm{T}+$ O 5/5 ?g, T 5 ?g y O 5 ?g en semana 24. Resultados: Las características basales fueron similares entre los pacientes con bronquitis $(n=2,210)$, enfisema $(n=2,351)$ o ambas $(n=1,179)$. Se observaron mejoras significativas en la función pulmonar y mejoras en SGRQ y TDI con $\mathrm{T}+\mathrm{O}$ en todos los grupos. Conclusión: $\mathrm{T}+\mathrm{O}$ mejoró el funcionamiento pulmonar, los síntomas y la calidad de vida en todos los pacientes con EPOC moderado a severo. La mejora en pacientes con enfisema fue ligeramente superior a la de pacientes con bronquitis crónica. 